\title{
Impact of Nitrogen Nutrition and Ectomycorrhizal Interaction on Populus x canescens Xylem Sap Composition and Defense
}

\author{
Dissertation \\ For the award of the degree \\ „Doctor rerum naturalium" \\ of the University of Göttingen
}

Within the doctoral program

"IRTG2172: PRoTECT: Plant Responses To Eliminate Critical Threats" of the Georg-August-University School of Science (GAUSS)

submitted by

\section{Karl Henrik Kasper}

from Bochum, Germany

\author{
Göttingen, 2020 \\ Department of Forest Botany and Tree Physiology \\ Büsgen-Institute \\ Georg-August-University Göttingen
}




\section{Thesis Committee}

Prof. Dr. Andrea Polle, Department of Forest Botany and Tree Physiology, Büsgen-Institute, University of Göttingen

Prof. Dr. Ivo Feussner, Department of Plant Biochemistry, Albrecht-von-Haller-Institute for Plant Science, University of Göttingen

Adjunct Prof. Dr. Guus Bakkeren, Department of Botany, University of British Columbia, Vancouver, Canada

\section{Members of the Examination Board}

Referee: Prof. Dr. Andrea Polle, Department of Forest Botany and Tree Physiology, BüsgenInstitute, University of Göttingen

$2^{\text {nd }}$ Referee: Prof. Dr. Ivo Feussner, Department of Plant Biochemistry, Albrecht-von-HallerInstitute for Plant Science, University of Göttingen

\section{Further members of the Examination Board:}

Adjunct Prof. Dr. Guus Bakkeren, Department of Botany, University of British Columbia, Vancouver, Canada

Prof. Dr. Gerhard Braus, Department of Molecular Microbiology \& Genetics, Institute of Microbiology and Genetics, University of Göttingen

PD Dr. Till Ischebeck, Department of Plant Biochemistry, Albrecht-von-Haller-Institute for Plant Science, University of Göttingen

PD Dr. Marcel Wiermer, RG Molecular Biology of Plant-Microbe Interactions, Albrecht-vonHaller-Institute for Plant Science, University of Göttingen

Date of oral examination: September, $4^{\text {th }} 2020$ 


\section{Affidavit}

Hereby, I confirm, that the dissertation "Impact of Nitrogen Nutrition and Ectomycorrhizal Interaction on Populus x canescens Xylem Sap Composition and Defense" has been written independently and no other sources and aids were used than quoted.

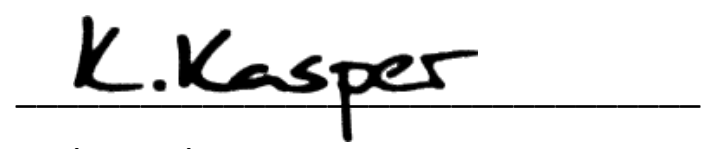

Karl Henrik Kasper, Göttingen 2020 


\section{Table of contents}

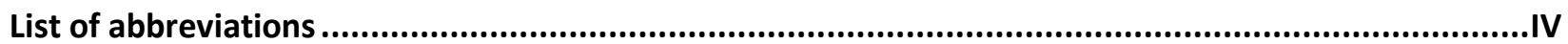

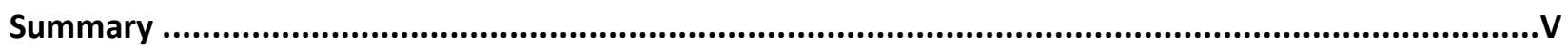

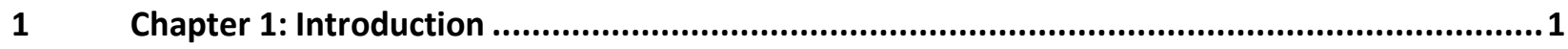

$1.1 \quad$ Ecology of Populus. spp. and Laccaria bicolor .................................................................... 1

$1.2 \quad$ Nitrogen uptake, metabolism and distribution in the plant .............................................. 4

1.3 Plant defense signaling and resistance strategies............................................................. 9

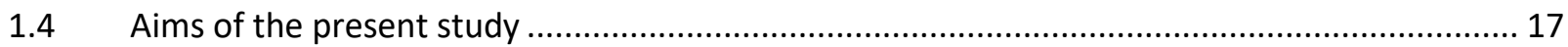

2 Chapter 2: Multi-omics of xylem sap uncovers dynamic modulation of poplar defenses by

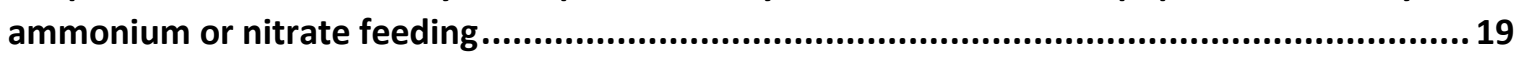

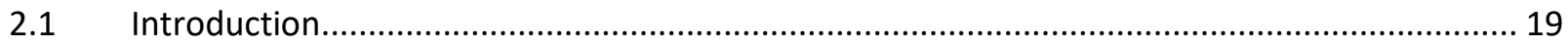

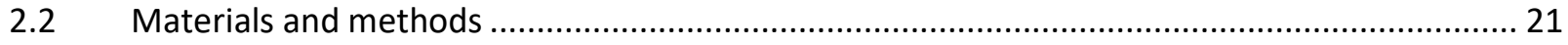

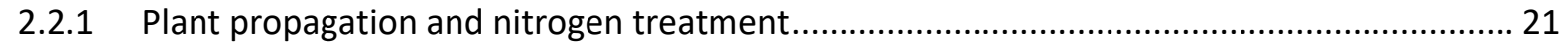

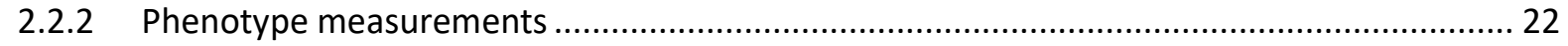

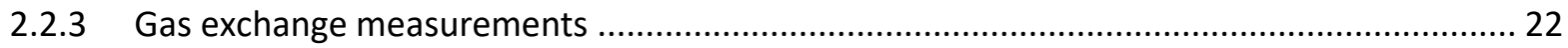

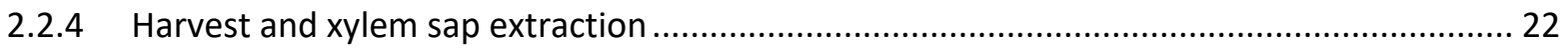

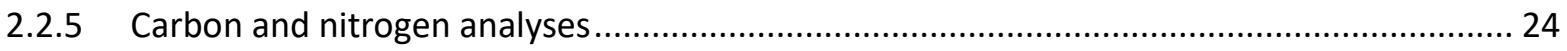

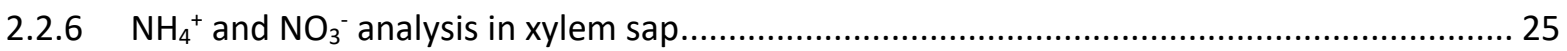

2.2.7 Measurements of xylem sap protein concentrations ...................................................... 25

2.2.8 Xylem sap metabolites and metabolomics ..................................................................... 26

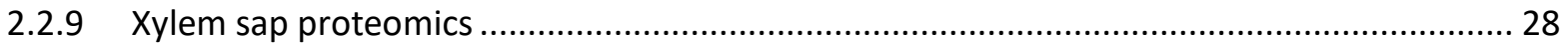

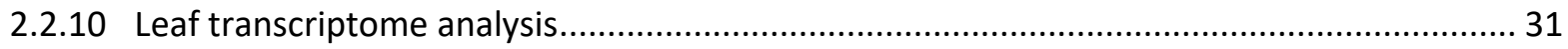

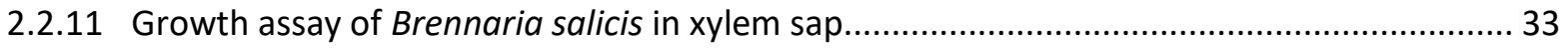

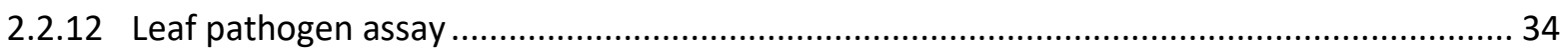

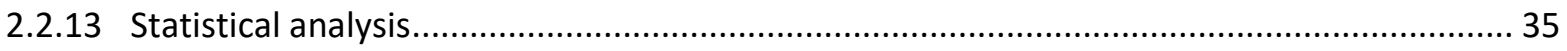

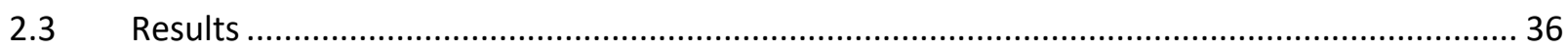

2.3.1 Ammonium and nitrate differentially shape primary metabolites in xylem sap .................. 36

2.3.2 Ammonium and nitrate-feeding impact phytohormones in the xylem sap ....................... 38

2.3.3 Poplar defense metabolites increase under low nitrogen supply ...................................... 39

2.3.4 Ammonium and nitrate have divergent effects on the xylem sap proteome..................... 42

2.3.5 Bioassays reveal effects of nitrogen nutrition on pathogen fitness .................................... 51

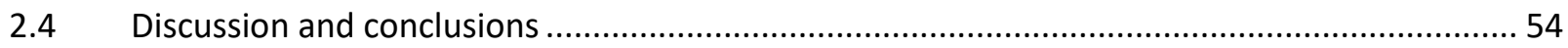

2.4.1 A meticulous xylem sap analysis shows distinct responses to nitrate and ammonium

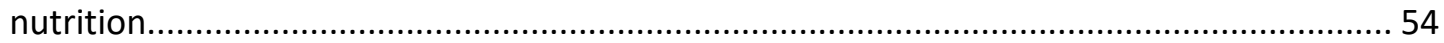


2.4.2 Nitrogen availability affects xylem sap signal and defense compounds............................. 56

2.4.3 High nitrogen increased susceptibility of poplar to a hemi-biotrophic pathogen .................57

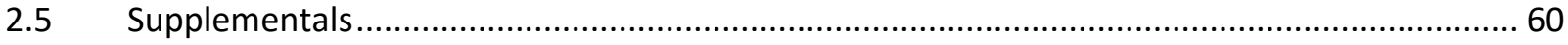

3 Chapter 3: Poplar mycorrhization affects xylem sap composition and defense responses ....... 75

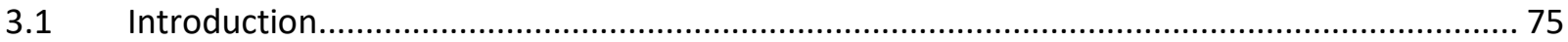

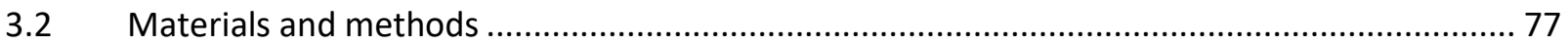

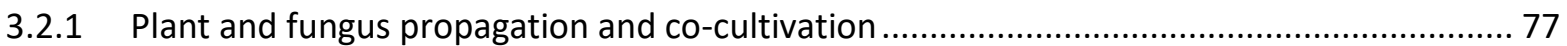

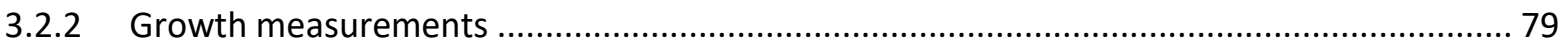

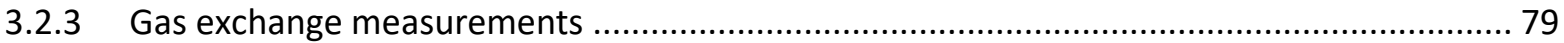

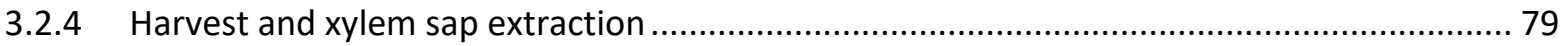

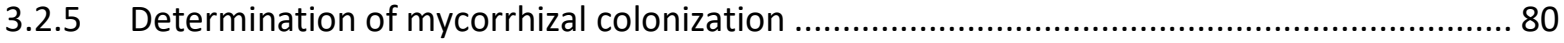

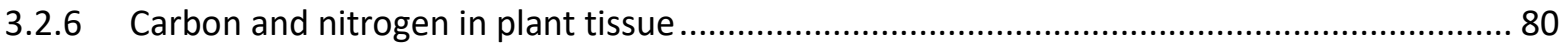

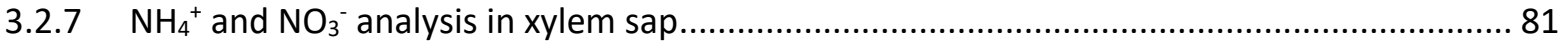

3.2.8 Measurements of xylem sap protein concentrations ........................................................ 81

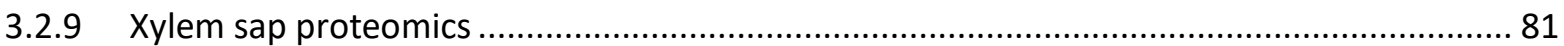

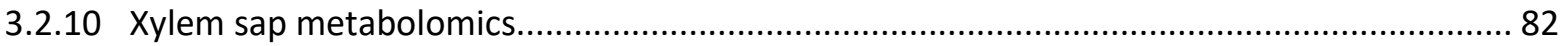

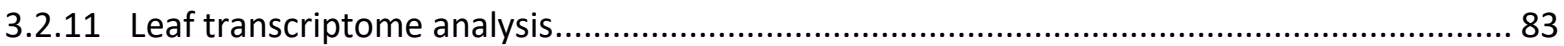

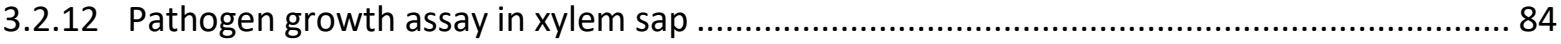

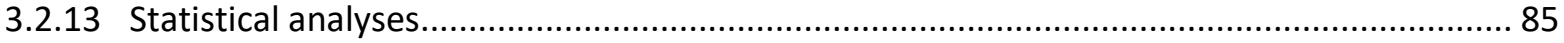

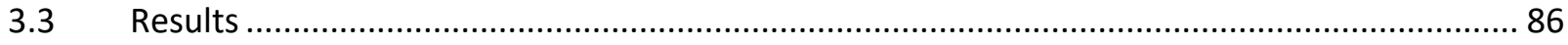

3.3.1 EMF interaction results in activation of SA and JA pathways, proanthocyanidin biosynthesis

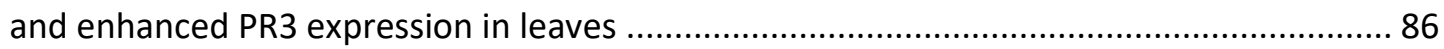

3.3.2 Mycorrhizal interaction has little impact on growth and physiology of greenhouse-grown poplar plants but increases $\mathrm{N}$ concentrations of roots........................................................ 94

3.3.3 Inorganic $\mathrm{N}$ and protein concentrations in xylem sap are not affected by ECM ................. 96

3.3.4 Xylem sap of mycorrhizal plants is enriched in putative SAR signaling proteins .................. 97

3.3.5 Mycorrhizal interaction has no influence on poplar xylem sap primary metabolite

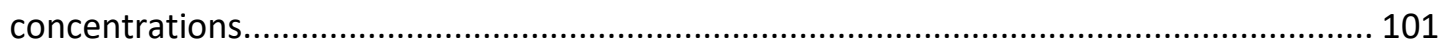

3.3.6 Xylem sap non-targeted metabolic fingerprinting ….................................................... 102

3.3.7 Accumulation of salicylic acid and pipecolic acid are reduced in xylem sap of mycorrhizal

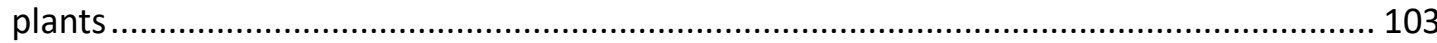

3.3.8 Reduced growth of pathogenic bacteria in xylem sap of mycorrhizal poplars ................... 104

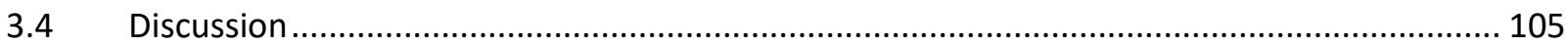

3.4.1 Interaction with Laccaria bicolor systemically activates Populus x canescens leaf defense 105

3.4.2 ECM promoted accumulation of two proteins involved in apoplastic plant defense.......... 106 
3.4.3 ECM modified xylem sap phytohormone concentrations ............................................... 108

3.4.4 The influence of ECM on xylem sap metabolite composition is low ............................... 108

3.4.5 EMF root colonization has only a small effect on endophyte growth in poplar xylem sap. 109

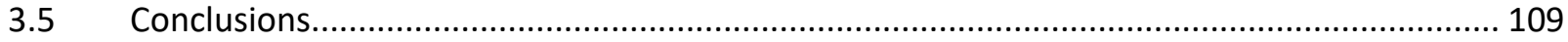

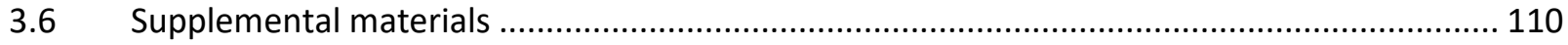

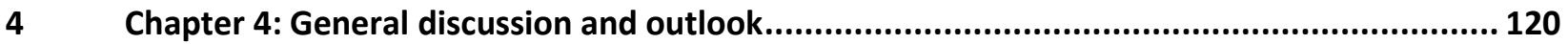

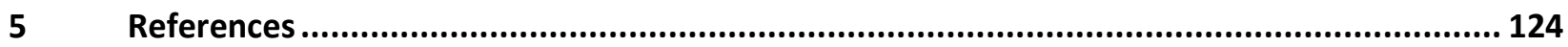

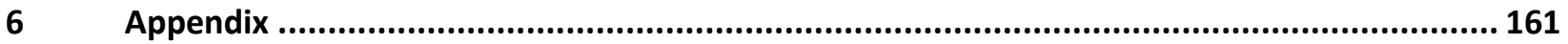

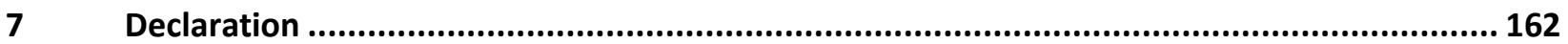

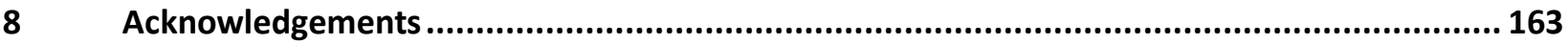

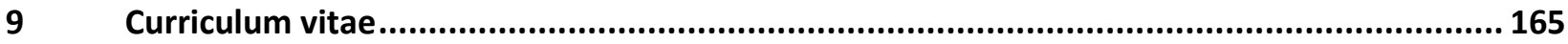

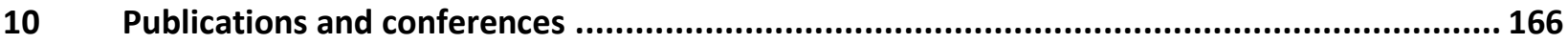




\section{List of abbreviations}

\begin{tabular}{|c|c|}
\hline Abbreviation & Definition \\
\hline $\mathrm{ABA}$ & Abscisic acid \\
\hline AMF & Arbuscular mycorrhizal fungi \\
\hline AMT & Ammonium transporter \\
\hline bp & base pair \\
\hline DAP & Differentially accumulated protein \\
\hline DEG & Differentially expressed gene \\
\hline ECM & Ectomycorrhizae \\
\hline EMF & Ectomycorrhizal fungi \\
\hline ETH & Ethylene \\
\hline FC & Fold change \\
\hline G6P & glucose-6-phosphate \\
\hline G6PD & glucose-6-phosphate dehydrogenase \\
\hline GC & Gas chromatography \\
\hline GO & Gene ontology \\
\hline HPLC & high-performance liquid chromatography \\
\hline ISR & Induced systemic resistance \\
\hline JA & Jasmonic acid \\
\hline JA-lle & Jasmonoyl-isoleucine \\
\hline LAT & Low-affinity transporter \\
\hline LC & liquid chromatography \\
\hline MAMP & Microbe-associated molecular pattern \\
\hline MAP & Mitogen-activated protein \\
\hline MeSa & Methyl salicylate \\
\hline MIR & Mycorrhiza induced resistance \\
\hline MS & Mass spectrometry \\
\hline $\mathrm{N}$ & Nitrogen \\
\hline $\mathrm{NH}_{4}^{+}$ & Ammonium \\
\hline NHP & $N$-hydroxypipecolic acid \\
\hline $\mathrm{NO}_{3}^{-}$ & Nitrate \\
\hline NRT & Nitrate transporter \\
\hline OD & Optical density \\
\hline PAMP & Pathogen-associated molecular pattern \\
\hline Pip & Pipecolic acid \\
\hline RT & Retention time \\
\hline SA & Salicylic acid \\
\hline SAG & Salicylic acid-glucoside \\
\hline SAR & Systemic aquired resistance \\
\hline XS & Xylem sap \\
\hline
\end{tabular}




\section{Summary}

Nitrogen $(\mathrm{N})$ is an essential macro-nutrient for plant growth and development. Inorganic $\mathrm{N}$ is taken up by plant roots as ammonium $\left(\mathrm{NH}_{4}{ }^{+}\right)$or nitrate $\left(\mathrm{NO}_{3}{ }^{-}\right)$. Roots of tree species are colonized by mycorrhizal fungi, which promote plant $\mathrm{N}$ supply. Once taken up, nitrogen is transported from the roots to the shoots via the xylem sap. The availability of $\mathrm{N}$ as well as the mutualistic interaction with mycorrhizal fungi can influence plant resistance towards pests and pathogens. It is unknown, if the availability of nitrate or ammonium in the nutrient solution affect the composition of the xylem sap, resulting different defense reactions in leaves. It is further unknown, if mycorrhizal interactions recruit nutrient signals to affect the defense of leaves. The main goal of this work was to analyze the influence of $\mathrm{N}$ availability and mycorrhizal interaction on the xylem sap composition of a tree species in a multi-omics approach.

For this purpose, two experimental approaches were chosen: Populus $\mathrm{x}$ canescens plants were cultivated (a) with different concentrations of $\mathrm{NH}_{4}{ }^{+}$or $\mathrm{NO}_{3}{ }^{-}$and (b) with or without interaction with ectomycorrhizal fungus (EMF) Laccaria bicolor. To comprehensively study the xylem sap composition, we used targeted and non-targeted metabolome analyses, proteome analyses with a label-free quantification approach, and spectrophotometric tests for nitrate, ammonium and protein analysis. We studied the leaf transcriptome by RNA sequencing to get insights into systemic plant responses to the treatments. To investigate plant resistance towards pathogens, we developed bioassays for a leaf and a vascular pathogen employing the necrotrophic fungus Marssonina castagnei and the biotrophic bacterium Brennaria salicis.

We addressed the following questions: i) How does the availability of different $\mathrm{N}$ forms and concentrations or ectomycorrhizal symbiosis influence the xylem sap composition? ii) Are systemic defense responses induced by varying $\mathrm{N}$ supply or interaction with EMF? iii) Do different $\mathrm{N}$ availabilities and ectomycorrhizal interaction influence resistance of leaves towards $M$. castagnei and attenuate growth $B$. salicis in xylem sap.

i) P. x canescens xylem sap proteome and metabolome were severely influenced by different $\mathrm{N}$ availabilities. Increasing $\mathrm{N}$ concentrations led to accumulation of xylem sap proteins, while not altering the xylem sap proteome functionality. The abundance of secondary metabolites in xylem sap decreased while primary metabolites increased with increasing $\mathrm{N}$ availability. The effect of 
ectomycorrhizal symbiosis was less intense but revealed differentially accumulated proteins and metabolites, known to be involved in long-distance stress signaling. Functional analyses of these candidate compounds are required in the future.

ii) Nitrogen concentrations and forms influenced the leaf transcriptomes. Low $\mathrm{NO}_{3}^{-}$treatment mainly induced responses following the salicylic acid (SA) signaling pathway while high $\mathrm{N}$ treatments induced jasmonic acid (JA)-dependent responses. Axenic co-cultivation of poplar with L. bicolor induced transcriptional responses of genes assigned to SA-, JA- and JA/Ethylene(ETH)dependent defense signaling, preparing the plant for the attack by herbivores or microbial pathogens.

iii) We successfully established a test system adapted to investigate bacterial growth in very low amounts of sample since xylem sap availability is a limiting factor. We found that high ammonium nutrition significantly enhanced bacterial growth in xylem sap compared with xylem sap of nitrate-fed poplar plants. The influence of ectomycorrhizal interaction on bacterial growth in xylem sap was low. We further established a detached leaf assay to test $P$. $x$ canescens resistance towards a necrotrophic pathogen, filling a gap in poplar research. Preliminary results suggest that nitrogen availability has a low or no effect on disease severity caused by $M$. castagnei.

In conclusion, the presented work generated the most comprehensive xylem sap analysis in a tree species and provides novel information on the flexibility of xylem sap composition in response to changes in $\mathrm{N}$ nutrition and ectomycorrhizal symbiosis. The results give valuable insights in xylem sap functionality and adaptation to environmental changes. Leaf transcriptome data revealed systemic induction of poplar defense responses by nutrition and mycorrhizal treatments. The development of two $P . \mathrm{x}$ canescens pathogen test systems are valuable tools for future research and can be used for poplar breeding programs. 


\section{Zusammenfassung:}

Stickstoff (N) ist ein essentieller Makronährstoff für das Pflanzenwachstum. Stickstoff wird in inorganischer Form von Pflanzenwurzeln als Ammonium $\left(\mathrm{NH}_{4}{ }^{+}\right)$oder Nitrat $\left(\mathrm{NO}_{3}{ }^{-}\right)$aufgenommen. Baumwurzeln sind von Mykorrhizapilzen kolonisiert, welche die pflanzliche Stickstoffaufnahme fördern. Nach der Aufnahme wird Stickstoff im Xylemsaft von den Wurzeln zum Schoss transportiert. Die Verfügbarkeit von Stickstoff und die Interaktion mit Mykorrhizapilzen kann die pflanzliche Resistenz gegen Schädlinge und Krankheiten beeinflussen. Es ist nicht bekannt of die Verfügbarkeit von Nitrat oder Ammonium in der Nährstofflösung die Zusammensetzung des Xylemsaftes beeinflusst und dadurch veränderte Abwehrreaktionen in den Blättern auslöst. Es ist auch nicht bekannt ob Mykorrhizainteraktionen Nährstoffsignale rekrutieren um damit die Abwehrmechanismen von Blättern zu beeinflussen. Das Hauptziel dieser Arbeit war es den Einfluss von Stickstoffverfügbarkeit und Mykorrhizainteraktion auf die Xylemsaftzusammensetzung in einem multi-omics Verfahren zu analysieren.

Dafür wurden zwei experimentelle Ansätze gewählt: Populus x canescens Pflanze wurden (a) unter verschiedenen Konzentrationen von $\mathrm{NH}_{4}{ }^{+}$und $\mathrm{NO}_{3}{ }^{-}$und (b) mit und ohne Interaktion mit dem ektomykorrhizapilz Laccaria bicolor kultiviert. Um die Xylemsaftzusamensetzung umfassend zu untersuchen wurden gerichtete und ungerichtete Metabolomanalysen, Proteomanalysen mit einer Label-freien Quantifizierung und Spektrophotometrische Tests zur Analyse von Nitrat, Ammonium und Proteinen genutzt. Per RNA Sequenzierung haben wir das Blatttranskriptom untersucht um Informationen zur Auswirkung der experimentellen Behandlungen auf systemische Pflanzenreaktionen zu erhalten. Um die Pflanzenresistenz gegen Krankheiten zu untersuchen haben wir Testsysteme für ein Blatt- und ein Vaskulaturpathogen entwickelt, in denen wir den nekrotrophen Pilz Marssonina castagnei und das biotrophe Bakterium Brennaria salicis genutzt haben.

Wir haben die folgenden Fragen adressiert: i) Wie wirkt sich die Verfügbarkeit von unterschiedlichen Stickstoffformen und -konzentrationen oder Ektomykorrhiza auf die Zusammensetzung des Xylemsaftes aus? ii) Werden systemische Abwehrreaktionen durch die Behandlungen induziert? iii) Wirken sich verschiedene Stickstoff Verfügbarkeiten und 
Ektomykorrhiza auf die Resistenz gegen M. castagnei aus und verringern sie das Wachstum von B. salicis im Xylemsaft?

i) Das P. x canescens Xylemsaft Proteom und Metabolom wurden stark durch unterschiedliche Stickstoffverfügbarkeiten beeinflusst. Erhöhte Stickstoffkonzentrationen haben zur Anreicherung von Xylemsaft Proteinen geführt, während sich an der Funktionalität des Proteoms nichts geändert hat. The Häufigkeit von Xylemsaft Sekundärmetaboliten hat abgenommen, während Primärmetabolite mit erhöhter Stickstoffverfügbarkeit zugenommen haben. Der Effekt der Ektomykorrhiza war weniger intensiv, bestimmte Proteine und Metabolite mit bekannten Funktionen in Langstreckensignalübertragung zur Induktion von Abwehrmechanismen. Die funktionelle Überprüfung dieser Signalstoff-Kandidaten sollte Gegenstand zukünftiger Forschungsarbeiten sein.

ii) Stickstoffkonzentration und -form haben das Blatttranskriptom beeinflusst. Die Behandlung mit niedrigen Nitratkonzentrationen hat Reaktionen hervorgerufen die dem Salicylsäure(SA)Signalweg folgen, während die Zugabe von hohen Stickstoffkonzentrationen Jasmonsäure (JA)abhängige Reaktionen Induziert hat. Axensiche Ko-Kultivierung von Pappel und L. bicolor hat Transkriptionsänderungen verursacht, die den SA-, JA-, und JA/Ethylen(ETH)-abhängigen Signalwegen folgen und damit die Pflanze auf den Befall von Herbivoren und verschiedenen Krankheiten vorbereitet.

iii) Wir haben erfolgreich ein Testsystem angepasst um bakterielles Wachstum in sehr geringen Mengen von Xylemsaft untersuchen zu können, weil die Probenmenge ein limitierender Faktor ist. Wir haben herausgefunden, dass hohe Ammoniumversorgung das Bakterienwachstum im Xylemsaft signifikant erhöht hat im Vergleich mit Xylemsaft von Nitrat-versorgten Pappeln. Der Einfluss der Ektomykorrhiza auf das bakterielle Wachstum war gering. Wir haben des Weiteren ein Testsystem entwickelt mit dem sich die Resistenz von $P . \times$ canescens gegenüber einem nekrotrophen Pilz testen lässt, dies füllt eine Lücke in der Pappelforschung. Erste Resultate deuten an, dass die Stickstoffversorgung entweder nur einen geringen oder keinen Einfluss auf Schwere einer M. castagnei-Infektion hat.

Zusammengefasst haben wir in der vorliegenden Arbeit die umfangreichste Xylemsaftanalyse einer Baumspezies generiert und präsentieren neue Informationen über die Flexibilität der Xylemsaftzusammensetzung in Reaktion zu veränderter Stickstoffversorgung und 
Ektomykorrhiza. Diese Ergebnisse geben wertvolle Einblicke in Xylemsaftfunktion und -adaption and wechselnde Umweltbedingungen. Die Blatttranskriptomedaten haben eine systemische Induktion von Pappelabwehr durch Ernährung und Mykorrhiza gezeigt. The Entwicklung von zwei $P . \mathrm{x}$ canescens Pathogen-Testsystem sind nützliche Methoden für zukünftige Forschungen und können in Pappel-Zuchtprogrammen genutzt werden. 


\section{Chapter 1: Introduction}

\subsection{Ecology of Populus. spp. and Laccaria bicolor}

Populus x canescens (Grey poplar, Fig. 1.1) is a member of the Saliaceae family (Stimm \& Weisgerber, 2008). It is a natural hybrid of $P$. alba and $P$. tremula, often associated with $P$. alba, Salix alba and S. fragilis in their native habitats of Eurasian floodplain forests (Röhrig \& Bartsch, 1992; Stimm \& Weisgerber, 2008). These habitats are connected to the moving water body. Flood plains are often impacted by agricultural run-offs, resulting in strong variations in nutrient concentrations (Craig et al., 2008; Jansson et al., 1994). Nitrate $\left(\mathrm{NO}_{3}{ }^{-}\right)$is the predominant nitrogen (N) source for poplars in these habitats (Rennenberg et al., 2009).

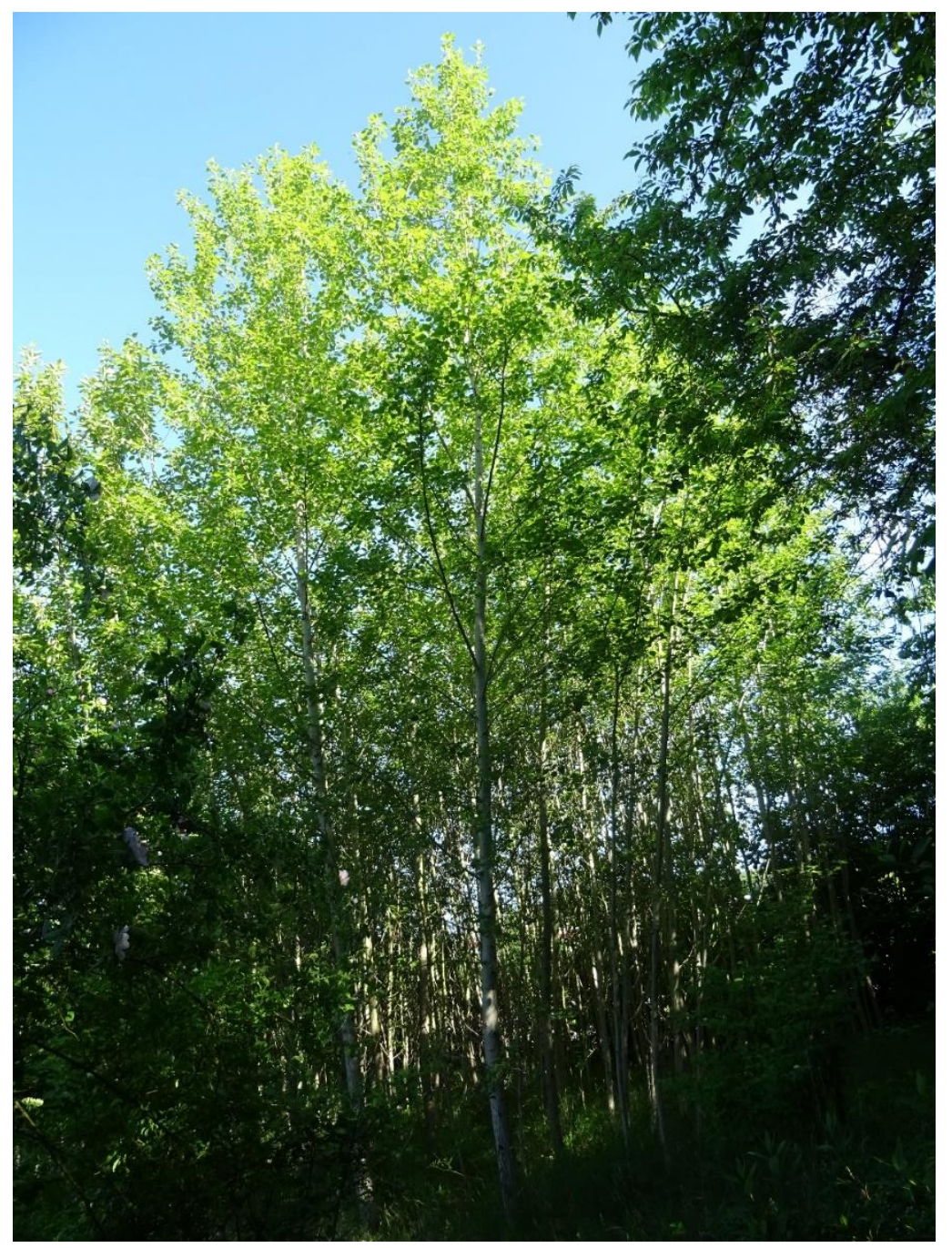

Figure 1.1: Habitus of Grey poplar (Populus x canescens), May 2020 Göttingen 


\section{Zusammenfassung}

In contrast to $P$. alba, the second parental species of $P$. $x$ canescens, $P$. tremula (European aspen) is known as a forest species. In natural forest soils, external $\mathrm{N}$ inputs are scarce and the available $\mathrm{N}$ is cycling within the ecosystem (Schimel \& Bennett, 2004). Depolymerisation and mineralization of organically bound $\mathrm{N}$ leads to oxidized $\mathrm{N}$ compounds, like $\mathrm{NO}_{3}{ }^{-}$, which is then reduced to ammonium $\left(\mathrm{NH}_{4}{ }^{+}\right)$and amino acids by microbial activities, thus, forming the dominant $\mathrm{N}$ source for forest trees (Rennenberg et al., 2009).

Due to its fast growth and stately habitus, $P . \times$ canescens is often used as a recreational element or wind breaker for parks, gardens and roads (Stimm \& Weisgerber, 2008). Additionally, this poplar hybrid is cultivated in short-rotation plantations for industrial biomass production (Müller et al., 2013; Polle \& Douglas, 2010; Sannigrahi et al., 2010). The $P$. x canescens clone INRA 7171B4 is a female line, widely used for research purposes, for example, for the analyses of nutrition(Dluzniewska et al., 2007; Siebrecht \& Tischner, 1999), stress- (Kaling et al., 2018; Polle et al., 2006), molecular- (Arisi et al., 1997; Kreuzwieser et al., 1999; Mader et al., 2016; Schnitzler et al., 2005; Will, 1999) and ectomycorrhiza (ECM)- (Bücking \& Heyser, 2001; Z.-B. Luo et al., 2009; Martin et al., 2016; Müller et al., 2013; Müller, 2014) related questions. The INRA clone 717-1B4 was the first tree species used for genetic engineering approaches (Leple et al., 1992) The first tree species, whose genome was completely sequenced and annotated, was $P$. trichocarpa (Nisqually), a female tree grown at a river bank in Washington state, USA (Tuskan et al., 2006).

The genomic information opened a variety of novel possibilities in tree biology, especially in poplar research (Jansson \& Douglas, 2007). The sequence of the $P$. x canescens genome was published about 10 years after that of $P$. trichocarpa (Mader et al., 2016).

As many tree species in temperate climate, roots of poplars are colonized by ectomycorrhizal fungi (EMF). These fungi interact with plant roots by generation of a new organ, called ectomycorrhiza (ECM). An ECM is characterized by the formation of a extramatrical mycelium, a fungal hyphae mantle around the plant root tip, and the Hartig net, a highly-branched hyphal network established between plant cells, without entering the cell lumen or crossing the Casparian stripe (Fig. 1.2) (Bonfante \& Genre, 2010; Martin et al., 2016; S. Smith \& Read, 2008). By these structures, the fungus receives photosynthetically fixed carbon directly from the plant (Nehls et al., 2007), while plants benefit from the symbiosis by improved water and nutrient 
supply. In particular, ECM has been recognized as a plant strategy to cope with low $\mathrm{N}$ availability (Chalot \& Brun, 1998).

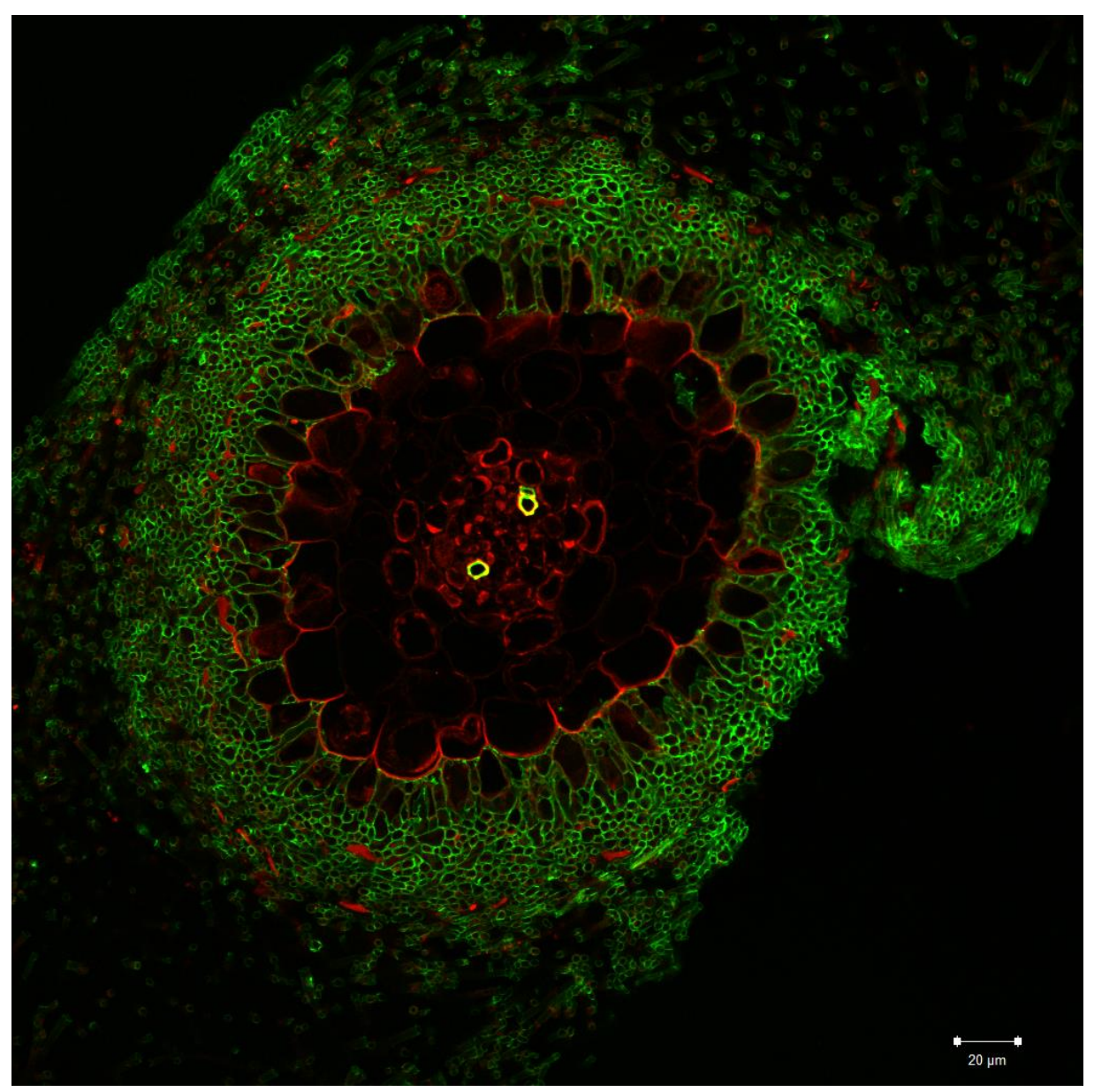

Figure 1.2 Cross section of Populus x canescens with Laccaria bicolor ectomycorrhiza. Plant cell walls were stained with propidium iodide and are shown in red, fungal tissue was stained with WGA Alexa488 and are colored green. Permission to use the picture was obtained from Dr. Clémence Bonnot, who owns all rights to the image

Poplars form ECM with more than 50 fungal species from the families of Amanitaceae, Russulaceae, Tricholomataceae, Cortinariaceae, Paxillaceae, Boletaceae, and Thelephoraceae (Cripps, 2001). However, most molecular studies to date, investigated the interaction of poplar with Laccaria bicolor (Bicoloured Deceiver) because L. bicolor was the first EMF that was sequenced (Martin et al. 2008). L. bicolor is distributed across temperate and boreal forests of North America and Northern Europe (Mueller \& Gardes, 1991). While L. bicolor is mycorrhizal with a range of trees, including poplars, it seems to prefer birch and pine (Philips, 2006). In 
addition, many environmental factors influence the colonization of root tips by EMF. For example, the mycorrhization rate of poplar was decreased when ECM plants were fertilized with N (Baum \& Makeschin, 2000). Poplar nitrate transporter expression was enhanced by ECM formation, independently of nitrate availability (Willmann et al., 2014) and ECM led to higher N concentrations in poplars (Gunderson et al., 2007; Kaling et al., 2018), underpinning the importance of ECM for plant $\mathrm{N}$ nutrition. However, this effect is abolished when sufficient nutrients are plant available and the carbon export to the fungus exceeds the benefits of plant nutrient import (Ingestad et al., 1986; R. Molina \& Chamard, 1983; Quoreshi \& Khasa, 2008; Rousseau \& Reid, 1991).

\subsection{Nitrogen uptake, metabolism and distribution in the plant}

For trees, as for other plants, $\mathrm{N}$ is a key nutrient. Because $\mathrm{N}$ is essential for nucleotide and protein production and many other primary plant functions, $\mathrm{N}$ scarcity leads to limitations in development and productivity (Robertson \& Vitousek, 2009). Plants can take up the inorganic $N$ forms ammonium $\left(\mathrm{NH}_{4}{ }^{+}\right)$and nitrate $\left(\mathrm{NO}_{3}{ }^{-}\right)$, as well as organic forms such as amino acids (Kielland, 1994). The availability of plant useable $\mathrm{N}$ forms in forest soils is dependent on climate, soil erosion, soil composition and microbial activity (LeBauer \& Treseder, 2008). For each $\mathrm{N}$ form, specialized transporter proteins are located in the plant plasma membrane. Roots take up $\mathrm{NH}_{4}{ }^{+}$ and $\mathrm{NO}_{3}{ }^{-}$by ammonium and nitrate transporters (AMTs and NRTs) and organic $\mathrm{N}$ by amino acid permeases (AAPs), lysine/histidine-like transporters (LHTs) and proline and glycine betaine transporters (ProTs) (Tegeder \& Masclaux-Daubresse, 2018) (Fig. 1.3). In poplar, 14 AMTs (Couturier et al., 2007) and 81 NRTs (Bai et al., 2013) have been identified. To cope with changing $\mathrm{NO}_{3}{ }^{-}$supply, low- and high-affinity transport systems (LATS, HATS) are available at the root plasma membrane. HATS are able to take up $\mathrm{NO}_{3}{ }^{-}$at very low levels, down to approximately $1 \mu \mathrm{M}$ (Miller et al., 2007). Both systems are symporters, taking up $\mathrm{NO}_{3}{ }^{-}$together with a proton, following the $\mathrm{H}^{+}$gradient (Miller et al., 2007). Nitrate uptake can be increased by mycorrhizal stimulation of $\mathrm{H}^{+}-$ ATPase activity (Sa et al., 2019). In root cortex cells, $\mathrm{NO}_{3}{ }^{-}$is reduced to nitrite catalyzed by NADHnitrate reductase (Nason, 1962). Nitrite is transported into the leucoplasts by specific nitrite transporters, for instance AtNITR2;1 in Arabidopsis thaliana (Maeda et al., 2014), where it is reduced to $\mathrm{NH}_{4}{ }^{+}$catalyzed by nitrite reductase (Miflin, 1974). Nitrate can also be loaded directly into the xylem and transported to the shoots (Fig. 1.3), whereas loading and xylem transport has 


\section{Zusammenfassung}

been discussed controversially for $\mathrm{NH}_{4}{ }^{+}$(Husted et al., 2000). When $\mathrm{NH}_{4}{ }^{+}$is taken up from the soil solution, it is transported into the leucoplasts, where it is converted via glutamine synthase (GS) to glutamine, which is then assimilated to glutamate by the GS/glutamine 2-oxoglutarate amino transferase (GOGAT) cycle (Xu et al., 2012). Glutamate is transported to the cytosol and either further converted to asparagine, catalyzed by asparagine synthase, or loaded to the xylem (Masclaux-Daubresse et al., 2010) (Fig. 1.3).

But plants do not only rely on direct uptake of nutrients, they are also provided with nutrients by mycorrhizal interactions (Melin \& Nilsson, 1952). Jentschke et al. (2001) showed that almost half of the $\mathrm{NH}_{4}{ }^{+}$taken up by the plant had been delivered by EMF under $\mathrm{N}$ scarcity. ECM take up inorganic $\mathrm{NO}_{3}{ }^{-}, \mathrm{NH}_{4}{ }^{+}$and organic $\mathrm{N}$ forms from the soil (Gobert \& Plassard, 2008). By release of enzymes and weak acids, they can access $\mathrm{N}$ pools which are inaccessible for plants (Lindahl \& Tunlid, 2015). L. bicolor possesses eight $\mathrm{NH}_{4}{ }^{+}$, one $\mathrm{NO}_{3}{ }^{-}$, and several organic $\mathrm{N}$ transporters, pointing to the species preference for $\mathrm{NH}_{4}{ }^{+}$over $\mathrm{NO}_{3}{ }^{-}$(Lucic et al., 2008). In L. bicolor, primary $\mathrm{NH}_{4}{ }^{+}$assimilation is achieved via the glutamine synthase pathway, which optionally can be supported by glutamate dehydrogenase under glutamine synthase-inhibiting conditions (Martin et al., 1994). $\mathrm{NO}_{3}{ }^{-}$is reduced via nitrate- and nitrite reductases, which cluster in the L. bicolor genome together with the only $\mathrm{NO}_{3}{ }^{-}$transporter (Lucic et al., 2008). In symbiosis, parts of the ECM-acquired $\mathrm{N}$ is transported to plant-fungal interface. The subsequent export to the apoplast by the Hartig net is poorly understood and most assumptions on fungal-plant nutrient exchange are based on results from studies in yeast (Nehls \& Plassard, 2018). While $\mathrm{NH}_{4}{ }^{+}$and AAs are translocted via the Hartig net, this pathway is less clear for $\mathrm{NO}_{3}{ }^{-}$(Sa et al. 2019). Amino acids are either converted to urease and further to ammonium or directly exported to the apoplast. The export of AAs is controversial because AAs also contain C skeltons, whose transloction would result in a loss of $\mathrm{C}$ for the fungus while the purpose of the interaction with the plant is to acquire $\mathrm{C}$ (Nehls \& Plassard, 2018). $\mathrm{NO}_{3}{ }^{-}$is hardly transported from fungal cells to the apoplast but rather reduced to $\mathrm{NH}_{4}{ }^{+}$or amino acids. $\mathrm{NH}_{4}{ }^{+}$and ammonia $\left(\mathrm{NH}_{3}\right)$ are candidates for fungal export to the apoplast (S. Smith \& Read, 2008). The preference for reduced N transport is supported by increased expression of transporters that enable $\mathrm{NH}_{4}{ }^{+}$and $\mathrm{NH}_{3}$ transport (e.g. aquaporins if the gradient is suitable for passive diffusion) through the EMF plasma membrane (Chalot et al., 2006; Dietz et al., 2011). In the apoplast $\mathrm{NH}_{3}$ is protonized by $\mathrm{H}^{+}$, generated by $\mathrm{H}^{+}$-ATPase $\left(\mathrm{H}^{+}\right.$-exporting), 
which show increased activity in mycorrhizal interaction (Guttenberger, 2000). Vesicle fusion has also been discussed for fungal $\mathrm{NH}_{3}$ export (Chalot et al., 2006). From the apoplast, $\mathrm{NH}_{4}{ }^{+}$can be imported to root cells by speciallized AMTs, which show enhanced expression in ECM (Selle et al., 2005). Transport of $\mathrm{NH}_{3}$ from apoplast into root cells has been suggested via non-specific channels (Chalot et al., 2006) (Fig. 1.3).

In A. thaliana, $\mathrm{NO}_{3}{ }^{-}$transport from root cells to xylem, via the apoplast, is achieved by NRT1.5 (Lin et al., 2008) and by amino acid permease 3 (AAP3) for AAs (Okumoto et al., 2004). The mechanism of xylem $\mathrm{NH}_{4}{ }^{+}$import is unknown, but AMTs, aquaporins and nonselective channels have been suggested to be involved in xylem loading of $\mathrm{NH}_{4}{ }^{+}$(Tegeder \& Masclaux-Daubresse, 2018).

Long distance transport of nutrients from the roots to the aboveground parts takes place in the plant vascular system, via the xylem sap (XS) (Fig. 1.3). The xylem sap is an aqueous solution which is transported upwards by two mechanisms, root pressure and transpiration (Marschner, 2011). Usually, transpiration is the dominating factor driving xylem sap movement. Transpiration causes a negative pressure within the xylem vessels compared to the atmospheric pressure, which together with the cohesion of $\mathrm{H}_{2} \mathrm{O}$ molecules, forces the aqueous solution upwards (Zimmermann et al., 1994). Under conditions of high humidity or decreased photosynthesis (e.g. during night), the root pressure drives the xylem sap movement. The root pressure is caused by the difference in osmotic potential resulting from active loading of ions and other osmotic substances, to the xylem. To equilibrate the osmotic potential, water streams into the xylem and thereby drives the acropetal movement (Schurr, 1998). 


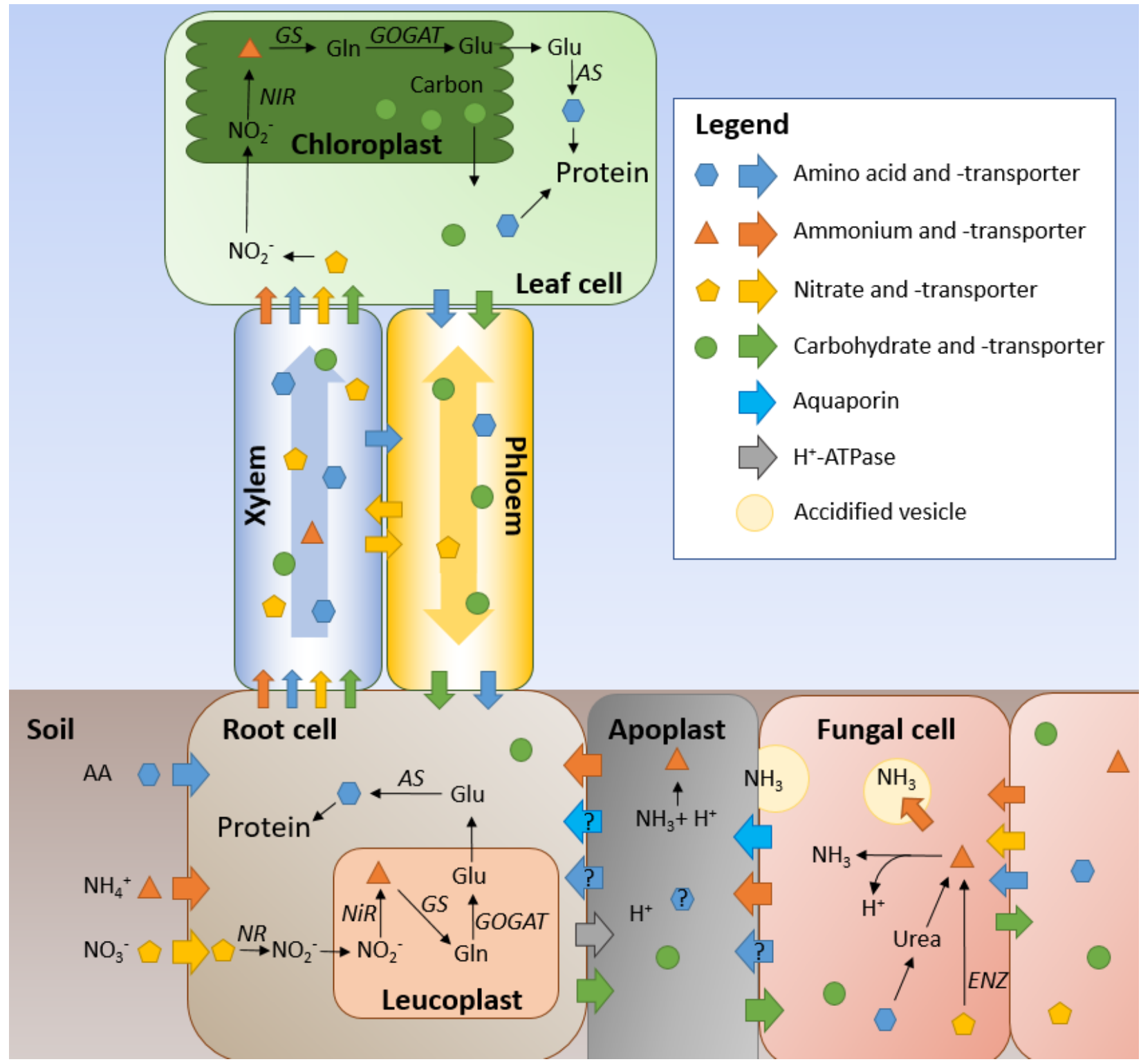

Figure 1.3: Schematic overview on nitrogen uptake, metabolism and transport in the plant and EMF. AA = amino acids, $\mathrm{NH}_{4}{ }^{+}=$ammonium, $\mathrm{NO}_{3}{ }^{-}=$nitrate, $\mathrm{NR}=$ nitrate reductase, $\mathrm{NIR}=$ nitrite reductase, $\mathrm{NO}_{2}{ }^{-}=$ nitrite, GS = glutamine synthase, Gln = glutamine, GOGAT = glutamine 2-oxoglutarate aminotransferase, ENZ = enzymatic. Black arrows represent enzymatic steps, colored arrows show transport.

In poplar xylem sap, nutrient concentrations undergo diurnal changes (Siebrecht \& Tischner, 1999). The maximum concentrations for all macronutrients is reached in the first half of the light period and the minimum just before the dark period begins (Siebrecht \& Tischner, 1999). $\mathrm{NH}_{4}{ }^{+}$ and $\mathrm{NO}_{3}{ }^{-}$are present in the xylem sap, with the latter being the more abundant one (Siebrecht et al., 2003). $\mathrm{N}$ can be exported from the xylem into the cells of photosynthetically active leaves or 
transferred to the phloem to cover for strong sink demand (Pate et al., 1975). Export to the phloem occurs via xylem parenchyma cells. In Arabidopsis, translocation is carried out by NRT1.8 for $\mathrm{NO}_{3}{ }^{-}$(J.-Y. Li et al., 2010) and AAP6 for AAs (Hunt et al., 2010). Xylem export to leaf mesophyll cells is not well understood for inorganic $\mathrm{N}$ forms. In $A$. thaliana AMT1;1 and AMT2;1 have been suggested to unload $\mathrm{NH}_{4}{ }^{+}$(Ludewig et al., 2007) but no NRTs for $\mathrm{NO}_{3}{ }^{-}$export have been characterized yet (Tegeder \& Masclaux-Daubresse, 2018). Mesophyll cell AA import is carried out by LYSINE HISTIDINE TRANSPORTER 1 (Hirner et al., 2006). In the mesophyll cells, $\mathrm{NO}_{3}{ }^{-}$and $\mathrm{NH}_{4}{ }^{+}$ are either temporary stored in the vacuoles (Martinoia et al., 2007) or reduced to amino acids in the leaf chloroplasts as decribed above for leucoplasts (Hörtensteiner \& Feller, 2002). Amino acids are either metabolized to proteins or loaded to the sieve elements of the phloem for further relocation to sink tissues (Tegeder \& Rentsch, 2010; Winter et al., 1992). In poplar, photosynthetically fixed C, i.e., mainly sucrose, passively diffuses through plasmodesmata into the phloem and is transported to sink tissues (C. Zhang et al., 2014).

ECM are a strong sink for carbohydrates. To avoid parasitism, ECM needs to be under control by the plant (Nehls et al., 2007). Poplar enhance monosaccharide importer (MST) PttMST3.1 accumulation at the EMF/plant interface to potentially compete for $C$ in the shared apoplast, when the ECM-provided nutrients are insufficient (Nehls et al., 2007). On the other hand, symbiotic EMF do not provide nutrients for free, as shown by a reduction of transfered phosphate when carbon supply from the plant was reduced (Bücking \& Heyser, 2001). In transgenic poplar lines overexpressing the poplar monosaccharide importer at the plant/fungal interface, EMF terminated the symbiosis completely (Grunze et al., 2004). However, the mechanism is not clear because a direct nitrogen-carbon trading has not been found in a range of different ECM (Valtanen et al. 2014). 


\subsection{Plant defense signaling and resistance strategies}

During their life cycle, plants have to cope with fluctuating nutrient supply and they have to defend themselves against a variety of stresses. In contrast to vertebrates, they lack adaptive immunity including mobile defender cells, which are translocated to the site of attack (Jones \& Dangl, 2006). Instead, each cell contains an innate immune system, which consists of different components such as structural, metabolite- and protein-based defense mechanisms (Ausubel, 2005; Dangl \& Jones, 2001). Physical barriers, such as bark, epidermal cuticle and cell walls, consisting of waxes, suberin, lignin, pectin, cellulose, and hemi-celluloses are part of plants' constitutive defense (Jones \& Dangl, 2006). In addition to physical barriers, plants possess a basal defense, providing a broad-spectrum resistance to many pathogens and herbivores, resulting in incompatibility of most host-invader interactions (Jones \& Dangl, 2006). Plants distinguish between biotrophic, and necrotrophic pathogen attack, as well as herbivory and wounding (Pieterse et al., 2014). Threat-specific elicitors (e.g. pathogen-associated molecular patterns, PAMPS) are recognized by the plant, leading to distinct defense responses (Glazebrook, 2005) (Fig. 1.4).

In general, recognition of biotrophic pathogens leads to salicylic acid (SA)-based defenses, whereas necrotrophic pathogens, herbivory and wounding results in jasmonic acid (JA)/ethylene (ETH)-regulated defenses (McDowell \& Dangl, 2000). A well investigated example in the herbaceous model plant Arabidopsis thaliana is the reception of the fungal cell wall compound chitin and chitooligomers by specialized pattern recognition receptors, such as chitin elicitor receptor kinase 1 (CERK1) (Petutschnig et al., 2010) and lysine motif-CONTAINING RECEPTOR-LIKE KINASE 5 (LYK5) (Couto \& Zipfel, 2016). Chitin acts as a PAMP, which is recognized by a CERK1/LYK5 heterodimer at the cell surface, leading to activation of a mitogen-activated protein kinase (MAPK) signaling cascade, eventually resulting in the transcription of PAMP-induced defense genes (e.g. PATHOGENESIS RELATED1, PR1) (Couto \& Zipfel, 2016). This type of resistance is also called PAMP-triggered immunity (PTI) and protects against biotrophic pathogens (Jones \& Dangl, 2006). PTI has also been reported for the very early stages of necrotrophic fungal recognition, before death of the host cells (Wang et al., 2014). Adapted biotrophic pathogens release effectors, which interfere with PTI, resulting in plant susceptibility called effectortriggered susceptibility (ETS) (Jones \& Dangl, 2006). To recognize these pathogen effectors inside 


\section{Zusammenfassung}

the cell, plants rely on nucleotide binding-leucine rich repeat (NB-LRR) proteins, to which the effectors bind to and thereby activate effector-triggered immunity (ETI), eventually, leading to hypersensitive response and programmed cell death (Cui et al., 2015). During co-evolution, pathogens have repeatedly lost recognizable effectors and plants have evolved new NB-LRR proteins to recognize novel effectors (Jones \& Dangl, 2006).

Resistance does not only occur at the site of attack, but can also be activated systemically throughout the plant (Pieterse et al., 2014). By local events of pathogen attack, herbivory, wounding or interaction with beneficial microbes long-distance signals are generated. The signals are transported to distal plant organs to prepare these systemic plant parts for potentially upcoming infections by activation of defense gene expression and callose deposition (MauchMani et al., 2017) (Fig. 1.4).

Systemic acquired resistance (SAR) is induced by pathogen attack and leads to an elevated level of SA, locally and in distant tissues (Vlot et al., 2009). By the activation of the SAR key regulator protein NPR1, either programmed cell death or SA-dependent defense gene expression, e.g. PR1, is initiated (van Loon et al., 2006). Additionally, signaling compounds are generated and transported to systemic plant parts, to prepare those for potentially upcoming attacks (Shah \& Zeier, 2013) (Fig. 1.4). Different compounds have been proposed to transmit SAR between local and the systemic plant tissues but a unifying concept is yet lacking. SAR, which could be triggered by the glycerol-3-phosphate derived molecule (Chanda et al., 2011), azelaic acid (Jung et al., 2009) or the abietane diterpenoid dehydroabietinal (Chaturvedi et al., 2012) seems to rely on the shuttling service of DIR1 (DEFECTIVE IN INDUCED RESISTANCE 1) (Shah \& Zeier, 2013). DIR1 is a non-specific lipid-transfer protein and analysis of its crystal structure revealed a central hydrophobic cavity able to mount lipids or other hydrophobic molecules (Isaacs et al., 2016). DIR1 is expressed in all living leaf cells and accumulates upon local infection (Champigny et al., 2013). It was found in SAR-activated phloem exudates (Champigny et al., 2013). Furthermore, the SARtransmitting compounds, which have been listed above, require functional DIR1 for defense promoting activity (Jung et al., 2009). DIR1-independent SAR signals are MeSA (methyl ester of salicylic acid) (Dempsey \& Klessig, 2012) and PIP (pipecolic acid) (Shah \& Zeier, 2013) (Fig. 1.4). Recognition of the systemic signal leads to expression and priming of NPR1-dependent genes and callose deposition in distal leaves (Pieterse et al., 2014). The production of PR proteins, especially 
of PR1, is a characteristics of SAR; PR1 is, therefore, a well-defined SAR marker gene (Cameron et al., 1999).

Local attack by a necrotrophic pathogen or herbivory result in the activation of JA or ET/JAdependent defense responses (Pieterse et al., 2014). JA-derived and other volatile organic compounds are released by the wounded leaf to attract antagonists of the attacking herbivore (Mccormick et al., 2014) or beneficial microbes (Liu \& Brettell, 2019) or to repel herbivores (Delaney et al., 2013). JA-derivates are also a long-distance signal leading to defense responses in systemic plant organs in response to wounding and herbivory (Sun et al., 2011). Upon reception of JA, herbivory-induced resistance (HIR) is activated. Intercellular JA concentrations increase and by binding of JA to CORONATINE INSENSITIVE 1 (COI1), JASMONATE-ZIM-DOMAIN (JAZ) proteins are released from COI 1 and degraded via the 26 s proteasome. In naïve cells, JAZ proteins repress JA-dependent defense responses. By their degradation, JASMONATE-INSENSITIVE-transcription factors (e.g. MYC2) are de-repressed which leads to expression of JA-dependent defense genes (Sun et al., 2011) (Fig. 1.4). 
Type of resistance Systemic aquired resistance

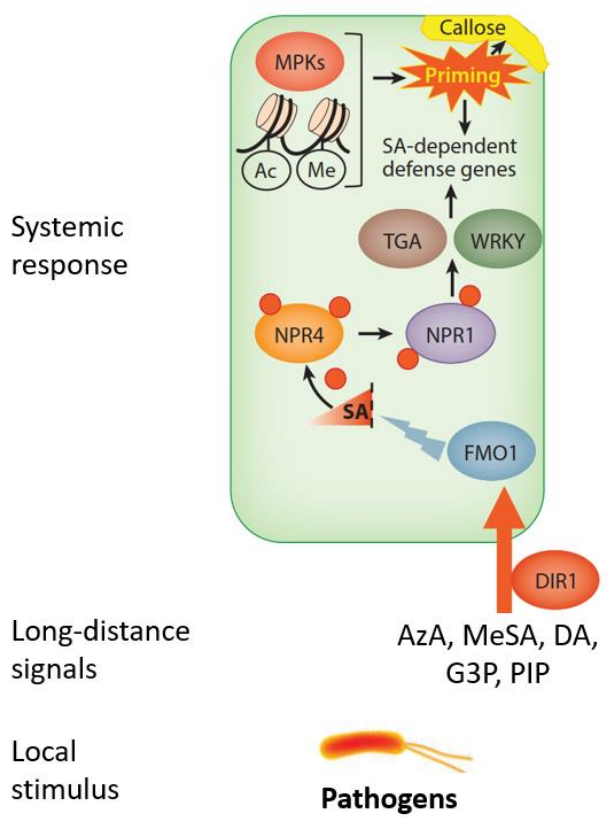

Herbivory induced resistance

$\| \amalg \rightarrow$ Indirect defense

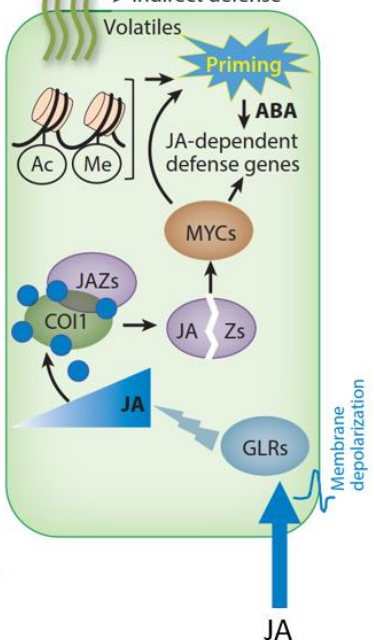

JA
Induced systemic resistance
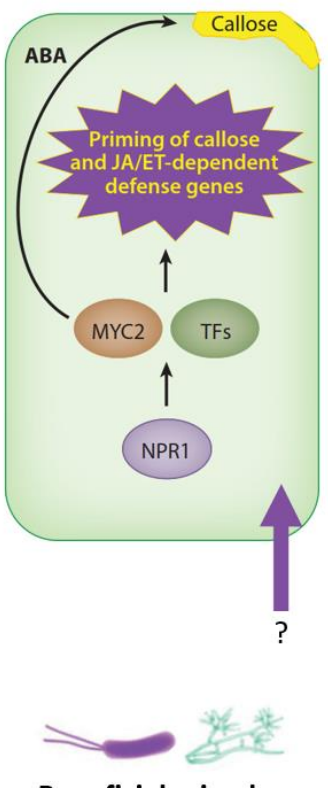

Herbivores

Fig. 1.4: Schematic overview of local stimuli leading to different systemic defense responses named systemic acquired resistance (SAR), herbivore-induced resistance (HIR) and induced systemic resistance (ISR). Colored arrows indicate long-distance transport and know long-distance signal compounds are shown below. Black arrows indicate established connections. Abbreviations: ABA, abscisic acid; Ac, acetylation; AzA, azelaic acid; COI1, CORONATINE INTENSITIVE1, DA, dehydroabietinal; DIR1, DEFECTIVE IN INDUCED RESISTANCE1 protein; ET, ethylene; FMO, FLAVIN-DEPENDENT MONOOXYGENASE; G3P, glycerol-3-phosphate; GLR, GLUTAMATE RECEPTOR-LIKE protein; JA, jasmonic acid; JAZ, JASMONATE-ZIMDOMAIN protein; Me, methylation; MeSA, methyl ester of SA; MPK, mitogen-activated protein kinases; MYC, JASMONATE-INSENSITIVE1; NPR, NONEXPRESSER OF PR GENES; PIP, pipecolic acid; SA, salicylic acid; TF, transcription factor; TGA, bZIP-transcription factor; WRKY, WRKY-transcription factor. Figure adapted from Figure 2 in Pieterse et al. (2014) 


\section{Zusammenfassung}

In recent years, it was recognized that beneficial microbes can strengthen plant defenses (Pieterse et al., 2014). In contrast to SAR, this response was denominated as "induced systemic resistance (ISR)" describing processes that trigger aboveground defenses when plants interact with growth promoting rhizobacteria (PGPR) (van Loon, 2007), arbuscular (Jung et al., 2012) or ectomycorrhizal fungi (Kaling et al., 2018; Szuba et al., 2019; Vishwanathan et al., 2020). The fitness improvement of plants resulting from the interaction of symbiotic fungi and plants is also termed mycorrhiza-induced resistance (MIR) (Jung et al., 2012). In contrast to SAR and HIR, little is known about the regulatory networks behind ISR and especially MIR (Mauch-Mani et al., 2017). Generally, one has to be cautious when considering MIR for different types of mycorrhizal fungi that employ different strategies to exchange molecules with plants. The two ecologically and economically most important types are arbuscular mycorrhizal fungi (AMF), which form highly folded arbuscules inside the cortical cells of plant roots and, EMF, forming a branched hyphal system between the cortical cells without penetrating the plasma membrane (Martin et al., 2016). Inasmuch MIR overlaps between these mycorrhizal life styles is not clear. However, in both cases formation of the symbiosis is dependent on the common symbiosis pathway (CSP) (Cope et al., 2019). In short, the mycorrhizal fungi secrete short-chain chitooligosaccharides (COs) and lipoCOs (LCOs) into the rhizosphere (Genre et al., 2013; Maillet et al., 2011). These molecules are perceived by lysine motif receptor-like kinases (LysM-RLK) of the plant cells, leading to calcium oscillation induced gene expression and eventually to the onset of mycorrhizal symbiosis (Choi et al., 2018).

In interaction with AMF, MIR seems to rely on preparing systemic tissues to react faster and more pronounced to pathogen attack (Mauch-Mani et al., 2017). This preparedness is achieved by a moderate accumulation of molecules involved in key steps of defense responses, such as transcription factors (e.g. MYC2 and WRKY-family members) and MAP-kinases (Jung et al., 2012). The systemic effect of AMF on leaf resistance towards pathogens is dependent on the lifestyle of the pathogen (Jung et al., 2012). AMF-caused MIR leads to less severe infections with necrotrophic pathogens (Campos-Soriano et al., 2012; de la Noval et al., 2007; Fritz et al., 2006; Song et al., 2015), small to no suppression of infections by hemibiotrophic pathogens (Chandanie et al., 2006; Lee et al., 2005) and a higher susceptibility towards viruses and biotrophic pathogens (Pozo \& Azcón-Aguilar, 2007). Song et al. (2015) showed that the interaction of AMF Funneliformis 


\section{Zusammenfassung}

mosseae and tomato (Solanum lycopersicum Mill.) leads to only minor changes in leaf gene expression of plant not challenged by a pathogen. However, subsequent to infection with the necrotrophic fungus Alternaria solani, the expression of genes involved in JA and SA biosynthesis, as well as of genes encoding pathogenesis-related proteins PR1, PR2 and PR3 and activity of chitinases and $\beta$-1,3-glucanases was much quicker and higher in mycorrhizal than in nonmycorrhizal plants, resulting in less severe plant disease symptoms (Song et al., 2015). The necessity of JA to induce these resistance modifications was demonstrated by using transgenic plants overexpressing prosystemin, an upstream component of JA-dependent defense responses and suppressor of prosystemin-mediated responses 2 plants, impaired in JA biosynthesis. The activity of these two defense enzymes were highly upregulated in arbuscular mycorrhizal prosystemin-overexpressing plants when challenged with A. solani. In contrast, no enzyme activity increase was measurable in arbuscular mycorrhiza pre-inoculated suppressor of prosystemin-mediated responses 2 plants when challenged with $A$. solani, clearly pointing out the importance of jasmonates in arbuscular mycorrhiza induced resistance (Song et al., 2015).

The effects of ECM on foliar pathogen-interaction are even less well investigated. Pfabel et al. (2012) showed that ECM can counteract the suppression of defensive metabolites, in poplar leaves infected with the biotrophic pathogen Melampsora larici-populina (Figure 1.5).

The effect of AMF-caused MIR on herbivory depends on the level of specialization of the insect (Jung et al., 2012). Polyphagus leaf chewers seem to underperform, while mono- and oligophagus chewers perform better, when feeding on plants with AMF-interaction (Figure 1.5). These responses are likely due to increased nutrition by AMF-interaction and adaptation to the plantspecific resistance compounds (Jung et al., 2012). The same holds true for the effect of ECM interaction on tree herbivory (Koricheva et al., 2009). On ECM trees, decreased leaf consumption was shown for generalist herbivores such as Anomala cupripes and Strepsicrates spp. on Eucalyptus urophylla (Gange et al., 2005), Otiorhyncus spp. larvae on Larix sibirica (Halldórsson et al., 2000) and Betula pubescens (Oddsdottir et al., 2010), and Lymantria dispar on Castanea dentata (Rieske et al., 2003) (Figure 1.5). The effect of ECM on herbivory by specialized poplar pest Chrysomela populi was investigated by Kaling et al. (2018) (Appendix 1). In a comprehensive transcriptomic and metabolomics analyses of systemic ECM-caused MIR effects in poplar leaves, Kaling et al (2018) showed that the expression of genes required in the flavonoid pathway was 


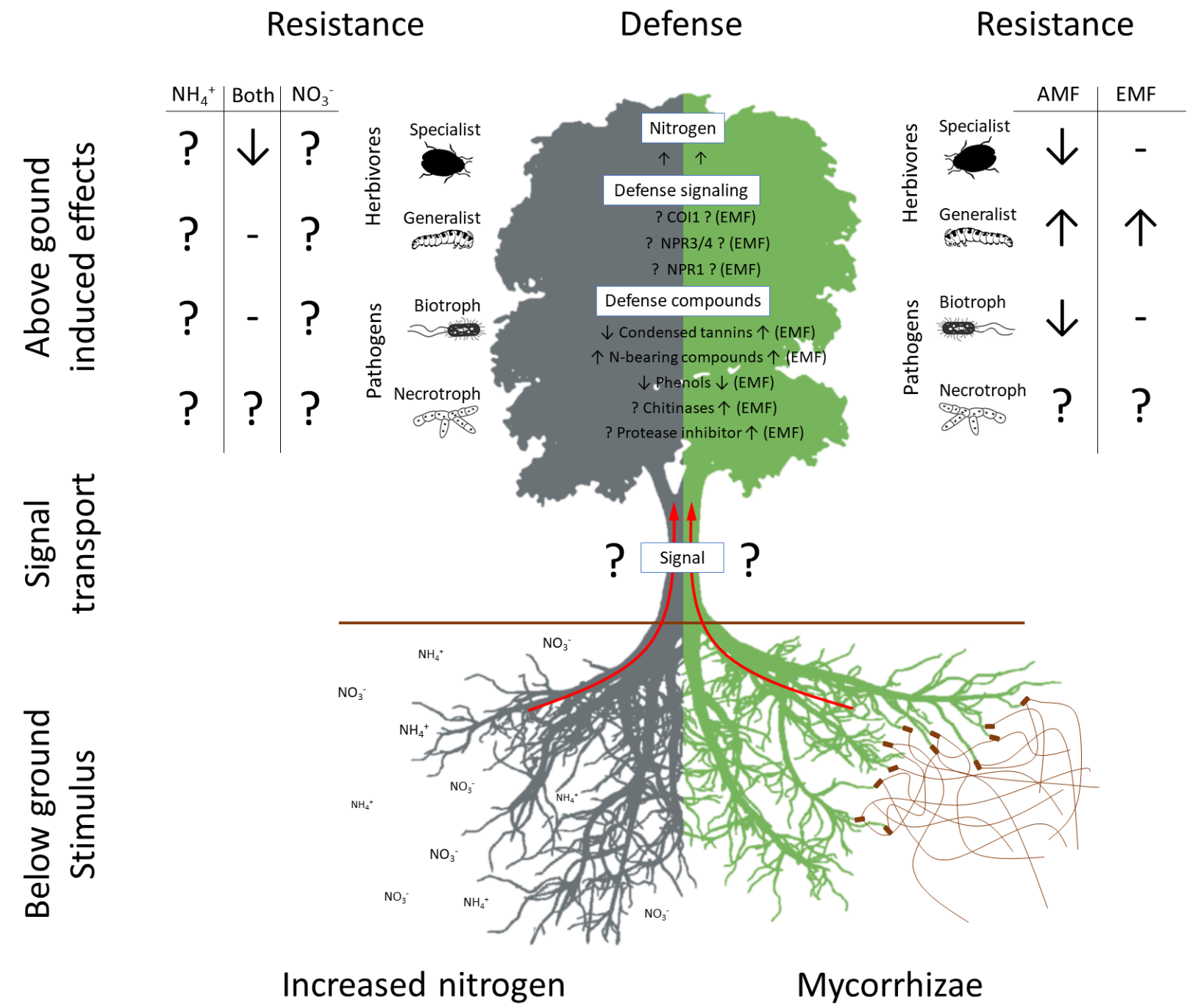

Figure 1.5: Overview of induced leaf defense changes and resistance by increased nitrogen and mycorrhizae. Information related to nitrogen is presented on the left, and to mycorrhizae on the right. The red arrows indicate direction of signal transport. Symbols indicate the effects, based on literature research: ?, no information available; $\uparrow$, increased/accumulated/enhanced expression; $\downarrow$, decreased/depleted/ reduced expression; -, no clear effect. $\mathrm{NH}_{4}{ }^{+}$, ammonium; $\mathrm{NO}_{3}{ }^{-}$, nitrate; both, $\mathrm{NH}_{4} \mathrm{NO}_{3} ; \mathrm{AMF}$, arbuscular mycorrhizal fungi; EMF, ectomycorrhizal fungi.

suppressed, while the aldoxime pathway was stimulated. These alterations were reflected in a modified leaf metabolome with less phenolic and more N-containing defense compounds (Figure 1.5) (Kaling et al. 2018). Among the N-bearing compounds, phenylacetaldoximes, which are highly toxic to insects (Irmisch et al., 2013), were significantly increased in herbivore-attacked poplar leaves of the mycorrhizal compared to the non-mycorrhizal poplars (Kaling et al., 2018). While foliage consumption was significantly, but not strongly reduced, poplar leaf beetles feeding on 


\section{Zusammenfassung}

ECM poplars showed drastically reduced egg production, supporting a systemic protective effect of ECM in poplar (Figure 1.5). Transcriptome analyses pointed to the involvement of JA-mediated defenses in ECM-caused MIR including accumulation of chitinases and protease inhibitors (Figure 1.5) (Kaling et al., 2018). This observation was underpinned when the influence of L. bicolor was studied in Arabidopsis. Although Arabidopsis - like all Brassicaceae (Fernández et al., 2019)cannot form mycorrhizal associations, the presence of $L$. bicolor enhances resistance against caterpillar (Trichoplusia ni) feeding (Vishwanathan et al., 2020). This response requires CERK1, JA signaling via COI1 and repression of SA signaling via NPR3/4 (Vishwanathan et al., 2020).

Information about MIR long-distance signal transmission is lacking. However, in root-rhizobia symbiosis, which show remarkable overlaps with AMF-symbiosis (C. Wang et al., 2018), specific peptides are generated in the roots and transported via the xylem to the shoots, where they are recognized by specialized receptors (Okamoto et al., 2013). Their recognition leads to the generation of signal molecules, transported basipetally via the phloem. At the roots they induce repression of further nodule formation, a mechanism called autoregulation of nodule formation (Okamoto et al., 2013). Obviously, the xylem sap functions as transport medium for long-distance signal transport in symbiotic root-shoot communication of rhizobia. Whether this is also true for ECM is still unknown.

The symbiosis between plants and EMF can lead to increased nitrogen nutrition of poplars (Gunderson et al., 2007; Kaling et al., 2018). Besides plant development and productivity, nitrogen metabolism is also linked to plant resistance (Mur et al., 2017). Not only the concentration of nitrogen, but also the plant available chemical forms, $\mathrm{NO}_{3}{ }^{-}$or $\mathrm{NH}_{4}{ }^{+}$influence the outcome of plantpathogen interactions (Mur et al., 2017). Enhanced N availability often shifts the balance between growth and defense, affecting plant resistance (Solomon et al., 2003). For example, Bryant et al. (1987) showed that increased $N$ availability in $P$. tremuloides results in increased leaf nitrogen contents, decreased condensed tannins, decreased phenol glycoside concentrations and a weight increase of specialist herbivore Choristoneura conflictana larvae feeding on the leaves (Figure 1.5). Along the same line, Populus spp. responded to low $N$ availability by increasing the concentrations of phenol glucosides, a critical class of poplar defense metabolites (Bryant et al., 1987; Lindroth \& Hwang, 1996). To explain the role of nitrogen in defense, Jones and Last (1991) suggested that a modification of the leaf carbon-to- $\mathrm{N}$-ratio in favor of $\mathrm{N}$ affects herbivory in two 
ways, firstly, pests feeding on foliage are offered a less attractive diet, and secondly $\mathrm{N}$ can be used by the plant to build up defensive compounds, e.g., aldoxime-derived cyanogenic glucoside (Sibbesen et al., 1995). This suggestion was supported by the study of Kaling et al. (2018). They showed that ECM P. x canescens plants contain higher leaf $\mathrm{N}$ concentration and shifted defense compounds from phenol- to $\mathrm{N}$-based defenses. However, at variance with these observations, in Betula pubescens ssp. tortuosa increased $\mathrm{N}$ fertilization had no effect on herbivory by larvae of generalist Epirrita autumnata, despite reduced amounts of phenolics and condensed tannins in the leaves (Figure 1.5) (Ruohomaki et al., 1996). Similarly, reduced N fertilization of Salix myrsinifolia resulted in increased leaf phenol concentrations but not in differences in infection severity of the biotrophic pathogen Melampsora sora compared to well fertilized plants (Figure 1.5) (Hakulinen, 1998). Therefore, it is still a matter of debate how differences in nitrogen influence the resistance levels in plants and whether or not EMF play a decisive role via nutrient modifications.

\subsection{Aims of the present study}

While the effects of nitrogen availability and MIR are currently intensively studied in crop plants and the model species Arabidopsis thaliana, much less in known about MIR in tree species (Figure 1.5). Earlier findings point to the xylem sap as a potential long-distance signal transportation medium in response to belowground stimuli but information on compositional changes of the xylem sap in response to changes in nitrogen nutrition and ECM are unavailable (Figure 1.5). No data are available for the effects of $\mathrm{N}$ supply and mycorrhizae on disease severity of necrotrophic or xylem inhabiting pathogens in trees (Figure 1.5). This lack of knowledge demonstrates the clear need for pathogen assays in a tree model species. Therefore, the main goals of the present work were to characterize the $P$. x canescens xylem sap composition and leaf transcriptome under the influences of different nitrogen availabilities and ECM. A further goal was to establish and apply test systems for a xylem sap pathogen and a necrotrophic $P$. $x$ canescens leaf pathogen. To achieve these aims, 
- the effects of different nitrogen concentrations and forms on xylem sap composition and poplar ( $P$. x canescens) resistance were tested. The proteomic and metabolomic xylem sap compositions were characterized to identify differences in potential long-distance signaling and defense compounds. The impact of differences in $\mathrm{NO}_{3}{ }^{-}$and $\mathrm{NH}_{4}{ }^{+}$supply on defense capabilities were tested by leaf transcriptome analysis, and a xylem sap and a leaf pathogen assay. The assays were used to study the growth of Brennaria salicis and the disease severity caused by Marssonina castagnei. To address these goals, a microscale xylem sap pathogen assay and a necrotrophic leaf pathogen assay were established (Chapter 2).

- the impact of ECM colonization of poplar roots on xylem sap proteomic and metabolomic composition, the presence of potential signaling compounds and the growth of the xylemresiding bacteria, Brennaria salicis were investigated. The leaf transcriptome of ECM and non-ECM poplar were studied under axenic conditions to identify mechanisms involved in ECM-caused MIR (Chapter 3).

The thesis concludes with a synopsis, in which a critical assessment of the experimental set up, wider conclusions and an outlook for future work are presented (Chapter 4). 


\section{Chapter 2: Multi-omics of xylem sap uncovers dynamic modulation of poplar defenses by ammonium or nitrate feeding}

\subsection{Introduction}

Nitrogen $(\mathrm{N})$ is a key plant growth factor, required for almost all plant functions (Marschner, 2011). In nature, $\mathrm{N}$ is present in inorganic forms as ammonium $\left(\mathrm{NH}_{4}{ }^{+}\right)$and nitrate $\left(\mathrm{NO}_{3}{ }^{-}\right)$and in organic forms, such as proteins, peptides, amino acids and others (Marschner, 2011). The dominant forms available for plant nutrition are nitrate and ammonium. Their concentrations in the environment are highly variable, depending on soil type, microbial $\mathrm{N}$ turn-over, atmospheric deposition and many other factors (Nie et al., 2017). Anthropogenic activities increase soil nitrogen in many regions, leading to excess of about $100 \mathrm{~kg} \mathrm{~N} \mathrm{ha}^{-1}$ on $23 \%$ of Germany's agricultural areas (Häußermann et al., 2019). In forests, $N$ is often a limiting factor for tree growth but large-scale $\mathrm{N}$ deposition has also increased $\mathrm{N}$ availability in many forest ecosystems (Rennenberg \& Dannenmann, 2015). Enhanced $\mathrm{N}$ availability causes growth promotion of forest trees, often resulting in nutrient imbalances (Rennenberg \& Dannenmann, 2015). Excess $\mathrm{N}$ has a number of negative consequences such as an enhanced release of the greenhouse gas $\mathrm{N}_{2} \mathrm{O}$ to the atmosphere (Merbach et al., 1996) and soil acidification with adverse effects on tree health and forest biodiversity (Jandl et al., 2012). It is therefore important to better understanding how longliving tree species cope with varying $\mathrm{N}$ in the environment.

Nitrogen is taken up by plant roots, metabolized and transported via the xylem sap to the leaves for further metabolization (Marschner, 2011). The influence of different $\mathrm{N}$ forms and concentrations on xylem sap composition has been evaluated in trees for $\mathrm{N}$ transport compounds (Gessler et al., 1998, 2004; Kato, 1981; Siebrecht \& Tischner, 1999; Tromp \& Ovaa, 1976; Weber et al., 1998). Siebrecht and Tischner (1999) reported concentrations of approximately $3 \mathrm{mM}$ nitrate and up $15 \mathrm{mM}$ glutamine- $\mathrm{N}$ in poplar xylem sap. The $\mathrm{N}$-containing metabolites varied with daytime, being high in the light phase and low at night (Siebrecht \& Tischner, 1999). After switching from nitrate to ammonium nutrition, the nitrate concentration in the xylem of poplar dropped quickly and the $\mathrm{NH}_{4}{ }^{+}$concentration increased (Siebrecht \& Tischner, 1999). In addition to mineral nutrients and amino acids, xylem sap also contains a huge array of proteins with roles in cell wall formation and defense (Dafoe \& Constabel, 2009; Pechanova et al., 2010). However, 


\section{Zusammenfassung}

comprehensive analyses, if and how changes in ammonium or nitrate availabilities influence the metabolome and proteome of the xylem sap are lacking.

Ecological studies reported that nitrogen nutrition affects the balance between growth and defense compounds, thereby, interfering with biotic stress tolerance (Harding et al., 2009; Manninen et al., 1998; Nerg et al., 2008; Rubert-Nason et al., 2015). For example, high nitrogen availability results in decreased tannin concentrations in poplar leaves (Madritch \& Lindroth, 2015) and enhanced development of the leaf feeding larvae of Choristoneura conflictana (Bryant et al., 1987). While studies with tree species are scarce, infection with fungal pathogens was investigated in various agricultural crops supplied with different $\mathrm{N}$ fertilizers (Mur et al., 2017). Under low $\mathrm{N}$, spore production of leaf rust on wheat was $70 \%$ reduced compared with high $\mathrm{N}$ supply (Robert et al., 2002). Powdery mildew disease severity on barley increased with increasing $\mathrm{N}$ supply (Jensen \& Munk, 1997). Furthermore, the $\mathrm{N}$ form - nitrate or ammonium - affected the interplay between plant defense and pathogen performance (Mur et al., 2017). Obviously, the xylem sap conveys information on changes in plant nutrition from roots to leaves but the consequences of these changes for foliar defense systems and pathogen susceptibility have not yet been studied.

The main aim of the present work was a comprehensive characterization of the metabolomes and proteomes in Populus $x$ canescens xylem sap in response to increasing nitrogen supplied either as nitrate or as ammonium. A further important goal was to investigate the responses of the leaf defense transcriptome to changes in $\mathrm{N}$ supply. To achieve these goals, Populus $\mathrm{x}$ canescens were cultivated in a sand : peat mixture and supplied with nutrient solutions containing low (0.4 mM), medium $(2.0 \mathrm{mM})$ or high $(8.0 \mathrm{mM})$ concentrations of $\mathrm{NH}_{4}{ }^{+}$or $\mathrm{NO}_{3}{ }^{-}$. We found divergent effects of $\mathrm{N}$ on the xylem sap composition of amino acids, carbohydrates, organic acids, secondary compounds and phytohormones. Protein diversity in the xylem sap increased with increasing $\mathrm{N}$ supply. Leaf transcriptomes exhibited low-nitrate driven activation of salicylic acid and high nitrogen-driven activation of jasmonate-related defenses. Bioassays were conducted to test whether changes in $\mathrm{N}$ nutrition affected poplar susceptibility to biotic stress. We investigated the growth of the gram-negative bacterium Brennaria salicis (formerly Erwinia salicis) in poplar xylem sap. B. salicis is known to live as an endophyte in the vascular system of Populus spp. (Maes et al., 


\section{Zusammenfassung}

2009) and is the causal agent of the watermark disease in Salix spp. (Day, 1924; Huvenne et al., 2009). Furthermore, we used leaf assays to study disease severity caused by the necrotrophic pathogen Marssonina castagnei (Desm. + Mont) Magn., (Call \& St. Clair, 2017), which is the causal agent of poplar leaf anthracnose (Spiers, 1989).

\subsection{Materials and methods}

\subsubsection{Plant propagation and nitrogen treatment}

Populus x canescens, clone INRA 717 1B4 (INRA, Nancy, France), plants were propagated and cultivated as described by Müller et al. (2013). Plants were in vitro multiplied by micro cuttings and grown on solid, half strength Murashige \& Skoog medium (Murashige \& Skoog, 1962) containing in $1 \mathrm{~L}$ deionized $\mathrm{H}_{2} \mathrm{O} 2.2 \mathrm{~g}$ MS medium (Duchefa Biochemie, Haarlem, Netherlands), $10 \mathrm{~g}$ sucrose (Duchefa), $0.5 \mathrm{~g}$ 2-(N-morpholino)ethanesulfonic acid (ULTRON grade, Merck, Darmstadt, Germany), and $5 \mathrm{~g}$ Gelrite (Duchefa), pH 5.7. The plantlets were kept for four weeks at $23{ }^{\circ} \mathrm{C}$ to $24{ }^{\circ} \mathrm{C}, 60$ to $85 \mu \mathrm{E} \mathrm{m} \mathrm{m}^{-2} \cdot \mathrm{s}^{-1}$ photosynthetically active radiation (PAR) and a $16 \mathrm{~h} / 8 \mathrm{~h}$ day/night regime. Rooted plantlets were transferred to the greenhouse and further cultivated at $21^{\circ} \mathrm{C}$ under ambient light with additional illumination of $150 \mu \mathrm{E} \mathrm{m} \mathrm{m}^{-2} \cdot \mathrm{s}^{-1} \mathrm{PAR}$ and a 16/8 $\mathrm{h}$ day/night cycle. They were potted into $0.65 \mathrm{~L}$ pots (Lamprecht-Verpackungen $\mathrm{GmbH}$, Göttingen, Germany) containing a mixture of washed and twice autoclaved sand (0.71 to 1.21 $\mathrm{mm}$ and 0.4 to $0.8 \mathrm{~mm}$ particle size (8:2 v/v), Dorfner $\mathrm{GmbH}$, Hirschau, Germany) and soil (Fruhstorfer Erde 'Nullerde', Hawita Gruppe GmbH, Vechta, Germany) at a ratio of 10:2 (v/v). For acclimation to greenhouse conditions, the plants were covered individually with a transparent plastic beaker for one week, which was gradually lifted during the second week and removed after 14 days. During the acclimation phase, all plants were daily irrigated with modified Long Ashton nutrient solution (cf. supplemental Table S2.1, after Hewitt, 1952) containing $2 \mathrm{mM} \mathrm{KNO}_{3}$. Excess nutrient solution ran off. The acclimated plants were divided into two groups and watered daily with modified Long Ashton nutrient solution, containing either ammonium (2 $\left.\mathrm{mM} \mathrm{NH}_{4} \mathrm{Cl}\right)$ or nitrate (2 $\mathrm{mM} \mathrm{KNO}_{3}$ ) as nitrogen sources (supplemental Table S2.1). The plants were irrigated daily and irrigation volume was increased with increasing plant height $(>10 \mathrm{~cm}, 50 \mathrm{~mL} ; 11$ to $30 \mathrm{~cm}, 100 \mathrm{~mL} ; 31-60 \mathrm{~cm}, 150 \mathrm{~mL} ;>61 \mathrm{~cm}, 250 \mathrm{~mL}$ ). The plants were transferred into $3 \mathrm{~L}$ pots (Lamprecht-Verpackungen) containing the same soil/sand mixture as above after 4 weeks of 


\section{Zusammenfassung}

greenhouse cultivation. After eight weeks of ammonium or nitrate pre-treatment, each group was split into three subgroups and supplied with $0.4 \mathrm{mM}(\mathrm{L}), 2.0 \mathrm{mM}(\mathrm{M})$ or $8.0 \mathrm{mM}(\mathrm{H}) \mathrm{NH}_{4} \mathrm{Cl}$ or $\mathrm{KNO}_{3}$, respectively, for three weeks (Experimental setup in supplemental Fig. S2.1). Each of the six treatment groups consisted of 10 to 12 individual plants, which were randomized regularly. The experiment was repeated three times but not all measurements were possible in all replications.

\subsubsection{Phenotype measurements}

The stem was marked $2 \mathrm{~cm}$ above ground. Growth measurements started 14 days after cultivation of the plants in the greenhouse and were conducted regularly once a week. Plant height was measured with a folding ruler and stem diameter was measured with an electronic caliper (Tchibo GmbH, Hamburg, Germany) at the marked position. Leaves were counted, taking into account only fully developed leaves with a length of the leaf blade longer than $2.5 \mathrm{~cm}$. The final measurements were conducted at the day of harvest.

\subsubsection{Gas exchange measurements}

Gas exchange was measured one day before harvest. A portable photosynthesis system (LI-6800, LI-COR Biosciences $\mathrm{GmbH}$, Bad Homburg, Germany) was attached to a fully developed top leaf with a blade length greater than $10 \mathrm{~cm}$, which was not shaded by other leaves. Measurements of net photosynthesis, transpiration, and stomatal conductance were conducted under saturating light conditions provided by photosynthesis system (PAR of $800 \mu \mathrm{E} \mathrm{m}^{-2} \mathrm{~s}^{-1}$ ) and at ambient $\mathrm{CO}_{2}$ concentrations of $387 \pm 17 \mathrm{ppm}$ and a mean leaf temperature of $32.6 \pm 4.7^{\circ} \mathrm{C}$. Each leaf was acclimated to the measuring conditions for $60 \mathrm{~s}$ and then measured 3 or 4 times in intervals of 60 s. Mean values of the repeated measurements were calculated and used for further analyses.

\subsubsection{Harvest and xylem sap extraction}

After 13 weeks of greenhouse cultivation, the plants ( $n=10$ to 12 per treatment and experiment) were harvested randomly within one day, starting after $3 \mathrm{~h}$ in the light phase. The shoot was cut $5 \mathrm{~cm}$ above the soil surface. The shoot was immediately separated into bark, wood, and leaves. Aliquots of tissues were weighed (lowest $5 \mathrm{~cm}$ of the debarked stem, a fully expanded $8 \mathrm{~cm}$-long 


\section{Zusammenfassung}

leaf), shock-frozen in liquid nitrogen and stored at $-80^{\circ} \mathrm{C}$. Three leaves, one fully expanded from the top, one from the middle section and one from the lower part of the plant were weighed separately and a photo was taken with a measuring scale and used for leaf area analysis with ImageJ (https://imagej.nih.gov/ij/, v. 1.52i, downloaded 2016). All leaves and the remaining stem were weighed separately and dried in paper bags for 7 days at $60^{\circ} \mathrm{C}$ and weighed again. To obtain the complete dry mass of a plant, the mass of the samples removed for other analyses was taken into account.

For xylem sap harvest, a modified protocol using the natural root pressure was used (Schurr, 1998). Immediately after removing the shoot, a strip of the top $1.5 \mathrm{~cm}$ of bark of the stump was removed by cutting with a razor blade through the bark and cambium and then peeling it off. The exposed wood was washed with deionized $\mathrm{H}_{2} \mathrm{O}$ and blotted with a paper towel. When the first drops of xylem sap accumulated on the cut wood surface, they were removed by washing with deionized $\mathrm{H}_{2} \mathrm{O}$ and the stump was blotted. Then, a $4 \mathrm{~cm}$ long piece of tight-fitting tube (Tygon ${ }^{\circledR}$, RCT GmbH \& Co., Heidelberg, Germany) was slipped over the exposed wood and secured at the stump with sticky tape (Durapore ${ }^{\circledR}, 3 \mathrm{M}$ Deutschland $\mathrm{GmbH}$, Neuss, Germany). The sap was pipetted into a $1.5 \mathrm{ml}$ ice cold reaction vessel (Eppendorf AG, Hamburg, Germany) every 10 minutes using a separate glass pipette for each plant. The xylem sap was collected for exactly $4 \mathrm{~h}$ and the samples were stored at $-80^{\circ} \mathrm{C}$.

After xylem sap harvest, the roots and soil were removed from the pot. The roots were washed, weighed, an aliquot was frozen in liquid nitrogen and stored at $-80^{\circ} \mathrm{C}$. The remaining part was dried and kept for further analyses.

\subsubsection{Test of xylem sap contamination}

To test for cytosolic contamination, we analyzed glucose 6-phosphate dehydrogenase activities in wood and xylem sap similar as described by (Polle et al., 1990). Frozen wood was milled (Ball mill MM200, Retsch GmbH, Haan, Germany) whilst cooling with liquid nitrogen. Then, 300 mg of the wood powder or $300 \mu \mathrm{L}$ of the xylem sap were added to $2 \mathrm{~mL}$ of extraction buffer $(0.1 \mathrm{M}$ sodium phosphate buffer, containing $0.5 \%$ Triton X-100 (Serva Electrophoresis GmbH, Heidelberg, Germany) and 200 mg insoluble polyvinylpyrrolidone, pH 7). The extraction buffer was prepared one day before use to enable swelling of the insoluble polyvinylpyrrolidone and kept at $4^{\circ} \mathrm{C}$. The extraction was done by mixing, incubation for $15 \mathrm{~min}$ on ice and centrifugation 
at $15000 \times g$ at $4^{\circ} \mathrm{C}$ for $30 \mathrm{~min}$. Then $500 \mu$ of the supernatant was filtered through a gel column (NAP 5 Sephadex ${ }^{\circledR}$, Thermo Fisher Scientific Inc., Waltham, Massachusetts, USA), which was equilibrated and eluted with $1000 \mu \mathrm{L}$ Tris(hydroxymethyl)aminomethan (Tris)-buffer (50 mM Tris $\mathrm{HCl}$ (Roth), $1 \mathrm{mM} \mathrm{MgCl}$ (Merck), pH 8.1). Glucose-6-phosphate activity was determined spectrophotometrically (Bergmeyer, 1974). For this purpose, $500 \mu$ l Tris-buffer, $300 \mu$ filtered extract, $20 \mu \mathrm{l} 40 \mathrm{mM}$ glucose-6-phosphate (Sigma-Aldrich) and $20 \mu \mathrm{l} 35 \mathrm{mM} \mathrm{NADP}^{+}$(KMF OptiChem, Lohmar, Germany) were added to a cuvette, mixed vigorously and measured at the wavelength of $341 \mathrm{~nm}$ and at room temperature. The production of NADH was recorded for 6 min and the increase in absorbance was used to calculate the enzyme activity with an extinction coefficient of $6.22 \mathrm{mM}^{-1} \mathrm{~cm}^{-1}$. Glucose-6-phosphate dehydrogenase activities accounted for 0.867 \pm 0.065 nkat $\mathrm{g}^{-1}$ fresh weight $(\mathrm{n}=3)$ in wood and were not detected in xylem sap $(-0.002 \pm$ $0.021 \mathrm{nkat} \mathrm{ml}^{-1}, \mathrm{n}=3$ ). If we assume that glucose-6-phosphate activity was evenly present in the moisture of fresh wood (about 70\%), it corresponded to $1.24 \mathrm{nkat} \mathrm{ml}^{-1}$. With the maximum activity of glucose-6-phosphate dehydrogenase in xylem sap of $0.02 \mathrm{nkat} \mathrm{ml}^{-1}$, the potential contamination of xylem sap with cellular compounds from wood was below $1.6 \%$. We further corroborated by proteome analyses that glucose-6-phosphate was not detected in xylem sap (see below). Therefore, we considered cytosolic contamination of the xylem sap as negligible.

\subsubsection{Carbon and nitrogen analyses}

Aliquots of dry leaf, stem and root tissue were ground to a fine powder in a ball mill (20 s for leaves, 30 s for roots and stems, frequency 30, Type MM400, Retsch, Haan, Germany). Five mg of each sample was weighed into a tin cartouche (IVA Analysentechnik GmbH \& Co.KG., Meerbusch, Germany). Carbon and nitrogen concentrations were determined with an element analyzer (Vario Micro Cube ${ }^{\mathrm{TM}}$, Elementar Analysesysteme GmbH, Langensebold, Germany). Acetanilide (SigmaAldrich) was used as the standard. During sample combustion, $\mathrm{O}_{2}$ was flushed for 90 s. Autonulldelay was set to 30 s for $\mathrm{N}$ and $2 \mathrm{~s}$ for $\mathrm{C}$ measurement. Peak expectation time was $60 \mathrm{~s}$ for $\mathrm{N}$ and 120s for C, respectively. Each plant was considered as a biological replicate. 


\subsection{6 $\mathrm{NH}_{4}{ }^{+}$and $\mathrm{NO}_{3}{ }^{-}$analysis in xylem sap}

Xylem sap ammonium and nitrate concentrations were measured with ammonium and nitrate Spectroquant ${ }^{\circledR}$ kits (Merck) for spectrophotometric analyses.

For xylem sap $\mathrm{NH}_{4}-\mathrm{N}$ measurement, $100 \mu \mathrm{l}$ xylem sap was alkalized with $1000 \mu \mathrm{L}$ reagent $\mathrm{NH}_{4}-1$ to convert all $\mathrm{NH}_{4}$ ions to $\mathrm{NH}_{3}$ ions. In the presence of hypochlorite ions, $\mathrm{NH}_{3}$ is converted to monochloramin. By addition of a default portion (measured with plastic spoon delivered with kit) of a phenol (reagent $\mathrm{NH}_{4}-2$ ), an indophenol derivate is formed, which was measured after $15 \mathrm{~min}$ of incubation at room temperature in $1.5 \mathrm{~mL}$ cuvettes (Polysterol, Sarstedt) in a spectrophotometer (DUTM 640, Beckman Coulter Inc., Brea, CA, USA) at $690 \mathrm{~nm}$ and at room temperature.

For xylem sap $\mathrm{NO}_{3}-\mathrm{N}$ measurement, $100 \mu \mathrm{L}$ xylem sap was mixed with $1000 \mu \mathrm{L}$ sulfuric and phosphoric acid (reagent $\mathrm{NO}_{3}-1$ ) and $100 \mu \mathrm{L}$ 2,3-dimethylphenol (reagent $\mathrm{NO}_{3}$-2), incubated for $10 \mathrm{~min}$ at room temperature and measured in $1.5 \mathrm{~mL}$ UV cuvettes (Halbmikro, Brand GmbH \& Co KG, Wertheim, Germany) in the spectrophotometer (DUTM 640) at room temperature. Generation of 4-nitro-2,6-dimethylphenol was determined at $340 \mathrm{Fnm}$. Calibration curves ranging from 0 to $240 \mathrm{nmol}$ in $100 \mu \mathrm{l}$ were generated with the respective Spectroquant kits as above using $\mathrm{NH}_{4} \mathrm{Cl}$ and $\mathrm{KNO}_{3}$ and used to calculate the concentrations of $\mathrm{NH}_{4}{ }^{+}$and $\mathrm{NO}_{3}{ }^{-}$in xylem sap.

\subsubsection{Measurements of xylem sap protein concentrations}

Xylem sap protein concentrations were determined with Pierce ${ }^{\circledast}$ Coomassie Plus kit (Thermo Fisher Scientific), which is based on the Bradford method (Bradford, 1976). Fifty $\mu$ xylem sap and $50 \mu \mathrm{l}$ Coomassie Plus were mixed in a flat bottom 96 well micro titer plate (Greiner AG, Kremsmünster, Austria) and incubated for $10 \mathrm{~min}$ at room temperature. During incubation, the plates were centrifuged for $5 \mathrm{~min}$ at $4000 \times \mathrm{g}$ to remove bubbles. Absorbance was measured at $595 \mathrm{~nm}$ in a plate reader (Infinite M200 Pro ${ }^{\circledR}$, Tecan Group AG, Männedorf, Switzerland). A dilution series ranging from $1.25 \mathrm{\mu g} \mathrm{ml}^{-1}$ to $10 \mathrm{\mu g} \mathrm{ml}^{-1}$ bovine serum albumin (BSA, Merck) was used for calibration and processed together with the samples.

To test, if the protein assays were disturbed by low molecular weight compounds in the xylem sap, $0.5 \mathrm{ml}$ aliquots of xylem sap were filtered through Sephadex columns (PD SpinTrap ${ }^{\circledR}$ G-25, GE Healthcare, Chicago, II, USA) using Tris-buffer (50 mM Tris HCl (Roth), 1 mM MgCl (Merck), pH 


\section{Zusammenfassung}

8.1) for column equilibration and sample elution. The protein concentrations were measured as above in the filtered extracts. The mean protein concentration differences between filtered and non-filtered xylem sap samples were below $20 \%$ and not significant, we therefore used xylem sap without pretreatment for protein determination.

\subsubsection{Xylem sap metabolites and metabolomics}

\subsubsection{Targeted primary metabolite analysis}

Primary metabolites and amino acids were analyzed by a targeted gas chromatography - mass spectrometry (GC-MS) method. Chemicals and $\mathrm{H}_{2} \mathrm{O}$ used for sample processing were analytical grade (Fisher Scientific). The xylem sap samples were prepared for GC-MS as described by Rotsch et al. (2017). For this purpose, $50 \mu \mathrm{l}$ unprocessed xylem sap were transferred to a $2 \mathrm{~mL}$ reaction tube (Eppendorf) and $200 \mu \mathrm{L}$ extraction medium (methanol : chloroform : $\mathrm{H}_{2} \mathrm{O}$ in a ratio of 32.75 : 12.5 : 6.25, v/v/v) and $50 \mu \mathrm{L}$ allo-inositol $\left(0.05 \mathrm{mg}^{-1}\right.$, diluted 1:5 in $\left.\mathrm{H}_{2} \mathrm{O}\right)$ were added. After mixing and centrifugation for $2 \mathrm{~min}$ at $20.000 \times \mathrm{g}, 80 \mu \mathrm{L}$ of the upper phase were transferred to a new $2 \mathrm{~mL}$ reaction tube (Eppendorf) and evaporated under constant $\mathrm{N}_{2}$ stream. For metabolite derivatization, $15 \mu \mathrm{L}$ MOX (30 mg methoxamine in $1 \mathrm{~mL}$ pyridine) solution was added and the samples were incubated overnight, in the dark and at room temperature. For trimethylsilylation of functional groups, $30 \mu \mathrm{L} \mathrm{N}$-methyl-N-(trimethylsilyl)trifluoroacetamide were added and the sample was incubated for 1-6 h. Sample separation and fragmentation was done according to Hofvander et al. (2016). For this purpose, $1 \mu \mathrm{L}$ of sample was injected into the GC (Sigma-Aldrich 5973 Network mass selective detector attached to an Agilent 6890 gas chromatograph (Agilent Technologies, Santa Clara, CA, USA), equipped with a capillary HP5-MS column; Agilent, J\&W Scientific, Folsom, Ca, USA). Using internal standards, the Golm metabolome database (GMD) (Kopka et al., 2005) and the National Institute of Standards and Technology (NIST) spectral library 2.0f (NIST, 2005, Gaithersburg, MD, USA), metabolites were identified with the software MSD ChemStation D.01.02.16 (Agilent Technologies). Relative quantification was done by ion count intensity comparison to the internal standard allo-inositol. 


\subsubsection{Non-targeted metabolite fingerprinting}

Non-targeted metabolite fingerprinting was conducted with LC-MS as described in detail by Feussner \& Feussner (2019). In brief: a methyl tert-butyl ether (MTBE), methanol and $\mathrm{H}_{2} \mathrm{O}$ based two-phase extraction (Matyash et al., 2008) was used to extract polar, semipolar as well as nonpolar metabolites from the xylem sap. Two hundred $\mu \mathrm{l}$ thawed xylem sap were added to $750 \mathrm{ml}$ methanol and $2.5 \mathrm{ml}$ MTBE in a Kimble glass tube (Gerresheimer Glass, Inc., Vineland, NJ, USA). The sample was vortexed and shaken for $1 \mathrm{~h}$ in the dark at $6{ }^{\circ} \mathrm{C}$, subsequently, $600 \mu \mathrm{l} \mathrm{H}_{2} \mathrm{O}$ were added. After $10 \mathrm{~min}$ of incubation, samples were centrifuged at $800 \times \mathrm{g}$ for $15 \mathrm{~min}$, resulting in the separation of an upper (non-polar) and lower (polar) phase. Both phases were separately transferred to new glass vials. Another phase separation was done with the polar phase. The newly formed non-polar phase was added to the previous formed non-polar phase from the first phase separation, dried under constant $\mathrm{N}_{2}$ stream and subsequently dissolved in $0.5 \mathrm{ml}$ methanol,

vortexed, transferred to a $1.5 \mathrm{ml}$ reaction vessel (Eppendorf), centrifuged for $2 \mathrm{~min}$ at $16000 \times \mathrm{g}$ and dried under an $\mathrm{N}_{2}$ stream. For metabolite fingerprinting analysis, the samples were dissolved in $100 \mu \mathrm{l}$ acetonitrile/ $\mathrm{H}_{2} \mathrm{O}(2: 3(\mathrm{v} / \mathrm{v}))$ by shaking for $15 \mathrm{~min}$. The samples were centrifuged for $10 \mathrm{~min}$ at $16000 \times \mathrm{g}$. Eighty $\mu \mathrm{l}$ of the formed supernatant were transferred into a glass micro vial (12 mm, $250 \mu \mathrm{l}$, Macherey-Nagel GmbH, Dueren, Germany) fixed by a spring in HPLC glass vials (1.5 ml, N9, Macherey-Nagel). The lower extraction phase was transferred into a $2 \mathrm{ml}$ reaction vessel (Eppendorf) and dried under $\mathrm{N}_{2}$ stream. Samples were then dissolved in $100 \mu \mathrm{l}$ of $100 \%$ methanol, mixed, shaken for $5 \mathrm{~min}$, centrifuged for $5 \mathrm{~min}$ at $16000 \times \mathrm{g}$, and dried under $\mathrm{N}_{2}$ stream. Subsequently the samples were dissolved in $15 \mu \mathrm{l}$ of methanol by shaking for $10 \mathrm{~min}$. Fifteen $\mu \mathrm{l}$ acetonitrile were added and the samples were shaken for further $10 \mathrm{~min}$. After adding $100 \mu \mathrm{l}$ of $\mathrm{H}_{2} \mathrm{O}$, the samples were shaken for $10 \mathrm{~min}$ and then centrifuged for $10 \mathrm{~min}$ at $16000 \times \mathrm{g}$. One hundred $\mu \mathrm{l}$ of the samples were transferred to a glass micro vial. Samples of the polar and the nonpolar extraction phases were covered with argon and immediately used for metabolic fingerprinting analysis. For analyses Ultra-high-performance liquid chromatography (UHPLC LC 1290 Infinity (Agilent Technologies) or UPLC (Waters Corporation) coupled to high resolutionmass spectrometry (HRMS, 6540 UHD Accurate-Mass Q-TOF LC-MS instrument (Agilent Technologies) or TOF-MS LCT Premier (Waters Corporation) was used. The settings applied for the analyses of the samples were described in detail by Feussner and Feussner (2019). Accurate 
mass data of the LC-HRMS were obtained either with Mass Hunter Acquisition B.03.01 (Agilent Technologies) and analyzed with Mass Hunter Qualitative Analysis (Agilent Technologies) or with MassLynx 4.1 (Waters Corporation). Peak picking and alignment were performed with Profinder B.08.00 (Agilent Technologies) or with MarkerLynx XS (Waters Corporation) software. Metabolite annotation was done by manual interpretation of MS/MS spectra and database search (modified from (Abreu et al., 2020; Green et al., o. J.). For further data processing, statistics, visualization as well as for data mining the MarVis-Suite toolbox (http://marvis.gobics.de/, Kaever et al., 2015) was used.

\subsubsection{Phytohormone analyses in xylem sap}

An LC-MS approach was used for phytohormone analysis, as described by Herrfurth and Feussner (2020). For phytohormones extraction, $200 \mu \mathrm{L}$ unprocessed xylem sap and $750 \mu \mathrm{L}$ phytohormone solution (10 ng D4 jasmonoyl-leucine (JA-Leu) (provided by Otto Miersch, Halle/Saale, Germany), 10 ng D5 JA, 10 ng D4 salicylic acid (both from C/D/N Isotopes Inc., Pointe-Claire, Canada) in 750 $\mu \mathrm{L}$ methanol) were mixed. The phytohormones were extracted as described for non-targeted metabolite fingerprinting (as described above, chapter 2.2.8.3). The combined upper phases were evaporated under constant $\mathrm{N}_{2}$ stream and re-suspended in $100 \mu \mathrm{L}$ of acetonitrile : $\mathrm{H}_{2} \mathrm{O}(20: 80$, $\mathrm{v} / \mathrm{v})$, containing $0.3 \mathrm{mM} \mathrm{NH}_{4} \mathrm{HCOO}(\mathrm{pH} \mathrm{3.5}$, adjusted with formic acid). An ultra-performance liquid chromatography system (ACQUITY UPLCTM system, Waters Corp.) was used for reversed phase separation, followed by nanoelectrospray ionization (nanoESI) with a chip ion source (TriVersa Nanomate; Advion BioSciences, Ithaca, NY, USA). Ionized phytohormones were determined with an AB Sciex 4000 QTRAP $^{\circledR}$ tandem mass spectrometer (AB Sciex, Framingham, MA, USA) in negative mode. Phytohormone quantification was performed using an internal standard based calibration curve including the data intensity $(\mathrm{m} / \mathrm{z})$ ratios of unlabeled/deuteriumlabeled versus molar amounts of unlabeled standards.

\subsubsection{Xylem sap proteomics}

All solvents used for processing of xylem sap and the resulting proteins were liquid chromatography-mass spectrometry (LC-MS) or high performance liquid chromatography (HPLC) grade and obtained from Fisher Scientific (Hampton, NH, USA). Four-hundred $\mu \mathrm{L}$ xylem sap were 


\section{Zusammenfassung}

lyophilized (Freeze dryer, Piatkowski Forschungsgeräte-Vertrieb, München, Germany) for 5 days. For protein denaturation and to reduce disulfide bonds, the samples were dissolved in $60 \mu \mathrm{L}$ ammonium hydrogen carbonate (ABC, Fluka Analytical, now Sigma-Aldrich and further-on called Sigma-Aldrich) containing D-1,4-dithiothreitol (DTT, Sigma-Aldrich) (100 mM ABC, 100 mM DTT, 1:4, v/v) and $75 \mu \mathrm{L}$ 2,2,2-trifluoroethanol (TFE) and incubated for $30 \mathrm{~min}$ in a $60^{\circ} \mathrm{C}$ water bath. Samples were centrifuged at $16.000 \times g$ for $10 \mathrm{~min}$ and $100 \mu \mathrm{L}$ supernatant were transferred to a $1.5 \mathrm{~mL}$ low binding micro reaction tube (Eppendorf). For SH-group alkalization, $5 \mu \mathrm{L} 500 \mathrm{mM}$ iodoacetamide (IAA, Sigma-Aldrich) were added and the sample was incubated in darkness for 30 min. Subsequently, $50 \mu \mathrm{L} \mathrm{H}_{2} \mathrm{O}$ were added to dilute the sample. For protein precipitation, $620 \mu \mathrm{L}$ methanol and $200 \mu \mathrm{L}$ chloroform were added and the sample was carefully mixed after each addition. Subsequently, $70 \mu \mathrm{L} 625 \mathrm{mM} \mathrm{NaCl}$ (Merck) and $395 \mu \mathrm{L} \mathrm{H}_{2} \mathrm{O}$ were added. The sample was mixed and centrifuged for $20 \mathrm{~min}$ at $16100 \mathrm{xg}$. The proteins accumulated in the interphase. The upper phase was removed by pipetting without disturbing the inter phase. Five hundred $\mu \mathrm{L}$ methanol were added, the sample mixed and centrifuged for $20 \mathrm{~min}$ at $16.000 \times \mathrm{g}$. Thereby, a protein pellet was formed. The supernatant was carefully decanted. The protein pellet was dried with an open lid at room temperature for about 25 min and then dissolved in $50 \mu \mathrm{L}$ $100 \mathrm{mM}$ Tris $\mathrm{HCl}$ (pH 8.0, Roth) by sonication for 3 s. For protein digestion, $1 \mu \mathrm{L}$ trypsin solution (100 ng $\mu^{-1}$ Sequencing grade, Roche Deutschland Holding GmbH, Mannheim, Germany) in 10 $\mathrm{mM} \mathrm{HCl}$ (Merck) was added and the sample incubated for $16 \mathrm{~h}$ at $37^{\circ} \mathrm{C}$ in a water bath. Digestion was stopped by addition of $20 \mu \mathrm{L} 20 \mathrm{mM}$ ammonium formate (AF, Sigma-Aldrich). The sample was centrifuged for $20 \mathrm{~min}$ at $16.000 \times \mathrm{g}$ and the peptides in the supernatant were purified.

For peptide purification, STAGE tips (Rappsilber et al., 2003) were used. A triple layer filter matrix (C18 Empore ${ }^{\mathrm{TM}}$ Disks, 3M) was inserted into $20 \mu \mathrm{L}$ pipette tips (Gilson Company Inc., Columbus, $\mathrm{OH}, \mathrm{USA}$ ) and this STAGE tip mounted on a $0.5 \mu \mathrm{L}$ micro reaction tube (Eppendorf) in a centrifuge (5415R, Eppendorf) (Fig. 3.3). The STAGE tip was loaded with solvents by adding subsequently the following liquids, each followed by centrifugation: $10 \mu \mathrm{L}$ methanol, $1 \mathrm{~min}$ at $1.800 \times g, 20 \mu \mathrm{L} 100 \%$ acetonitrile (ACN), $1 \mathrm{~min}$ at $1.800 \times \mathrm{g}$, and $20 \mu \mathrm{L} \mathrm{AF}, 4 \mathrm{~min}$ at $1.800 \times \mathrm{g}$. Subsequently, $60 \mu \mathrm{L}$ of peptide solution were added and centrifuged for $10 \mathrm{~min}$ at $1.800 \times \mathrm{g}$. Fifteen $\mu \mathrm{L} 20 \mathrm{mM}$ AF were added and centrifuged for $2 \mathrm{~min}$ at $1.800 \times \mathrm{g}$, followed by $2 \mathrm{~min}$ at $2.600 \times \mathrm{g}$. For peptide elution, the STAGE tip was placed in a new, low-bind $0.5 \mu \mathrm{L}$ micro reaction tube (Eppendorf) and $40 \mu \mathrm{L}$ of 
$60 \%$ ACN in $20 \mathrm{mM} \mathrm{AF} \mathrm{(pH} \mathrm{10)} \mathrm{were} \mathrm{added} \mathrm{to} \mathrm{the} \mathrm{tip.} \mathrm{The} \mathrm{STAGE} \mathrm{tip} \mathrm{was} \mathrm{centrifuged} \mathrm{for} 4 \mathrm{~min}$ at $1.800 \times \mathrm{g}$, followed by $2 \mathrm{~min}$ at $3.000 \times \mathrm{g}$. The solution that had passed through the STAGE tip was evaporated in a vacuum concentrator (Eppendorf). Peptides were dissolved in $2 \%$ acetonitrile, $0.1 \%$ formic acid (FA) in $\mathrm{H}_{2} \mathrm{O}$ in a volume to obtain a final concentration of $6 \mathrm{ng}$ peptides in $100 \mu \mathrm{L}$ solvent, taking into account a $30 \%$ loss during processing.

Further sample processing was performed in the Service Unit for Proteomics of Goettingen University according to the following pipeline: $2 \mu \mathrm{L}$ of each sample were used for peptide separation by reverse phase liquid chromatography in an RSLCnano Ultimate 3000 system (Thermo Fisher Scientific). Proteomics were performed exactly as described by Horianopoulos et al. (2020): "Peptides were loaded on an Acclaim PepMap 100 pre-column (100 $\mu \mathrm{m}$ x 2 cm, C18,

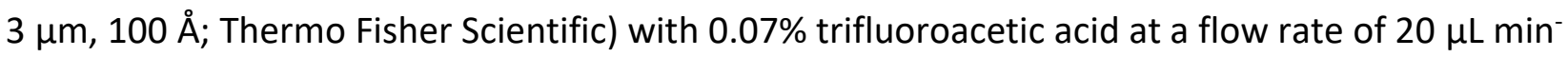
${ }^{1}$ for 3 min. Analytical separation of peptides was performed on an Acclaim PepMap RSLC column

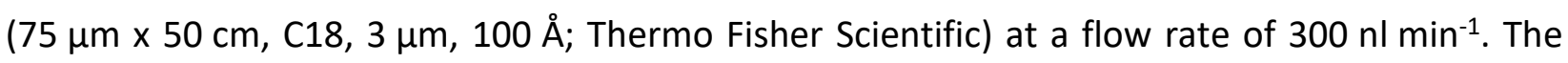
solvent composition was gradually changed within $94 \mathrm{~min}$, starting from $96 \%$ solvent A $(0.1 \%$ formic acid) and $4 \%$ solvent B ( $80 \%$ acetonitrile, $0.1 \%$ formic acid) to $10 \%$ solvent B within 2 minutes, to $30 \%$ solvent B within the next $58 \mathrm{~min}$, to $45 \%$ solvent B within the following $22 \mathrm{~min}$, and to $90 \%$ solvent B within the last 12 min of the gradient. All solvents were Optima grade for LC-MS (Thermo Fisher Scientific). The eluting peptides were on-line ionized by nano-electrospray (nESI) deploying the Nanospray Flex Ion Source (Thermo Scientific) at $1.5 \mathrm{kV}$ (liquid junction) and transferred into a Q Exactive High Field mass spectrometer (Thermo Fisher Scientific). Full scans in a mass range of 300 to $1650 \mathrm{~m} / \mathrm{z}$ were recorded at a resolution of 30,000 , followed by datadependent top 10 higher-energy collisional dissociation fragmentation at a resolution of 15,000 (dynamic exclusion enabled). LC-MS method programming and data acquisition were performed with the XCalibur 4.0 software (Thermo Fisher Scientific)."

The resulting raw data were used for protein identification using MaxQuant Software v1.6.6.0 (Cox \& Mann, 2008). For database search and annotation, a JGI/Phytozome12-derived Populus trichocarpa (v.3.1, Tuskan et al., 2006) specific database and the Andromeda algorithm (MaxQuant v.1.6.6.0) were used. Label-free quantification of annotated proteins was done with Perseus software v.1.6.6.0 (Cox \& Mann, 2008). The presence of a signal peptide, assigning proteins to the classical secretory pathway was determined with SignalP-5.0 Server 


\section{Zusammenfassung}

(http://www.cbs.dtu.dk/services/SignalP/, assessed 02/2020, Armenteros et al., 2019). Protein functional group assignment was done with MapMan (https://mapman.gabipd.org/, assessed 02/2020, Thimm et al., 2004). AgriGo (http://systemsbiology.cau.edu.cn/agriGOv2/index.php, accessed 10/2019, Du et al., 2010) was used for functional group enrichment analysis.

\subsubsection{Leaf transcriptome analysis}

One expanded top leaf that emerged after beginning of the nitrogen treatments was snap frozen in liquid nitrogen and stored at $-80^{\circ} \mathrm{C}$. Leaves from five $(8 \mathrm{mM}$ nitrogen treatments) or four plants of each of the other treatments were used for RNA sequencing (RNAseq) analyses. RNA extraction.

Leaves were homogenized to a fine powder, while cooling with liquid nitrogen. RNA was extracted with the innuPrep Plant RNA kit (Analytik Jena) (treatments $\mathrm{H} \mathrm{NH}_{4}{ }^{+}$and $\mathrm{H} \mathrm{NO}_{3}{ }^{-}$) or the CTAB (cetyltrimethyl ammoniumbromide) method similar as described by Chang et al. (1993): $150 \mathrm{mg}$ of frozen tissue powder was extracted in $800 \mu \mathrm{L}$ CTAB buffer ( $20 \mathrm{~g}$ hexadecyltrimethylammonium bromide (CTAB, Roth), $15.76 \mathrm{~g}$ Tris $\mathrm{HCl}$ (Roth), $9.505 \mathrm{~g}$ ethylenediaminetetraacetic acid (Roth), $116.88 \mathrm{~g} \mathrm{NaCl}$ (Merck), $20 \mathrm{~g}$ soluble polyvinylpyrrolidone (Sigma-Aldrich) and $16 \mu$ mercaptoethanol (Roth), dissolved in $1 \mathrm{~L}$ double deionized $\mathrm{H}_{2} \mathrm{O}_{\mathrm{dd}}$ ) and mixed vigorously. The mixture was incubated by shaking for $15 \mathrm{~min}$ at $65^{\circ} \mathrm{C}$ in a thermocell mixingblock (MB-105, $1.000 \mathrm{rpm}$, Hangzhou Bioer Technology, Hangzhou, China) and then 15 min at room temperature. Eight hundred $\mu \mathrm{L}$ of a chloroform (Roth) : iso-amylalcohol (Merck) (24:1 v/v) solution was added, followed by 15 min of incubation by shaking at room temperature in a thermocell mixingblock (MB-105, $1.400 \mathrm{rpm}$, Bioer). Then, the mixture was centrifuged at $21.000 \times \mathrm{g}$ for $5 \mathrm{~min}$ at room temperature for phase separation. The upper phase was transferred to a new $2 \mathrm{~mL}$ reaction tube (Eppendorf) and the middle and lower phase were discarded. The phase separation was repeated with the upper phase as described above until no middle phase formation was visible anymore. The resulting pure upper phase was transferred to a $1.5 \mu \mathrm{L}$ reaction tube (Eppendorf) and its volume was determined. A volume of $-20^{\circ} \mathrm{C}$ cold $10 \mathrm{M}$ lithium chloride (Merck) was added that corresponded to $25 \%$ of the upper phase volume and the sample was mixed. For RNA precipitation, the sample was incubated overnight on ice. Subsequently, the sample was 


\section{Zusammenfassung}

centrifuged for $20 \mathrm{~min}$ at $4{ }^{\circ} \mathrm{C}$ at $21.000 \times g$ and the supernatant was decanted. The pellet was resuspended in $400 \mu \mathrm{L}$ SSTE-buffer (per $100 \mathrm{~mL} \mathrm{H} \mathrm{O}_{\mathrm{dd}}$ : $0.5 \mathrm{~g}$ sodium dodecyl sulfate (Roth), $0.157 \mathrm{~g}$ Tris $\mathrm{HCl}$ (Roth), $0.042 \mathrm{~g}$ EDTA (Roth), $5.844 \mathrm{~g} \mathrm{NaCl}$ (Merck), pH 8.0) and shaken for $10 \mathrm{~min}$ at $42{ }^{\circ} \mathrm{C}$ on a thermo block (MB-105, $850 \mathrm{rpm}$, Bioer). For purification of the RNA, $400 \mu \mathrm{L}$ chloroform : isoamylalcohol (Merck) (24:1 v/v) were added and the sample was centrifuged at $22.000 \times \mathrm{g}$ for $5 \mathrm{~min}$ at room temperature. The upper phase was transferred to a new $1.5 \mathrm{~mL}$ reaction tube and extracted with $400 \mu \mathrm{L}$ chloroform : isoamyl alcohol solution as above. The procedure was repeated until no phase separation occurred anymore. The resulting upper phase was added to $800 \mu \mathrm{L}$ of pre-cooled $\left(-20^{\circ} \mathrm{C}\right) 96 \%$ ethanol in a $1.5 \mathrm{~mL}$ reaction tube (Eppendorf). For precipitation, the sample was incubated at $-80^{\circ} \mathrm{C}$ for $1 \mathrm{~h}$. Then, it was centrifuged for $20 \mathrm{~min}$ at $4{ }^{\circ} \mathrm{C}$ and $21.000 \times g$. The supernatant was decanted and $500 \mu \mathrm{L} 70 \%$ ethanol were added and the sample subsequently centrifuged for $10 \mathrm{~min}$ at $21.000 \times \mathrm{g}$ and room temperature. The supernatant was removed, $80 \mu \mathrm{L}$ ethanol added and the sample centrifuged for $10 \mathrm{~min}$ at 21.000 $\mathrm{x} g$ and room temperature. Then, ethanol was evaporated in a vacuum concentrator (Thermo Savant SpeedVac SPD111V , Fisher Scientific) at $45^{\circ} \mathrm{C}$. The pellet was resuspended in $30 \mu \mathrm{L}$ RNAsefree $\mathrm{H}_{2} \mathrm{O}$ (Applichem $\mathrm{GmbH}$, Darmstadt, Germany) by mixing the sample for 10 min at $42{ }^{\circ} \mathrm{C}$ in a thermocell mixingblock (850 rpm, Bioer). The purified RNA samples were stored at $-80{ }^{\circ} \mathrm{C}$ for further processing.

\subsubsection{RNA sequencing}

RNA concentration and purity were measured with a spectrophotometer (NanoDrop2000, Thermo Fisher Scientific) and $A_{260} / A_{280}$ values of approximately 2 were considered acceptable for RNA sequencing. The RNA concentrations of the leaf samples ranged from 92 to $2000 \mathrm{ng} \mathrm{LL}^{-1}$. For RNA sequencing and library generation, we used $10 \mu \mathrm{L}$ of each sample containing at least $1 \mu \mathrm{g}$ RNA and $3 \mu \mathrm{L}$ for RNA integrity number (RIN) value determination. These analyses were conducted by Chronix Biomedical (Göttingen, Germany), using the RNA Nano Chip Kit (Bioanalyzer 2100, Agilent Technologies). Of 5 analyzed samples, the four samples with highest RIN values were used for further processing (Supplemental Table S2.2). Enrichment of Poly-A RNA was performed with the New England Biology (NEB)-Next Poly (A) mRNA Magnetic Isolation Module (New England Biolabs, Ipswich, MA, USA) following manufacturers' manual. Seventyfive bp single-read sequences were generated using NextSeq500 (Illumina, Inc., San Diego, C, 
USA) instrument. The sequences were used to create libraries with NEBNext Ultra RNA Library Prep Kit for Illumina (New England Biolabs).

\subsubsection{Bioinformatic analysis of RNAseq data}

Adapter trimming and quality filtering was done with fastP, using default parameters (Chen et al., 2018). Criteria for quality filtering included base accuracy, $N$ base number and read length. This procedure resulted in $13 \times 10^{6}$ to $21 \times 10^{6}$ reads per sample (Supplemental Table S2.2). Reads were mapped against the Populus tremula x alba 717-1B4 data base (Mader et al., 2016), v. 2, downloaded from http://aspendb.uga.edu) with the read alignment tool Bowtie2 (Langmead \& Salzberg, 2012). The relative number of reads successfully mapped to a gene model ranged from $89 \%$ to $94 \%$ (with one outlier, $\mathrm{M} \mathrm{NH}_{4}{ }^{+}{ }_{-} 2=77.47 \%$ ) in our samples (Supplemental Table S2.2). Linux command-line utility grep (Torvalds, 2015) was used to extract information from mapping files, which were integrated to count tables with statistical software R base version (R Core Team, 2014). In R, package DESeq2 (Love et al., 2014) was used to identify differentially expressed genes (DEGs) between the treatments. The criteria of DEG were set to $p<0.05$ and a fold change of below 0.5 or above 2.0. Raw data were deposited in the ArrayExpress database (http://www.ebi.ac.uk/arrayexpress) under the accession number E-MTAB-8930. DEGs per treatment were mapped on KEGG pathways ( https://www.genome.jp/kegg/, assessed 02/2020, Kanehisa \& Goto, 2000). Gene ontology enrichment analyses were executed with Metascape (https://metascape.org, accessed 06/2020, Zhou et al., 2019). To identify DEGs with roles in poplar microbe, wounding and phytohormone interactions, DEGs provided by Kaling et al. (2018), Luo et al. (2019), Phlippe et al. (2010) and Rinaldi et al. (2007) were downloaded and used in silico for searches of overlap genes.

\subsubsection{Growth assay of Brennaria salicis in xylem sap}

Bacterial stocks of Brennaria salicis (formerly Erwinia salicis) strain PD135 (NCCB 87018) were purchased from the Westerdijk Fungal Biodiversity Institute (Wageningen, Netherlands). B. salicis was stored in glycerol stock at $-80^{\circ} \mathrm{C}$ and reactivated on tryptic soy broth (TSB) plates (Art, No. 100550, Merck). After $24 \mathrm{~h}$ incubation at $22{ }^{\circ} \mathrm{C}$ in the dark, one inoculation loop filled with bacterial cells was added to $30 \mathrm{~mL}$ liquid TSB. The solution was incubated at $28^{\circ} \mathrm{C}$ and $160^{\circ} \mathrm{rpm}$ for $24^{\circ} \mathrm{h}$ (Maes et al., 2009). Of the bacterial solution, $1.5 \mathrm{~mL}$ were transferred to a $2 \mathrm{~mL}$ reaction 


\section{Zusammenfassung}

vessel (Sarstedt). The bacteria were spun down at $3930 \times g$ (Rotanta 96R, Hettich GmbH \& Co. KG, Tuttlingen, Germany) and the supernatant was discarded. Optical density (OD), measured at $600 \mathrm{~nm}$, was adjusted to OD = 1 by diluting the culture with $1 \mathrm{mM} \mathrm{MgCl}$ (R. L. Smith \& Maguire, 1998). Eight replicates of $100 \mu \mathrm{l}$ xylem sap of each nitrogen treatment and 8 controls $\left(100 \mu \mathrm{l} \mathrm{H}_{2} \mathrm{O}\right)$ were added to a flat bottom, 96-well plate (Greiner) and $2.5 \mu \mathrm{L}$ bacterial solution was added. The plate was introduced to an automated plate reader (Infinite 200Pro, Tecan) and incubated for $24 \mathrm{~h}$ using the following modified protocol (Tecan Trading AG, 2012): During incubation the temperature was set to $28{ }^{\circ} \mathrm{C}$ and orbital amplitude to $5 \mathrm{~mm}$. The OD was measured at $600 \mathrm{~nm}$ every $30 \mathrm{~min}$.

\subsubsection{Leaf pathogen assay}

The necrotrophic pathogenic fungus Marssonina castagnei (Desm. + Mont) Magn., (Call \& St. Clair, 2017) strain Cs2 (ATCC 56782) was purchased from American type culture collection (Manasas, VA, USA). For reproduction and sporulation, the fungus was cultured for three months on nutrient medium (20 g malt extract agar for microbiology (Art. No. 70145, Merck) and 15 g Micro agar (Art. No. M1002, Duchefa Biochemie, Haarlem, Netherlands) in $1 \mathrm{~L}^{-1} \mathrm{H}_{2} \mathrm{O}$ ) at $22^{\circ} \mathrm{C}, 60 \%$ air humidity, 125 $\mu \mathrm{E} \mathrm{m} \mathrm{m}^{-2} \cdot \mathrm{s}^{-1} \mathrm{PAR} 12 / 12 \mathrm{~h}$ day/night cycle. To harvest the conidia, the culture was rinsed with autoclaved tap water and the fluid was collected in a $50 \mathrm{~mL}$ reaction tube (Sarstedt). Then, fungal tissue was removed from the culture medium with a scalpel and transferred to the reaction tube containing the fluid with the conidia. Autoclaved tap water was added until all fungal material was covered. The solution was shaken for $20 \mathrm{~min}$ on a plate shaker at $190 \mathrm{rpm}$. To separate the approximately $20 \mu \mathrm{m}$ long conidia from the fungal hyphae, the mixture was filtered through a $100 \mu \mathrm{m}$ cell strainer (Th. Geyer GmbH \& CO. KG, Renningen, Germany) and the liquid was collected in a new $50 \mathrm{ml}$ reaction tube. The suspension was then centrifuged for $5 \mathrm{~min}$ at $9.000 \mathrm{x}$ $g$ and the supernatant reduced to approximately $3 \mathrm{~mL}$ with a $20 \mathrm{~mL}$ glass pipette (Sarstedt) attached to an automated pipette controller (Pipetboy, Integra Biosciences GmbH, Biebertal, Germany). The pellet was then suspended in the remaining solution and the spore concentration determined with a Neubauer improved hemocytometer (Paul Marienfeld GmbH \& Co. KG, LaudaKönigshofen, Germany). The spore concentration was adjusted to $500.000 \mathrm{ml}^{-1}$ by addition of autoclaved tap water or repeated centrifugation and removal of supernatant. 


\section{Zusammenfassung}

Leaves for the pathogen assay were cut off the plants and placed with the upper surface upwards in a $12 \mathrm{~cm}$ x $12 \mathrm{~cm}$ square petri dish containing $60 \mathrm{~mL}$ solid water agar (20 g Micro agar (Duchefa) $\mathrm{L}^{-1} \mathrm{H}_{2} \mathrm{O}$ ). The petiole was stuck into the agar to prevent it from drying-out. Twenty $\mu \mathrm{L}$ of spore suspension, containing approximately 20,000 spores, were added on the leaf blade avoiding major leaf veins, on the adaxial side of the leaf. A $20 \mu \mathrm{L}$ droplet of $\mathrm{H}_{2} \mathrm{O}_{\text {dd }}$ was added to the opposite side of the middle vein as control. The petri dishes were sealed with Parafilm (Bemis comp., Neenah, WI, USA) and placed in a climate chamber. Leaves were inoculated for 10 days under the same conditions as described for the fungal cultures above. Disease severity was determined by visual assessment of fungal and lesion development at the point of inoculation. The disease severity was classified in 6 levels $(0=$ no signs of fungal development, $1=$ fungal growth, $2=$ leaf blade necrosis $<1 \mathrm{~mm}, 3$ = leaf blade necrosis 1 to $3 \mathrm{~mm}, 4=$ leaf blade necrosis 3 to $10 \mathrm{~mm}, 5=$ leaf blade necrosis $>10 \mathrm{~mm}$ ). Leaves exhibiting vein necrosis, an atypical symptom for $M$. castagnei infection (Spiers, 1984), were recorded separately.

Necrotic tissue of different samples was cut and transferred into petri dishes containing malt medium (described above). The samples were incubated under same conditions as described above for M. castagnei cultivation. After three weeks, samples of the fungal cultures that grew out of the leaf tissue were transferred to specimen slides (Gerhard Menzel GmbH, Braunschweig, Germany) covered with $10 \mu \mathrm{L}$ demineralized $\mathrm{H}_{2} \mathrm{O}$ and a cover slides (AL Labortechnik, Zeillern, Austria). Morphology of developed conidia was observed at $40 \mathrm{x}$ magnification under a compound microscope (Axio Observer Z.1, Zeiss, Jena, Germany) and photographed with a camera (AxioCam MRZ, Zeiss) attached to the microscope

\subsubsection{Statistical analysis}

Data was tested on normal distribution by visual inspection of residuals and in doubt, by conduction of Shapiro Wilk test (Kim, 2013). If data was not normally distributed it was log transformed. Statistics were calculated in Origin (OriginLab, 2011) and R (R Core Team, 2014), using generalized mixed models, Tukey-HSD test, Welch's t-test and the packages Multcomp (Hothorn et al., 2008), vegan (Oksanen et al., 2007), Ime4 (Bates et al., 2015), DESeq2 (Love et al., 2014), emmeans (Lenth et al., 2018), ggfortify (Tang et al., 2016) and cluster (Maechler, 2019). Diagrams were generated in R (R Core Team, 2014), Origin (OriginLab, 2011), Microsoft Excel 
(Microsoft, 2016), Microsoft PowerPoint (Microsoft, 2016), InteractiVenn (Heberle et al., 2015, http://www.interactivenn.net/), MetaScape (Zhou et al., 2019, https://metascape.org), HeatMapper (Babicki et al., 2016, http://www.heatmapper.ca/) and Paintomics (García-Alcalde et al., 2011, http://www.paintomics.org/). Leaf area was analyzed with biological image analysis software Fiji (Schindelin et al., 2012).

\subsection{Results}

\subsubsection{Ammonium and nitrate differentially shape primary metabolites in xylem sap}

Feeding poplars with nitrate or ammonium strongly affected the concentrations of these nutrients in poplar xylem sap (Table 2.1). The concentrations of $\mathrm{NO}_{3}{ }^{-}$increased with increasing nitrate and of $\mathrm{NH}_{4}{ }^{+}$with increasing ammonium supply (Table 2.1). Intermediate and high ammonium nutrition further resulted in high amino acid concentrations in the xylem sap, whereas the increase in amino acids was less pronounced under high nitrate nutrition (Fig. 2.1a). The main amino acids detected under the current measuring conditions were derived from glutamate (Fig. 2.1a, supplemental Fig. S2.3). Since glutamine and glutamate spontaneously cyclize to pyroglutamate during LC-MS/MS measuring conditions (Purwaha et al., 2014), the contributions of those individual compounds to xylem sap amino acids cannot be distinguished here. Other studies found glutamine as the major amino acid in poplar xylem sap (Dickson et al., 1985; Siebrecht $\&$ Tischner, 1999). Therefore, it is reasonable to assume that glutamine was also main compound in our study.

Table 2.1: Xylem sap $\mathrm{NH}_{4}$-nitrogen and $\mathrm{NO}_{3}$-nitrogen concentrations and photosynthetic rate of Populus $\mathrm{x}$ canescens plants treated with different forms and concentrations of nitrogen

\begin{tabular}{|c|c|c|c|c|c|}
\hline \multicolumn{2}{|c|}{ Treatment } & $\begin{array}{c}\text { Mean plant dry mass } \\
\left.\text { (g plant }^{-1}\right)\end{array}$ & 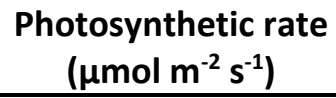 & $\begin{array}{l}\mathrm{XS} \mathrm{NH} \mathrm{N}_{4}-\mathrm{N} \\
(\mathrm{mM})\end{array}$ & $\begin{array}{c}\mathrm{XS} \mathrm{NO} \mathrm{N}_{3} \mathrm{~N} \\
(\mathrm{mM})\end{array}$ \\
\hline & $\mathrm{L}$ & $10.73 \pm 1.69 \mathrm{a}$ & $6.26 \pm 2.04 \mathrm{ab}$ & $8.5 \pm 4.8 \mathrm{a}$ & $2.7 \pm 1.0 \mathrm{a}$ \\
\hline \multirow[t]{3}{*}{$\mathrm{NH}_{4}^{+}$} & $M$ & $10.78 \pm 1.07 a$ & $6.45 \pm 2.36 b$ & $33.5 \pm 10.7 a$ & $1.6 \pm 0.2 \mathrm{a}$ \\
\hline & $\mathrm{H}$ & $13.27 \pm 1.38 b$ & $7.95 \pm 3.63 c$ & $210.8 \pm 33.2 b^{*}$ & $1.2 \pm 0.2 \mathrm{a}$ \\
\hline & $L$ & $10.82 \pm 1.40 \mathrm{a}$ & $4.31 \pm 0.91 \mathrm{a}$ & $7.1 \pm 2.9 \mathrm{a}$ & $3.3 \pm 1.0 \mathrm{a}$ \\
\hline \multirow[t]{2}{*}{$\mathrm{NO}_{3}^{-}$} & $M$ & $11.24 \pm 1.07 \mathrm{a}$ & $5.69 \pm 1.66 \mathrm{ab}$ & $26.3 \pm 7.0 \mathrm{a}$ & $81.2 \pm 92.0 \mathrm{a}$ \\
\hline & $\mathrm{H}$ & $13.73 \pm 1.19 \mathrm{c}$ & $12.29 \pm 1.20 \mathrm{~d}$ & $29 \pm 18.4 \mathrm{a}$ & $386.4 \pm 268.5 b^{*}$ \\
\hline
\end{tabular}

$\mathrm{NH}_{4}{ }^{+}=$ammonium, $\mathrm{NO}_{3}{ }^{-}=$nitrate, $\mathrm{L}=0.4 \mathrm{mM}, \mathrm{M}=2.0 \mathrm{mM}, \mathrm{H}=8.0 \mathrm{mM}, \mathrm{N}=$ nitrogen, $\mathrm{XS} \mathrm{NH}_{4}-\mathrm{N}$ and $\mathrm{NO}_{3}{ }^{-}$ $\mathrm{N}$ conc., $\mathrm{n}=5,{ }^{*} \mathrm{n}=10$, means of one column denoted by the same letter did not significantly differ at $p$ $<0.05$ according to Tukey-HSD test or generalized mixed models with experimental repetition set as random factor. 


\section{Zusammenfassung}

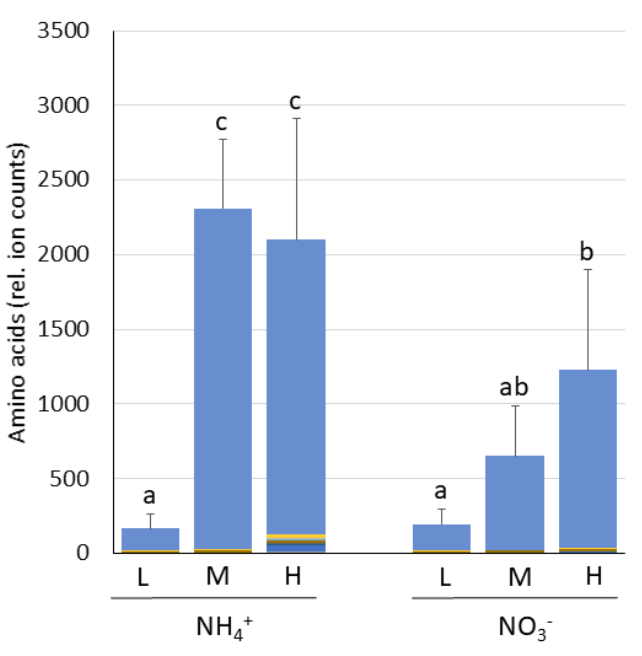
- P-Glu, Glu, Gln
Valine
ar Tyrosine
- Threonine
- Serine
- Proline
- Lysine
- Leucine
n Iso-Leucine
- Glycine
- $\gamma$-Aminobutyric acid
- Aspartate
- Asparagine
a-cyano-Alanine
- Alanine
- 2-Amino butyrate
- $\beta$-Alanine

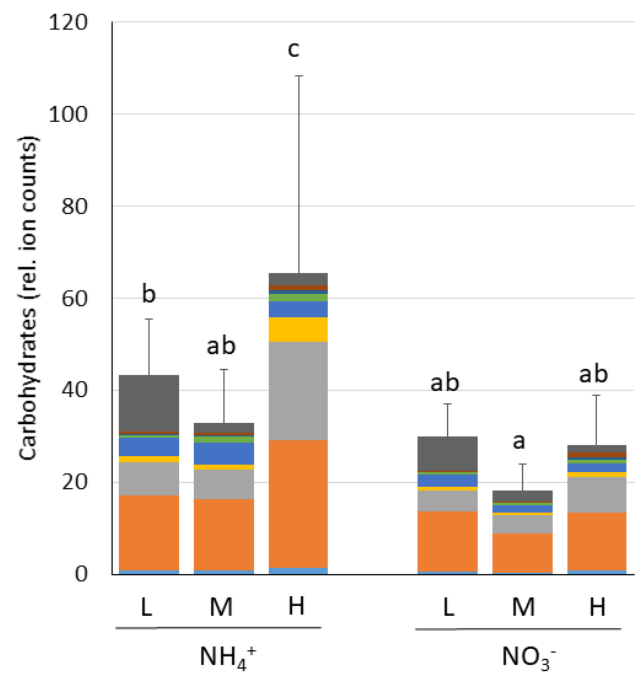

- Sucrose

- Pentose 3

- Pentose 2

- Pentose 1

nexoketose

- Hexoaldose

- Glucose

- Fructose

Desoxyhexose

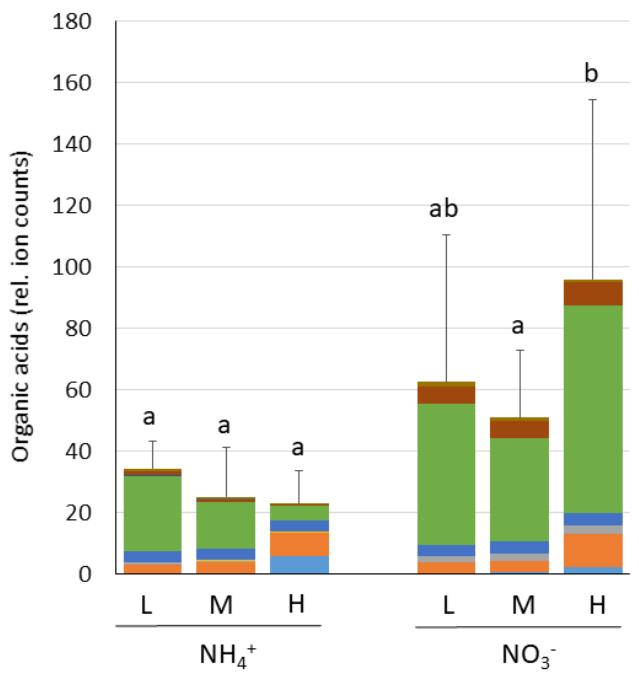

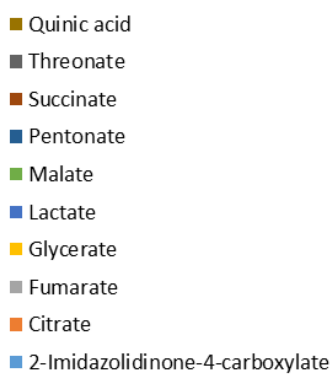

Figure 2.1: Relative abundances of Populus $x$ canescens xylem sap a) amino acid, b) sugar and c) organic acids. $\mathrm{NH}_{4}{ }^{+}=$ammonium, $\mathrm{NO}_{3}{ }^{-}=$nitrate, $\mathrm{L}=0.4 \mathrm{mM}, \mathrm{M}=2.0 \mathrm{mM}, \mathrm{H}=8.0 \mathrm{mM}, \mathrm{n}=8$. Means denoted by the same letter did not significantly differ at $p<0.05$ according to Tukey-HSD test. 
Increasing $\mathrm{N}$ availability caused increasing concentrations of $\mathrm{N}$-bearing compounds in the xylem sap. Enhanced $\mathrm{N}$ translocation to aboveground plant organs resulted in enhanced photosynthesis, growth, biomass, and increased tissue concentrations of N (Table 2.1, Table 2.2; Supplement Fig. S2.2) as observed in other studies with poplars (Euring et al., 2014; Gan et al., 2016)

Table 2.2: Mean plant and tissue N-concentrations of Populus $\mathrm{x}$ canescens plants treated with different forms and concentrations of nitrogen

\begin{tabular}{cccccc}
\hline Treatment & $\begin{array}{c}\text { Mean whole-plant } \mathbf{~} \\
\left(\mathbf{m g ~ g}^{-1}\right)\end{array}$ & $\begin{array}{c}\text { Mean root } \mathbf{~} \\
\left(\mathbf{m g ~ g}^{-1}\right)\end{array}$ & $\begin{array}{c}\text { Mean stem N } \\
\left(\mathbf{m g ~ g}^{-1}\right)\end{array}$ & $\begin{array}{c}\text { Mean leaf N } \\
\left(\mathbf{m g ~ g}^{-1}\right)\end{array}$ \\
\hline & $\mathrm{L}$ & $2.86 \pm 0.44 \mathrm{a}$ & $0.95 \pm 0.07 \mathrm{ab}$ & $0.56 \pm 0.05 \mathrm{a}$ & $1.22 \pm 0.17 \mathrm{a}$ \\
$\mathrm{NH}_{4}{ }^{+}$ & $\mathrm{M}$ & $3.77 \pm 0.37 \mathrm{~b}$ & $1.09 \pm 0.05 \mathrm{bc}$ & $0.91 \pm 0.02 \mathrm{~b}$ & $2.05 \pm 0.31 \mathrm{bc}$ \\
& $\mathrm{H}$ & $4.7 \pm 0.59 \mathrm{c}$ & $1.62 \pm 0.06 \mathrm{~d}$ & $2.07 \pm 0.07 \mathrm{~d}$ & $2.5 \pm 0.52 \mathrm{~cd}$ \\
& $\mathrm{~L}$ & $2.45 \pm 0.26 \mathrm{a}$ & $0.88 \pm 0.06 \mathrm{a}$ & $0.52 \pm 0.07 \mathrm{a}$ & $1.03 \pm 0.07 \mathrm{a}$ \\
$\mathrm{NO}_{3}{ }^{-}$ & $\mathrm{M}$ & $3.85 \pm 0.11 \mathrm{~b}$ & $1.16 \pm 0.07 \mathrm{c}$ & $0.9 \pm 0.05 \mathrm{~b}$ & $1.86 \pm 0.18 \mathrm{~b}$ \\
& $\mathrm{H}$ & $4.85 \pm 0.32 \mathrm{c}$ & $1.84 \pm 0.17 \mathrm{e}$ & $1.72 \pm 0.06 \mathrm{c}$ & $2.99 \pm 0.23 \mathrm{~d}$ \\
\hline
\end{tabular}

$\mathrm{NH}_{4}{ }^{+}=$ammonium, $\mathrm{NO}_{3}{ }^{-}=$nitrate, $\mathrm{L}=0.4 \mathrm{mM}, \mathrm{M}=2.0 \mathrm{mM}, \mathrm{H}=8.0 \mathrm{mM}, \mathrm{PS}=$ photosynthesis, $\mathrm{N}=$ nitrogen, $\mathrm{n}=5$ (except $\mathrm{NH}_{4}{ }^{+}-\mathrm{M}, \mathrm{NO}_{3}{ }^{-}-\mathrm{M} \&-\mathrm{H} n=4$ ), means of one column denoted by the same letter did not significantly differ at $\mathrm{p}<0.05$ according to Tukey-HSD test

In addition to the effects on $\mathrm{N}$-related compounds in xylem sap, ammonium and nitrate nutrition caused unforeseen alterations of C-bearing compounds: soluble carbohydrates were higher under ammonium and soluble organic acids under nitrate nutrition (Fig. 2.1 b, c). Fructose and glucose were the most prominent carbohydrates and malate the most abundant organic acid in xylem sap (Fig. 2.1 b,c).

\subsubsection{Ammonium and nitrate-feeding impact phytohormones in the xylem sap}

Xylem sap of low ammonium-fed poplars contained the highest concentrations of salicylic acid (SA), SA-glucoside, and jasmonoyl-isoleucine (JA-Ile) (Fig. 2.2a,b,c) The concentrations of these phytohormones decreased with increasing $\mathrm{N}$ concentrations and were generally higher in ammonium- than in nitrate-fed plants. Pipecolic acid (Pip) and $\mathrm{N}$-hydroxypipecolic acid (NHP) increased with increasing $\mathrm{NH}_{4}{ }^{+}$supply (Fig. 2.2d,e). Xylem sap of poplars fed with high ammonium contained the highest Pip and NHP levels, whereas NHP was not significantly affected by changes in nitrate supply (Fig. 2.2d,e). These phytohormones are involved in the defense against biotrophic fungi and mediate systemic acquired resistance (Antico et al., 2012; Bernsdorff et al., 
2016; Vlot et al., 2009). Abscisic acid, which is important to signal drought stress, was unaffected by differences in $\mathrm{N}$ supply (Fig. 2f).
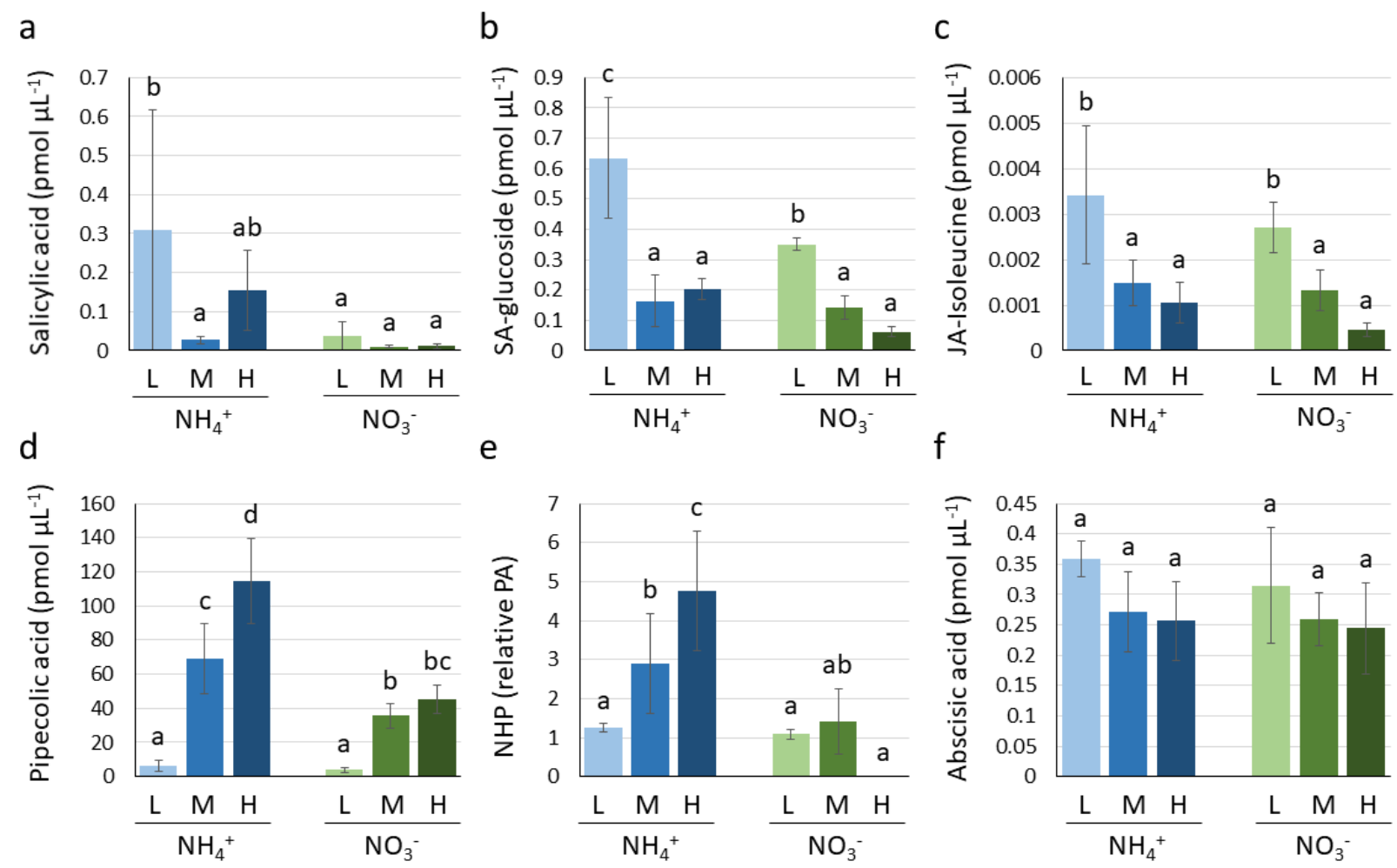

Figure 2.2: Nitrogen treated Populus $x$ canescens xylem sap phytohormone concentrations. a) Salicylic acid, b) Salicylic acid-glucoside, c) Jasmonoyl-Isoleucine, d) Pipecolic acid, e) $\mathrm{N}$-hydroxypipecolic acid, f) Abscisic acid. $\mathrm{NH}_{4}{ }^{+}=$ammonium, $\mathrm{NO}_{3}{ }^{-}=$nitrate, $\mathrm{L}=0.4 \mathrm{mM}, \mathrm{M}=2.0 \mathrm{mM}, \mathrm{H}=8.0 \mathrm{mM}, \mathrm{PA}=$ peak area. $\mathrm{n}=6\left(\mathrm{~L} \mathrm{NO}_{3}{ }^{-} \mathrm{n}=5\right)$, Data were $\log _{2}$ transformed. Means denoted by the same letter did not significantly differ at $p<0.05$ according to Tukey-HSD test

\subsubsection{Poplar defense metabolites increase under low nitrogen supply}

We characterized the xylem sap metabolome by non-targeted analyses using an LC TOF-MS system in one experiment and an LC QTOF-MS system in other independent experiment. The features (i.e., potential metabolites) discovered in both experiments were significantly correlated despite the use of different analytical platforms (Supplemental Fig. 2.4). Since the LC QTOF-MS method is more sensitive, data from that experiment were chosen for in-depth analyses. By this approach, we identified 2179 features using the positive and negative ionization modes (Electronic supplemental file: Thesis_KKasper_E-table_Metabolomics). Feature intensities were compared among the treatments and those features were removed that did not differ 
significantly (FDR adjusted $p<10^{-6}$ ) between at least two treatments. A PCA of the remaining 863 features showed that PC1 separated the features by increasing N concentrations and PC2 according to the $\mathrm{N}$ form supplied to the plants (Fig. 2.3a). The vast majority of these features has not yet been identified. To enhance knowledge on the compounds, present in poplar xylem sap, we conducted manual MS/MS library search. This led to annotation of 70 metabolites, many of which were confirmed by targeted approaches including the organic acids, carbohydrates and amino acids found by GC-MS (Fig. 2.1, Supplemental Table S2.3). Furthermore, we identified phytohormones in the xylem sap (e.g. abscisic acid, pipecolic acid, $N$-hydroxypipecolic acid, derivatives of jasmonate and salicylate), whose presence was confirmed by dedicated analyses (see above, Fig 2.2). Overall, the combined approaches of targeted primary metabolite analysis, LC-MS phytohormone quantification and non-targeted LC-MS metabolite fingerprinting with subsequent MS/MS based metabolite confirmation lead to the identification of 123 metabolites and forms the largest xylem sap metabolite database currently available (Supplemental Table S2.4).

In the annotated data set, we further focused on secondary metabolites potentially involved in poplar defense, mainly belonging to the categories of salicinoids, phenylpropanoids, phenolics, flavonoids, and benzoates (Fig. 2.3b). The main components in xylem sap were salicinoids, phenylpropanoids, and benzoates (Fig. 2.3b). Overall, the concentrations of the secondary metabolites decreased with increasing nitrogen-feeding (Fig. 2.3b). Among the salicinoids, salicortin was the main compound, declining strongly with increasing $\mathrm{N}$ supply (Fig. 2.3c). We also detected salicin and tremulacin, which had the highest concentrations in xylem sap of poplars fed with low N (Fig 2.3c). Although salicin has been detected in several poplar species before (e.g. Tschaplinski et al., 2014), this is the first report for this compound in P. x canescens. In earlier studies, we did not detect salicin in leaves $P$. x canescens (Kaling et al. 2018). 

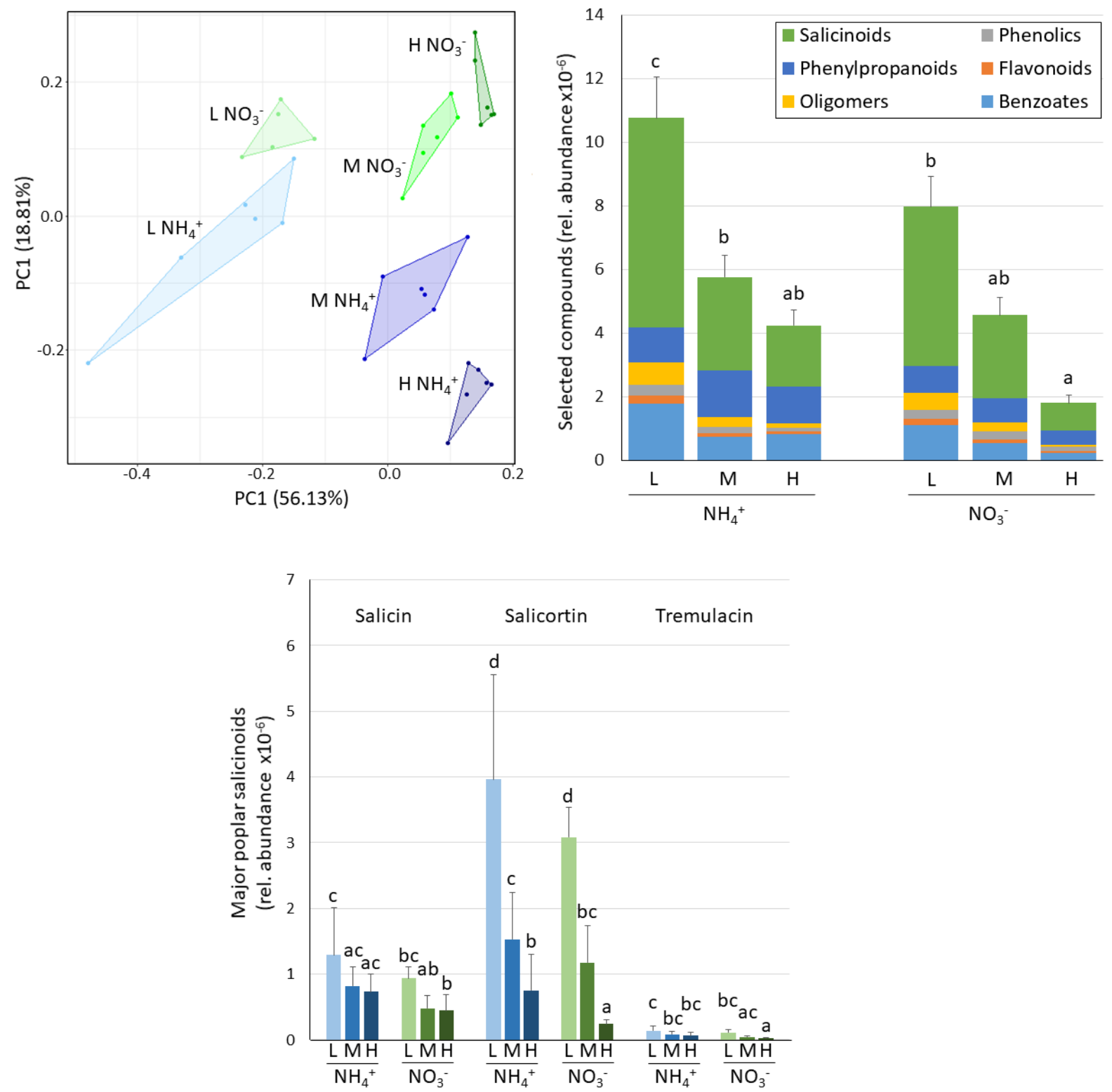

Figure 2.3: Populus $x$ canescens xylem sap secondary metabolite profile of plants treated with different nitrogen forms and concentrations. a) PCA of all putative metabolites. PC1 explains separation by N concentration and PC2 separation by $\mathrm{N}$ form, b) Mean total intensities of MS/MS confirmed members of 6 important poplar secondary metabolite classes, c) Mean intensities of three major salicinoid compounds in poplar. $\mathrm{NH}_{4}{ }^{+}=$ammonium, $\mathrm{NO}_{3}{ }^{-}=$nitrate, $\mathrm{L}=0.4 \mathrm{mM}, \mathrm{M}=2.0 \mathrm{mM}, \mathrm{H}=8.0 \mathrm{mM} . \mathrm{n}=6(\mathrm{~L}$ $\mathrm{NO}_{3}{ }^{-} \mathrm{n}=5$ ). d) Data were $\log _{2}$ transformed, means denoted by the same letter did not significantly differ at $p<0.05$ according to Tukey-HSD test 


\subsubsection{Ammonium and nitrate have divergent effects on the xylem sap proteome}

With increasing ammonium nutrition, the protein concentrations of the xylem sap increased drastically, whereas the increases caused by high nitrate nutrition were less pronounced (Table 2.3). Correspondingly, proteome analyses revealed the highest protein diversity in the xylem sap of high ammonium-fed plants (Table 2.3), covering $55.6 \%$ of the total number of proteins (407) discovered in poplar xylem saps (Electronic supplemental file: Thesis_KKasper_Etable_Proteomics). Nitrate-fed plants showed lower protein diversity than ammonium-fed plants (Table 2.3). A high number of the xylem sap proteins contained a signal peptide, targeting the compound to the extracellular compartment (51.6\%) (Electronic supplemental file: Thesis_KKasper_E-table_Proteomics). Since proteins can also be targeted by other mechanisms to the apoplast (Feussner \& Polle, 2015), and since we did not detected significant contamination of the xylem sap with the intracellular marker enzymes activities (cf. Materials and methods), the proteins without known apoplastic target sequence were also likely xylem sap constituents (Electronic supplemental file: Thesis_KKasper_E-table_Proteomics).

Table 2.3: Xylem sap protein concentrations and amount of identified proteins per treatment of Populus $x$ canescens plants supplied with different forms and concentrations of nitrogen

\begin{tabular}{|c|c|c|c|}
\hline \multicolumn{2}{|c|}{ Treatment } & XS Protein $\left(\mu \mathrm{g} \mathrm{mL}^{-1}\right)$ & \multirow{2}{*}{ Identified proteins } \\
\hline $\mathrm{NH}_{4}^{+}$ & $L$ & $3.7 \pm 1.4 \mathrm{a}$ & \\
\hline & M & $5.7 \pm 1.8 \mathrm{a}$ & 232 \\
\hline & $\mathrm{H}$ & $23.7 \pm 2.5 c$ & 275 \\
\hline \multirow[t]{3}{*}{$\mathrm{NO}_{3}^{-}$} & L & $\pm 0.5 \mathrm{a}$ & 161 \\
\hline & $M$ & $\pm 1.0 \mathrm{a}$ & 221 \\
\hline & $\mathrm{H}$ & $\pm 2.8 \mathrm{~b}$ & 259 \\
\hline
\end{tabular}

$\mathrm{XS}=$ Xylem sap, $\mathrm{NH}_{4}{ }^{+}=$ammonium, $\mathrm{NO}_{3}{ }^{-}=$nitrate, $\mathrm{L}=0.4 \mathrm{mM}, \mathrm{M}=2.0 \mathrm{mM}$,

$H=8.0 \mathrm{mM}, \mathrm{n}=5$. Means denoted by the same letter did not significantly differ at

$p<0.05$ according to Tukey-HSD test

Venn diagrams for ammonium-treatments showed that the majority of protein was present in xylem sap independent on the concentration of $\mathrm{NH}_{4}{ }^{+}$in the nutrient solution (Fig. 2.4a). This was also true for nitrate-treatments (Fig. 2.4b). Overall, the overlap of proteins between the treatments was high (Fig. 2c, d). Still, high nitrogen supply resulted in a higher number of unique proteins than intermediate or low nitrogen supply (Fig. 2.4a,b). 
a

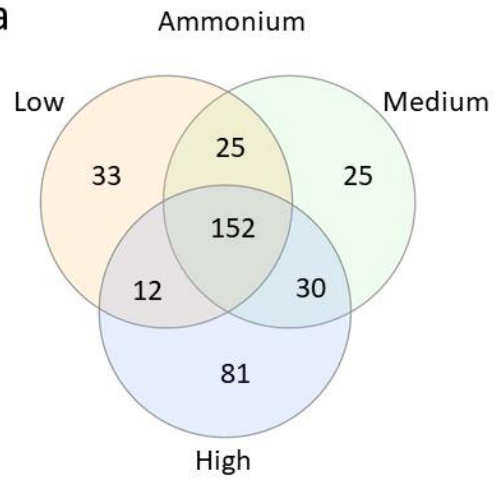

C

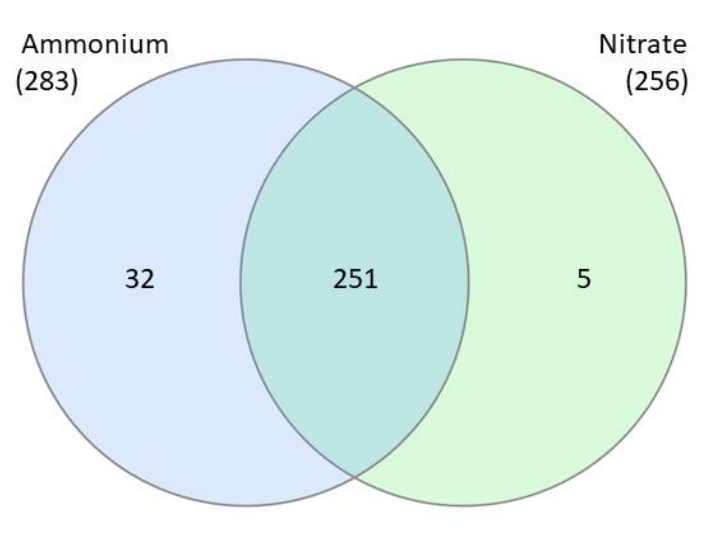

b
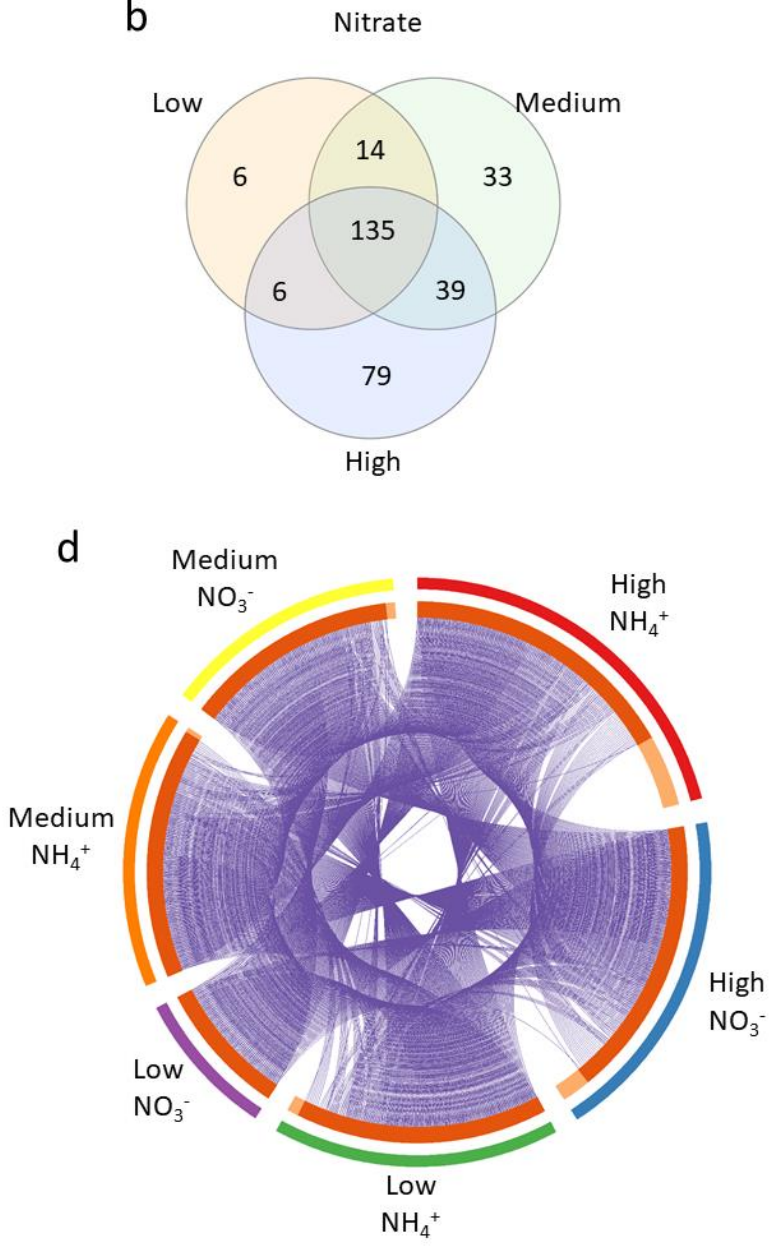

Figure 2.4: Visualization of xylem sap proteome of Populus $x$ canescens treated with different concentrations and forms of nitrogen. Venn diagrams showing the overlap and unique proteins identified in xylem sap of poplars treated with different amounts of a) ammonium and b) nitrate. c) Venndiagram showing the unique and shared XS proteins identified in all concentrations of ammonium treatments vs. all concentrations of nitrate treatments d) A circos diagram showing the overlap of proteins between treatments. Colors of the most outer ring indicate the different treatments. Light orange colored parts of the inner ring indicate XS proteins unique for that treatment and dark orange parts represent proteins that were identified in more than one treatment. Purple strings show which treatments shared same proteins. $\mathrm{NH}_{4}{ }^{+}=$ammonium, $\mathrm{NO}_{3}{ }^{-}=$nitrate, Low $=0.4 \mathrm{mM}$, Medium $=2.0 \mathrm{mM}$, High $=8.0 \mathrm{mM} . \mathrm{n}=5$

To obtain information on the functional composition of xylem sap proteins, we conducted a GO term and KEGG analysis on the Metascape platform. We found 15 significantly enriched functions, among which six were related to cell wall and carbohydrate metabolism and four to oxidative stress and immune defense (Fig. 2.5). Both high and low $\mathrm{N}$ nutrition were accompanied by 
relatively high numbers of GO terms (11 to 14 ), only intermediate nitrate-fed plants exhibited a low number of five GO terms. "Carbohydrate-" and " $\mathrm{H}_{2} \mathrm{O}_{2}$ catabolic processes" and "response to bacterium" were significant GO terms across all $\mathrm{N}$ treatments (Fig. 2.5). This observation underpins that proteins involved in oxidative and biotic stress responses were significantly enriched in xylem sap, regardless of the $\mathrm{N}$ supply (Fig. 2.5). The GO term immune response comprised natriuretic protein, LYM1, peroxidases, chitinases, and bifunctional inhibitor/lipidtransfer protein/seed storage $2 S$ albumin superfamily protein. The xylem sap proteome was further characterized by a high number of proteins involved in cell wall metabolism and lignification (Fig. 2.5), including, for instance, xylanases, glucanases, peroxidases, laccases supporting functions such as pectin and hemicellulose metabolism and catalytic activities driving the last step of lignification by $\mathrm{H}_{2} \mathrm{O}_{2}$-dependent peroxidases and $\mathrm{O}_{2}$-dependent laccases.

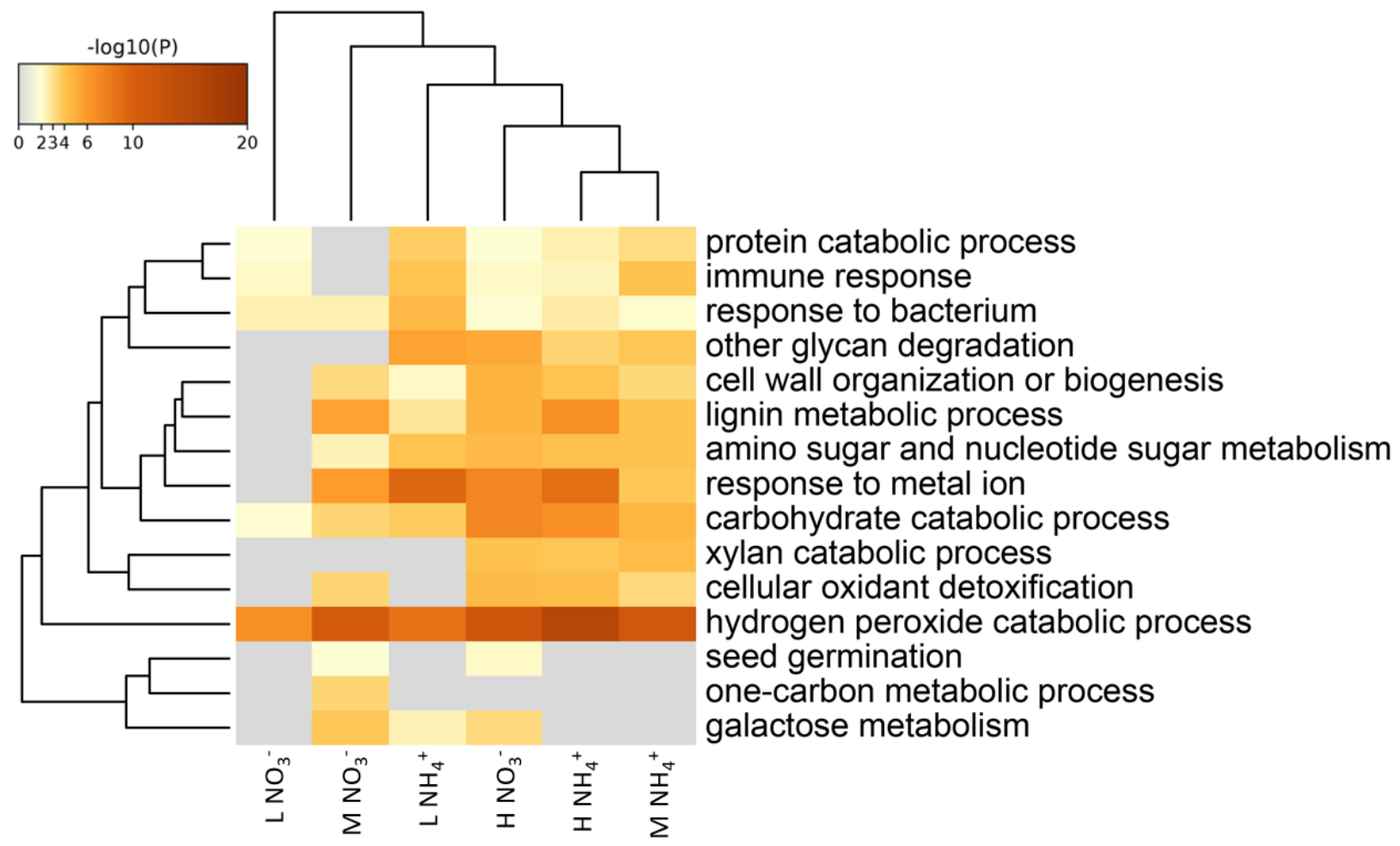

Fig. 2.5: Display of Populus $x$ canescens xylem sap proteome function enrichment compared to whole plant background. Arabidopsis homologues were used for analysis. Plants were treated with different forms and concentrations of nitrogen. $\mathrm{NH}_{4}{ }^{+}=$ammonium, $\mathrm{NO}_{3}{ }^{-}=$nitrate, $\mathrm{L}=0.4 \mathrm{mM}, \mathrm{M}=2.0 \mathrm{mM}$, $H=8.0 m M . n=5$. 
We used protein abundances (including proteins present in at least 4 of 6 or 3 of 5 samples) to test for significant differences among $\mathrm{N}$ treatments. We identified 59 significantly regulated xylem sap proteins in response to changes in $\mathrm{N}$ nutrition (Fig. 2.6). The highest number of significant effects were observed between intermediate and high nitrogen supply (Fig. 2.6). The responses were stronger in xylem sap of poplars fed with nitrate than in those fed with ammonium (Fig.2.6) but under both conditions, a similar set of stress-related protein was affected that was related to "biotic stress"(putative chitinase, peroxidase, DIR5 and ChiC [Glycosyl hydrolase family protein with chitinase insertion domain] proteins) (Fig. 2.6).

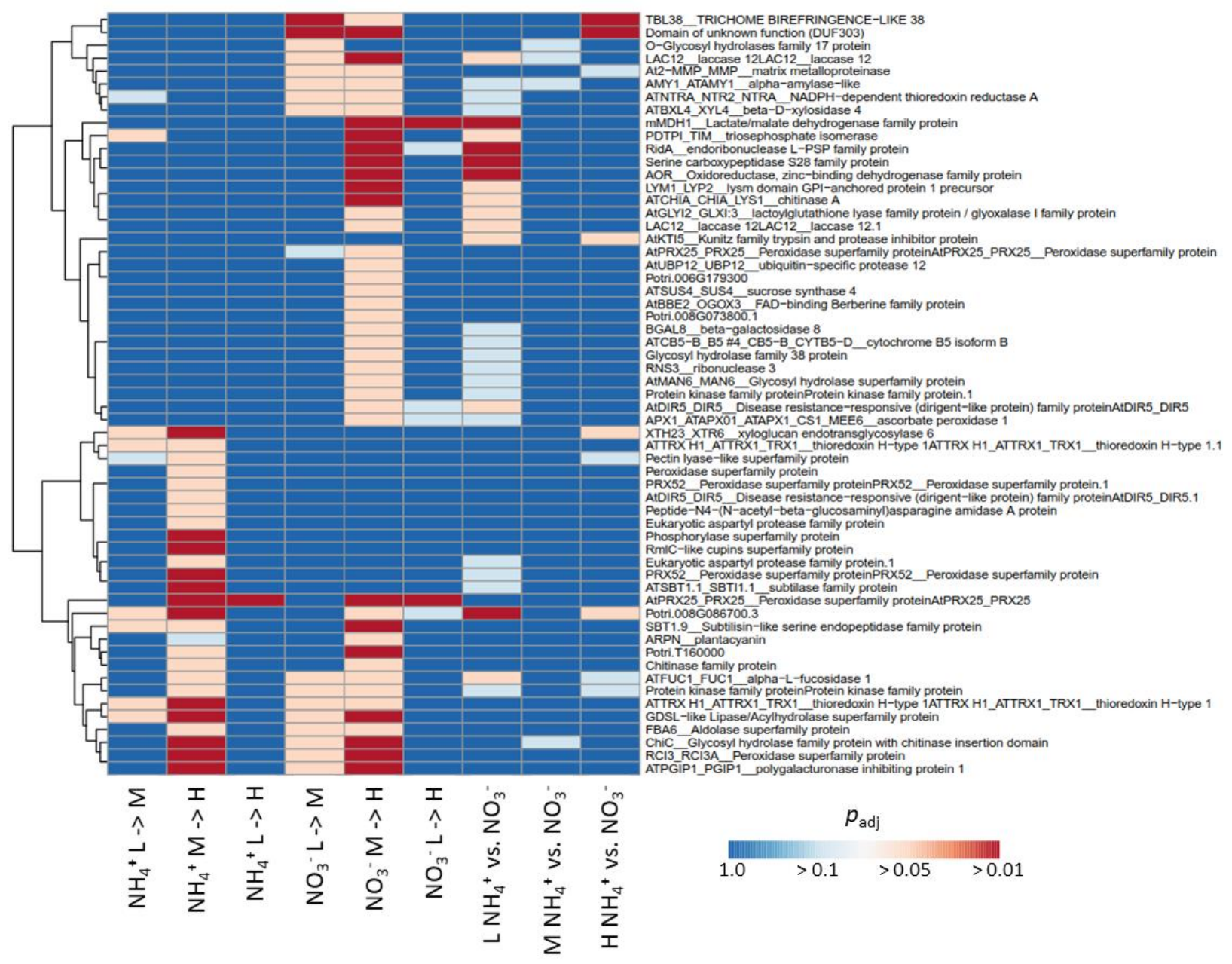

Figure 2.6: Significance display of differentially accumulated proteins in xylem sap of Populus x canescens treated with different nitrogen concentrations and forms. Comparisons were made between different concentrations of the same applied $\mathrm{N}$ form and between same concentrations of different $\mathrm{N}$ forms. $\mathrm{NH}_{4}{ }^{+}=$ammonium, $\mathrm{NO}_{3}{ }^{-}=$nitrate, $\mathrm{L}=0.4 \mathrm{mM}, \mathrm{M}=2.0 \mathrm{mM}, \mathrm{H}=8.0 \mathrm{mM} . \mathrm{n}=5, p_{\text {adj }}$ was calculated with DESeq2 package in $\mathrm{R}$ and $p_{\text {adj }}$ values clustered for heatmap presentation 


\subsubsection{Increase in nitrogen supply elicit stronger responses of leaf transcriptome than changes in the nitrogen form}

The presence of proteins potentially involved in biotic immune responses and defense metabolites in xylem sap of poplars fed with increasing nitrate or ammonium supply and the strong effects on phytohormones might imply that differences in $\mathrm{N}$ nutrition and $\mathrm{N}$ form reprogram poplar protective systems. To test this idea, we analyzed leaf transcriptomes. RNA sequence analysis resulted in the identification of 23,557 expressed genes among which 826 were differentially expressed genes (DEGs, 3.5\% of total) between the applied nitrogen forms, ammonium and nitrate (Electronic supplemental file: Thesis_KKasper_E-table_Chapter 2 Transcriptomics). The number of DEGs responding to ammonium versus nitrate nutrition was moderate (54 DEGS) under intermediate $\mathrm{N}$ supply and higher under low (379 DEGs) as well as high $\mathrm{N}$ supply (393 DEGS) (Fig. 2.7a). Furthermore, the overlaps between the DEGs responding to the $\mathrm{N}$ forms were small or lacking, indicating unique transcriptomic response patterns when plants were fed with a distinct $\mathrm{N}$ concentration (Fig. 2.7a). In other words, nitrate-feeding did not elicit a shared group of DEGs compared to ammonium feeding or vice versa. Consequently, responses to $\mathrm{N}$ forms resulted in few distinct $\mathrm{GO}$ terms for each level of $\mathrm{N}$ supply (Supplemental Fig. S2.5). Under high N, ammonium supply stimulated GO terms related to defense (JA metabolic process, innate immune response) and under low N, stress-related GO terms (response to bacterium, response to oxidative stress, response to water, response to auxin) appeared (Supplemental Fig. S2.5). 
a

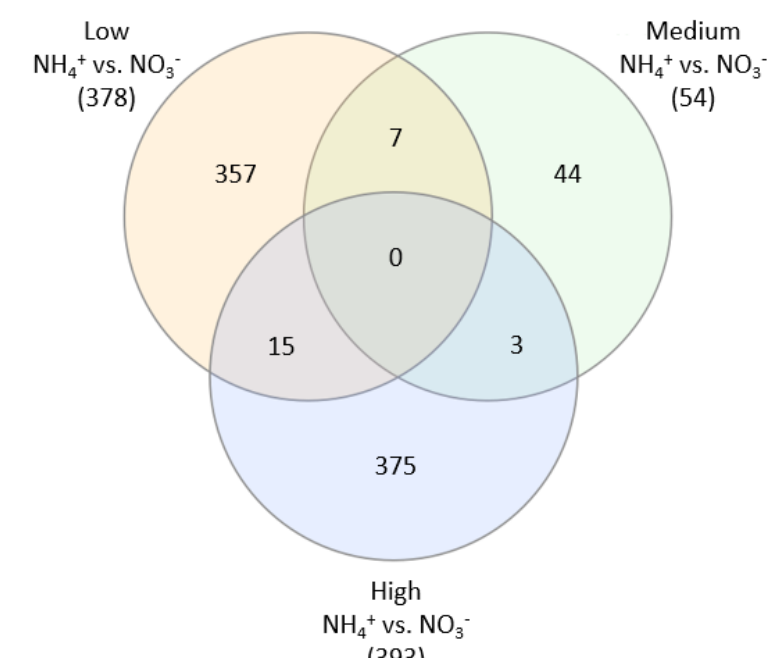

(393) b

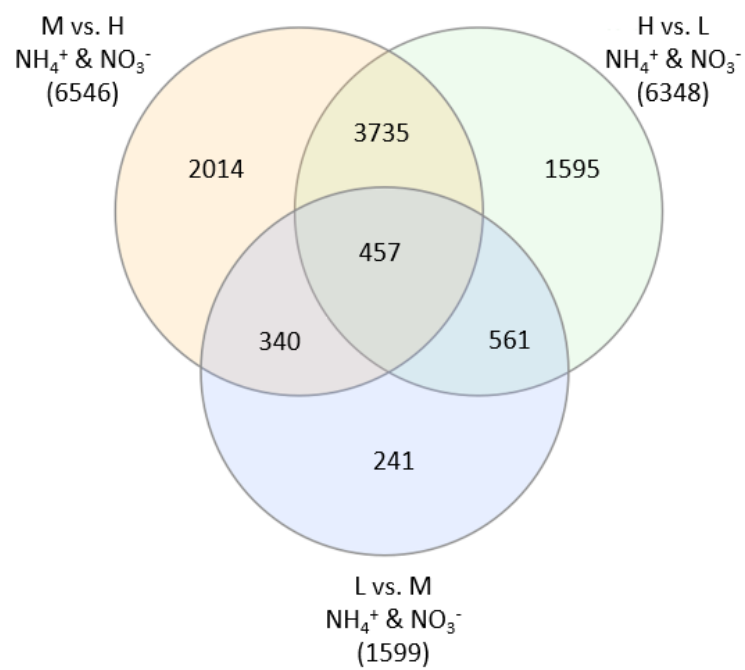

Figure 2.7: Differentially expressed genes (DEG) in leaf transcriptome data of Populus $\mathrm{x}$ canescens plants treated with different forms and concentrations of nitrogen. a) Venn diagram showing the overlap of DEGs between treatments of the same concentration but different $\mathrm{N}$ forms. b) Venn diagram displaying DEGs between two concentrations and for both $\mathrm{N}$ sources, as well as the overlap between all concentration comparisons. $\mathrm{NH}_{4}{ }^{+}=$ammonium, $\mathrm{NO}_{3}{ }^{-}=$nitrate, $\mathrm{L}=0.4 \mathrm{mM}, \mathrm{M}=2.0 \mathrm{mM}, \mathrm{H}=8.0 \mathrm{mM}$. Low and Medium $\mathrm{n}=4$, High $\mathrm{n}=5$

In contrast to the relatively small changes in response to the $\mathrm{N}$ form, the change in $\mathrm{N}$ concentrations in the nutrient solution had drastic effects on the leaf transcriptomes. A huge number of genes $(16,291$ corresponding to $69.2 \%$ of the annotated genes) were differentially expressed between at least two of the treatments. The increase from low to intermediate $\mathrm{N}$ feeding stimulated lower numbers of DEGs than the increase from intermediate to high $\mathrm{N}$ supply (Fig. 2.7b). The largest numbers of DEGs were found when the transcriptomes of leaves from plants fed with low $\mathrm{N}$ were compared with those from high- $\mathrm{N}$ fed plants (Fig. 2.7b). Among the top 20 significantly affected GO terms, 12 were related to developmental processes (Fig. 2.8), underlining the observed growth stimulation in response to increasing $\mathrm{N}$ supply (Table 2.2). When the $\mathrm{N}$ supply increased from low $\mathrm{N}$ to high $\mathrm{N}$, the GO term "immune system response" was significantly enriched (Fig. 2.8). 


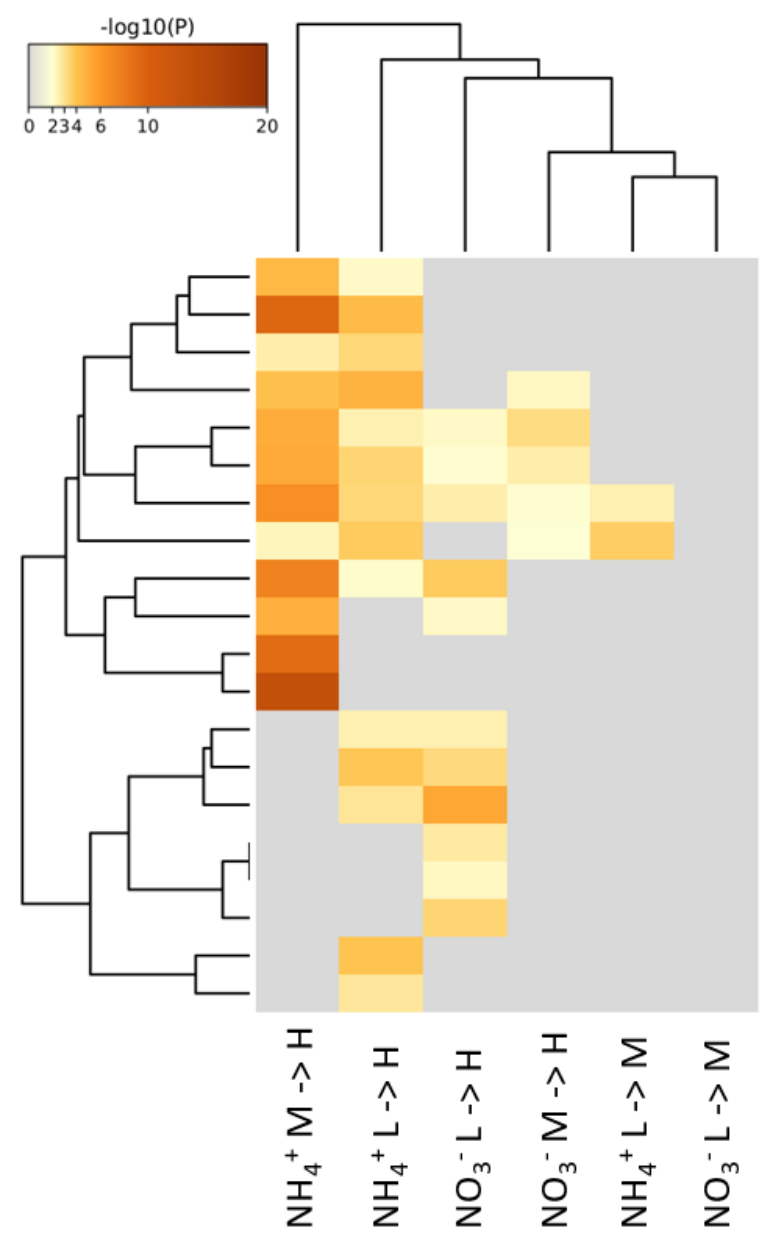

meristem development cell division

regulation of cellular component organization symbiont process tissue development chromosome organization phenylpropanoid biosynthetic process response to light stimulus immune system process regulation of developmental process microtubule-based movement plant-type secondary cell wall biogenesis plant organ morphogenesis protein modification by small protein removal regulation of response to stimulus response to lipid positive regulation of response to stimulus leaf development stomatal movement negative regulation of cellular biosynthetic process

Fig. 2.8: Enriched gene ontology terms of Populus $x$ canescens leaf transcriptome. Plants were treated with different forms and concentrations of nitrogen. $\mathrm{NH}_{4}{ }^{+}=$ammonium, $\mathrm{NO}_{3}{ }^{-}=$nitrate, $\mathrm{L}=0.4 \mathrm{mM}$, $\mathrm{M}=2.0 \mathrm{mM}, \mathrm{H}=8.0 \mathrm{mM} . \mathrm{n}=5$

We extracted all DEGs and mapped them on KEGG pathways (Supplemental Fig. S2.6 to S2.8). We found a strong coverage of the flavonoid pathway (Supplemental Fig. S.2.6), genes involved in plant pathogen interactions (Supplemental Fig. S2.7) and phytohormone signaling pathways (Supplemental Fig. S2.8). While the genes in the flavonoid pathway were generally suppressed, with the exception of low-nitrate fed plants, many key genes involved stress signaling and defense were upregulated under high nitrogen treatments (Supplemental Fig. S.2.8, S2.9). 


\subsubsection{PR genes related to systemic acquired resistance are up-regulated under high nitrogen treatments}

To investigate whether changes in $\mathrm{N}$ concentrations or $\mathrm{N}$ forms activated phytohormonemediated systemic resistance, we compared our DEGs with those published for poplar leaves, responding to caterpillar feeding, poplar leaf beetle and forest tent beetle feeding, fungal attack and treatments with SA and JA (Kaling et al., 2018; Luo et al., 2019; Philippe et al., 2009, 2010; Rinaldi et al., 2007, Supplemental Table S2.7). Our gene set contained 24 DEGs with potential roles in SAR and biotic defenses that overlapped with DEGs induced by phythohormones, insects or the biotrophic fungus Melampsora larici-populina and M. medusae (Fig. 2.9). Under low nitrate supply, two putative homologues of the SA marker gene SARD1 (Potri.012G054900, Potri.015G045300) were upregulated in leaves, in addition to homologues of WKRY70, SAGT1, NPR1, and JAZ1 (Fig. 2.9). Most of these genes showed enhanced transcript levels in response to SA treatment (J. Luo et al., 2019) or Melampsora challenge (J. Luo et al., 2019; Rinaldi et al., 2007) (Fig. 2.9). Transcript levels of putative ethylene (ETH) response factor ERF1 (Potri.005G223200, Potri.008G166200) and the ETH dependent PR-gene PR4 (Potri.013G041600, Potri.013G041700) were upregulated under high $\mathrm{N}$ supply, regardless of whether the $\mathrm{N}$ source was nitrate or ammonium (Fig. 2.9a,b). The JA biosynthesis marker gene AOS (Potri.014G038700) was upregulated in high $\mathrm{N}$ treated plants while simultaneously, the expression of the SA induced suppressor of JA-mediated defense gene expression JAZ1 (Potri.006G139400) was downregulated in high $\mathrm{NO}_{3}{ }^{-}$treated plants. Nine homologues of putative JA and ETH dependent systemic acquired resistance marker gene PR3 (Supplemental Table S2.7) and JA/ETH dependent plant defensin PDF2.3 (Potri.T011200), as well as a JA responsive (J. Luo et al., 2019) antiherbivory (Kaling et al., 2018) Kunitz-trypsin-inhibitor (Potri.019G088200) were upregulated under high $\mathrm{N}$ concentrations (Fig. 2.9). Among the three homologues of the SA and JA regulated transcription factor WRKY70, one (Potri.013G090300) was upregulated under high $\mathrm{N}$ supply, while another potential WRKY7O homologue responded to low $\mathrm{NO}_{3}{ }^{-}$treatment (Potri.006G109100) (Fig. 2.9). The genes involved in jasmonic acid and ethylene biosynthesis and response that were upregulated under high nitrogen availability (this study) were also enhanced in response to JA (J. Luo et al., 2019) and herbivory (Kaling et al., 2018; Philippe et al., 2009, 2010) (Fig. 2.9). 

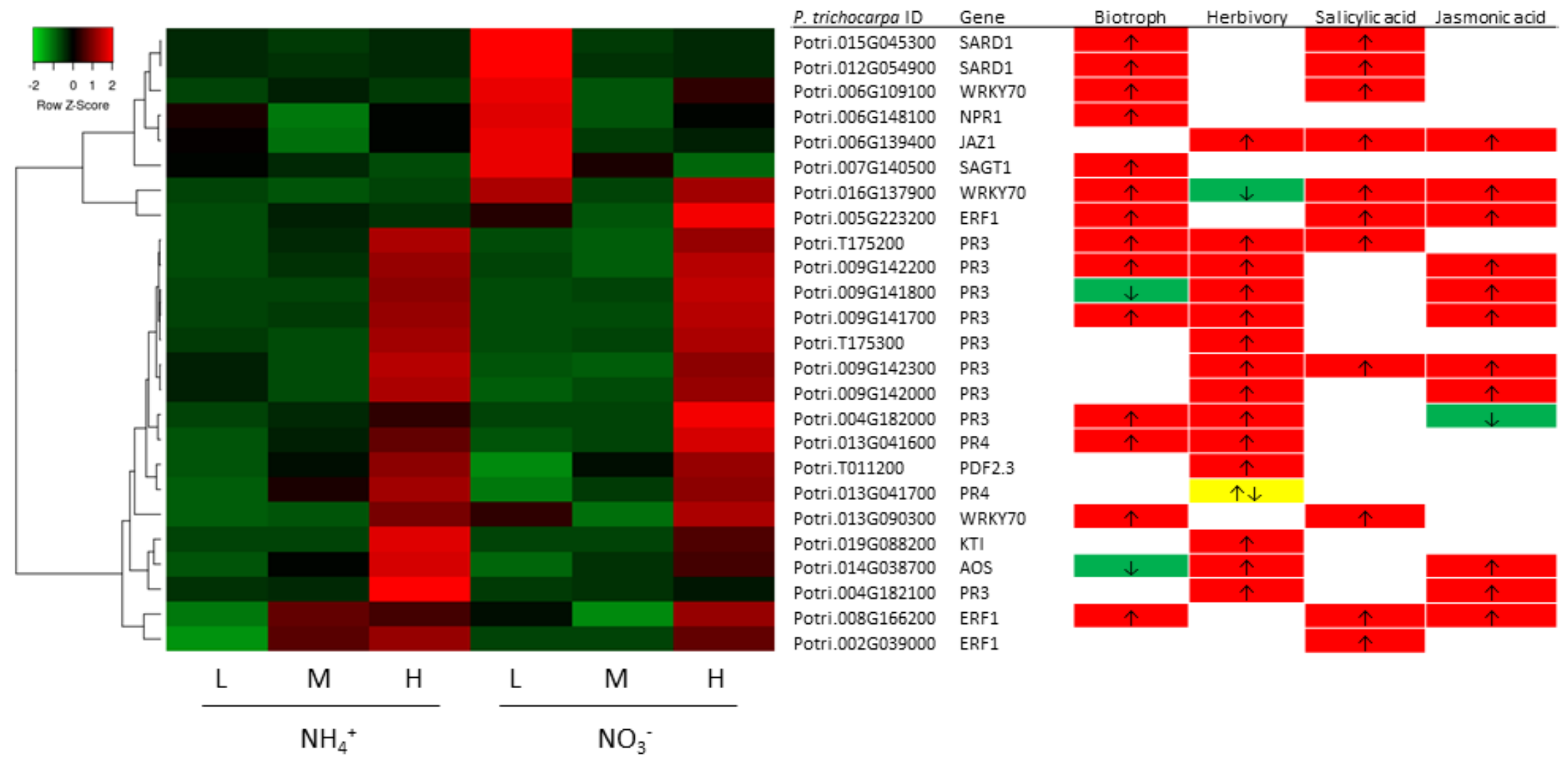

Figure 2.9: Populus $x$ canescens were treated with different forms and concentrations of nitrogen and leaf transcriptome data was investigated on differentially expressed genes with prior shown functions in poplar and linked to response to the phytohormones salicylic acid and jasmonic acid or to attack of biotrophic pathogens or herbivory. Right of the heatmap is the $P$. trichocarpa gene model and the gene name are stated. In the table, red background colours indicate upregulation, green background colours downregulation and yellow background colour differential regulation of the marker genes in other poplar studies. $\uparrow$ upregulation, $\downarrow$ downregulation, $\mathrm{NH}_{4}{ }^{+}=$ammonium, $\mathrm{NO}_{3}{ }^{-}=$nitrate, $\mathrm{L}=0.4 \mathrm{mM}, \mathrm{M}=2.0 \mathrm{mM}, \mathrm{H}=8.0 \mathrm{mM}, \mathrm{SA}=$ Salicylic acid, JA = Jasmonic acid, ETH = Ethylene, $\mathrm{L}$ and $\mathrm{M} \mathrm{n}=4, \mathrm{H} \mathrm{n}=5$ 


\subsubsection{Bioassays reveal effects of nitrogen nutrition on pathogen fitness}

Growth of Brennaria salicis, a potentially pathogenic endophyte in the vascular system of Salicaceae, increased in xylem sap with increasing $\mathrm{N}$ supply of the poplars (Fig. 2.10). Highest growth was found in xylem sap poplars fed with high ammonium supply (Fig. 2.10). Xylem sap from plants with intermediate ammonium supply and high nitrate supply showed similar growth rates of B. salicis (Fig. 2.10). The lowest growth of B. salicis was found in xylem sap of poplars with low nitrate supply (Fig. 2.10).

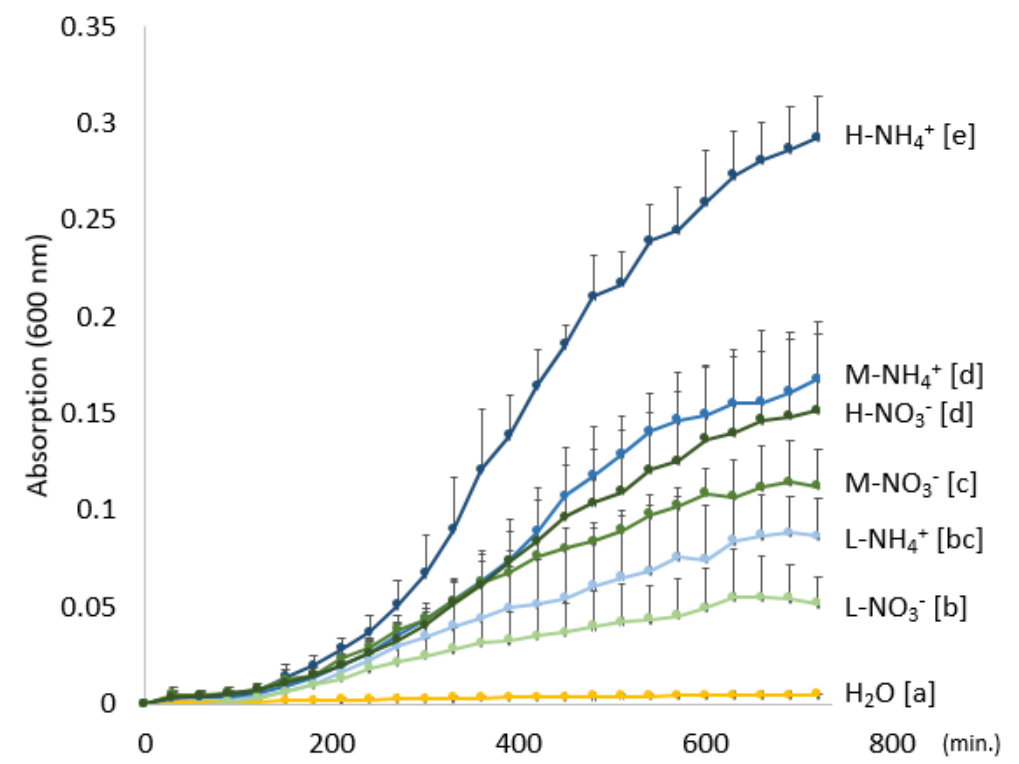

Figure 2.10: Brennaria salicis development in xylem sap of Populus $\mathrm{x}$ canescens, treated with different forms and concentrations of nitrogen. Measured by optical density (OD) at $600 \mathrm{~nm}$ over $12 \mathrm{~h}$.

$\mathrm{NH}_{4}{ }^{+}=$ammonium, $\mathrm{NO}_{3}{ }^{-}=$nitrate, $\mathrm{L}=0.4 \mathrm{mM}, \mathrm{M}=2.0 \mathrm{mM}, \mathrm{H}=8.0 \mathrm{mM} . \mathrm{n}=8$, means denoted by the same letter did not significantly differ at $p<0.05$ according to Tukey-HSD test 
We established a P. x canescens leaf pathogen assay employing the necrotrophic poplar pathogen Marssonina castagnei. After $10 \mathrm{~d}$ incubation of leaves with the pathogen, we classified either no necrotic lesions, small lesions or large lesions on the infected leaf area (Fig. 2.11a). In addition, we observed vein necrosis, an atypical symptom for Marssonina castagnei (Fig. 2.11a). Approximately, 50 to $60 \%$ of the infected leaves showed mild to strong symptoms, but no differences among leaves from different $\mathrm{N}$ treatments (Fig. 2.11b). The severity of vein necrosis was significantly increased in high $\mathrm{NH}_{4}{ }^{+}$treated plants in comparison to all other treatments (Fig. 2.11c). Under high nitrate, about $26 \%$ of the leaves developed vein necrosis compared to less than $7 \%$ or $3 \%$ under intermediate or low nitrate supply (Fig. 2.11c). However, this trend was not significant because of the limited number of replicates available.

Phenotypic analysis of fungal cultures grown out of necrotic samples showed that leaf blade and vein necrosis were caused by two different fungal species. The fungus grown out of leaf blade necrosis developed 1-celled microconidia, corresponding to the description of $M$. castagnei telemorph form Drepanopeziza populi-albae (Spiers \& Hopcroft, 1998) (Fig. 2.11d). The fungus cultured from vein necrosis exhibited the formation of cub-shaped, multi cell macroconidia, a structure that has not been described for M. castagnei (Fig. 2.11e). Since the unknown fungus was present in the leaf before setup of the pathogen assay but did not cause any necrosis, it must be considered as a hemibiotrophic pathogen (Chowdhury et al., 2017). 
a

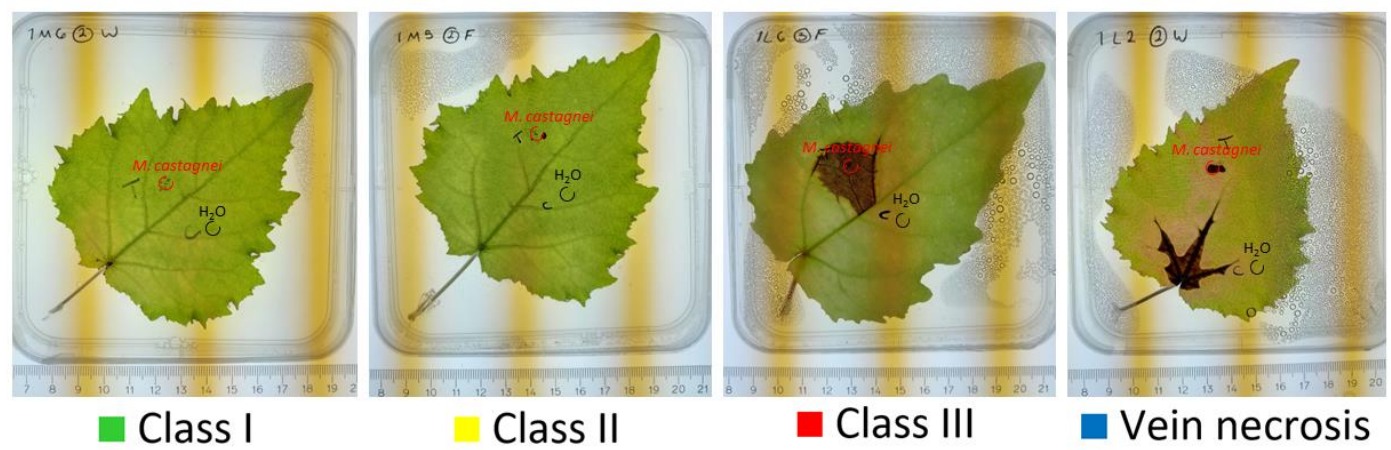

$\mathrm{b}$

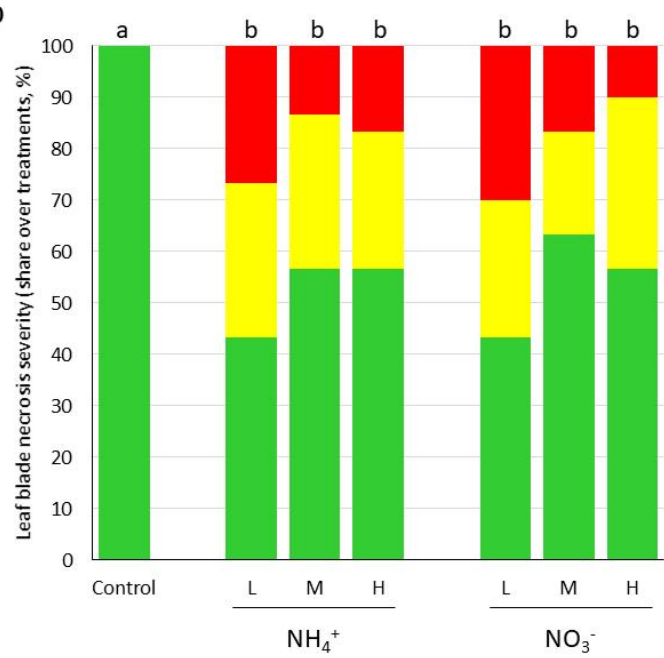

d

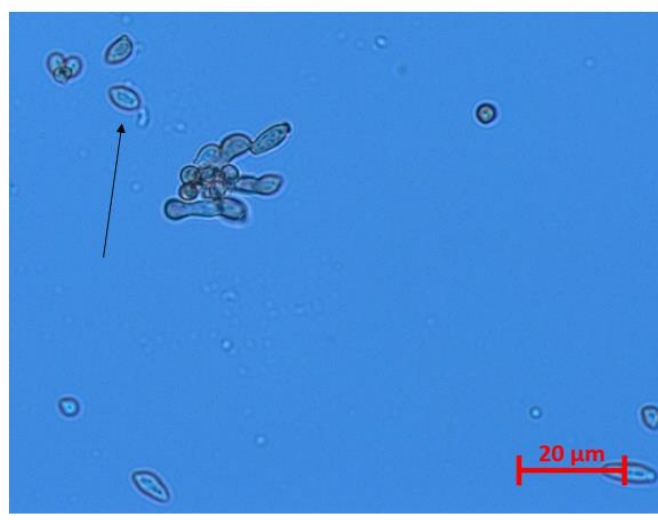

C

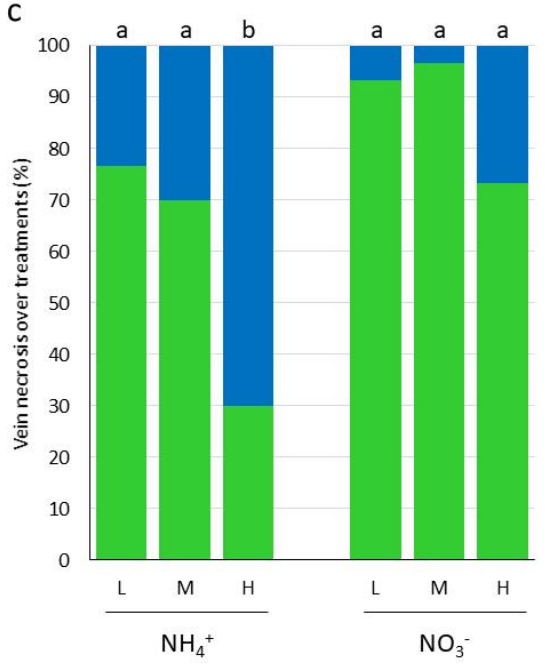

$\mathrm{e}$

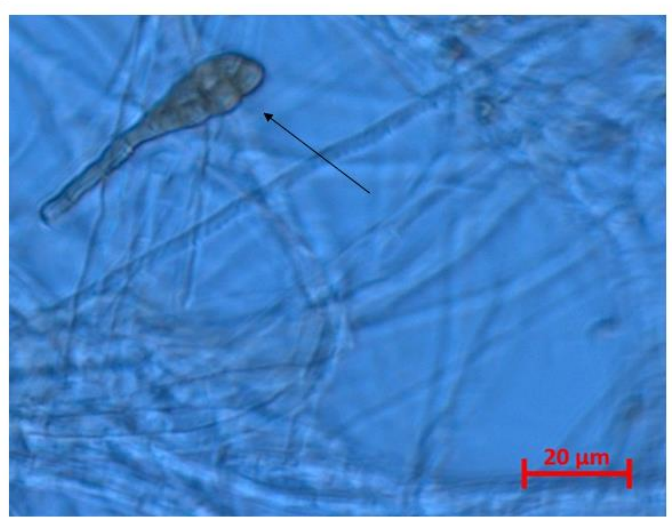

Figure 2.11: Marssonina castagnei infection assay on leaves of Populus $x$ canescens, treated with different forms and concentrations of nitrogen. Disease severity was analyzed ten days after inoculation. a) scale defining disease symptom development for classification, b) distribution of disease severity caused by necrotrophic pathogen $M$. castagnei, c) share of leaves with vein necrosis, caused by an unknown hemibiotrophic pathogen, d) microconidia produced by fungus that caused leaf blade necrosis, e) macroconidia produced by fungus that caused vein necrosis. $\mathrm{NH}_{4}{ }^{+}=$ammonium, $\mathrm{NO}_{3}{ }^{-}=$nitrate, $\mathrm{L}=0.4 \mathrm{mM}$, $\mathrm{M}=2.0 \mathrm{mM}, \mathrm{H}=8.0 \mathrm{mM} . \mathrm{n}=30$, means denoted by the same letter did not significantly differ at $p<0.05$ according to a) estimated marginal means, pairwise Tukey-HSD test, and b) Tukey-HSD test 


\subsection{Discussion and conclusions}

\subsubsection{A meticulous xylem sap analysis shows distinct responses to nitrate and ammonium nutrition}

Here, we present the first multi-omics study connecting nitrogen nutrition, xylem sap composition and leaf responses. An important result was that changes in nitrogen nutrition result in profound changes in xylem sap composition. These changes affected not only mobile transport forms of nitrogen (nitrate, ammonium, amino acids) and the proteome but all compound classes studied here, including phytohormones, soluble carbohydrates, organic acids, flavonoids, phenolics, benzoates, and many other metabolites. The present study reports the largest metabolite library to date available for plant xylem saps.

In agreement with previous studies (Siebrecht \& Tischner, 1999), we found that a switch from nitrate to ammonium nutrition caused a switch in the dominance of these compounds in the xylem sap. The nitrate concentrations in the xylem sap (about $3 \mathrm{mM}$ ) found in our study under low nitrate supply were similar to those reported by Siebrecht et al (2003). In addition to inorganic $\mathrm{N}$, amino acids play a major role as a transport form of nitrogen in the xylem sap (Grassi et al., 2002). In poplars under field and laboratory conditions, glutamine is generally most abundant XS amino-N form (Dickson et al., 1985; Escher et al., 2004; Siebrecht \& Tischner, 1999). In our study, glutamic acid-based amino acids dominated as well, but the fractions of glutamine and glutamate in xylem sap could not be distinguished because of cyclization of glutamate and glutamine to pyroglutamic acid (Purwaha et al., 2014) that happens in the GC-MS analysis applied here (T. Ischebeck, personal communication, June 16, 2020).

In soil solution, the concentrations of nitrate and ammonium vary strongly temporally and spatially, requiring acclimation of plant uptake (Glass et al., 2002). Here, we show that the form of applied nitrogen resulted in specific effects in some compound classes. For example, high ammonium supply caused a significant increase in xylem sap carbohydrates, whereas the malate concentrations increased only under high nitrate. Malate is an important metabolite with major functions during carbohydrate degradation for energy production and in anaplerotic reactions. The metabolite ratio of carbohydrates-to-malate regulates photosynthesis by affecting stomatal conductance (Gago et al., 2016; Lima et al., 2019). In line with this notion, we found that the shift 
in the malate-to-sugar ratio under high nitrate had a much stronger stimulating effect on photosynthesis than high ammonium, although both treatments resulted in similar whole-plant $\mathrm{N}$ concentrations.

Most $\mathrm{N}$-containing compounds found in the xylem sap increased with increasing nitrogen supply, regardless of the $\mathrm{N}$ source but the effects were generally stronger for ammonium than for nitrate nutrition. A novel result is that this behavior was also found for Pipecolic acid (Pip). Pip is phytohormone, involved in long-distance signaling of SAR (Bernsdorff et al., 2016; Shah \& Zeier, 2013) but its presence in xylem sap has not been reported before. Pip is converted to $N$ hydoxypipecolic acid (NHP), which eventually triggers plant immunity responses (Hartmann et al., 2017). Rekhter et al. (2019) showed that conversion of Pip into NHP is not dependent on SA but Hartmann and Zeier (2019) pointed out the positive interplay of NHP and SA in SAR establishment. NHP and SA were also detected in xylem saps but they showed divergent responses to changes N nutrition. NHP and SA were low in XS of nitrate-fed plants, regardless the N concentration, whereas NHP increased with increasing ammonium supply. These differences may have implications for SAR. Future studies must clarify if the transmission of SAR signals is influenced by nitrogen nutrition.

Secondary metabolites play eminent roles in trees species for defense and lignin production (Polle et al., 2013). However, little information is available for the regulation of these compounds in apoplastic compartments. An interesting notion of the present study was that all classes of the MS/MS confirmed secondary, phenol-based metabolites were higher abundant in poplar xylem sap when plants were treated with lower concentrations of N. Trade-off between the production amino- and phenol-based compounds has often reported and is thought to reflect an ecological plant strategy for carbon utilization (Barker et al., 2019). For example, in poplar leaves, secondary metabolites and especially salicinoids were upregulated with decreased $\mathrm{N}$ supply (Bryant et al., 1987; Lindroth \& Hwang, 1996), which modifies the palatability of leaves for a number of herbivores (Fabisch et al., 2019). However, in xylem sap this clear antagonism in response to changes in $\mathrm{N}$ availability has not been reported before. Our bioassays underpin that changes of XS composition strongly affected the proliferation of the endophytic bacterium B. salicis. The growth conditions were most favorable in xylem sap of high-ammonium supplied poplars, which 


\section{Zusammenfassung}

contained the highest amino acid and carbohydrate levels, while the abundance of phenol-based compounds was low. Obviously, defense proteins, which were also enhanced in the xylem sap of high-ammonium supplied poplars, could not attenuate growth of $B$. salicis. Our results imply that B. salicis is adapted to vascular conditions and provide valuable guidance for future mechanistic analysis of factors that regulate the interaction of vascular endophytes with their host environment.

\subsubsection{Nitrogen availability affects xylem sap signal and defense compounds}

Many compounds present in the xylem sap have functions in signaling and defenses (Carella et al., 2016; Turnbull \& Lopez-Cobollo, 2013). One of the most studied phytohormones in xylem sap is abscisic acid (ABA). ABA increases under drought in XS (Hansen \& Dörffling, 1999; Korovetska et al., 2014; Schachtman \& Goodger, 2008). A study with Ricinus communis found that the supply with $\mathrm{NH}_{4}{ }^{+}$instead of $\mathrm{NO}_{3}{ }^{-}(1 \mathrm{mM})$ also caused a pronounced increase of $\mathrm{ABA}$ in the xylem sap (Peuke et al., 1998). However, in poplar application of ammonium instead of nitrate did not affect ABA levels. This response was expected for well-irrigated plants.

Other phytohormones such as salicylic acid (SA), salicylic-glucoside (SAG) and jasmonoylisoleucine (JA-Ile) showed strong responses to poplar $\mathrm{N}$ nutrition. These phytohormones have been studied in XS of crops. For instance, they occur in xylem sap of Brassica napus in the concentration range from 20 to 200 nM (Ratzinger et al., 2009). In poplar xylem sap, we found slightly higher concentrations of these compounds (30 to $600 \mathrm{nM}$ ). Jasmonoyl isoleucine, SA and the derivative SAG decreased in xylem sap of plants supplied with high nitrogen. Both Ja-Ile and SA play intricate - but partly divergent - roles in signaling of plant biotic stresses (Pieterse et al., 2014). Whether they contributed to reprogramming of the poplar leaf transcriptome remains elusive (see below).

The xylem sap proteome is dominated by proteins required to maintain the integrity of the xylem architecture (cell wall-related enzymes, general metabolism) and a wide array of proteins such as peroxidases, proteases, chitinases, etc., required as first line of stress defense against invading pests (Rodríguez-Celma et al., 2016). The protein concentration in xylem sap are low, ranging from 5 and $12 \mu \mathrm{g} \mathrm{mL}-1$ across the plant species examined so far (Rodríguez-Celma et al., 2016) 


\section{Zusammenfassung}

which is in line with our findings in poplar xylem sap, with the exception of high ammonium treated plants, in which protein concentrations increased up more then $20 \mu \mathrm{g} \mathrm{mL}^{-1}$. The xylem sap proteome of eight plant species contained approximately 350 non-redundant proteins (Rodríguez-Celma et al., 2016). Previous studies identified 97 proteins in $P$. trichocarpa $\times$. deltoides (Dafoe \& Constabel, 2009) and 102 proteins in P. deltoides xylem sap (Pechanova et al., 2010). With the identification of 407 protein sequences, we report the largest proteome database in poplar xylem sap, so far. Matching these sequences to Arabidopsis gene loci as done by Rodríguez-Celma et al. (2016), still 203 unique proteins were found. Dafoe and Constable (2009) used a pressure extraction method and reported that $33 \%$ of the identified proteins contained a signal peptide. In our study, we controlled contamination and found that about $51.6 \%$ of the protein contained a signal peptide. This fraction is comparable to those (57\%) reported for $P$. deltoides xylem sap (Pechanova et al., 2010) and for the average of xylem sap proteins across eight different plant species (Rodríguez-Celma et al., 2016). The functional composition found here was also similar to that reported before (Carella et al., 2016; Rodríguez-Celma et al., 2016), supporting species-independent conserved functions of xylem sap proteomes. Our finding that higher $\mathrm{N}$ supply enriched the xylem sap with proteins of similar classes additionally points to conserved XS functions. However, under high $\mathrm{N}$ fraction a number of xylem sap proteins showed significant treatment effects due to differential accumulation of peroxidases, chitinases and dirigent-proteins. Proteins in these classes also accumulated in the xylem sap of crop plants upon attack by vascular pathogen (Floerl et al., 2012; J. Yang et al., 2020). The N-dependent regulation of the abundances of xylem sap proteins with anti-microbial characteristics and the enhancement of SAR-related phytohormones suggest local (xylem sap) and systemic (leaves) changes of poplar pathogen resistance.

\subsubsection{High nitrogen increased susceptibility of poplar to a hemi-biotrophic pathogen}

Physiological and transcriptomic changes in response to changes in nitrogen availability have often been studied in poplar (Euring et al., 2014; Luo et al., 2015; Wei et al., 2013, Lu et al. 2019, Gan et al. 2016) but little is known how different $\mathrm{N}$ forms and concentrations influence certain phytohormone signaling pathways and pathogen resistance of poplar leaves. Here, we demonstrated that increasing $\mathrm{N}$ concentrations have drastic effects on the overall leaf 
transcriptomes while the supply with nitrate or ammonium mounted different defense pathways. Using a comparative approach with published studies (Kaling et al., 2018; J. Luo et al., 2019; Philippe et al., 2010; Rinaldi et al., 2007), we showed that high N-nutrition led to enhanced expression of JA and ETH-dependent defense responses, while low-nitrate supply activated SAdependent responses. Since low-nitrate poplars contained low concentrations of SA, at least lower concentrations than low- and high-ammonium plants, it appears unlikely that xylem sap SA was involved in the induction of SA-related responses in transcriptome, as suggested earlier (Vernooij et al., 1994). Similarly, the lowest JA-Ile concentrations were present in xylem sap from poplar supplied with high nitrogen level, whereas these plants showed the strongest activation of JA/ETH responses such as an enhanced expression of genes responsible for JA and ETH biosynthesis, enhanced expression of genes coding for pathogenesis-related proteins and of JA and ETH-related transcription factors. The findings agree with nitrogen experiments in Solanum lycopersicum (Vega et al., 2015). Vega et al. (2015) found that increased $\mathrm{NO}_{3}{ }^{-}$supply recruited JA/ETH-dependent defense responses and increased the resistance against the necrotrophic pathogen Botrytis cinerea. However, in a first experiment with poplar leaves we did not observe significantly increased resistance against the necrotrophic pathogen Marssonina castagnei although severe necrosis were less pronounced (about 10\%) on leaves from high nitrate treatment compared to leaves from low nitrate treatment (25\%). A complication was a secondary infection that led to strong vein necrosis and might have interfered with the $M$. castagenei assay. Based on morphological differences, we were able to discern the two infectious fungal species and based on life-style to identify the unknown fungus as a potential hemi-biotroph. Interestingly, the hemi-biotroph developed stronger vein necrosis on leaves from high-N plants. Apple trees treated with increased $\mathrm{N}$ fertilization also showed increased susceptibility towards a hemibiotrophic pathogen (Venturia inaequalis, Leser \& Treutter, 2005). Since resistance against pathogens with (hemi-)biotrophic lifestyles is afforded by SA-dependent defense responses (L. Yang et al., 2015), the increased susceptibility of high $\mathrm{N}$ treated poplars might result from the antagonism between JA and ETH-dependent versus SA-dependent defense responses (Glazebrook, 2005). It is obvious that the current experiments with necrotrophic and biotrophic fungi have to be repeated to obtain more solid data. However, this was not possible in the present thesis due to time constraints. 
Despite these limitations, this study clearly shows that nitrogen nutrition had a strong influence on the mode of defense in poplar leaves. It is unknown which changes in xylem sap composition transmitted these responses. However, our encompassing characterization of the xylem sap identified $\mathrm{N}$-driven differences in the abundance of defense proteins, salicinoid-derived compounds, many other secondary compounds, primary metabolites and phytohormones, which may be candidates for reprogramming the leaf transcriptome. These findings are of high importance since many areas in Germany experience continued N over-fertilization (Häußermann et al., 2019) and a likely to be threatened by emerging biotic and abiotic stress factors in a changing climate (Plothe, 2019). 


\subsection{Supplementals}

Table S2.1: Composition of the nutrient solutions used to irrigate

Populus $\mathrm{x}$ canescens during the experiment

\begin{tabular}{|c|c|c|c|c|}
\hline $\mathrm{N}$ type & Treatment & Applied $\mathrm{N}$ concentration & Chemical compound & $\mathrm{mmol} \mathrm{L}^{-1}$ \\
\hline \multirow{9}{*}{$\mathrm{NH}_{4}^{+}$} & \multirow{3}{*}{ Low } & \multirow{3}{*}{$0.4 \mathrm{mmol} \mathrm{L}^{-1}$} & $\mathrm{KCl}$ & 4 \\
\hline & & & $\mathrm{NH}_{4} \mathrm{Cl}$ & 0.4 \\
\hline & & & $\mathrm{CaCl}_{2} \times 2 \mathrm{H}_{2} \mathrm{O}$ & 2 \\
\hline & \multirow{3}{*}{ Medium } & \multirow{3}{*}{$2 \mathrm{mmol} \mathrm{L}^{-1}$} & $\mathrm{KCl}$ & 4 \\
\hline & & & $\mathrm{NH}_{4} \mathrm{Cl}$ & 2 \\
\hline & & & $\mathrm{CaCl}_{2} \times 2 \mathrm{H}_{2} \mathrm{O}$ & 2 \\
\hline & \multirow{3}{*}{ High } & \multirow{3}{*}{$8 \mathrm{mmol} \mathrm{L}^{-1}$} & $\mathrm{KCl}$ & 4 \\
\hline & & & $\mathrm{NH}_{4} \mathrm{Cl}$ & 8 \\
\hline & & & $\mathrm{CaCl}_{2} \times 2 \mathrm{H}_{2} \mathrm{O}$ & 2 \\
\hline \multirow{7}{*}{$\mathrm{NO}_{3}^{-}$} & \multirow{3}{*}{ Low } & \multirow{3}{*}{$0.4 \mathrm{mmol} \mathrm{L}^{-1}$} & $\mathrm{KNO}_{3}$ & 0.4 \\
\hline & & & $\mathrm{KCl}$ & 3.6 \\
\hline & & & $\mathrm{CaCl}_{2} \times 2 \mathrm{H}_{2} \mathrm{O}$ & 2 \\
\hline & \multirow{3}{*}{ Medium } & \multirow{3}{*}{$2 \mathrm{mmol} \mathrm{L}^{-1}$} & $\mathrm{KNO}_{3}$ & 2 \\
\hline & & & $\mathrm{KCl}$ & 2 \\
\hline & & & $\mathrm{CaCl}_{2} \times 2 \mathrm{H}_{2} \mathrm{O}$ & 2 \\
\hline & High & $8 \mathrm{mmol} \mathrm{L}^{-1}$ & $\begin{array}{l}\mathrm{KNO}_{3} \\
\mathrm{Ca}\left(\mathrm{NO}_{3}\right)_{2} \times 4 \mathrm{H}_{2} \mathrm{O}\end{array}$ & $\begin{array}{l}4 \\
2 \\
\end{array}$ \\
\hline & \multirow{10}{*}{ 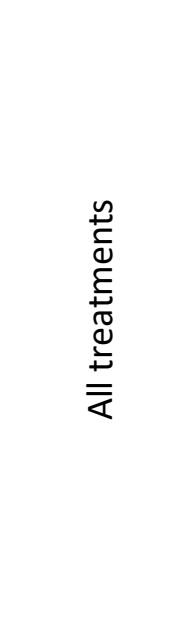 } & & $\mathrm{MgSO}_{4} \times 7 \mathrm{H}_{2} \mathrm{O}$ & 0.1501 \\
\hline & & & $\mathrm{KH}_{2} \mathrm{PO}_{4}$ & 0.2999 \\
\hline & & & $\mathrm{K}_{2} \mathrm{HPO}_{4}$ & 0.0207 \\
\hline & & & $\mathrm{H}_{3} \mathrm{BO}_{3}$ & 0.0050 \\
\hline & & & $\mathrm{MnSO}_{4} \times \mathrm{H}_{2} \mathrm{O}$ & 0.0010 \\
\hline & & & $\mathrm{Na}_{2} \mathrm{MoO}_{4} \times 2 \mathrm{H}_{2} \mathrm{O}$ & 0.0035 \\
\hline & & & $\mathrm{CoSO}_{4} \times 7 \mathrm{H}_{2} \mathrm{O}$ & 0.0001 \\
\hline & & & $\mathrm{ZnSO}_{4} \times 7 \mathrm{H}_{2} \mathrm{O}$ & 0.0001 \\
\hline & & & $\mathrm{CuSO}_{4} \times 7 \mathrm{H}_{2} \mathrm{O}$ & 0.0001 \\
\hline & & & EDTA - Fe $\times 3 \mathrm{H}_{2} \mathrm{O}$ & 0.0174 \\
\hline
\end{tabular}


Table S2.2: Quality and output from RNAseq procedure and subsequent data processing

\begin{tabular}{lrrrrrr}
\hline Treatment & PlantNo & RIN values & Raw reads & Processed (fastP) & Mapped & Mapped (\%) \\
\hline $\mathrm{L} \mathrm{NH}_{4}{ }^{+}$ & 1 & 5.7 & 13783616 & 13734565 & 12763277 & 92.93 \\
$\mathrm{~L} \mathrm{NH}_{4}{ }^{+}$ & 4 & 5.9 & 18551988 & 18484328 & 17256570 & 93.36 \\
$\mathrm{~L} \mathrm{NH}_{4}{ }^{+}$ & 5 & 5.8 & 14487052 & 14434266 & 13545914 & 93.85 \\
$\mathrm{~L} \mathrm{NH}_{4}{ }^{+}$ & 9 & 5.6 & 14735119 & 14677327 & 13749307 & 93.68 \\
$\mathrm{M} \mathrm{NH}_{4}{ }^{+}$ & 2 & 5.5 & 12954047 & 12891433 & 9986520 & 77.47 \\
$\mathrm{M} \mathrm{NH}_{4}{ }^{+}$ & 4 & 5.9 & 16377042 & 16316270 & 15260381 & 93.53 \\
$\mathrm{M} \mathrm{NH}_{4}{ }^{+}$ & 7 & 5.7 & 17865955 & 17791507 & 16725784 & 94.01 \\
$\mathrm{M} \mathrm{NH}_{4}{ }^{+}$ & 10 & 5.7 & 14358012 & 14305123 & 13472200 & 94.18 \\
$\mathrm{H} \mathrm{NH}_{4}{ }^{+}$ & 2 & 9.2 & 18486815 & 18382349 & 17130455 & 93.19 \\
$\mathrm{H} \mathrm{NH}_{4}{ }^{+}$ & 4 & 9.1 & 18465611 & 18366167 & 16819299 & 91.58 \\
$\mathrm{H} \mathrm{NH}_{4}{ }^{+}$ & 6 & 8.9 & 17824503 & 17723713 & 16341968 & 92.20 \\
$\mathrm{H} \mathrm{NH}_{4}{ }^{+}$ & 7 & 8.9 & 16415811 & 16327898 & 15166057 & 92.88 \\
$\mathrm{H} \mathrm{NH}_{4}{ }^{+}$ & 9 & 9.2 & 19294962 & 19165705 & 17989286 & 93.86 \\
$\mathrm{~L} \mathrm{NO}_{3}{ }^{-}$ & 2 & 5.1 & 14353980 & 14296524 & 12860357 & 89.95 \\
$\mathrm{~L} \mathrm{NO}_{3}{ }^{-}$ & 7 & 5.4 & 15737311 & 15680877 & 14672981 & 93.57 \\
$\mathrm{~L} \mathrm{NO}_{3}{ }^{-}$ & 8 & 5.4 & 21088585 & 21009692 & 18712433 & 89.07 \\
$\mathrm{~L} \mathrm{NO}_{3}{ }^{-}$ & 10 & 5.2 & 19085946 & 19010101 & 17561946 & 92.38 \\
$\mathrm{M} \mathrm{NO}_{3}{ }^{-}$ & 2 & 5.8 & 17404205 & 17341032 & 16174619 & 93.27 \\
$\mathrm{M} \mathrm{NO}_{3}{ }^{-}$ & 4 & 5.7 & 16581387 & 16515881 & 14817873 & 89.72 \\
$\mathrm{M} \mathrm{NO}_{3}^{-}$ & 6 & 5.5 & 16875880 & 16811495 & 14940152 & 88.87 \\
$\mathrm{M} \mathrm{NO}_{3}^{-}$ & 8 & 5.7 & 14858631 & 14807888 & 13873352 & 93.69 \\
$\mathrm{H} \mathrm{NO}_{3}^{-}$ & 2 & 8.9 & 16038666 & 15951508 & 14735951 & 92.38 \\
$\mathrm{H} \mathrm{NO}_{3}^{-}$ & 3 & 9.2 & 18069065 & 17966498 & 16676325 & 92.82 \\
$\mathrm{H} \mathrm{NO}_{3}^{-}$ & 6 & 8.8 & 17821171 & 17717955 & 16321945 & 92.12 \\
$\mathrm{H} \mathrm{NO}_{3}^{-}$ & 7 & 9.1 & 18702122 & 18595466 & 17301826 & 93.04 \\
$\mathrm{H} \mathrm{NO}_{3}^{-}$ & 9 & 8.9 & 15211278 & 15124643 & 13957851 & 92.29 \\
\hline & & & & & &
\end{tabular}


Table S2.3: Populus $\mathrm{x}$ canescens xylem sap metabolites identified by targeted GC-MS over different nitrogen treatments

\begin{tabular}{|c|c|c|c|c|c|c|c|}
\hline & \multirow[b]{2}{*}{ Identified by } & \multicolumn{3}{|c|}{ Ammonium } & \multicolumn{3}{|c|}{ Nitrate } \\
\hline & & Low & Medium & High & Low & Medium & High \\
\hline \multicolumn{8}{|l|}{ Amino acids } \\
\hline beta-Alanine & ES & 0.81 & 0.89 & 1 & 0.55 & 0.62 & 0.53 \\
\hline 2-Amino butyrate & SL NIST & 0 & 0 & 1 & 0 & 0.01 & 0.42 \\
\hline Alanine & ES & 0.03 & 0.1 & 1 & 0.04 & 0.1 & 0.33 \\
\hline Alanine, 3-cyano- & SL Golm & 0 & 0.01 & 1 & 0.01 & 0.01 & 0.07 \\
\hline Asparagine & ES & 0 & 0.01 & 1 & 0 & 0.01 & 0.16 \\
\hline Aspartate & ES & 0.05 & 0.25 & 1 & 0.03 & 0.04 & 0.32 \\
\hline GABA & ES & 0.04 & 0.18 & 1 & 0.02 & 0.04 & 0.16 \\
\hline Glutamate & ES & 0.16 & 1 & 0.69 & 0.19 & 0.3 & 0.5 \\
\hline Glutamine & ES & 0.01 & 0.51 & 1 & 0.02 & 0.06 & 0.17 \\
\hline Glycine & ES & 0.35 & 0.52 & 1 & 0.48 & 0.44 & 0.6 \\
\hline Isoleucine & ES & 0.03 & 0.12 & 1 & 0.07 & 0.1 & 0.21 \\
\hline Leucine & ES & 0.71 & 0.69 & 1 & 0.61 & 0.88 & 0.77 \\
\hline Lysine & ES & 0.03 & 0.31 & 1 & 0.03 & 0.07 & 0.16 \\
\hline Pyroglutamate & ES & 0.07 & 1 & 0.86 & 0.08 & 0.27 & 0.52 \\
\hline Proline & ES & 0.12 & 0.11 & 1 & 0.05 & 0.08 & 0.13 \\
\hline Serine & ES & 0.01 & 0.07 & 1 & 0.02 & 0.06 & 0.05 \\
\hline Threonine & ES & 0.03 & 0.2 & 1 & 0.09 & 0.14 & 0.14 \\
\hline Tyrosine & ES & 0.03 & 0.18 & 1 & 0.05 & 0.06 & 0.14 \\
\hline $\begin{array}{l}\text { Valine } \\
\text { Organic acids }\end{array}$ & ES & 0.04 & 0.24 & 1 & 0.09 & 0.17 & 0.3 \\
\hline Citrate & ES & 0.25 & 0.29 & 0.66 & 0.36 & 0.33 & 1 \\
\hline Fumarate & ES & 0.3 & 0.21 & 0.09 & 0.59 & 0.66 & 1 \\
\hline $\begin{array}{l}\text { Glycerate } \\
\text { 2-Imidazolidone- }\end{array}$ & ES & 0.49 & 0.63 & 1 & 0.38 & 0.35 & 0.47 \\
\hline 4-carboxylate & SL Golm & 0.02 & 0.04 & 1 & 0.03 & 0.07 & 0.45 \\
\hline Lactate & ES & 0.75 & 0.73 & 0.86 & 0.7 & 1 & 0.87 \\
\hline Malate & ES & 0.34 & 0.21 & 0.07 & 0.59 & 0.44 & 1 \\
\hline Pentonate & SL NIST & 0.52 & 0.98 & 1 & 0.4 & 0.36 & 0.52 \\
\hline Succinate & ES & 0.15 & 0.12 & 0.03 & 0.64 & 0.71 & 1 \\
\hline $\begin{array}{l}\text { Threonate } \\
\text { Others }\end{array}$ & ES & 0.34 & 1 & 0.8 & 0.38 & 0.56 & 0.91 \\
\hline Ethanolamine & ES & 0.75 & 0.33 & 1 & 0.26 & 0.16 & 0.19 \\
\hline Glycerol & ES & 0.82 & 0.7 & 1 & 0.64 & 0.55 & 0.61 \\
\hline Hexitol & SL NIST & 0.59 & 0.55 & 1 & 0.36 & 0.21 & 0.27 \\
\hline myo-Inositol & ES & 0.31 & 0.32 & 1 & 0.36 & 0.26 & 0.14 \\
\hline Pentol & SL NIST & 0.69 & 1 & 1 & 0.71 & 0.57 & 0.68 \\
\hline
\end{tabular}




\begin{tabular}{llrrrrrr}
$\begin{array}{l}\text { Phosphate } \\
\text { Sugars }\end{array}$ & ES & 0.59 & 1 & 0.78 & 0.36 & 0.3 & 0.59 \\
Deoxyhexose & SL Golm & 0.53 & 0.61 & 1 & 0.37 & 0.29 & 0.53 \\
Fructose & ES & 0.52 & 0.5 & 1 & 0.42 & 0.28 & 0.4 \\
Glucose & ES & 0.27 & 0.26 & 1 & 0.18 & 0.15 & 0.29 \\
Hexoaldose & SL NIST & 0.18 & 0.16 & 1 & 0.11 & 0.09 & 0.17 \\
Hexoketose & SL NIST & 0.86 & 1 & 0.72 & 0.58 & 0.34 & 0.39 \\
Pentose 1 & SL NIST & 0.29 & 0.73 & 1 & 0.21 & 0.27 & 0.62 \\
Pentose 2 & SL NIST & 0.21 & 0.45 & 1 & 0.13 & 0.16 & 0.41 \\
Pentose 3 & SL NIST & 0.39 & 0.44 & 1 & 0.19 & 0.17 & 0.71 \\
Sucrose & ES & 1 & 0.19 & 0.18 & 0.62 & 0.17 & 0.15 \\
\hline
\end{tabular}

Data was normalized to one. Low $=0.4 \mathrm{mM}$, Medium $=2.0 \mathrm{mM}$, High $=8.0 \mathrm{mM}, \mathrm{ES}=$ calibrated standard, SL Golm = Golm Metabolome Database, SL NIST = NIST spectral library $2.0 f$

Table S2.4: Metabolite profile of Populus x canescens xylem sap

\begin{tabular}{|c|c|c|}
\hline Metabolite & Metabolite identified via & Observed by \\
\hline 1-( $\beta$-D-Ribofuranosyl)nicotinamide & MS/MS (LC-MS) & 2 \\
\hline 12-Oxo-phytodienoic acid & MS/MS (LC-MS) & 3 \\
\hline 1-O-(4-Coumaroyl)- $\beta$-D-glucose & MS/MS (LC-MS) & 2 \\
\hline 2,5-Dihydroxybenzoate-glucoside & MS/MS (LC-MS) & 2 \\
\hline 2,5-Dihydroxysalicylate-glucoside & MS/MS (LC-MS) & 2 \\
\hline 2-Amino-6-hydroxypurine & MS/MS (LC-MS) & 2 \\
\hline 2-Aminobutyric acid & GOLM DB (GC-MS) & 1 \\
\hline 2-Hydroxyglutaric acid & MS/MS (LC-MS) & 2 \\
\hline 2-Imidazolidone-4-carboxylate & GOLM DB (GC-MS & 1 \\
\hline 2-O-acetylsalicin & MS/MS (LC-MS) & 2 \\
\hline 3-Cyano-alanine & GOLM DB (GC-MS) & 1 \\
\hline 3-Dihydroxybenzoic acid & MS/MS (LC-MS) & 2 \\
\hline 4-Aminobutyric acid & GOLM DB (GC-MS) & 1 \\
\hline 4-Hydroxybenzoate-glucoside & MS/MS (LC-MS) & 2 \\
\hline 4-Methylbenzoic acid & MS/MS (LC-MS) & 2 \\
\hline 5-Hydroxyconiferyl alcohol derived & MS/MS (LC-MS) & 2 \\
\hline 7-O-Methylnaringenin-7-furanosyl-(1-6)-glucopyranside & MS/MS (LC-MS) & 2 \\
\hline Abscisic acid & MS/MS (LC-MS) & 2,3 \\
\hline Alanine & GOLM DB (GC-MS) & 1 \\
\hline Arbutin (hydroquinone glucoside) & MS/MS (LC-MS) & 2 \\
\hline Aromadendrin-7-O-glucoside & MS/MS (LC-MS) & 2 \\
\hline Asparagine & MS/MS (LC-MS) & 1,2 \\
\hline Aspartic acid & GOLM DB (GC-MS) & 1 \\
\hline Blumenol A & MS/MS (LC-MS) & 2 \\
\hline Caffeic acid 3-glucoside & MS/MS (LC-MS) & 2 \\
\hline
\end{tabular}




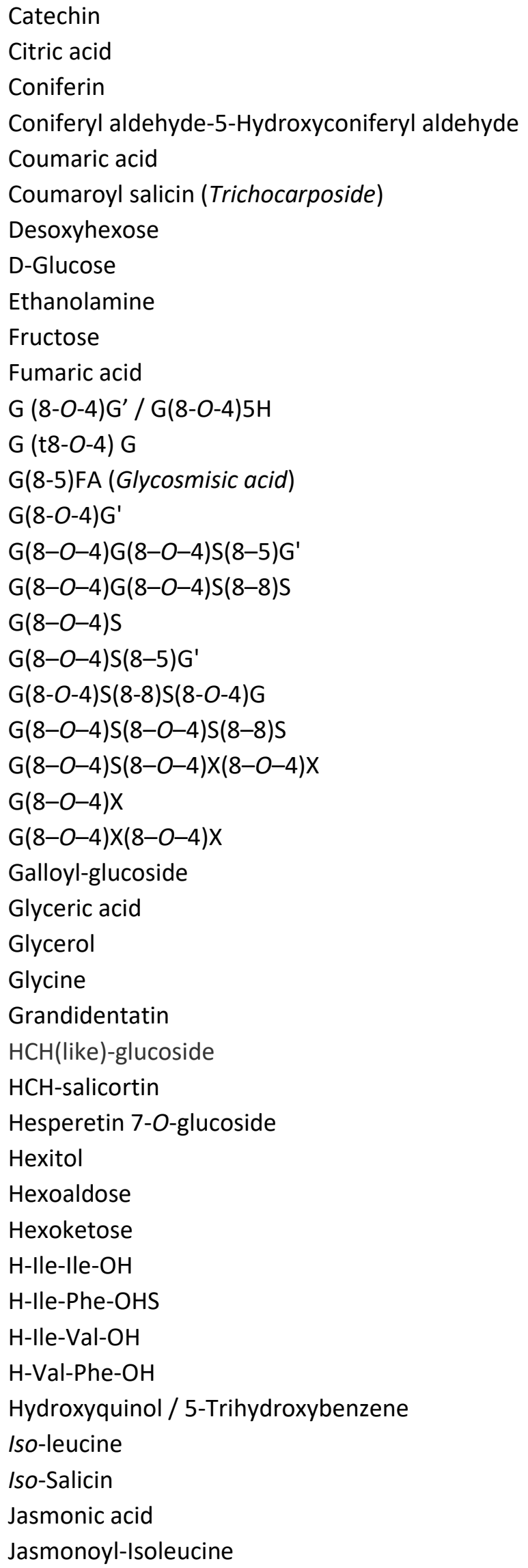

MS/MS (LC-MS)
MS/MS (LC-MS)
MS/MS (LC-MS)
MS/MS (LC-MS)
MS/MS (LC-MS)
MS/MS (LC-MS)
GOLM DB (GC-MS)
MS/MS (LC-MS)
GOLM DB (GC-MS)
MS/MS (LC-MS)
MS/MS (LC-MS)


Jasmonoyl-Leucine

Lactic acid

L-Glutamate

L-Glutamine

L-Isoleucine

L-Leucine

L-Proline

L-Threonine

L-Valine

Lysine (4 TMS)

Malate

Malic acid

Matairesinol

Methyljasmonate

myo-Inositol

$N$-hydoxypipecolic aicd

Nicotinate D-ribonucleoside

p-Aminobenzoic acid

Pentol

Pentonate

Pentose 1

Pentose 2

Pentose 3

Phosphoric acid

Pipecolic acid

Plastoquinol-1

Populin

Porphobilinogen

Protochlorophyllide

Quinic acid

$\mathrm{S}(8-0-4)$ Esculetin

$S(8-0-4) S(8-5) G$

Salicin

Salicortin

Salicyl alcohol

Salicylic acid

Salicylic acid-glucoside

Salicyloylsalicin

Salicyloylsalicin-C7H12O7

Salirepin

Scopoletin-C5H9O5

Scopoletin-glucoside

Serine

Succinic acid
MS/MS (LC-MS) 3

GOLM DB (GC-MS) 1

MS/MS (LC-MS) 1,2

MS/MS (LC-MS) 1,2

MS/MS (LC-MS) 1,2

MS/MS (LC-MS) 1, 2

MS/MS (LC-MS) 1,2

MS/MS (LC-MS) 1, 1,2

MS/MS (LC-MS) 1, 1

GOLM DB (GC-MS) 1

MS/MS (LC-MS) 1,2

MS/MS (LC-MS) 1, 1

MS/MS (LC-MS) 2

MS/MS (LC-MS) 2

GOLM DB (GC-MS) 1

MS/MS (LC-MS) 3

MS/MS (LC-MS) 2

MS/MS (LC-MS) 2

NIST DB (GC-MS) 1

NIST DB (GC-MS) 1

GOLM DB (GC-MS)

GOLM DB (GC-MS) 1

GOLM DB (GC-MS) 1

GOLM DB (GC-MS) 1

MS/MS (LC-MS) 2, 3

MS/MS (LC-MS) 2

MS/MS (LC-MS) 2

MS/MS (LC-MS) 2

MS/MS (LC-MS) 2

MS/MS (LC-MS) 1,2

MS/MS (LC-MS) 2

MS/MS (LC-MS) 2

MS/MS (LC-MS) 2

MS/MS (LC-MS) 2

MS/MS (LC-MS) 2

MS/MS (LC-MS) 2, 3

MS/MS (LC-MS) 2

MS/MS (LC-MS) 2

MS/MS (LC-MS) 2

MS/MS (LC-MS) 2

MS/MS (LC-MS) 2

MS/MS (LC-MS) 2

GOLM DB (GC-MS) 1

MS/MS (LC-MS) 1,2 
Sucrose

Syringic acid-glucoside

Threonic acid

Tremulacin

Tyrosine

Vanilat-glucoside

Xylulose

$\beta$-Alanine

$\gamma$-Glutamyl- $\beta$-cyanoalanine

$\gamma$-Glutamyl- $\gamma$-aminobutyraldehyde

$\begin{array}{rr}\text { MS/MS (LC-MS) } & 1,2 \\ \text { MS/MS (LC-MS) } & 2 \\ \text { MS/MS (LC-MS) } & 1,2 \\ \text { MS/MS (LC-MS) } & 2 \\ \text { MS/MS (LC-MS) } & 1,2 \\ \text { MS/MS (LC-MS) } & 2 \\ \text { MS/MS (LC-MS) } & 1,2 \\ \text { GOLM DB (GC-MS) } & 1 \\ \text { MS/MS (LC-MS) } & 2 \\ \text { MS/MS (LC-MS) } & 2\end{array}$

1, Targeted primary metabolite analysis by GC-MS; 2 , Non-targeted metabolite fingerprinting by LCMS; 3, Targeted phytohormone analysis by LC-MS

Table S2.5: Overview of differentially expressed genes in leaves of Populus $x$ canescens plants treated with different concentrations and forms of nitrogen. "First set" refers to leaf transcriptome data of plants treated with $\mathrm{N}$ type and $\mathrm{N}$ concentration named under "comparison of sets" first, and "Second set" to the second named conditions.

\begin{tabular}{|c|c|c|c|}
\hline \multirow[b]{2}{*}{ Comparison of sets } & \multirow[b]{2}{*}{ DEGs } & \multicolumn{2}{|c|}{ Upregulation } \\
\hline & & In first set & In second set \\
\hline $\mathrm{NH}_{4}^{+} \mathrm{L}$ vs. $\mathrm{NH}_{4}^{+} \mathrm{M}$ & 229 & 103 & 126 \\
\hline $\mathrm{NH}_{4}{ }^{+} \mathrm{M}$ vs. $\mathrm{NH}_{4}{ }^{+} \mathrm{H}$ & 9696 & 4703 & 4993 \\
\hline $\mathrm{NH}_{4}^{+} \mathrm{L}$ vs. $\mathrm{NH}_{4}^{+} \mathrm{H}$ & 9747 & 4525 & 5222 \\
\hline $\mathrm{NO}_{3}{ }^{-} \mathrm{L}$ vs. $\mathrm{NO}_{3}{ }^{-} \mathrm{M}$ & 3380 & 1633 & 1747 \\
\hline $\mathrm{NO}_{3}{ }^{-} \mathrm{M}$ vs. $\mathrm{NO}_{3}{ }^{-} \mathrm{H}$ & 10948 & 5397 & 5551 \\
\hline $\mathrm{NO}_{3}{ }^{-} \mathrm{L}$ vs. $\mathrm{NO}_{3}^{-} \mathrm{H}$ & 10949 & 5387 & 5562 \\
\hline $\mathrm{L} \mathrm{NH}_{4}^{+}$vs L NO $3_{3}^{-}$ & 379 & 194 & 185 \\
\hline $\mathrm{M} \mathrm{NH}_{4}^{+}$vs $\mathrm{LNO}_{3}^{-}$ & 54 & 26 & 28 \\
\hline $\mathrm{H} \mathrm{NH}_{4}^{+}$vs $\mathrm{LNO}_{3}^{-}$ & 393 & 205 & 188 \\
\hline
\end{tabular}


Table S2.6: Phytohormone biosynthesis and response marker gene list from literature

\begin{tabular}{|c|c|c|c|}
\hline Phytohormone & Gene & Ath locus & Publication \\
\hline Abscisic acid & ABA1 & AT5G67030 & Barrero et al. 2005 \\
\hline Abscisic acid & ABA2 & AT1G52340 & Gonzáles-Guzmán et al. 2002 \\
\hline Abscisic acid & ABA3 & AT1G16540 & Léon-Klosterziel et al. 1996 \\
\hline Abscisic acid & MYB96 & AT5G62470 & Lee and Seo, 2019 \\
\hline Auxin & ARF6 & AT1G30330 & Nagpal et al. 2005 \\
\hline Auxin & ARF8 & AT5G37020 & Nagpal et al. 2005 \\
\hline Ethylene & ERF9 & AT5G44210 & Hu et al., 2008 \\
\hline Ethylene & ERF1 & AT3G23240 & Gaudinier et al. 2018 \\
\hline Ethylene & EIN3 & AT3G20770 & Mao et al., 2008 \\
\hline Ethylene & $\mathrm{ACC}$ & At1g62960 & Iwai et al., 2006 \\
\hline Ethylene & TAR2 & AT4G24670 & Pacheco-Villalobos et al., 2013 \\
\hline Ethylene & PAL & AT2G37040 & Sandoya et al.,2014 \\
\hline Ethylene & ETO1 & AT3G51770 & Li et al. 2018 \\
\hline Ethylene & PR4 & AT3G04720 & Anderson et al. 2004 \\
\hline Jasmonic acid/Ethylene & PR3 & AT3G12500 & Schmitz et al., 2010 \\
\hline Jasmonic acid/Ethylene & PDF2.3 & AT2G02130 & Pieterse and van Loon, 1999 \\
\hline Jasmonic acid & AOS & AT5G42650 & Walia et al., 2007 \\
\hline Jasmonic acid & LOX & AT1G17420 & Walia et al., 2007 \\
\hline Jasmonic acid & MYC2 & AT1G32640 & Pauwels et al. 2010 \\
\hline Jasmonic acid & JAZ1 & AT1G19180 & Pauwels et al. 2010 \\
\hline Jasmonic acid & FAD8 & AT5G05580 & Amiard et al. 2006 \\
\hline Jasmonic acid & NINJA & AT4G28910 & Pauwels et al. 2010 \\
\hline Salicylic acid/Jasmonic acid & WRKY70 & AT3G56400 & Shimono et al., 2007 \\
\hline Salicylic acid & NPR1 & AT1G64280 & Shimono et al., 2007 \\
\hline Salicylic acid & SAGT1 & AT2G43820 & Umemure et al., 2009 \\
\hline Salicylic acid & SARD1 & AT1G73805 & Zhang et al. 2010 \\
\hline Salicylic acid & ICS1 & AT1G74710 & Zhang et al. 2010 \\
\hline Salicylic acid & PR1 & AT2G14610 & Zhang et al. 2010 \\
\hline Salicylic acid & PR2 & AT3G57260 & Zhang et al. 2010 \\
\hline Pipecolic acid & FMO1 & AT1G19250 & Bernsdorff et al., 2016 \\
\hline Pipecolic acid & SARD4 & AT5G52810 & Zhang et al. 2016 \\
\hline Pipecolic acid & ALD1 & AT2G13810 & Zhang et al. 2016 \\
\hline
\end{tabular}


Table S2.7: Poplar defense gene expression patterns from reference studies in reaction to exogenous application of jasmonic acid and salicylic acid (Ref. 4), herbivory by Malacosoma disstria (Ref. 2) or Chrysomela populi (Ref. 3) and attack of biotrophic pathogen Melampsora larici-populina (Ref. 1 \& 4)

\begin{tabular}{|c|c|c|c|c|c|}
\hline Pathway & Gene & Ath gene locus & Potri ID & Ref. & Expression pattern in reference \\
\hline ETH & ERF1 & AT3G23240 & Potri.002G039000 & 4 & 个SA \\
\hline ETH & ERF1 & AT3G23240 & Potri.005G223200 & 4 & 个JA, 个SA, 个biotroph \\
\hline ETH & ERF1 & AT3G23240 & Potri.008G166200 & 3,4 & 个JA, 个SA, 个biotroph \\
\hline ETH & PR4 & АT3G04720 & Potri.013G041600 & $1,3,4$ & 个herbivory, 个biotroph \\
\hline ETH & PR4 & AT3G04720 & Potri.013G041700 & 1,4 & 个herbivory, $\downarrow$ herbivory \\
\hline$J A$ & AOS & AT5G42650 & Potri.014G038700 & 3,4 & $\uparrow J A, \uparrow$ herbivory, $\downarrow$ biotroph \\
\hline$J A$ & KTI & AT1G17860 & Potri.019G088200 & 3 & 个herbivory \\
\hline JA / ETH & PDF2.3 & AT2G02130 & Potri.T011200 & 3 & 个herbivory \\
\hline JA / ETH & PR3 & AT3G12500 & Potri.004G182000 & 3,4 & $\downarrow J A, \uparrow$ herbivory, $\uparrow$ biotroph \\
\hline JA / ETH & PR3 & AT3G12500 & Potri.004G182100 & 3,4 & 个JA, 个herbivory \\
\hline JA / ETH & PR3 & AT3G12500 & Potri.009G141700 & $1,3,4$ & 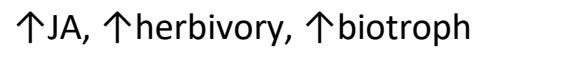 \\
\hline JA / ETH & PR3 & AT3G12500 & Potri.009G141800 & 3,4 & $\uparrow J A, \uparrow$ herbivory, $\downarrow$ biotroph \\
\hline JA / ETH & PR3 & AT3G12500 & Potri.009G142000 & 3,4 & 个JA, 个herbivory \\
\hline JA / ETH & PR3 & AT3G12500 & Potri.009G142200 & $2,3,4$ & 个JA, 个herbivory, 个biotroph \\
\hline JA / ETH & PR3 & AT3G12500 & Potri.009G142300 & 3,4 & 个JA, 个SA, 个herbivory \\
\hline JA / ETH & PR3 & AT3G12500 & Potri.T175200 & 3,4 & 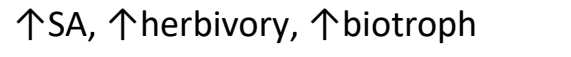 \\
\hline JA / ETH & PR3 & AT3G12500 & Potri.T175300 & 3,4 & 个herbivory \\
\hline SA / JA & WRKY70 & AT3G56400 & Potri.006G109100 & 4 & 个SA, 个biotroph \\
\hline SA / JA & WRKY70 & AT3G56400 & Potri.016G137900 & $1,3,4$ & 个JA, 个SA, $\downarrow$ herbivory, $\uparrow$ biotroph \\
\hline SA / JA & WRKY70 & AT3G56400 & Potri.013G090300 & 4 & 个SA, 个biotroph \\
\hline SA / JA & JAZ1 & AT1G19180 & Potri.006G139400 & 3,4 & 个JA, 个SA, 个herbivory \\
\hline SA & NPR1 & AT1G64280 & Potri.006G148100 & 4 & 个biotroph \\
\hline SA & SARD1 & AT1G73805 & Potri.012G054900 & 4 & 个SA, 个biotroph \\
\hline SA & SARD1 & AT1G73805 & Potri.015G045300 & 4 & 个SA, 个biotroph \\
\hline
\end{tabular}

$\mathrm{ETH}=$ ethylene, JA = jasmonic acid, SA = salicylic acid, Ref. = Reference paper, 1 = Rinaldi et al. 2007, 2 = Philippe et al. 2010, 3 = Kaling et al. 2018, $4=$ Luo et al. 2019, $\&=$ influenced by both phytohormones, vs. = involved in antagonism of phytohormones, $\uparrow$ upregulation, $\downarrow$ downregulation 


\begin{tabular}{|c|c|c|c|c|c|c|c|}
\hline Phase: & Propagation & Acclimation & Pre-treatment & Treatmer & & & \\
\hline Duration: & 4 weeks & 2 weeks & 8 weeks & 3 weeks & & & \\
\hline \multirow[t]{3}{*}{ N sources: } & \multirow[t]{3}{*}{$1 / 2 \mathrm{MS}$} & \multirow[t]{3}{*}{$2 \mathrm{mM} \mathrm{KNO}_{3}$} & \multirow{3}{*}{$\begin{array}{l}2.0 \mathrm{mM} \mathrm{NH}_{4} \mathrm{Cl} \text { or } \\
2.0 \mathrm{mM} \mathrm{KNO}_{3}\end{array}$} & & Low (L) & Medium (M) & High $(\mathrm{H})$ \\
\hline & & & & $\mathrm{NH}_{4} \mathrm{Cl}$ & $0.4 \mathrm{mM}$ & $2.0 \mathrm{mM}$ & $8.0 \mathrm{mM}$ \\
\hline & & & & $\mathrm{KNO}_{3}$ & $0.4 \mathrm{mM}$ & $2.0 \mathrm{mM}$ & $8.0 \mathrm{mM}$ \\
\hline Cultivation: & in vitro & \multicolumn{6}{|c|}{ Greenhouse } \\
\hline
\end{tabular}
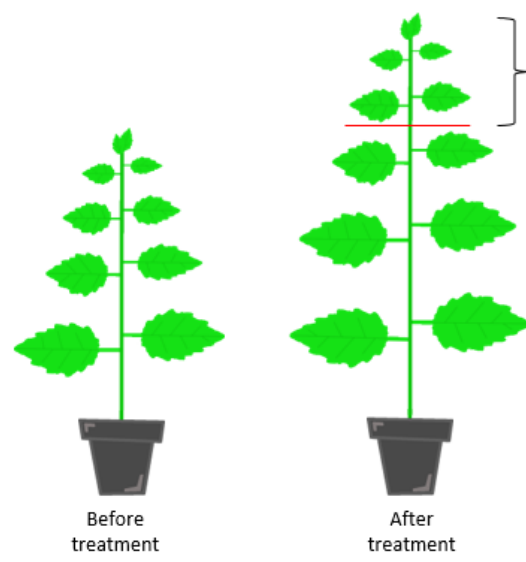

Gain during treatment

Figure S2.1: Schematic experimental setup including conducted analyses and treatment nomenclature: $\mathrm{NH}_{4} \mathrm{Cl}=\mathrm{NH}_{4}{ }^{+}, \mathrm{KNO}_{3}=\mathrm{NO}_{3}{ }^{-}, \mathrm{L}=0.4 \mathrm{mM}, \mathrm{M}=2.0 \mathrm{mM}, \mathrm{H}=8.0 \mathrm{mM}, \mathrm{G} 6 \mathrm{PD}=$ Glucose-6-phosphate dehydrogenase, $\mathrm{MS}=$ Murashige $\&$ Skoog

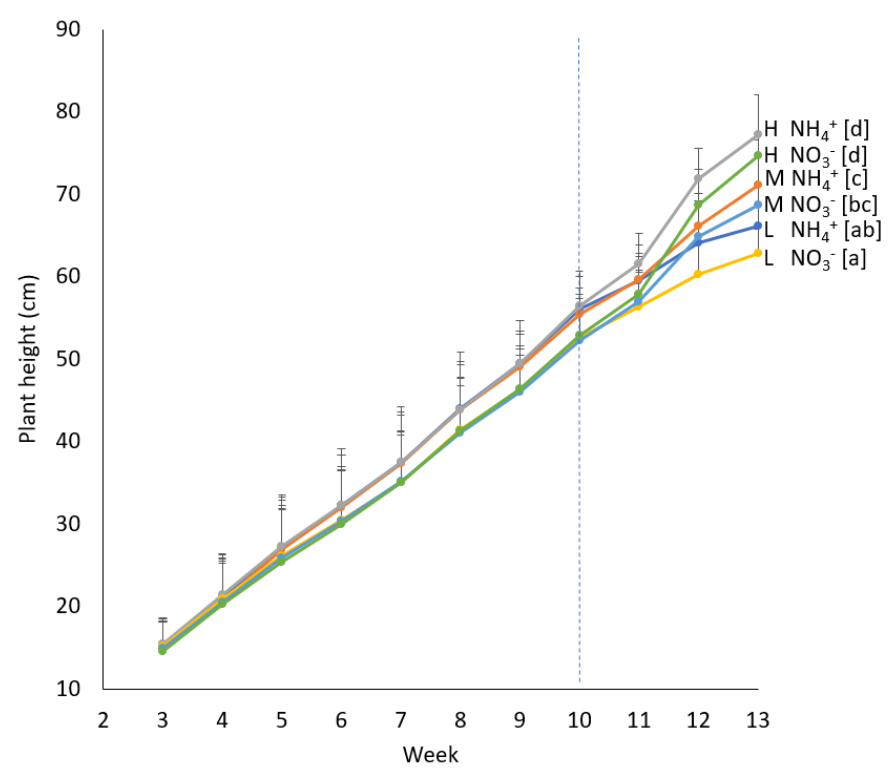

Figure S2.2: Plant height development comparisons of Populus $\mathrm{x}$ canescens plants treated with different $\mathrm{N}$ forms and $\mathrm{N}$ concentrations beginning at week 10 of the experiment. Begin of treatment is indicated by dashed blue line. No measurements were possible during the first two weeks of greenhouse cultivation. $\mathrm{NH}_{4}{ }^{+}=$ammonium, $\mathrm{NO}_{3}{ }^{-}=$nitrate, $\mathrm{L}=0.4 \mathrm{mM}, \mathrm{M}=2.0 \mathrm{mM}, \mathrm{H}=8.0 \mathrm{mM}$ 


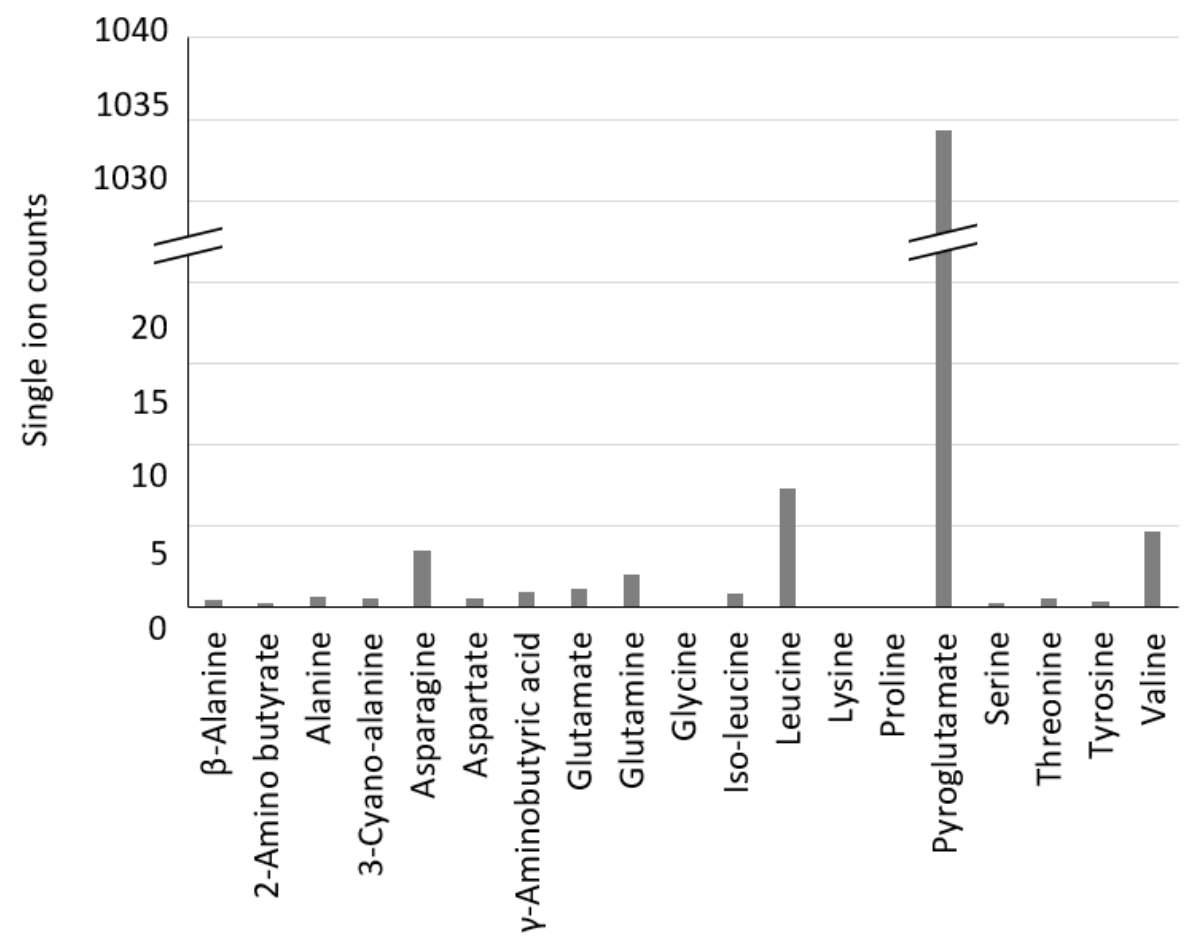

Figure S2.3: Mean intensities of Populus $x$ canescens xylem sap protein amino acid sequences, over all nitrogen treatments

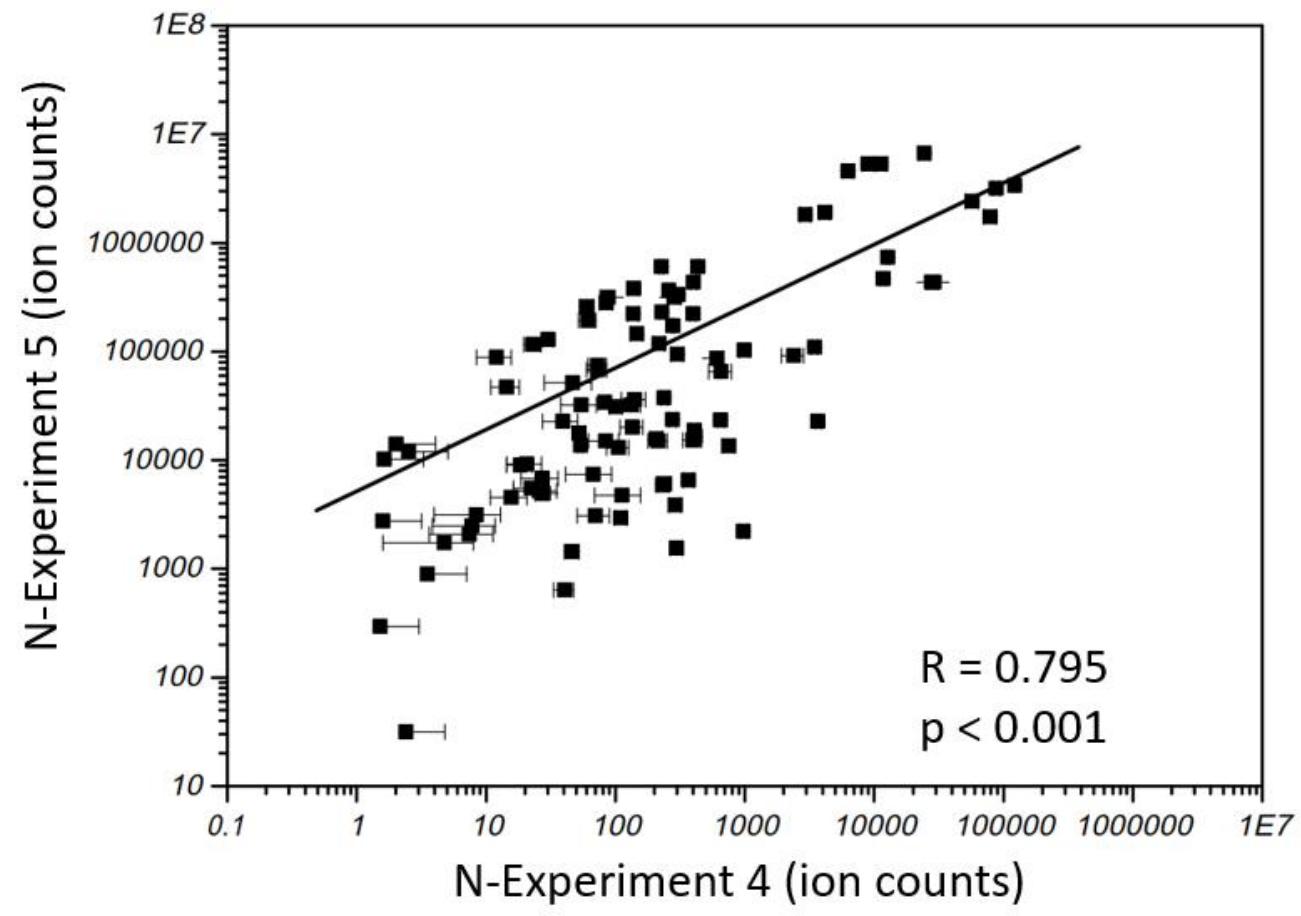

Figure S2.4: Correlation analysis of xylem sap metabolites confirmed in both independent experiments of Populus $\mathrm{x}$ canescens treated with different forms and concentrations of nitrogen. $\mathrm{X}$ and $\mathrm{Y}$ axis were $\log _{10}$ transformed. 
a
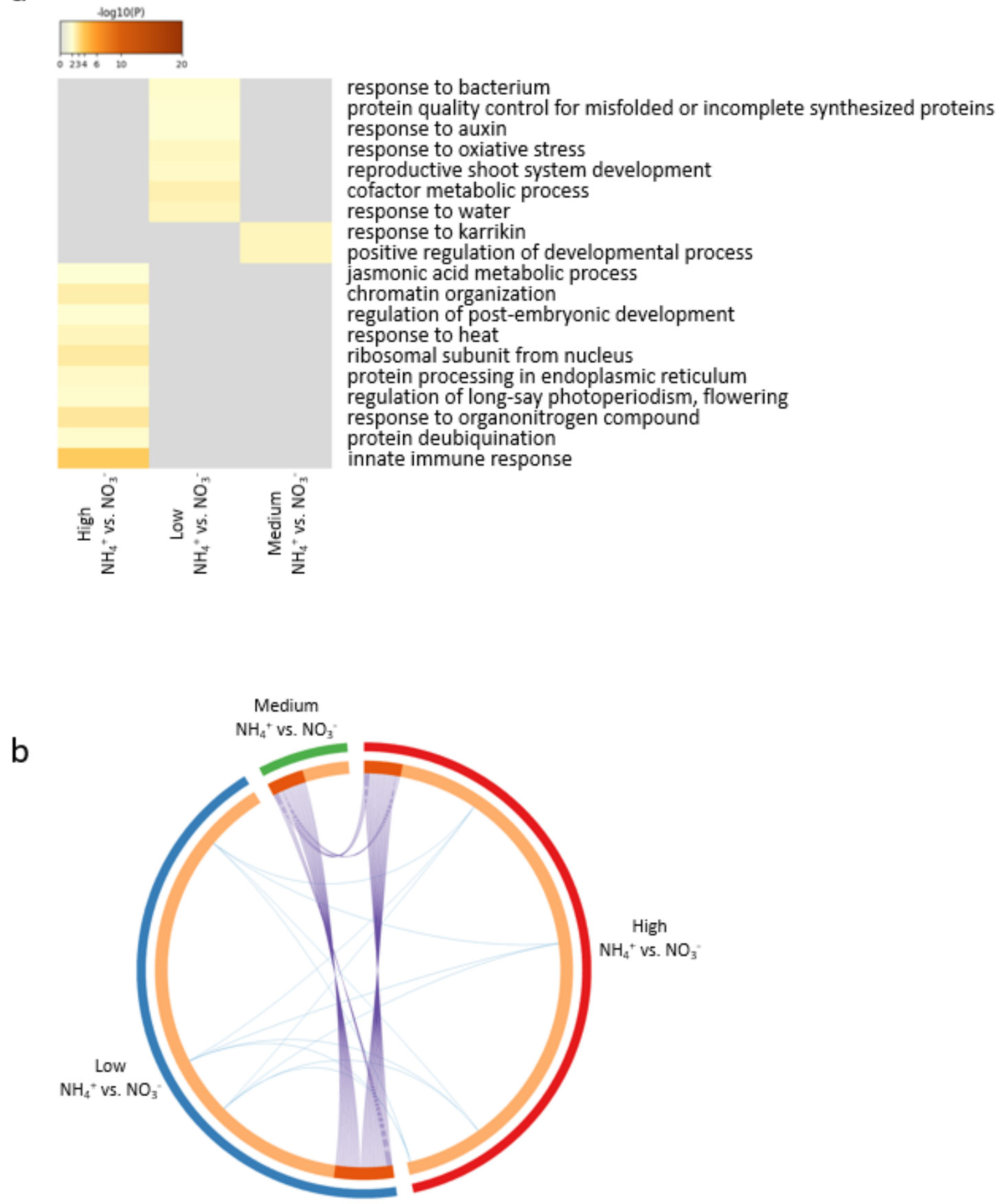

Figure S2.5: Comparison of differentially expressed genes in leaves of Populus $x$ canescens treated with different nitrogen forms and concentrations. a) Enriched gene ontology terms of treatment comparisons of same nitrogen concentration but different nitrogen form. b) A circos diagram showing the overlap of DEGs between different $\mathrm{N}$ concentrations of the same $\mathrm{N}$ forms. Colors in the most outer ring indicate the different DEG sets and their size. Light orange color in the inner ring indicates the DEGs unique for that comparison and dark orange colors the DEGs which occurred in other comparisons as well. Purple strings show overlap of genes between gene sets and blue strings indicate genes sharing the same ontology term. $\mathrm{NH}_{4}{ }^{+}=$ammonium, $\mathrm{NO}_{3}{ }^{-}=$nitrate, $\mathrm{L}=0.4 \mathrm{mM}, \mathrm{M}=2.0 \mathrm{mM}, \mathrm{H}=8.0 \mathrm{mM}, \mathrm{n}=6$ 


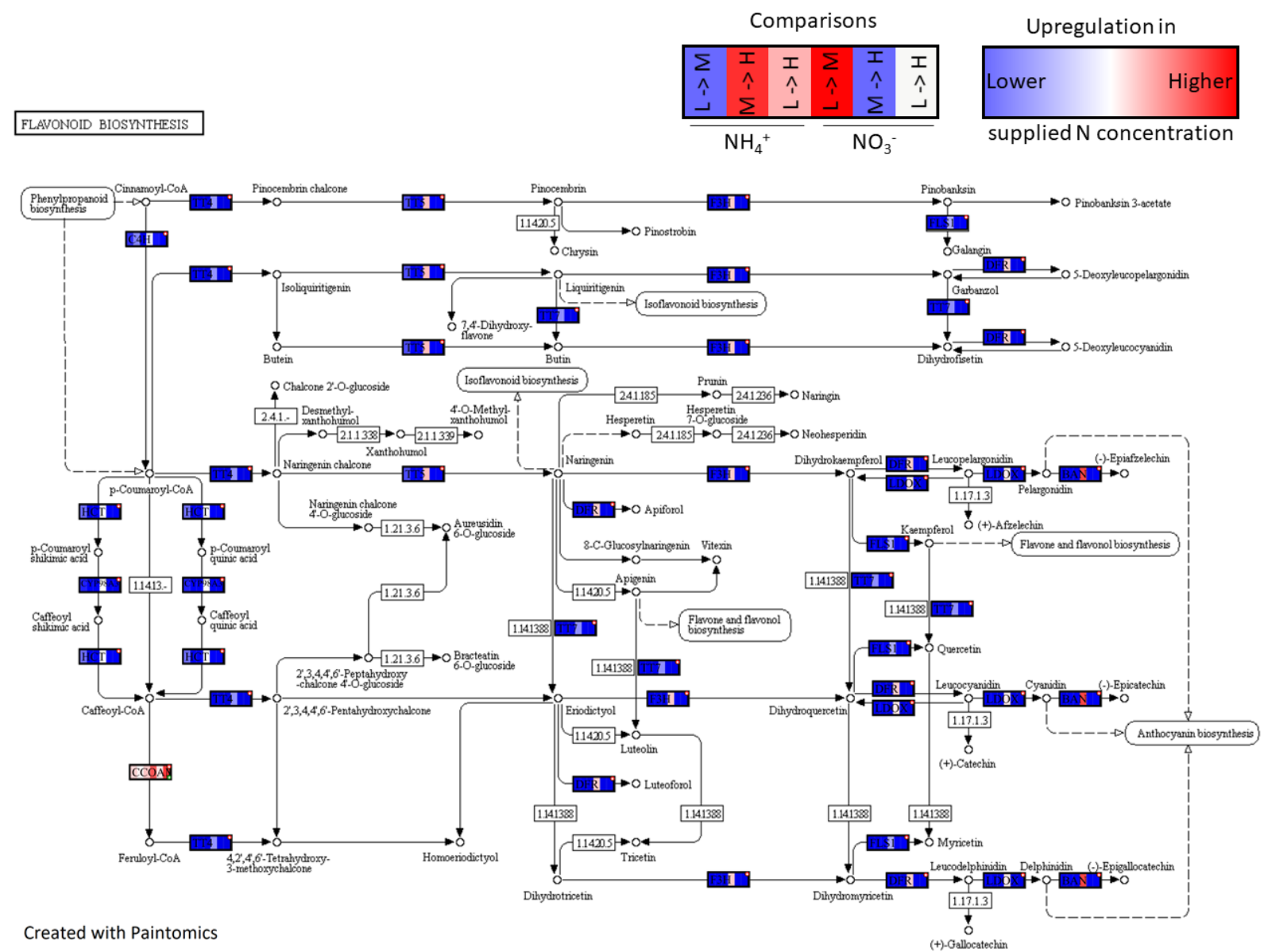

Figure S2.6: Flavonoid biosynthesis pathway mapping of differentially expressed genes in Populus $\mathrm{x}$ canescens leaves, treated with different forms and concentrations of nitrogen. Different concentrations with in $\mathrm{NH}_{4}{ }^{+}$or $\mathrm{NO}_{3}{ }^{-}$were compared. Blue indicates an upregulation in the lower concentration, and red an upregulation of the expression in the higher concentration of the comparison, respectively. $\mathrm{NH}_{4}{ }^{+}=$ammonium, $\mathrm{NO}_{3}{ }^{-}=$nitrate, $\mathrm{L}=0.4 \mathrm{mM}, \mathrm{M}=2.0 \mathrm{mM}, \mathrm{H}=8.0 \mathrm{mM}, \mathrm{SA}=$ Salicylic acid, JA = Jasmonic acid, $\mathrm{ETH}=$ Ethylene, $\mathrm{L}$ and $\mathrm{M} \mathrm{n}=4, \mathrm{H} \mathrm{n}=5$ 


\section{Zusammenfassung}

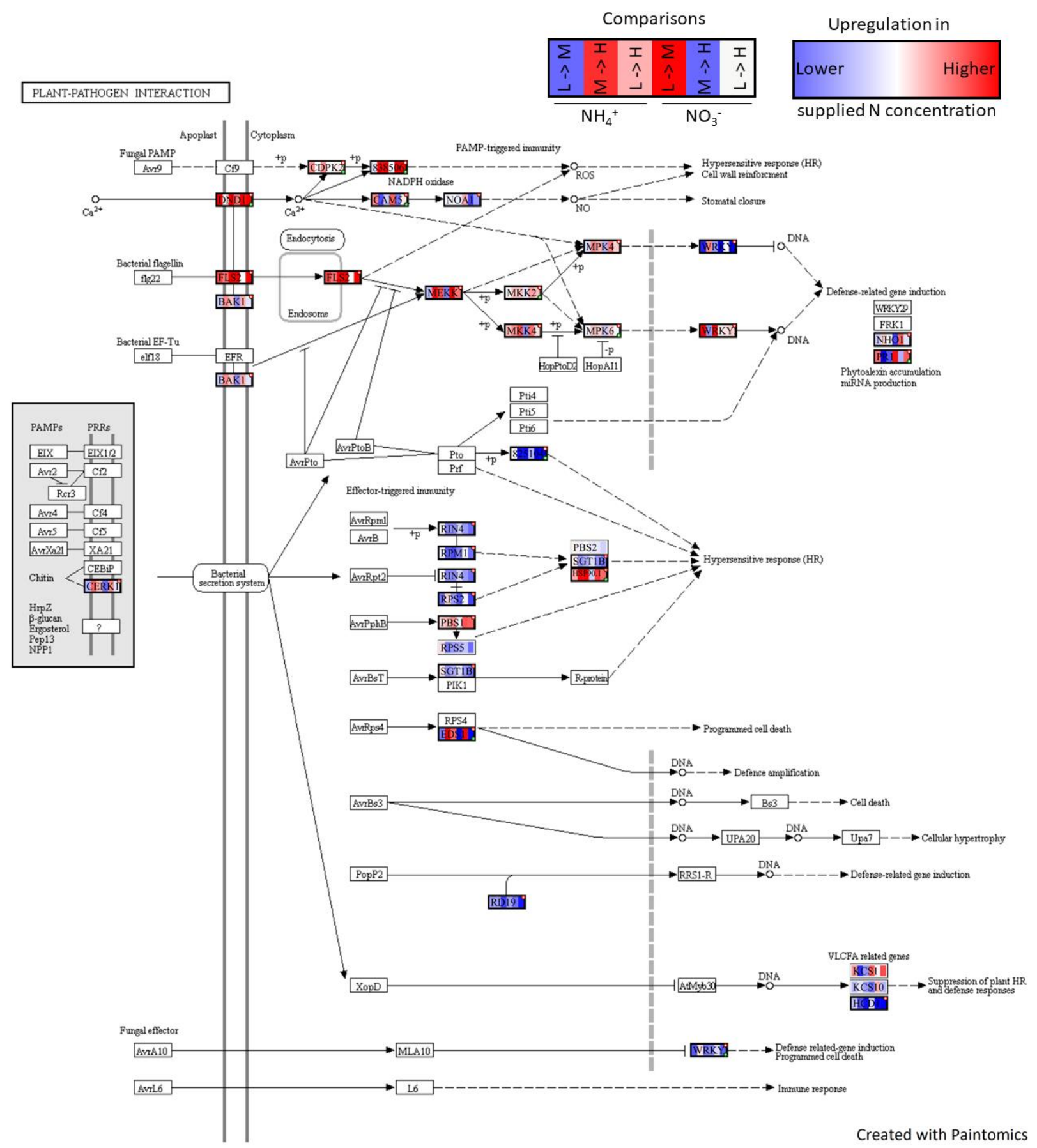

Figure S2.7: Plant-pathogen interaction pathway mapping of differentially expressed genes in Populus $\mathrm{x}$ canescens leaves, treated with different forms and concentrations of nitrogen. Different concentrations within $\mathrm{NH}_{4}{ }^{+}$or $\mathrm{NO}_{3}{ }^{-}$were compared. Blue indicates an upregulation in the lower concentration, and red an upregulation of the expression in the higher concentration of the comparison, respectively. $\mathrm{NH}_{4}{ }^{+}=$ammonium, $\mathrm{NO}_{3}{ }^{-}=$nitrate, $\mathrm{L}=0.4 \mathrm{mM}, \mathrm{M}=2.0 \mathrm{mM}, \mathrm{H}=8.0 \mathrm{mM}, \mathrm{SA}=$ Salicylic acid, $\mathrm{JA}$ = Jasmonic acid, $\mathrm{ETH}=$ Ethylene, $\mathrm{L}$ and $\mathrm{M} \mathrm{n}=4, \mathrm{H} \mathrm{n}=5$ 


\section{Zusammenfassung}

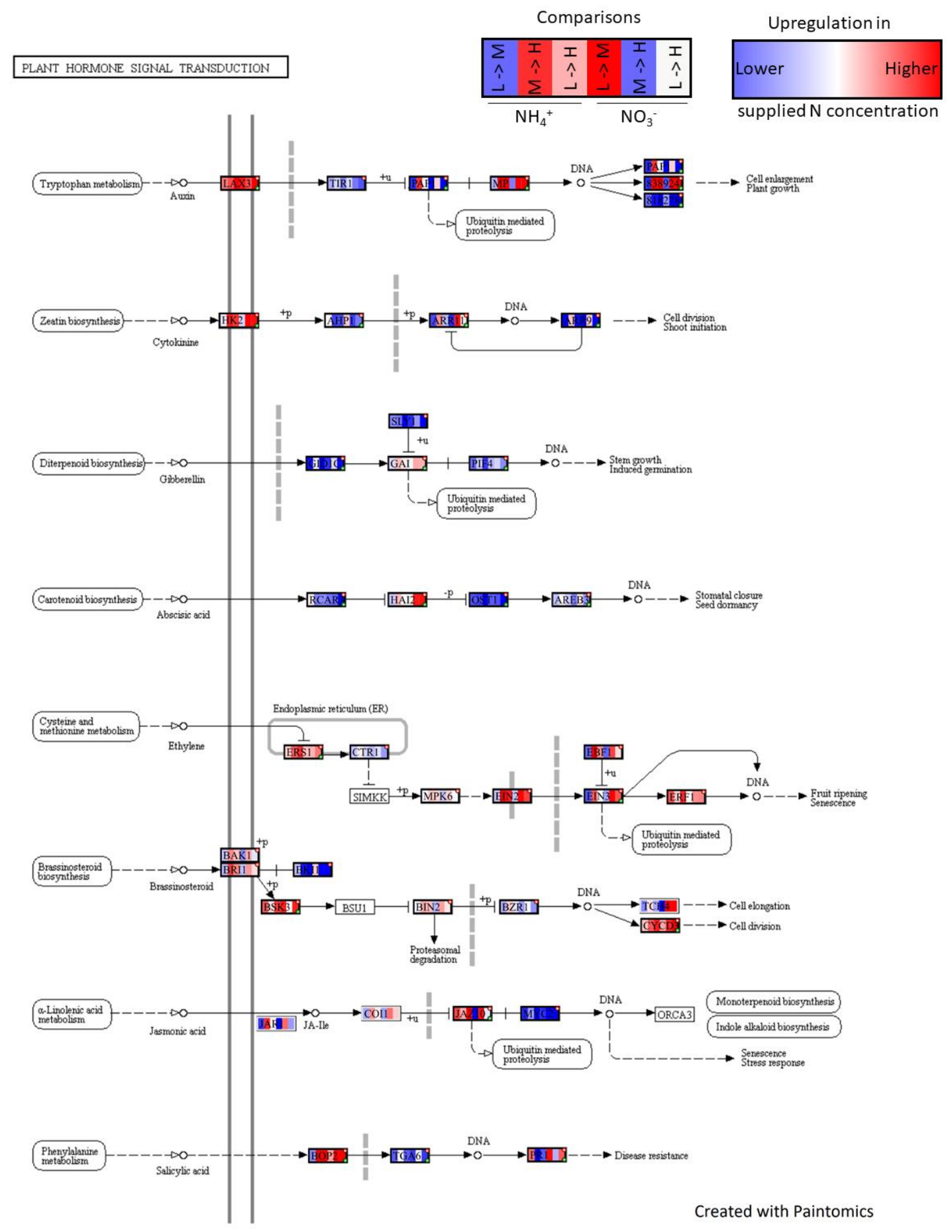

Figure S2.8: Plant hormone signal transduction pathway mapping of differentially expressed genes in Populus $\mathrm{x}$ canescens leaves, treated with different forms and concentrations of nitrogen. Different concentrations within $\mathrm{NH}_{4}{ }^{+}$or $\mathrm{NO}_{3}^{-}$were compared. Blue indicates an upregulation in the lower concentration, and red an upregulation of the expression in the higher concentration of the comparison, respectively. $\mathrm{NH}_{4}{ }^{+}=$ammonium, $\mathrm{NO}_{3}{ }^{-}=$nitrate, $\mathrm{L}=0.4 \mathrm{mM}, \mathrm{M}=2.0 \mathrm{mM}, \mathrm{H}=8.0 \mathrm{mM}, \mathrm{SA}=$ Salicylic acid, $\mathrm{JA}$ $=$ Jasmonic acid, $\mathrm{ETH}=$ Ethylene, $\mathrm{L}$ and $\mathrm{M} \mathrm{n}=4, \mathrm{H} \mathrm{n}=5$ 


\section{Chapter 3: Poplar mycorrhization affects xylem sap composition and defense responses}

\subsection{Introduction}

Fast growing poplars are of high economic and ecological importance in many countries worldwide (Polle \& Douglas, 2010). Poplars occur across various ecosystems, for example, in boreal and temperate forests, on lowland riverbanks, and in subtropical and arid regions (Rennenberg et al., 2010; Settler, 1998). They are used as alley trees, windbreakers, to prevent soil erosion and to stabilize river banks (Settler, 1998). In plantations, poplars are cultivated to cover the industrial wood demand and as a source for bioenergy production (Polle et al., 2013). As fast-growing tree species, poplars have a high water and nutrient demand, which has to be met to maintain productivity (Euring \& Polle, 2015).

Ectomycorrhizal fungi (EMF) can access mineral nutrients in soil, which are inaccessible to plant roots (Smith \& Read, 2008). EMF colonize root tips, forming a symbiotic interaction with the plant, denominated "ectomycorrhiza" (ECM). In this interaction, the fungal mycelium establishes a dense sheath around the root tips and grows in between root cortical cells. A shared apoplast is established in which nutrients and water are transferred from the fungus to the plants, while carbohydrates are offered by the plant to the fungus (Smith \& Read, 2008). The interaction between the symbiosis partners does not only provide both parties with nutrient resources but also can increase tree performance against biotic threats (Mauch-Mani et al., 2017). For example, feeding damage by polyphagous insects on ECM-trees is reduced in comparison to non-ECM trees (Gange et al., 2005; Halldórsson et al., 2000; Oddsdottir et al., 2010; Rieske et al., 2003). Kaling et al. (2018) showed that the formation of ECM between P. $x$ canescens and Laccaria bicolor led to significant changes in the defense leaf metabolome. The defense metabolites shifted from phenol- to N-based compounds, resulting in a decreased performance of the specialized poplar pest Chrysomela populi on leaves of ECM versus non-ECM trees (Kaling et al. 2018). An ECMinduced reprogramming of the leaf defense proteome was reported by Szuba et al. (2019). They found differences in the accumulation of stress response proteins upon colonization of $P . \mathrm{x}$ canescens with the ectomycorrhizal fungus Paxillus involutus. The signals by which poplar leaves respond to belowground colonization with EMF are unknown. 
Evidence has been gathered, pointing to the vascular system as the main transportation route for long-distance defense signaling (Carella et al., 2016). While the phloem is known to play an important role for the circulation of signals, the xylem is considered as the unidirectional fast lane from roots to shoots (Shah \& Zeier, 2013). A main function of the xylem sap is the transport of water, mineral nutrients and organic compounds to the leaves (Schulze, 1994). The xylem sap contains amino acids, carbohydrates, and carboxylates (Furukawa et al., 2011; Siebrecht et al., 2003, Chapter 2). To protect the xylem from invading pathogens, the xylem sap is equipped with a huge array of defense proteins (Carella et al., 2016). Colonization with vascular pathogens leads to upregulation of defense proteins in the xylem and attenuates fungal proliferation (e.g. Floerl et al., 2008). In rhizobial symbiosis, the xylem sap carries long-distance signals from the below-to the aboveground compartment (Staehelin et al., 2011). Whether root colonization by mycorrhizal fungi can also influence the xylem sap composition and enhance resistance to vascular pathogens, is unknown.

The overarching goal of this study was to increase knowledge on how EMF influence plant health. We hypothesized that the leaf transcriptome of $P$. $x$ canescens with roots hosting fully developed L. bicolor ECM exhibit systemic changes in comparison with non-ECM plants in absence of other biotic interactors. To test this hypothesis, we used an axenic system in which sterile-cultured poplar plantlets ( $P . \mathrm{x}$ canescens) were colonized by L. bicolor avoiding interference with other microbes. We investigated the leaf transcriptome of ECM- and non-ECM plants and compared the resulting differentially expressed genes (DEGs) with those previously identified in leaves of EMC and non-EMC poplar plants grown outdoors (Kaling et al., 2018). Thereby, we obtained a systemic core response to ECM. We found significant reprogramming of defense signaling and expression of pathogenesis-related (PR) genes. Based on these results, we further hypothesized that ECM modifies the composition of the xylem sap impeding growth of vascular pathogens. To test these hypotheses, we conducted comparative analyses of the xylem sap metabolome and proteome. We further tested the growth the gram-negative bacterium Brennaria salicis in xylem sap from ECM and non-ECM poplars. B. salicis is the causal agent of the watermark disease in willows and a poplar xylem endophyte (Maes et al., 2009). 


\subsection{Materials and methods}

\subsubsection{Plant and fungus propagation and co-cultivation}

Populus x canescens, clone INRA 717 1B4 (INRA, Nancy, France), plantlets were in vitro micropropagated as described before (Chapter 2.2.1).

Laccaria bicolor, diploid strain S238N (Di Battista et al., 1996), was used for mycorrhizal inoculation. A $5 \times 5 \mathrm{~mm}$ piece of vegetative mycelium from a stock culture (originally kindly provided by Dr. F. Martin, INRA, Nancy) was transferred to a plastic Petri dish (12 cm in diameter, Sarstedt AG \& Co. KG, Nümbrecht, Germany), containing $60 \mathrm{~mL}$ solid M-MMNS medium (Kulmann, 2005) (Supplemental Table S3.1). The fungus was cultivated at $21^{\circ} \mathrm{C}$ for three weeks in darkness. Square Petri dishes (12 x $12 \mathrm{~cm}$, Greiner AG, Kremsmünster, Austria) were filled with $50 \mathrm{~mL}$ MMMNS medium. Cellophane stripes ( 6 x $12 \mathrm{~cm}$, Deti GmbH, Meckesheim, Germany) were washed twice by boiling in deionized $\mathrm{H}_{2} \mathrm{O}_{\mathrm{d}}$ for $1 \mathrm{~h}$ and subsequent sterilization by two runs of autoclaving (2 Bar, $120^{\circ} \mathrm{C}, 20 \mathrm{~min}$, HST 6x6x6, Zirbus technology GmbH, Bad Grund, Germany). Two stripes were placed side-by-side in one square Petri dish, on top of the M-MMNS medium. Seven $3 \mathrm{x}$ $3 \mathrm{~mm}$ pieces of three-week-old vegetative L. bicolor mycelium were placed on each cellophane stripe. The fungus was cultured on the stripes at $21^{\circ} \mathrm{C}$ for three weeks in darkness. Then, the newly formed mycelium of the different inoculation pieces covered most surface of the cellophane stripes but did not overgrow each other. The cellophane stripes for controls were prepared accordingly but without addition of mycelium.

For the establishment of $L$. bicolor - P. x canescens mycorrhizal roots, the axenic sandwich system described by Müller et al. (2013) was used (Fig. 3.1). Square Petri dishes (12 x $12 \mathrm{~cm}$, Greiner) were filled with $90 \mathrm{~mL}$ M-MMNS medium. After solidification, the medium was cut in two halves and one was transferred to a new square Petri dish, resulting a set-up with half-filled Petri dishes. A sterilized stripe of cellophane $(6 \times 12 \mathrm{~cm}$, Deti) without fungal culture was placed on the medium. Three-week-old P. x canescens plantlets, which had formed roots, were carefully pulled out of half strength MS and transferred individually into a prepared square Petri dish. The roots were spread on the cellophane, separated from the medium and the shoot was placed in the empty compartment. A cellophane stripe with the L. bicolor culture was placed on the roots with the mycelium facing downwards to the roots. The upper layer of cellophane was gently pushed 
down to remove air bubbles and to ensure contact between the roots and the mycelium. For the control plants, cellophane stripes without mycelium were used. The Petri dishes were sealed with Parafilm ${ }^{\mathrm{TM}}$ (Bemis Company Inc., Neenah, WI, USA). Plant and fungus were co-cultivated for three weeks at $24{ }^{\circ} \mathrm{C}, 60 \%$ air humidity, $125 \mu \mathrm{E} \mathrm{m}^{-2} \mathrm{~s}^{-1} \mathrm{PAR} 16 \mathrm{~h} / 8 \mathrm{~h}$ day/night regime in a cultivation chamber (AR-75L, Percival Scientific Inc., Perry, IA, USA). The light source was fluorescent lamps (L18W/840, Osram).

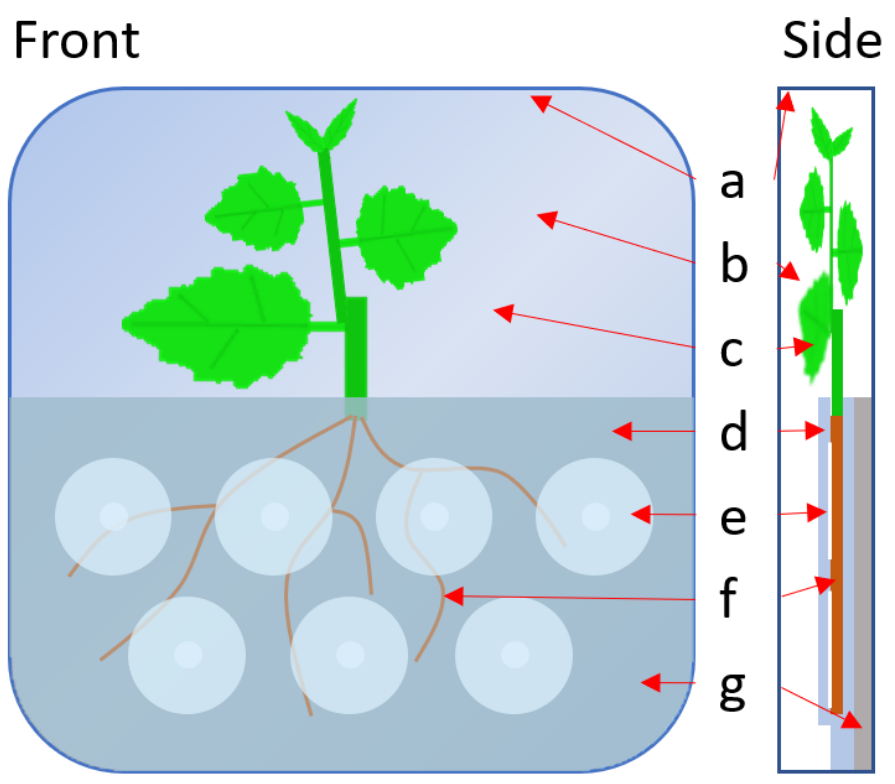

Figure 3.1: Schematic front and side views of Populus $x$ canescens and Laccaria bicolor co-cultivation in the sandwich system. a, Petri dish; b, air filled space; c, P. $x$ canescens plantlet; $d$, cellophane layers; e, $L$. bicolor mycelium; $\mathrm{f}, P$. $\mathrm{x}$ canescens roots; $\mathrm{g}, \mathrm{M}-\mathrm{MMNS}$ medium

For the greenhouse experiment, soil for cultivation of mycorrhizal and non-mycorrhizal plants was prepared as follows: $15 \mathrm{~L}$ soil (Fruhstorfer Erde 'Nullerde', Hawita, Vechta, Germany) were autoclaved twice (as above) and transferred to a $40 \times 60 \times 8 \mathrm{~cm}(\mathrm{l}, \mathrm{w}, \mathrm{h}$ ) plastic box. L. bicolor mycelium was cultivated in Pachlewski medium P05 (amounts of nutrients per $1 \mathrm{~L} \mathrm{H}_{2} \mathrm{O}_{\mathrm{d}}$ : $0.5 \mathrm{~g}$ $\mathrm{C}_{4} \mathrm{H}_{12} \mathrm{~N}_{2} \mathrm{O}_{6}$ (Merck KGaA, Darmstadt, Germany), 1 g KH $\mathrm{PO}_{4}$ (Carl Roth GmbH \& Co. KG, Karlsruhe, Germany), $0.5 \mathrm{~g} \mathrm{MgSO}_{4}$ X 7 $\mathrm{H}_{2} \mathrm{O}$ (Roth), $5 \mathrm{~g} \mathrm{D}+$ maltose (Sigma-Aldrich Chemie GmbH, Taufkirchen, Germany), $20 \mathrm{~g}$ D+ glucose (Merck), $100 \mu \mathrm{L}$ thiamine $\mathrm{HCl}$ (Merck), $1 \mathrm{~mL}$ Kanieltra (Yara Nanterre Cedex, France), $\mathrm{pH}$ 5.8) for 3 weeks at $22^{\circ} \mathrm{C}$ in the dark on a rotating table. Subsequently the medium was removed by filtering the mycelium through a metal sieve. The mycelium was then 


\section{Zusammenfassung}

washed under streaming $\mathrm{H}_{2} \mathrm{O}_{\text {dd }}$ for $3 \mathrm{~min}$. The excess water was removed and the remaining fungal mycelium homogenized (Ultra-Turrax, IKA-Werke GmbH \& CO. KG, Staufen, Germany) for $30 \mathrm{~s}$. For the control, $120 \mathrm{~mL} \mathrm{H} \mathrm{O}_{\text {dd }}$ were added to the soil, and for the treatment, $120 \mathrm{~mL}$ of blended mycelium was added to the soil. The boxes were closed with a lid and sealed with sticky tape (tesa Werk Hamburg GmbH, Hamburg, Germany). The inoculated and non-inoculated soils were incubated for three weeks at $21^{\circ} \mathrm{C}$ in darkness and then used for poplar cultivation.

We synthesized mycorrhizal poplars and potted them into inoculated soil. Non-mycorrhizal poplars were potted in non-inoculated soil. The following protocol was applied: after three weeks of co-cultivation with L. bicolor, poplar roots in inoculated Petri dishes were colonized and the cultures were out planted and cultivated under greenhouse conditions as described in Chapter 2.2.1, with minor modifications. Plants were watered daily with a modified Long Ashton nutrient solution (Hewitt, 1952), containing $2 \mathrm{mM} \mathrm{KNO}_{3}$ as $\mathrm{N}$ source (Supplemental Table S3.2). Temperature variations followed roughly outdoor conditions with the exception that heating was switched on when the temperature fell below $21^{\circ} \mathrm{C}$ and aeration started when the air temperature exceeded $23^{\circ} \mathrm{C}$. Thereby, the air temperature ranged from 15 to $41{ }^{\circ} \mathrm{C}$. Individual plants were randomized regularly. Three independent experiments were conducted, each with about 6 to 8 plants per treatment.

\subsubsection{Growth measurements}

Growth was monitored as described in Chapter 2.2.2.

\subsubsection{Gas exchange measurements}

Gas exchange rates were measured as described before (Chapter 2.2.3) and at ambient $\mathrm{CO}_{2}$ concentrations of $389 \pm 5 \mathrm{ppm}$ and an air temperature in the measuring chamber of $24.2 \pm 1.1^{\circ} \mathrm{C}$. Gas exchange was determined in two experiments. Young, fully expanded leaves were used. Each tested leaf was adapted to the measuring conditions for $60 \mathrm{~s}$ and then measured 3 times in intervals of $60 \mathrm{~s}$.

\subsubsection{Harvest and xylem sap extraction}

The plants were harvested as described in Chapter 2.2.4 with minor modifications. Xylem sap was collected by the root pressure method, which shows no detectable contamination with cytosolic 
components (Chapter 2.2.4.1). Six $\mathrm{mL}$ reaction vessels (Sarstedt) for XS collection were cooled in liquid nitrogen instead of ice.

\subsubsection{Determination of mycorrhizal colonization}

A stereomicroscope (DFC 420, Leica Camera AG, Wetzlar, Germany) was used to examine the mycorrhization rate of the root tips. Approximately 150 root tips of different parts of the root system were inspected and counted. Root tips were categorized in ECM root tips and non-ECM root tips (Fig. 3.2). The relative mycorrhizal colonization was calculated:

$$
\text { Mycorrhization rate }(\%)=\frac{\mathrm{n} \text { ECM root tips }}{\mathrm{n} \text { all vital root tips }} \times 100
$$
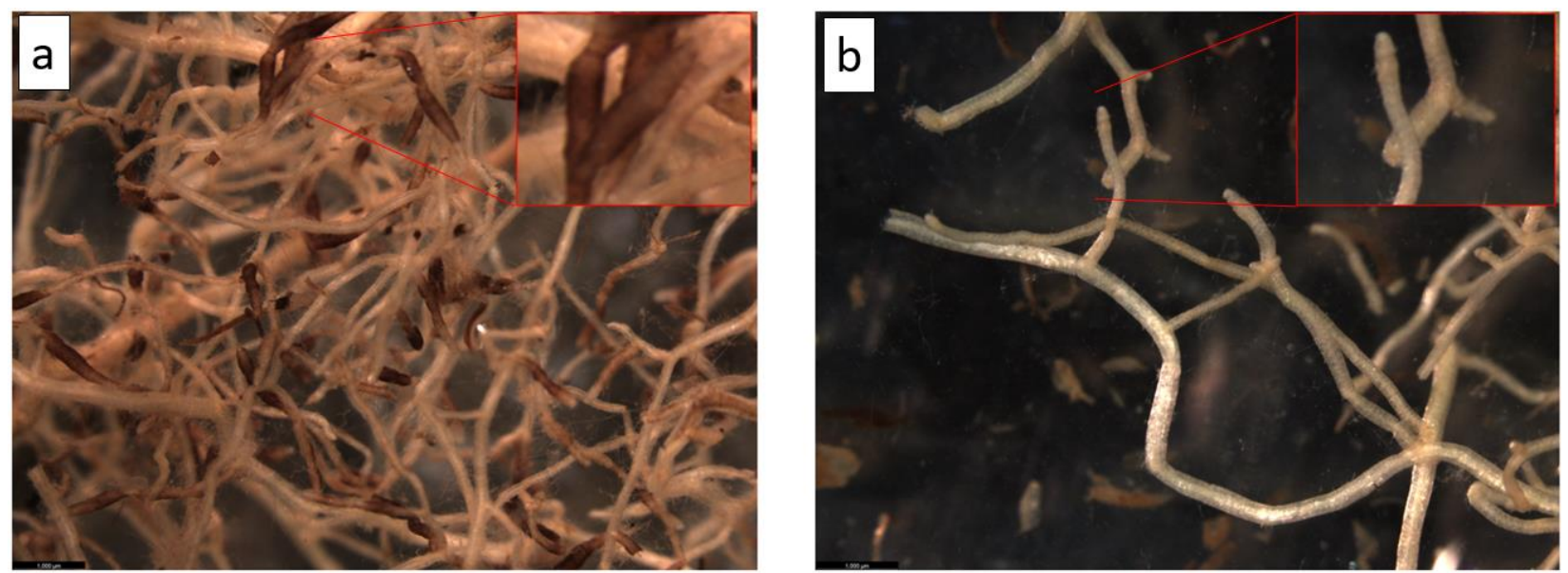

Figure 3.2: Morphology of Populus x canescens root tips, a) in ectomycorrhizal interaction with Laccaria bicolor, and b) non-ectomycorrhizal

\subsubsection{Carbon and nitrogen in plant tissue}

Carbon and nitrogen analyses were conducted as described before (Chapter 2.2.5). Each plant was considered as a biological replicate. Six (Exp. 1 and 2) and five (Exp. 3) biological replicates were analyzed for each experiment, treatment and tissue. 


\subsection{7 $\mathrm{NH}_{4}{ }^{+}$and $\mathrm{NO}_{3}{ }^{-}$analysis in xylem sap}

Xylem sap ammonium and nitrate concentrations were measured as described above (Chapter 2.2.6).

\subsubsection{Measurements of xylem sap protein concentrations}

Xylem sap protein concentrations were determined with the Bradford method, as described in Chapter 2.2.7.

\subsubsection{Xylem sap proteomics}

\subsubsection{Xylem sap protein extraction, digestion and peptide purification}

Protein extraction, digestion and peptide purification were done as described before (Chapter 2.2.9), with minor modifications. Proteins were extracted and analyzed in XS from three independent experiments ( $n=6, n=5, n=5$ biological replicates per treatment).

\subsubsection{Xylem sap proteome analysis}

Proteome analyses were conducted as described above (Chapter 2.2.9)

\subsubsection{Bioinformatic analyses of proteome data}

Bioinformatic analyses of proteome data were performed as described before (Chapter 2.2.9) with minor modifications. For database search and annotation, a JGI/Phytozome12-derived Populus trichocarpa v 3.1 (Tuskan et al., 2006) and JGI/MycoCosm-derived Laccaria biclor v 2.0 (Martin et al., 2008) specific database and the Andromeda algorithm (MaxQuant v.1.6.6.0) were used. A protein was considered confirmed when it was identified by at least 2 unique peptides. Label-free quantification was done for confirmed proteins present in more than half of the samples of a treatment (Exp. 1: 4 of 6, Exp. 2: 3 of 5, Exp. 3: 3 of 5). Additionally, the confirmed protein had to be present in at least 2 of 3 independent experiments. Further statistics were done as described in chapter 2.2.9, with the additions, that amino acid sequence blast, GO term annotation and enrichment analyses, and Interpro domain annotation was done with OmicsBox (v. 1.2.4, test version, BioBam Bioinformatics, 2019) including BlastP (Mahram \& Herbordt, 2015). 


\subsubsection{Xylem sap metabolomics}

As described in Chapter 2.2.8, xylem sap metabolites were analyzed with two targeted approaches (gas chromatography (GC)-MS-based, phytohormone analyses) and an LC-MS-based nontargeted metabolite fingerprinting approach.

\subsubsection{Phytohormone analyses in xylem sap}

Xylem sap phytohormone quantification was done as described in Chapter 2.2.8.3 with slight modifications. Metabolites were extracted of $100 \mu \mathrm{L} \mathrm{XS}$ and $750 \mu \mathrm{L}$ phytohormone solution (5 $\mathrm{ng}$ D4 jasmonoyl-leucine (JA-Leu) (provided by Otto Miersch, Halle/Saale, Germany), 5 ng D5 JA, 5 ng D4 salicylic acid (both from C/D/N Isotopes Inc., Pointe-Claire, Canada) in $750 \mu \mathrm{L}$ methanol) and both, positive and negative phase were analyzed. The modification was applied because in a pretest, the number of identified phytohormones could by increased when both phases were analyzed instead of only the negative phase, respectively (Fig. 3.3).

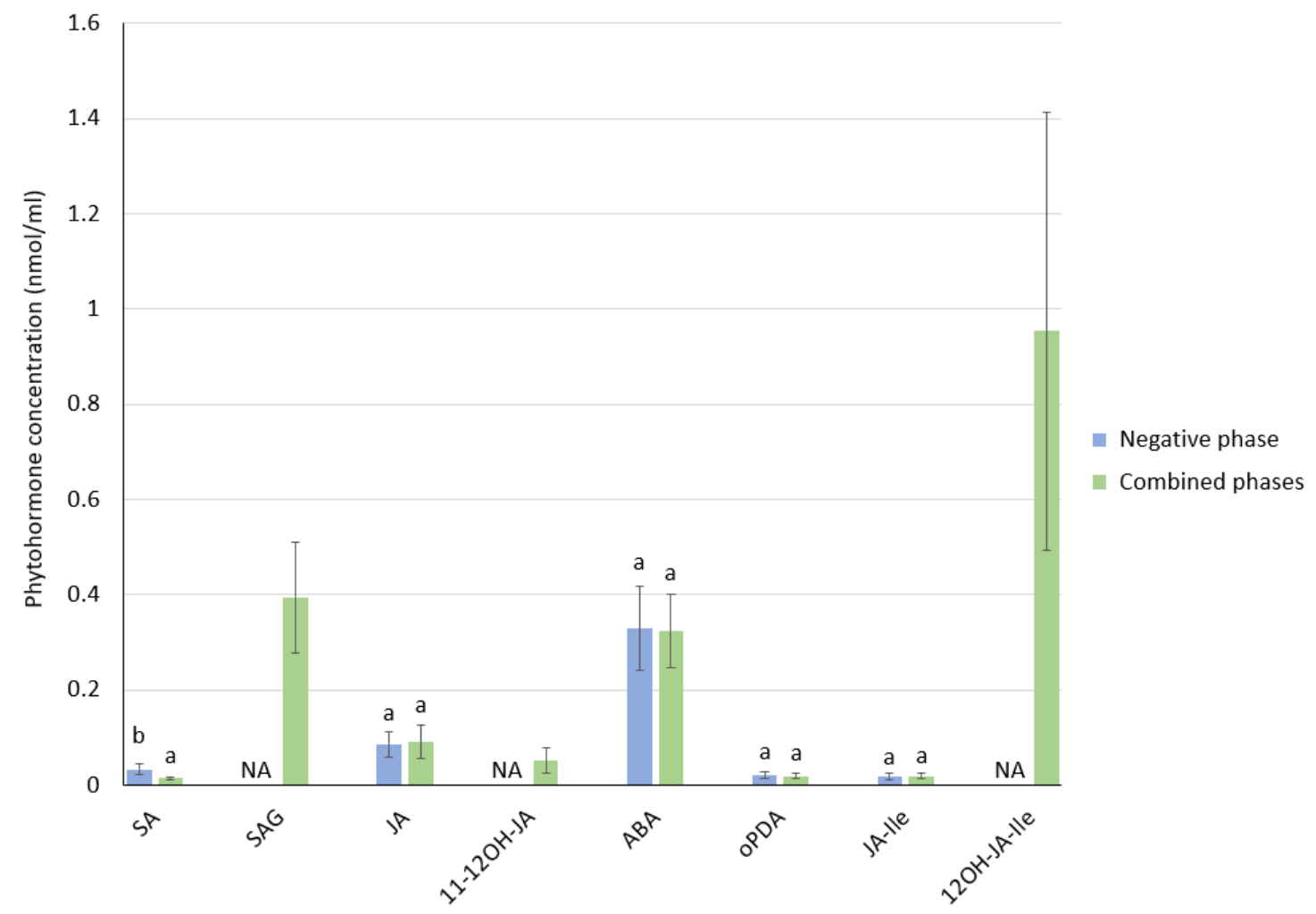

Figure 3.3: Comparison of xylem sap phytohormone analysis of only negative phase and of the combination of negative and positive phases. $N A=$ signal below detection limit. $S A=$ salicylic acid, SAG = SA-glucoside, $\mathrm{JA}=$ jasmonic acid, $11-12 \mathrm{OH}-\mathrm{JA}=$ methyl jasmonate, $\mathrm{ABA}=$ abscisic acid, oPDA $=12-$ oxo-phytodienoic acid, JA-Ile = jasmonoyl-isoleucine, $12 \mathrm{OH}$-JA-lle $=12$-hydroxy-jasmonoyl-isoleucine. $\mathrm{n}=6$, letters indicate significant differences according to Welch two-sample t-test with $p<0.05$. 


\subsubsection{Targeted primary metabolite analysis}

Primary metabolite analyses were performed as described before (Chapter 2.2.8.1)

\subsubsection{Non-targeted metabolite fingerprinting}

Non-targeted metabolite fingerprinting was conducted as described in Chapter 2.2.8.2. with the exception, that only the UPLC (Waters Corporation) coupled to high resolution-mass spectrometry (HRMS, 6540 UHD Accurate-Mass Q-TOF LC-MS instrument (Agilent Technologies) system was used and that data acquisition was done with Mass Hunter Acquisition B.03.01 (Agilent Technologies) and analyzed with Mass Hunter Qualitative Analysis (Agilent Technologies).

MS/MS based identity confirmation of putative metabolites was done manually and based on the accurate mass obtained by MS/MS analyses and mass spectra library database search (modified after Abreu et al., 2020) in a XS metabolite dataset (Chapter 2.2.8.2), which was used as the library for the current experiment. Masses and retention times (RT) were compared with the library and metabolite identities were confirmed when mass did not differ more than 0.1 Dalton and retention times not more than $0.3 \mathrm{~min}$.

\subsubsection{Leaf transcriptome analysis}

Leaves of in vitro grown mycorrhizal and non-mycorrhizal poplar plants were used for transcriptome analysis. The plants and fungi were propagated and co-cultivated as described above (Chapter 3.2.1) for three weeks. Four independent batches of plants were grown subsequently over a period of about 4 months, each consisting of 5 ECM and 5 non-ECM poplar plantlets (Batch 1 to $3=5$ plants, Batch $4=8$ plants). The plants of one treatment were pooled to obtain sufficient tissue for RNA extraction. After harvest, the leaves were immediately immersed in liquid nitrogen and stored at $-80^{\circ} \mathrm{C}$.

\subsubsection{RNA extraction}

The leaves were milled in liquid nitrogen (MM400, Retsch) and the tissue powder of individual plants belonging to the same batch were pooled thereafter, keeping non-ECM-poplar and ECMpoplar separately.

RNA extraction was performed according to Chang et al. (1993) and as described in Chapter 2.2.10. 


\subsubsection{RNA sequencing}

RNA preparation and sequencing were done as described in Chapter 2.2.10.1. Sample RNA concentration ranged between 97.4 and $368.36 \mathrm{ng} / \mu \mathrm{L}$ in $30 \mu \mathrm{L}$ (Supplemental Table S3.4) Samples with RIN values above 5.5 were used for further processing (Supplemental Table S3.4).

\subsubsection{Bioinformatic analysis of RNAseq data}

Bioinformatic processing of RNAseq data was done as describes in before (Chapter 2.2.10.2). This procedure resulted in $14 \times 10^{6}$ to $18 \times 10^{6}$ reads per sample (Supplemental Table S3.4). Reads were mapped against Populus tremula x alba 717-1B4 (Mader et al., 2016), v. 2, downloaded from http://aspendb.uga.edu) with the read alignment tool Bowtie2 (Langmead \& Salzberg, 2012). The relative number of reads successfully mapped to a gene model ranged from $89 \%$ to $94 \%$, depending on sample (Supplemental Table S3.4). Raw data have been deposited in in the ArrayExpress database (http://www.ebi.ac.uk/arrayexpress) under accession number E-MTAB8929. As mentioned in Chapter 2.2.10.2, a poplar RNAseq database was used to identify DEGs with confirmed roles in poplar responses to pathogen and phytohormone treatments (Electronic supplemental file: Thesis_KKasper_E-table_Chapter 3 - Transcriptomics). Gene ontology enrichment analyses of leaf transcriptome data were conducted with PLAZA 4.5 (Bonferroni correction, $p<0.05$, Van Bel et al., 2018) using the $P$. trichocarpa genome as the reference. KEGGbased (Kanehisa \& Goto, 2000) Paintomics platform (García-Alcalde et al., 2011, http://www.paintomics.org/) was used for pathway mapping.

\subsubsection{Pathogen growth assay in xylem sap}

Brennaria salicis xylem sap assay was performed as described in Chapter 2.2.11. The time courses of the OD recordings were analyzed in $\mathrm{R}$ with the package nls2 (Grothendieck, 2013) and plotted with ggplot2. In a pre-experiment xylem sap and deployed $\mathrm{H}_{2} \mathrm{O}_{\mathrm{dd}}$ were mixed with liquid TSB and inoculated as described above. No increase in OD was measureable over $12 \mathrm{~h}$, indicating, that xylem sap and $\mathrm{H}_{2} \mathrm{O}_{\text {dd }}$ did not contain bacteria before the main experiment (Fig. 3.4). 


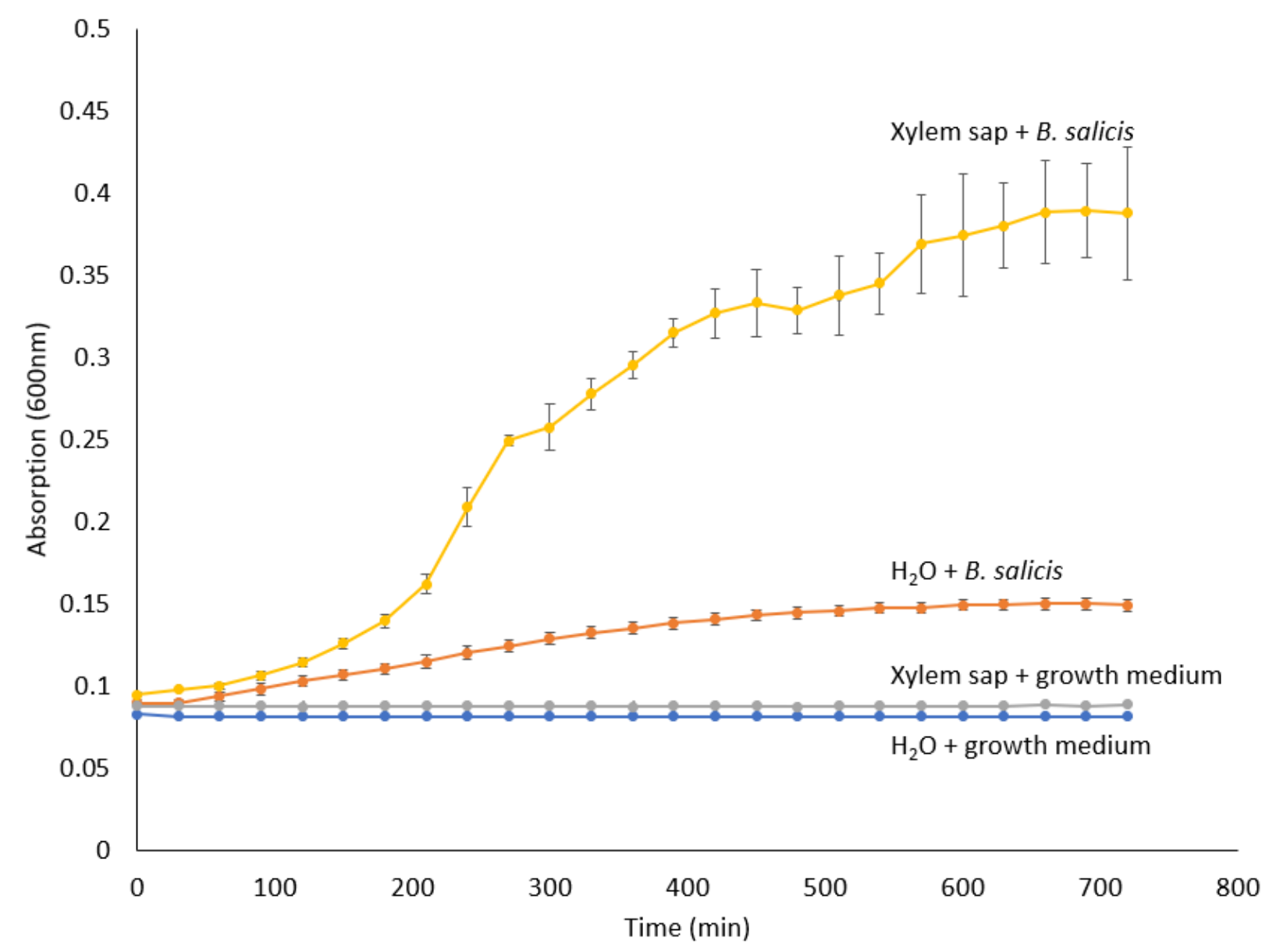

Figure 3.4: Brennaria salicis xylem sap micro-scale growth test pre-experiment. Bacterial growth was evaluated by increase in optical density (OD) at $600 \mathrm{~nm}$ over $12 \mathrm{~h} . \mathrm{n}=3$

\subsubsection{Statistical analyses}

The same statistical analyses and programs were used as described in Chapter 2.2.13. Additionally the $R$ package nls2 (Grothendieck, 2013), PLAZA 4.5 (Van Bel et al., 2018, https://bioinformatics.psb.ugent.be/plaza/versions/plaza_v4_5_dicots/) and OmicsBox (v. 1.2.4, test version, BioBam Bioinformatics, 2019) were used. 


\subsection{Results}

\subsubsection{EMF interaction results in activation of SA and JA pathways, proanthocyanidin biosynthesis and enhanced PR3 expression in leaves}

In total, 23876 genes were annotated with 6848 (28.7\%) being differentially expressed genes (DEG) between control and mycorrhizal plants. Of the DEGs, 3163 genes were upregulated and 3685 genes were downregulated (Supplemental file: Thesis_KKasper_E-table_Chapter 3 Transcriptomics). The overlap between leaf transcriptome data of this study and the study by Kaling et al. (2018) was 91 DEGs (Fig. 3.5), however, not all showed the same direction of regulation. Among the 91 DEGS, 33 were jointly up-regulated in both studies (Supplemental file: Thesis_KKasper_E-table_Chapter 3 - Transcriptomics), while no overlapping DEGs were downregulated in leaves of ECM- compared with leaves of non-ECM plants (Fig. 3.5). The remaining genes were differentially regulated between the studies.

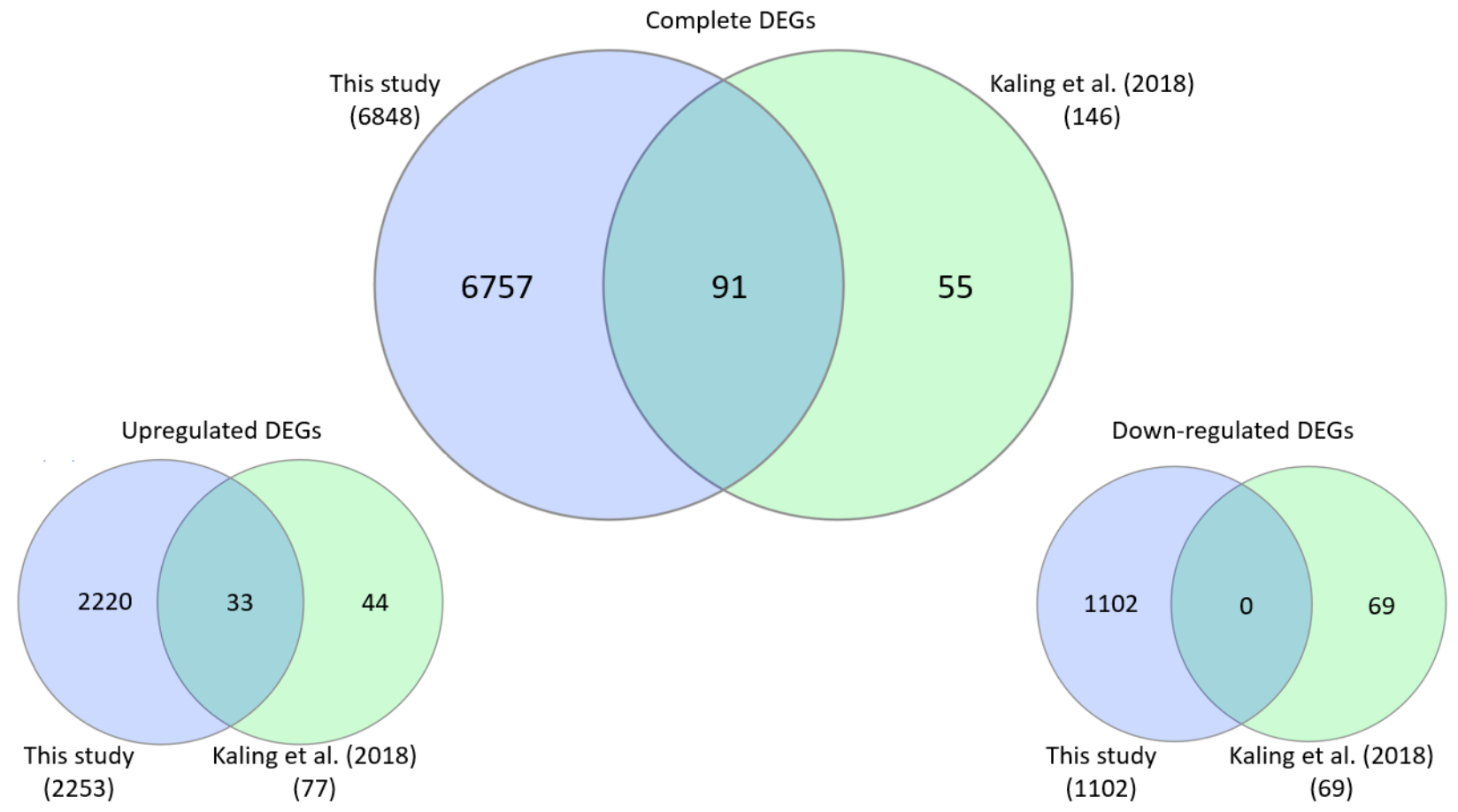

Figure 3.5: Overlap of differentially expressed genes of this study and the data published by Kaling et al. (2018). Both studies investigated the leaf transcriptome of non-mycorrhizal or Laccaria bicolorectomycorrhizal Populus $\mathrm{x}$ canescens plants. 
Using the data set of plantlets grown under axenic conditions in this study, the gene ontology (GO) term enrichment analysis showed that the identified DEGs ( $p<0.05$, Log fold change $>1.5$ ), were mainly involved in cell wall biosynthesis and metabolism, secondary metabolite biosynthesis and jasmonic acid metabolism (Fig. 3.6). The most depleted GO terms were involved in DNA and RNA processing (Fig. 3.6). Further significantly upregulated GO terms included phytohormone perception, signaling and response, including GO terms 'response to abscisic acid' ( $\log _{2} \mathrm{FC}=0.46$, $p=0.002)$, 'cellular response to hormone stimulus' ( $\left.\log _{2} \mathrm{FC}=0.5, p<0.001\right)$, and 'jasmonic acid mediated signaling pathway' ( $\log _{2} \mathrm{FC}=0.98, p<0.001$ ) and defense responses, such as 'defense response to fungus' ( $\left.\log _{2} \mathrm{FC}=0.71, p<0.001\right)$, and 'defense response to other organism' $\left(\log _{2}\right.$ $\mathrm{FC}=0.39, p=0.018)$ (Supplemental Table S3.5).

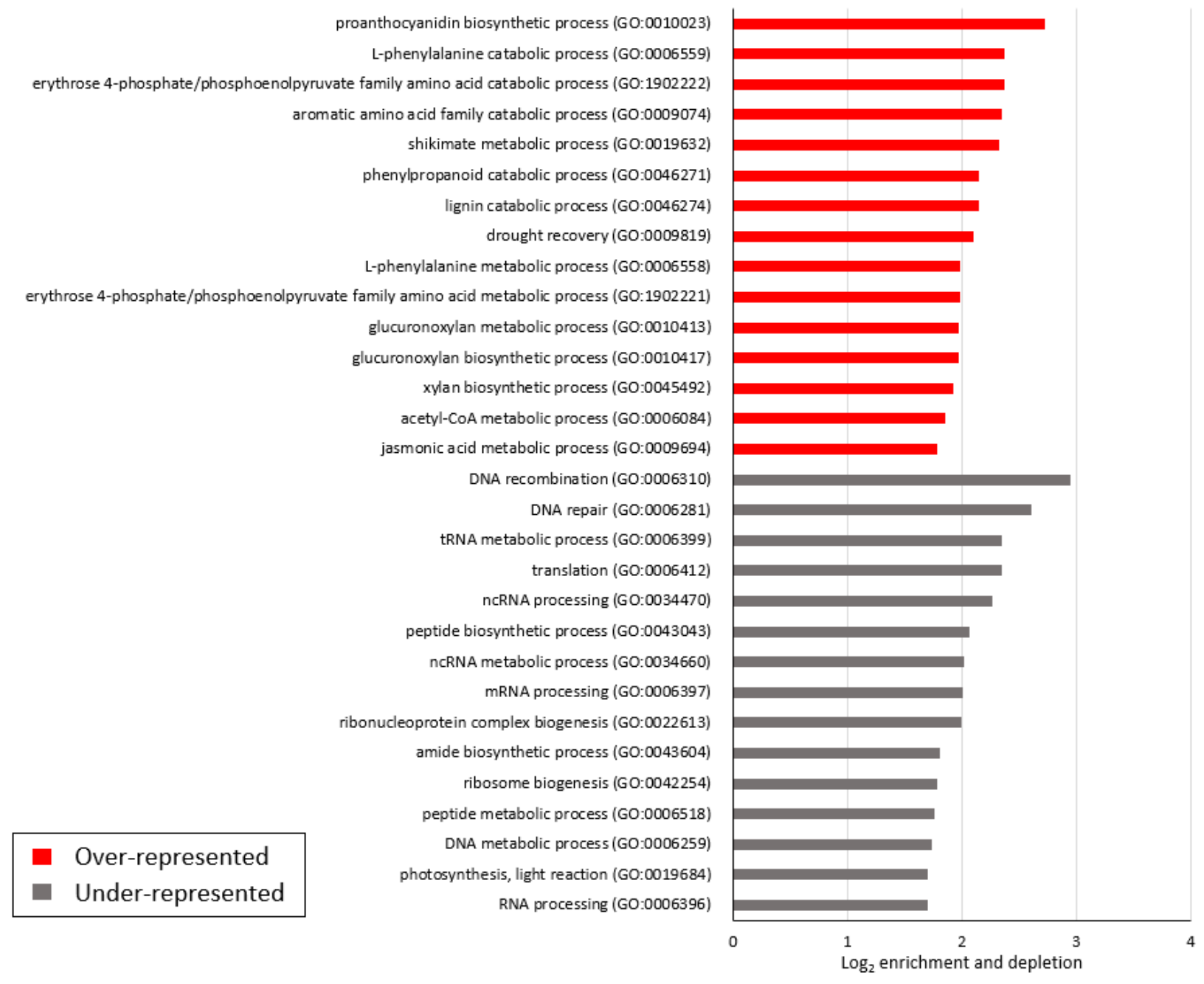

Figure 3.6: Bar chart visualization of fifteen most over- and under-represented gene onotology terms in leaf transcriptome data of Laccaria bicolor-mycorrhizal Populus x canescens plants, compared to species background. 
A hierarchic display of most enriched GO terms additionally showed the induction of secondary metabolites with anti-microbial properties (flavonoids, anthocyanins, proanthocyanidins) and plant response down-stream of jasmonic acid-dependent signaling pathways (response to chitin, wounding and jasmonic aicd) (Fig. 3.7).

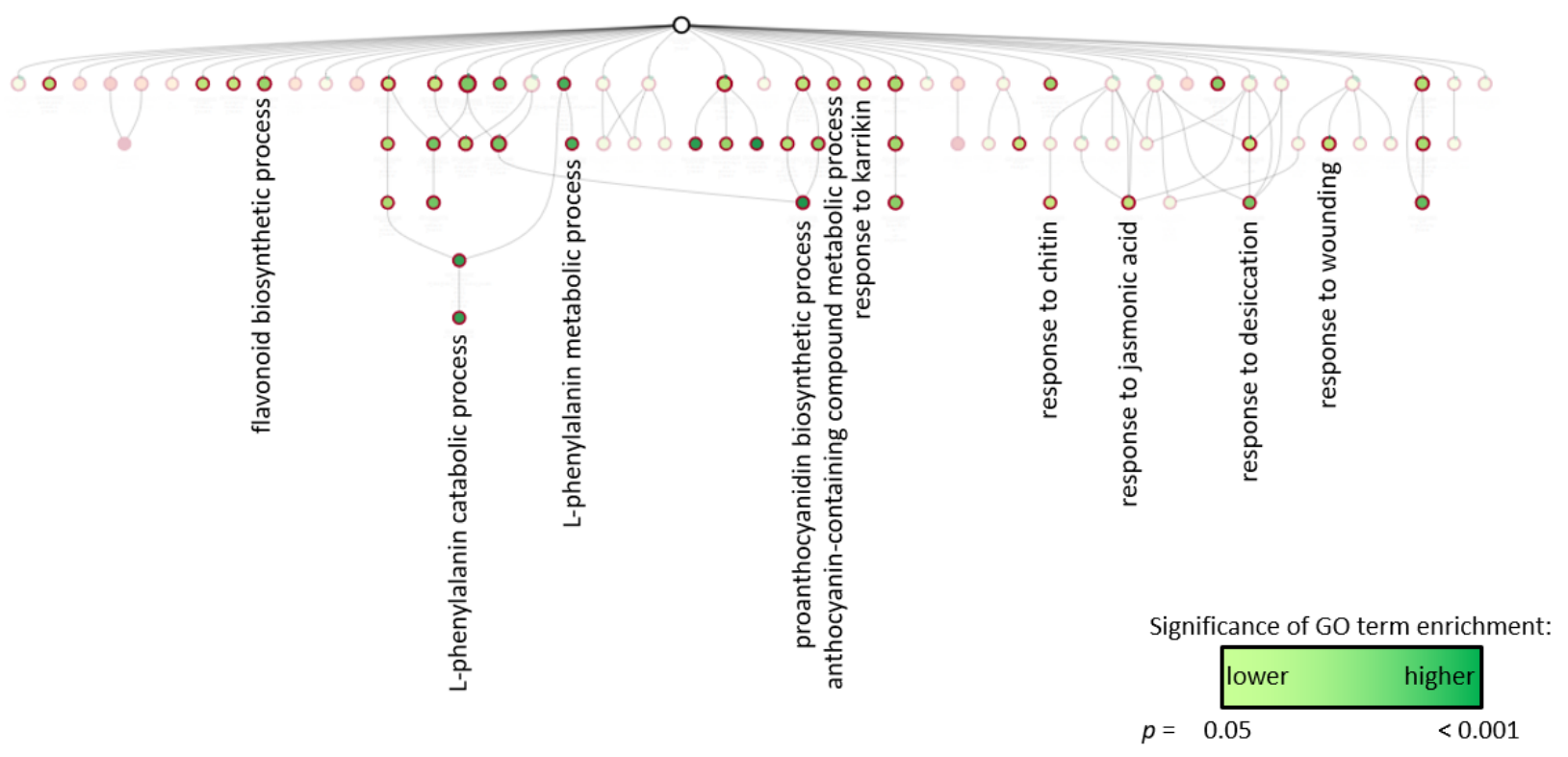

Figure 3.7: Hierarchic representation of enriched gene ontology terms in Laccaria bicolor-mycorrhizal Populus $x$ canescens leaf transcriptome data compared to control plants. GO terms involved in plant defense were labeled. Circles represent GO terms and their inner color indicates the enrichment from weakly enriched (yellow) to strongly enriched (green)

To acquire further insights in the phytohormonal regulation, a KEGG-based pathway mapping (García-Alcalde et al., 2011; Kanehisa \& Goto, 2000) analysis was conducted with the Arabidopsis homologues of the identified DEGs. In leaves of ECM-poplar, the signaling pathways for defenses related to jasmonic acid and salicylic acid were consistently upregulated compared with non-ECM poplars (Fig. 3.8). 


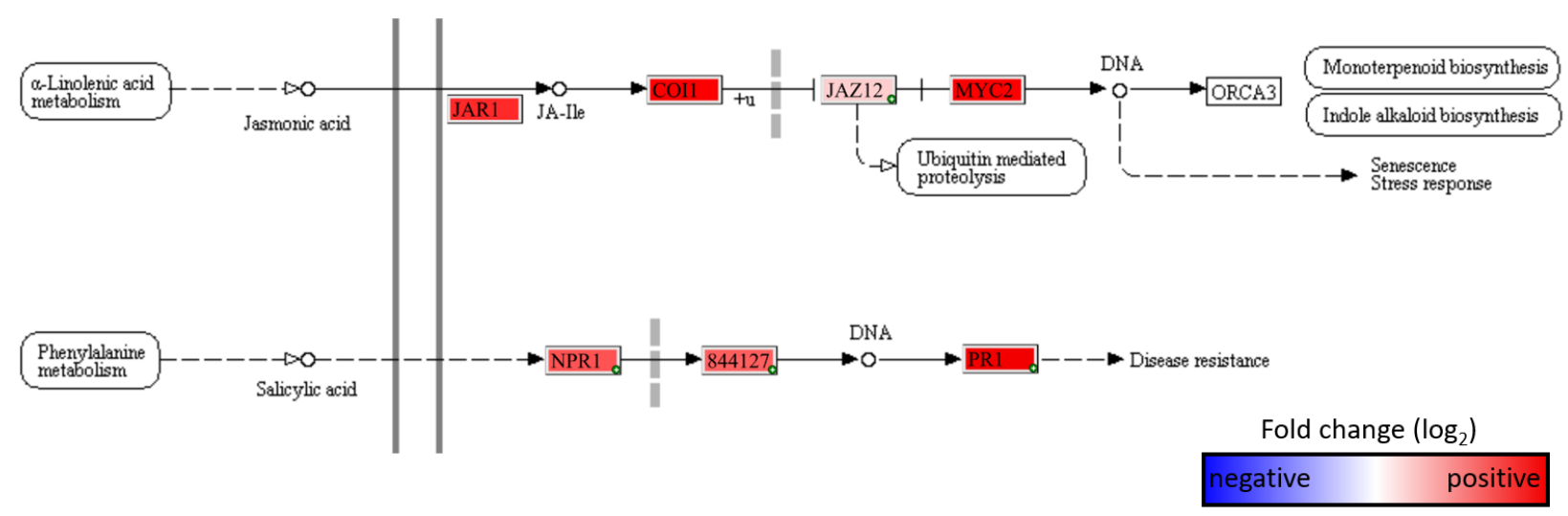

Figure 3.8: Differentially expressed genes between leaves of mycorrhizal Populus $x$ canescens and nonmycorrhizal control plants mapped on KEGG plant hormone signaling pathways for jasmonic acid and salicylic acid. Arabidopsis homologues were used for pathway analysis with Paintomics.

In the 'Plant-pathogen interaction' pathway, PAMP-associated transcript abundances of genes putatively encoding CERK1, MPK3 and 4, WRKY22-transcription factors as well as pathogenesisrelated protein 1 (PR1) were enhanced in ECM compared with non-ECM plants (Fig. 3.9).

A lysine motif domain-containing protein encoding gene (LYK4) that is involved in Arabidopsis chitin perception was additionally upregulated in mycorrhizal plants (Table 3.1). The analysis of earlier studies (Kaling et al., 2018; J. Luo et al., 2019; Miranda et al., 2007) showed upregulation of these genes in poplar under biotic stress conditions (herbivory or biotrophic fungi) or after phytohormone treatment (JA or SA) (Table 3.1).

Table 3.1: Chitinaceous molecule receptor and downstream genes with observed functions in poplar and significant $p$ values in mycorrhizal plant RNAseq data

\begin{tabular}{lllllll}
\hline Gene name & Function & Ath locus & Potri ID & Ref. & Studied challenge & $\boldsymbol{p}$ value \\
\hline Upregulated & & & & & & \\
CERK1 & Receptor & AT3G21630 & Potri.002G226600 & 3 & Biotroph & 0.017 \\
LYK4 & Receptor & AT2G23770 & Potri.010G078700 & 2 & Herbivory & 0.024 \\
MPK3 & Response & AT3G45640 & Potri.009G066100 & 3 & SA & 0.047 \\
MPK4 & Response & AT4G01370 & Potri.002G162500 & 1 & Biotroph & 0.005 \\
WRKY22 & Response & AT4G01250 & Potri.002G164400 & 3 & SA, JA, biotroph & 0.020 \\
\hline
\end{tabular}

Ref. = References: 1) Poplar vs. Melampsora medusae (Miranda et al., 2008), 2) Poplar vs. Chrysomela populi (Kaling et al., 2018), 3) Poplar vs. SA, JA or Melampsora larici-populina (Luo et al., 2019). SA = salicylic acid, JA = jasmonic acid. $\log _{2} \mathrm{FC}$ and $p$ values were determined with DESeq2 package in $\mathrm{R}$ 
PLANT-PATHOGEN INTERACTION
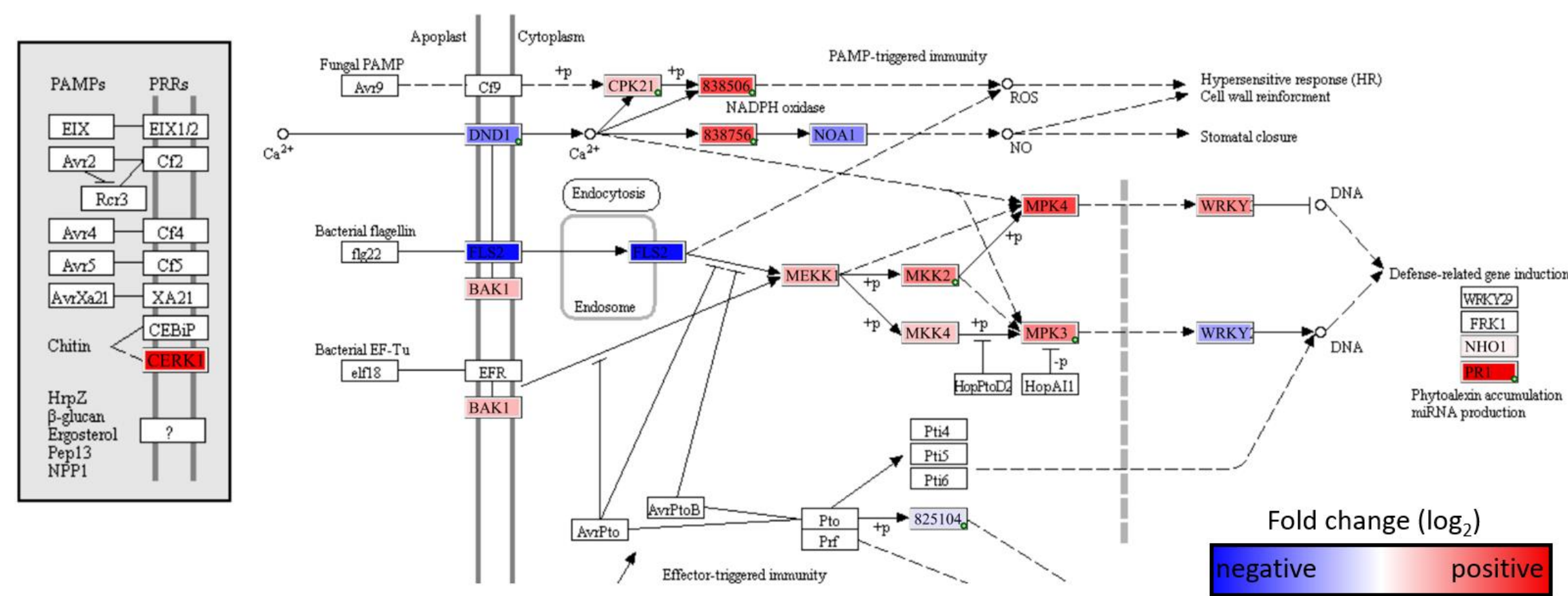

Figure 3.9: Differentially expressed genes in leaves of mycorrhizal (Laccaria bicolor interaction) Populus x canescens and non-mycorrhizal control plants mapped on KEGG pathway "Plant-pathogen interaction" pathway. Arabidopsis best match homologues were used for pathway analysis with Paintomics. 
To obtain further support for the function of identified DEGs in poplar, a literature-based phytohormone marker-gene database was generated (Table 3.2). Additionally, a database of genes involved in poplar-phytohormone, poplar-pathogen and poplar-herbivore interactions was generated from publicly available transcriptome data (Electronic supplemental file: Thesis_KKasper_E-table_Chapter 3 - Transcriptomics). The Arabidopsis-based hormone marker database was compared to poplar transcriptome data generated in challenge experiments with biotrophic pathogens, herbivory and phytohormone application (Kaling et al., 2018; J. Luo et al., 2019; Philippe et al., 2010; Rinaldi et al., 2007) and reduced to overlaps between both datasets. The resulting table was used for comparison to present transcriptome data. Genes potentially involved in ethylene, jasmonic acid and salicylic acid signaling pathways were upregulated in leaves of mycorrhizal plants (Fig. 3.10). A putative negative regulator of ethylene (ETO1) biosynthesis was down-regulated, as well as cytoplasmic enzymes putatively involved in abscisic acid biosynthesis (ABA2 and ABA3) (Fig. 3.10), while the putatively plastidal abscisic acid biosynthesis enzyme ABA1 was upregulated in mycorrhizal plants (Fig. 3.10). Three homologues of putative jasmonic acid- and ethylene-dependent chitinases (PR3) were upregulated while an ethylene-dependent chitinase (PR4) was downregulated by mycorrhizal interaction (Fig. 3.10). One homologue of nuclear transcription factor and negative regulator of jasmonic acidresponsive gene expression ETHYLENE-INSENSITIVE3 (EIN3) was upregulated (Fig. 3.10) in mycorrhizal plants and one homologue down-regulated (Fig. 3.10). Two homologues of the Arabidopsis enzyme FLAVIN-DEPENDENT MONOOXYGENASE 1 (FMO1), which is involved in pipecolic acid conversion, were found, one up- and one down-regulated by mycorrhizal interaction (Fig. 3.10). 
Table 3.2: Plant hormone pathway marker genes with observed responses in poplar to phytohormone and pathogen treatments and significant $p$ values in mycorrhizal plant RNAseq data of this study

\begin{tabular}{|c|c|c|c|c|c|c|}
\hline Gene name & $\begin{array}{l}\text { Involved } \\
\text { phytohormone/s }\end{array}$ & Ath locus & Potri ID & Ref. & $\log _{2} F C$ & $p$ value \\
\hline \multicolumn{7}{|c|}{ Upregulated } \\
\hline MYC2 / JIN1 & $\mathrm{JA}$ & AT1G32640 & Potri.002G176900 & 5 & 1.75 & 0.006 \\
\hline WRKY7O & SA & АT3G56400 & Potri.013G090300 & 5 & 1.51 & 0.019 \\
\hline PR3 & JA/Ethylene & AT3G12500 & Potri.009G141700 & $3 ; 4 ; 5$ & 1.40 & 0.007 \\
\hline PAD4 & SA & АT3G52430 & Potri.005G068700 & 5 & 1.37 & 0.000 \\
\hline SARD1 & SA & AT1G73805 & Potri.012G054900 & 5 & 1.33 & 0.012 \\
\hline ERF1 & Ethylene & AT3G23240 & Potri.005G223200 & 5 & 1.33 & 0.017 \\
\hline$P R 3$ & JA/Ethylene & AT3G12500 & Potri.T175200 & $4 ; 5$ & 1.26 & 0.031 \\
\hline$P R 3$ & JA/Ethylene & AT3G12500 & Potri.009G142200 & $3 ; 4 ; 5$ & 1.25 & 0.028 \\
\hline WRKY7O & SA & AT3G56400 & Potri.016G137900 & $1 ; 4 ; 5$ & 1.16 & 0.011 \\
\hline EDS1 & SA & AT3G48090 & Potri.015G069600 & 5 & 1.10 & 0.045 \\
\hline$A B A 1$ & $A B A$ & AT5G67030 & Potri.001G229100 & 4 & 0.81 & 0.016 \\
\hline SARD1 & SA & AT1G73805 & Potri.015G045300 & 5 & 0.69 & 0.010 \\
\hline EIN3 & Ethylene & AT3G20770 & Potri.010G247500 & $4 ; 5$ & 0.57 & 0.003 \\
\hline NPR1 & SA & AT1G64280 & Potri.006G148100 & 5 & 0.54 & 0.028 \\
\hline EIN3 & Ethylene & AT3G20770 & Potri.008G011300 & 5 & 0.43 & 0.040 \\
\hline \multicolumn{7}{|c|}{ Down-regulated } \\
\hline EIN3 & Ethylene & AT3G20770 & Potri.004G197400 & 4 & -0.31 & 0.033 \\
\hline$A B A 2$ & ABA & AT5G67030 & Potri.005G138400 & 5 & -0.38 & 0.019 \\
\hline ETO1 & Ethylene & AT3G51770 & Potri.009G075300 & 5 & -0.57 & 0.001 \\
\hline$A B A 3$ & ABA & AT5G67030 & Potri.007G044300 & 5 & -0.65 & 0.003 \\
\hline$P R 4$ & Ethylene & AT3G04720 & Potri.013G041600 & $1 ; 4 ; 5$ & -0.75 & 0.035 \\
\hline
\end{tabular}

Ref. = References: 1) Rinaldi et al. (2007), 2) Azaies et al. (2009), 3) Phillipe et al (2010), 4) Kaling et al. (2018), 5) Luo et al. (2019). $\log _{2}$ FC and $p$ values were determined with DESeq2 package in $\mathrm{R}$ 


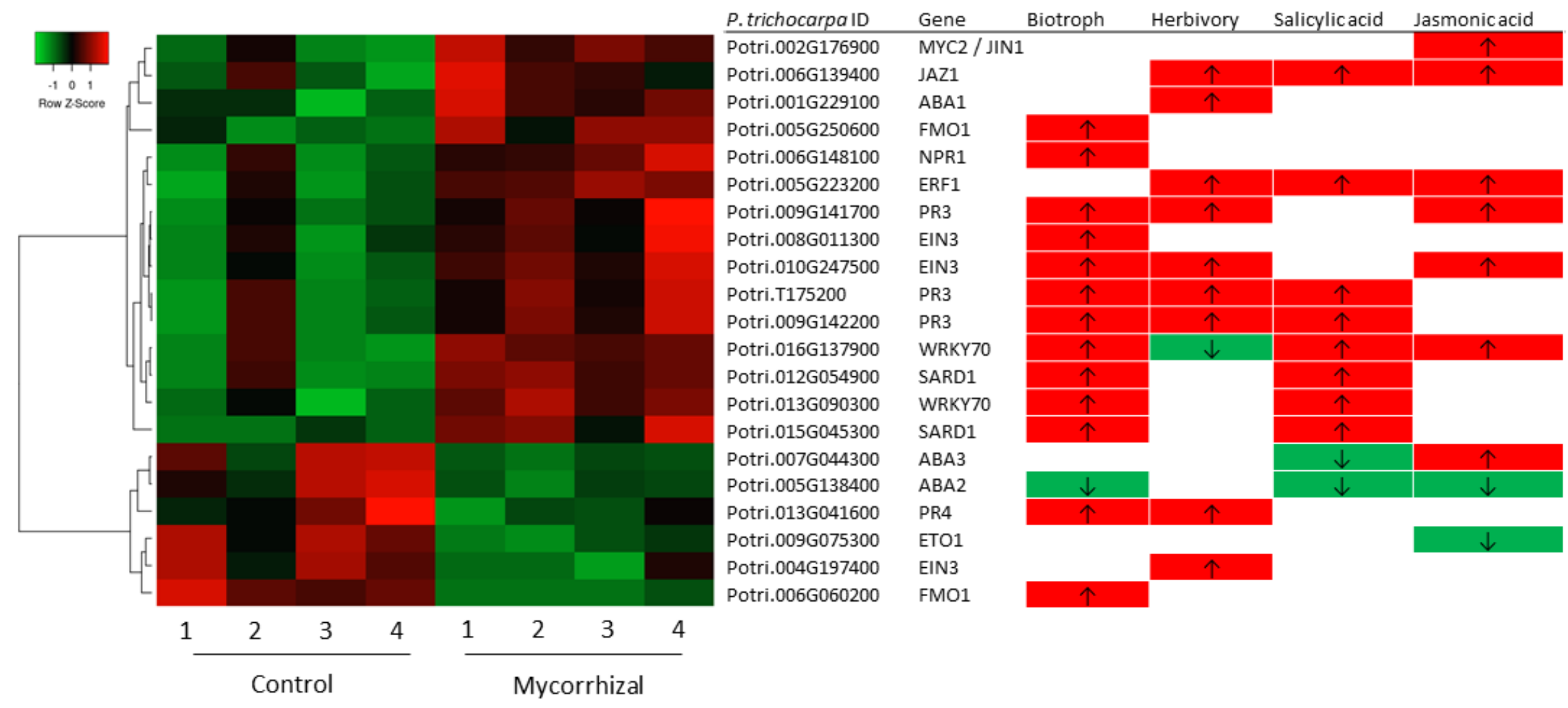

Figure 3.10: Comparison of differentially expressed genes in Laccaria bicolor-mycorrhizal and non-mycorrhizal control Populus $x$ canescens leaves with DEGs of other poplar studies and linked to response to the phytohormones salicylic acid and jasmonic acid or to attack of biotrophic pathogens or herbivory. Right of the heatmap is the $P$. trichocarpa gene model and the gene name are stated. In the table, red background colours indicate upregulation, green background colours downregulation of the marker genes in other poplar studies. $\uparrow$ upregulation, $\downarrow$ downregulation. $N=4$ 


\subsubsection{Mycorrhizal interaction has little impact on growth and physiology of greenhouse- grown poplar plants but increases $\mathbf{N}$ concentrations of roots}

The significant transcriptomic responses of leaves suggest that systemic signals are transmitted when poplar roots are colonized with EMF. Since the sterile cultured plants are too small to collect sufficient amounts of xylem sap, we used greenhouse-grown ECM- and non-inoculated control plants for analyses. After 12 weeks of greenhouse cultivation, the mycorrhization rate of ECMplants was $34.4 \pm 15.4 \%$ and the controls $1.5 \pm 1.9 \%$. The control plants were bigger than the ECM-plants but the difference was small (-4\%, $p=0.004)$ (Fig. 3.12). The total plant dry weight did not differ between treatments (Table 3.3). Control plants produced 2 leaves more than the ECM plants, which led to an increased leaf area of control plants compared to the ECM plants (Table 3.3).

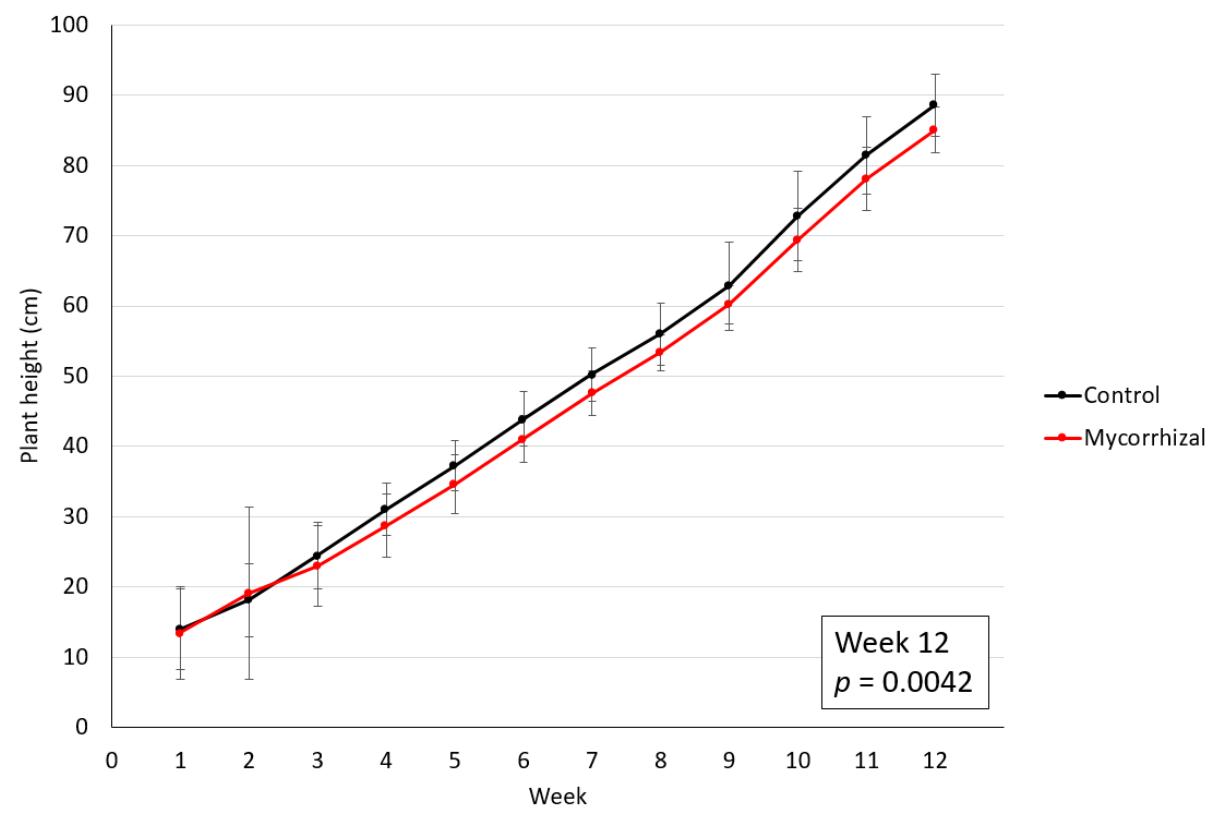

Figure 3.12: Plant heights of three independent experimental repetitions. Data show means $\pm S D, n=17$ per treatment. $p$ was calculated with generalized mixed-effects model analysis using experiments as random factor

Carbon (C) and $\mathrm{N}$ concentrations were measured in leaves, roots and stems of plants from three independent experiments (Table 3.3). No differences were found between leaf and stem $\mathrm{C}$ and $\mathrm{N}$ concentrations of mycorrhizal versus control plants. Root $\mathrm{N}$ concentrations were higher in mycorrhizal plants in comparison with roots of control plants (Table 3.3). This affected the $\mathrm{C} / \mathrm{N}$ 
ratio, which was accordingly lower in roots of mycorrhizal plants, than in roots of control plants (Table 3.3).

Table 3.3: Comparison of habitus and tissue $\mathrm{C}$ and $\mathrm{N}$ data between Populus $\mathrm{x}$ canescens plants cultivated with (mycorrhizal) and without (control) ectomycorrhizal fungus Laccaria bicolor. Data show means \pm SD.

\begin{tabular}{lrrrr}
\hline & Control & Mycorrhizal & $\boldsymbol{p}$ value & $\mathbf{n}$ \\
\hline Height (cm) & $88.58 \pm 1.07 \mathrm{~b}$ & $84.97 \pm 0.81 \mathrm{a}$ & 0.0042 & 17 \\
Leaves (Nr.) & $39.24 \pm 0.56 \mathrm{~b}$ & $36.94 \pm 0.60 \mathrm{a}$ & 0.0037 & 17 \\
Leaf area (m) & $0.17 \pm 0.03 \mathrm{~b}$ & $0.15 \pm 0.03 \mathrm{a}$ & 0.0001 & 15 \\
Total DW (g) & $21.69 \pm 4.87 \mathrm{a}$ & $21.07 \pm 2.19 \mathrm{a}$ & 0.6714 & 11 \\
Leaf C (\%) & $44.42 \pm 0.85 \mathrm{a}$ & $44.53 \pm 0.64 \mathrm{a}$ & 0.3847 & 17 \\
Leaf N (\%) & $1.25 \pm 0.16 \mathrm{a}$ & $1.2 \pm 0.13 \mathrm{a}$ & 0.1079 & 17 \\
Leaf C/N & $36.2 \pm 4.5 \mathrm{a}$ & $37.42 \pm 3.7 \mathrm{a}$ & 0.1401 & 17 \\
Stem C (\%) & $43.84 \pm 0.65 \mathrm{a}$ & $43.63 \pm 0.51 \mathrm{a}$ & 0.08447 & 17 \\
Stem N (\%) & $0.72 \pm 0.15 \mathrm{a}$ & $0.72 \pm 0.11 \mathrm{a}$ & 0.9624 & 17 \\
Stem C/N & $63.42 \pm 12.13 \mathrm{a}$ & $61.69 \pm 7.88 \mathrm{a}$ & 0.5469 & 17 \\
Root C (\%) & $40.27 \pm 3.98 \mathrm{a}$ & $41.22 \pm 3.75 \mathrm{a}$ & 0.484 & 16 \\
Root N (\%) & $0.85 \pm 0.11 \mathrm{a}$ & $0.94 \pm 0.12 \mathrm{~b}$ & 0.02968 & 16 \\
Root C/N & $47.64 \pm 4.43 \mathrm{a}$ & $44.11 \pm 4.53 \mathrm{~b}$ & 0.01889 & 16 \\
\hline
\end{tabular}

Different letters behind SD indicate significant differences according to generalized mixed-effects model analyses using experiments as random factor, $p<0.05$

No differences between ECM and control plants were found for photosynthesis, transpiration, and stomatal conductance (Table 3.4). Sub-stomatal cavity $\mathrm{CO}_{2}$ concentration was higher in mycorrhizal plants than in control plants (Table 3.4). During the measurements, mean leaf temperatures were $25.2 \pm 0.3^{\circ} \mathrm{C}$ in experiment 1 and $23.0 \pm 0.2^{\circ} \mathrm{C}$ in experiment 3 .

Table 3.4: Photosynthesis $(A)$, transpiration rate $(E)$, stomatal conductance $\left(g_{s}\right)$ and sub-stomatal cavity $\mathrm{CO}_{2}$ concentration $\left(\mathrm{C}_{\mathrm{i}}\right)$ in mycorrhizal (Laccaria bicolor) and non-mycorrhizal poplar. Measurements were conducted after 13 weeks of co-cultivation. Data show means $( \pm S D, n=11)$.

\begin{tabular}{|c|c|c|c|c|}
\hline Treatment & $A\left(\mu \mathrm{mol} \mathrm{m} \mathrm{m}^{-2} \mathrm{~s}^{-1}\right)$ & $E\left(\mathrm{~mol} \mathrm{~m}^{-2} \mathrm{~s}^{-1}\right)$ & $\mathrm{g}_{\mathrm{s}}\left(\mathrm{mol} \mathrm{m} \mathrm{m}^{-2} \mathrm{~s}^{-1}\right)$ & $\mathrm{C}_{\mathrm{i}}\left(\mu \mathrm{mol} \mathrm{mol} \mathrm{m}^{-1}\right)$ \\
\hline Control & $6.59 \pm 1.93 \mathrm{a}$ & $0.002 \pm 0.001 \mathrm{a}$ & $0.13 \pm 0.05 a$ & $291.83 \pm 20.29 a$ \\
\hline Mycorrhizal & $6.39 \pm 1.72 \mathrm{a}$ & $0.002 \pm 0.0003 a$ & $0.15 \pm 0.04 \mathrm{a}$ & $307.29 \pm 10.00 b$ \\
\hline$p$ avlue & 0.6132 & 0.308 & 0.3897 & 0.0195 \\
\hline
\end{tabular}

Different letters behind SD indicate significant differences according to generalized mixed-effects model analyses, using experiments as random factor, $p<0.05$. 


\subsubsection{Inorganic $\mathbf{N}$ and protein concentrations in xylem sap are not affected by ECM}

The xylem sap contained about 15 times higher $\mathrm{NO}_{3}{ }^{-}$than $\mathrm{NH}_{4}{ }^{+}$concentrations (Fig. 3.13). The mean $\mathrm{XS} \mathrm{NH}_{4}-\mathrm{N}$ concentrations were not different between control and mycorrhizal plants $(p=$ 0.363). $\mathrm{XS} \mathrm{NO}_{3}-\mathrm{N}$ concentrations of mycorrhizal plants were not significantly higher than in control plants ( $p=0.473$ ) (Fig. 3.13). In XS from both experiments analyzed here, the fluctuations of $\mathrm{NO}_{3}-$ $\mathrm{N}$ concentrations were considerably higher than those of $\mathrm{XS} \mathrm{NH}_{4}-\mathrm{N}$ concentrations.

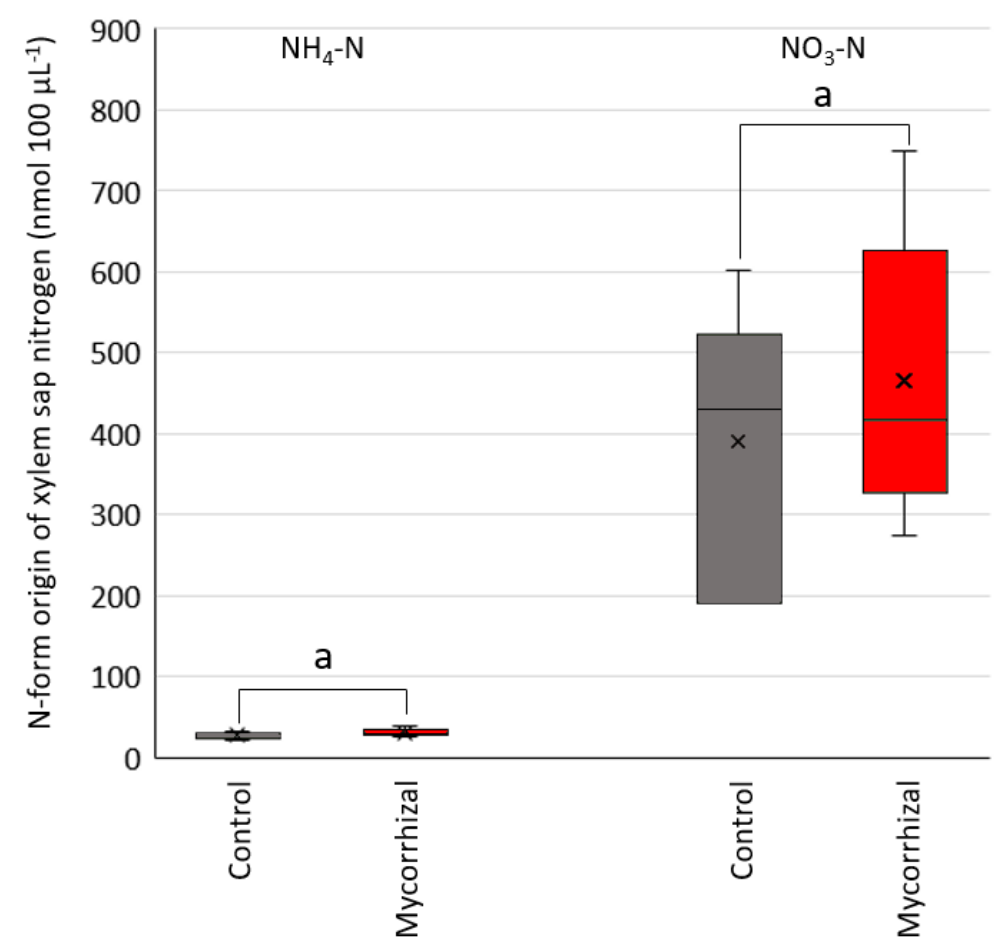

Figure 3.13: Xylem sap $\mathrm{NH}_{4}-\mathrm{N}$ and $\mathrm{NO}_{3}-\mathrm{N}$ concentrations of Laccaria bicolor-ECM or control Populus $\mathrm{x}$ canescens plants. $n=6$, different letters above the connection lines indicate significant differences according to Welch two-sample t-test with $p<0.05$

In three independent experiments, no difference was observed between the average XS protein concentration of control and mycorrhizal plants (Fig. 3.14). 


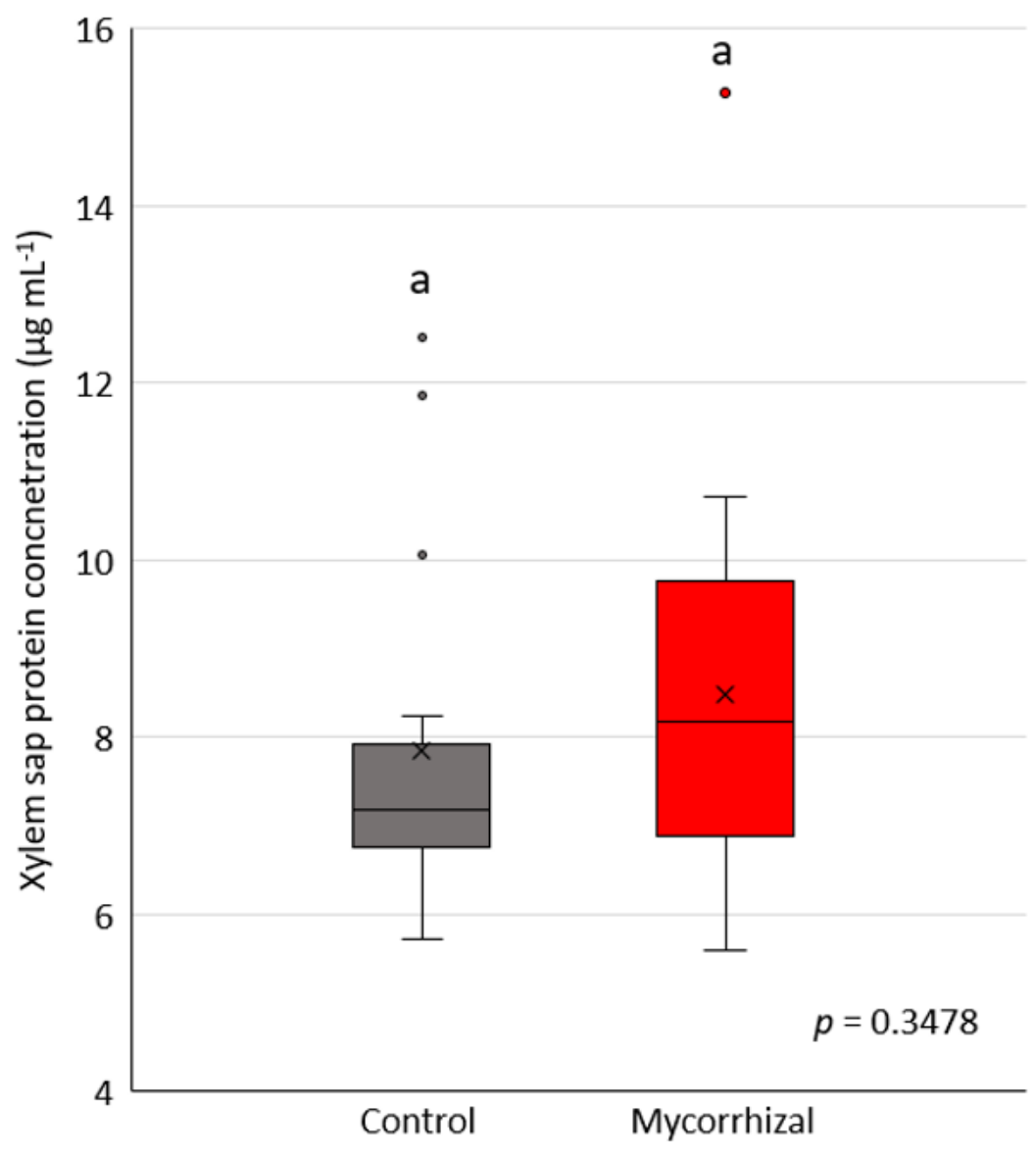

Figure 3.14: Xylem sap protein concentration. Control $n=16$, mycorrhizal $n=18$, different letters indicate significant differences according to generalized mixed-effects model analysis, using experiment as random factor, $p<0.05$

\subsubsection{Xylem sap of mycorrhizal plants is enriched in putative SAR signaling proteins}

The number of identified proteins and differentially accumulated proteins (DAPs) varied between xylem sap from three independent experiments (Table 3.5). In each experiment xylem saps from at least 5 individual plants per treatment were investigated $\left(n_{\exp 1}=6, n_{\exp 2}=5, n_{\exp 3}=5\right)$. Proteins present in 4 of 6 (Exp. 1) or 3 of 5 (Exp. 2 and 3) samples and identified by at least 2 unique peptides were used for label-free quantification. The overlap (383 proteins) between the three experiments (Supplemental file: Thesis_KKasper_E-table_Chapter 3 - Proteomics), were termed the combined proteome and further evaluated. BlastP identified most proteins by assigning the 
amino acid sequences to $P$. trichocarpa proteins (365 of 383) (Fig. 3.15). No sequence was assigned to Laccaria bicolor, although the data base for L. bicolor was included in the analyses.

Table 3.5: Protein identifications and number of differentially accumulated proteins between xylem sap samples of control and Laccaria bicolor-ECM Populus $x$ canescens plants

\begin{tabular}{rrrr}
\hline Experiment & Identified proteins & Upregulated DAPs & Down-regulated DAPs \\
\hline 1 & 561 & 8 & 11 \\
2 & 450 & 6 & 3 \\
3 & 581 & 14 & 11
\end{tabular}

DAP $=$ differentially accumulated protein according to DESeq2 ANOVA with $p_{\text {adj }}<0.05$.

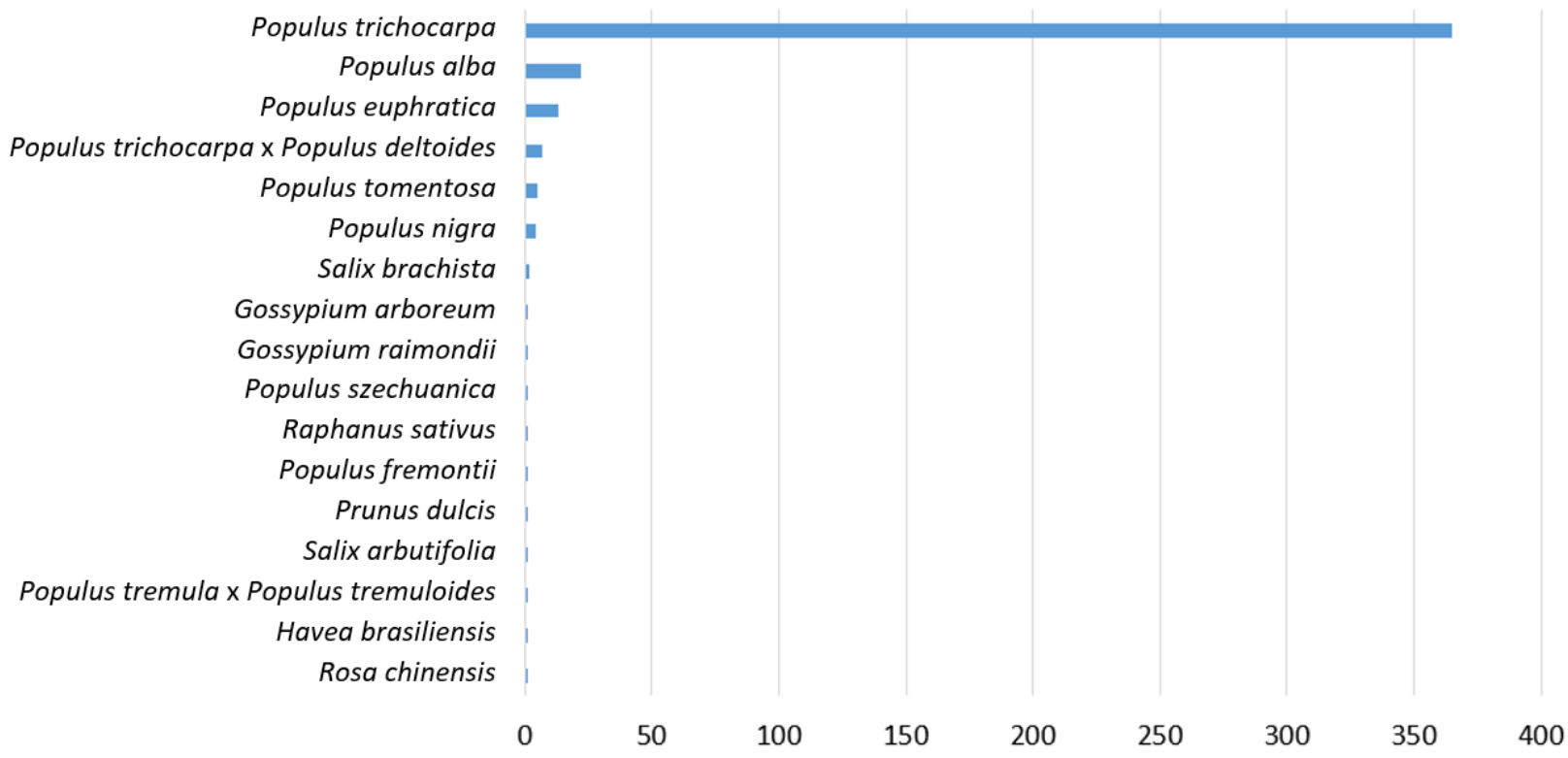

Figure 3.15: Origin of identified proteins in xylem sap sampled from Populus $\mathrm{x}$ canescens plants. Analysis was conducted by comparison (BlastP) to NCBI proteome databases.

The molecular weight of the identified proteins varied in the range from $8.9 \mathrm{kDa}$ (cinnamyl alcohol dehydrogenase 6) to $147.7 \mathrm{kDa}$ (putative leucine-rich repeat-containing protein DDB_G0290503) (Fig. 3.16a). 148 proteins (39\%) of the proteins were predicted to contain a signal peptide (SP) (Fig. 3.16b). In a GO term analysis of biological processes, most XS proteins were assigned to “metabolic process" (224 proteins), "cellular process" (184) and "response to stimulus" (70) (Fig. 3.16c). Five proteins were assigned to "immune system process" (Fig. 3.16d), three of which were 
Results

lipid-transfer proteins, one a peroxidase and one an aspartyl protease. All contained extracellular signal peptide sequence (Fig. 3.16d).

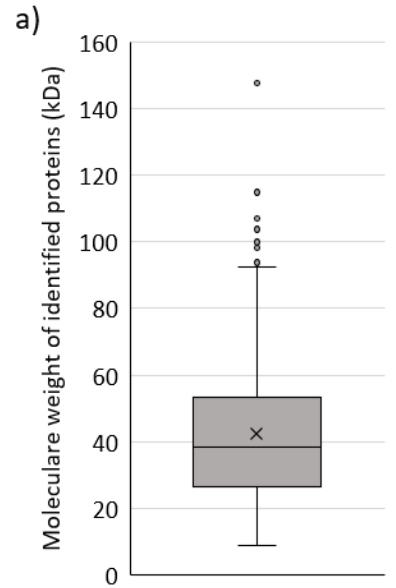

b)

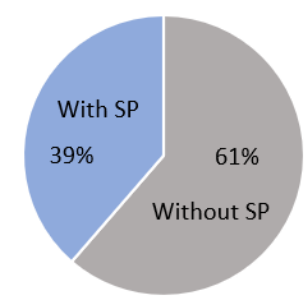

c)

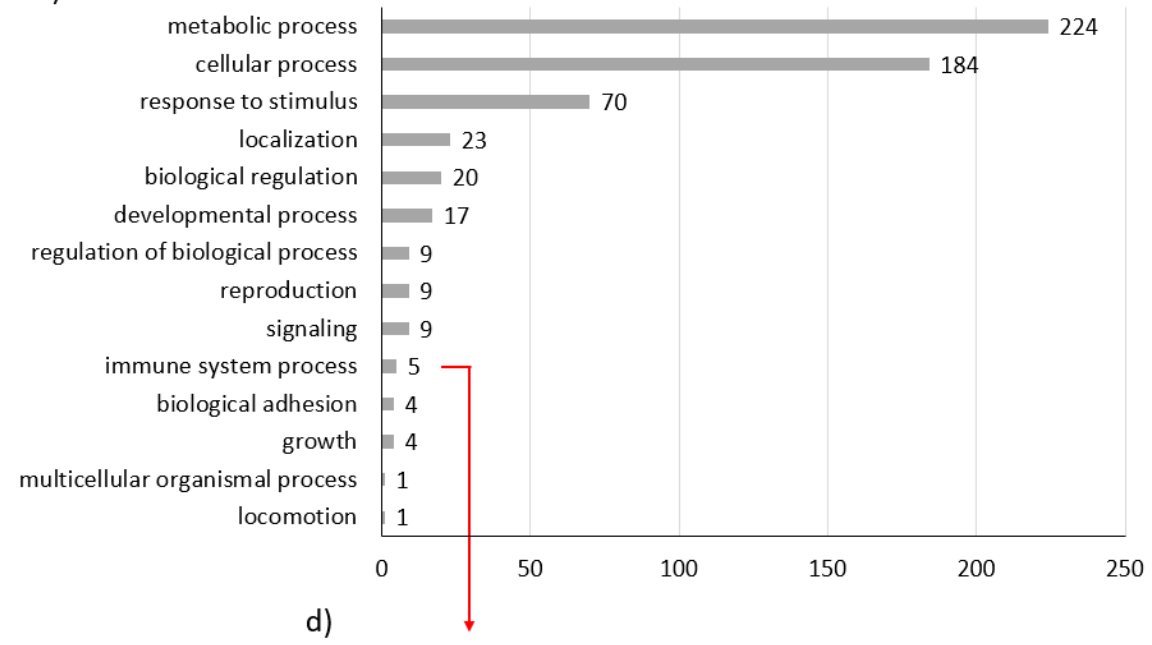

\begin{tabular}{llll}
\hline Uniprot IDs & Potri IDs & Description & SP \\
\hline A9PCK2 & Potri.015G051800 & Aspartyl protease & yes \\
B9HHI8 & Potri.008G061800 & Lipid transfer protein & yes \\
B9IA56 & Potri.014G143200 & Peroxidase & yes \\
B9IFZ8 & Potri.016G104300 & Lipid transfer protein & yes \\
A0A2K1YWY6 & Potri.010G196300 & Lipid transfer protein & yes \\
\hline
\end{tabular}

Figure 3.16: Statistics and GO term analysis of combined Populus $x$ canescens xylem sap proteome. A) Distribution of protein molecular weights, b) Shares of proteins containing a signal peptide (SP) and without a signal peptide, c) Biological process GO terms (level 2) of combined proteome, d) Information on proteins involved in biological process "immune system process".

No protein of the 'combined proteome' was present exclusively in one experimental condition (control or mycorrhizal) and absent in the other. In all experimental repetitions, two proteins were differentially accumulated between XS of control and mycorrhizal plants. DIR1 (DEFECTIVE IN INDUCED RESISTANCE1)-like and a peroxidase (PRX77) were both significantly higher accumulated in XS of mycorrhizal plants (Fig. 3.17). 
Results

a

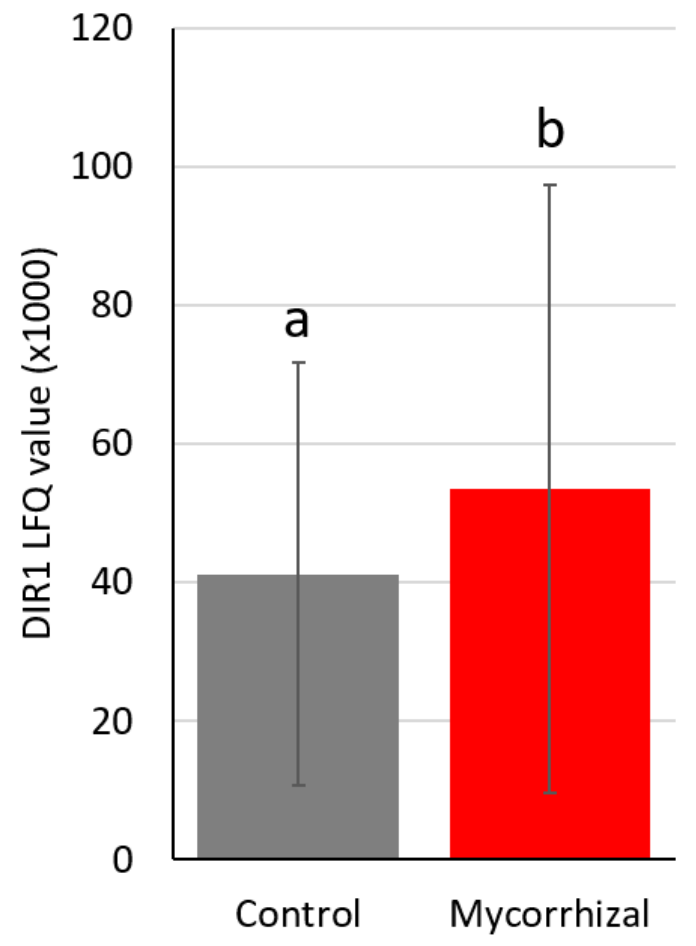

b

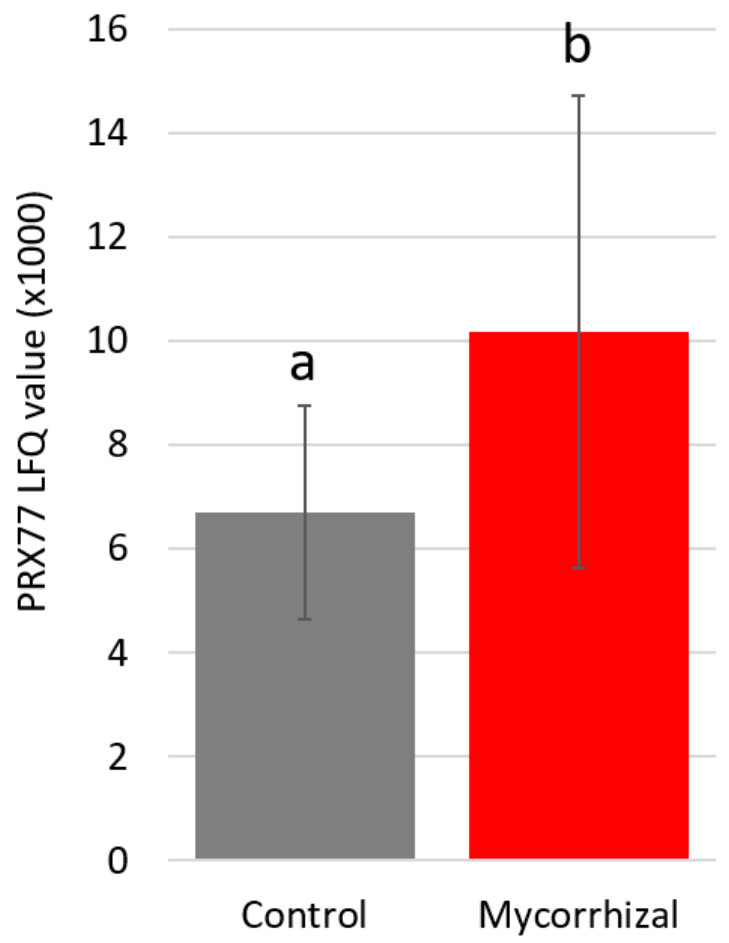

Figure 3.17: Label-free quantification of differentially accumulated proteins a) DIR1 (DEFECTIVE IN INDUCED RESISTANCE1) and b) PRX77 (Class III Peroxidase) in xylem sap of control and Populus $\mathrm{x}$ canescens-Laccaria bicolor ECM-plants. Means were calculated over all three independent experimental repetitions. Means denoted by same letters did not significantly differ at $p<0.05$ according to generalized mixed-effects model analysis, using experiment as random factor. 


\subsubsection{Mycorrhizal interaction has no influence on poplar xylem sap primary metabolite concentrations}

No differences were found between the relative abundances of primary metabolites in XS of nonmycorrhizal and mycorrhizal plants (Fig. 3.18). Among the compounds identified, glutamatederived amino acids were the most abundant amino acids, malate the most organic acid and sucrose the most abundant sugar (Supplemental Table S3.6).

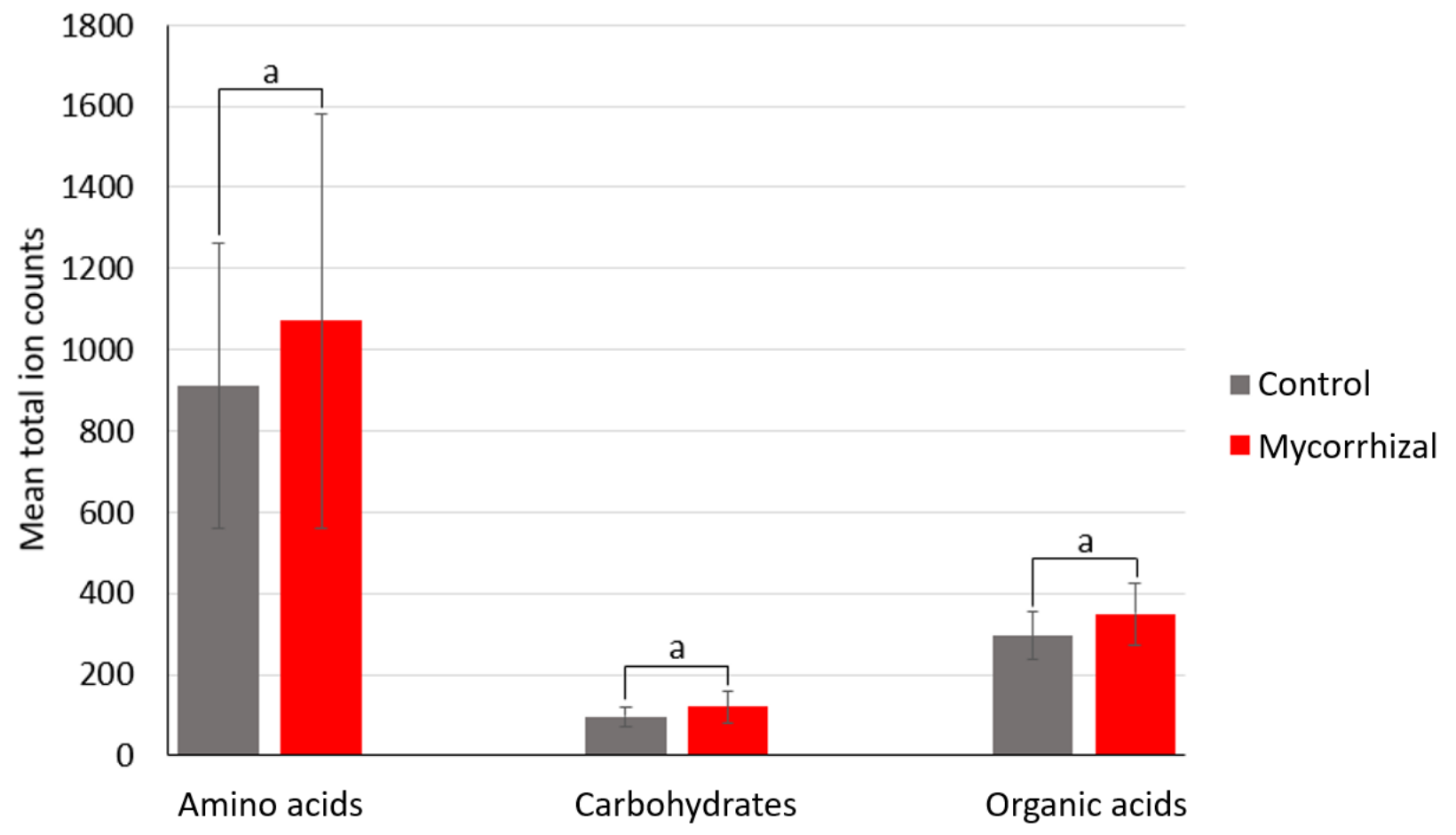

Figure 3.18: Total ion counts of primary metabolite classes amino acids, sugars and organic acids, measured in xylem sap of Laccaria bicolor-mycorrhizal and control Populus $\mathrm{x}$ canescens plants. Means denoted by same letters did not significantly differ according to Welch two-sample t-test with $p<0.05$ 


\subsubsection{Xylem sap non-targeted metabolic fingerprinting}

In total, 1039 putative metabolites were detected in XS of control and mycorrhizal $P . \times$ canescens plants (Electronic supplemental file: Thesis_KKasper_E-table_Chapter 3 - Metabolomics). In general, treatment effects were small but across all putative metabolites a significant separation of the metabolomes in XS from ECM plants from that of non-ECM plants was observed (Fig. 3.19). Four putative metabolites were up- and 7 putative metabolites were down-regulated in xylem sap of mycorrhizal plants. Putative identities of upregulated metabolites were: flavonol rhamnetin ( $\left.\log _{2} \mathrm{FC}=7.8, p_{\text {adj }}<0.001\right)$, phenylpropanoid sinapaldehyde $\left(\log _{2} \mathrm{FC}=0.7, p_{\text {adj }}=0.004\right)$, lignin oligomer $\mathrm{G}(8-0-4) \mathrm{G}\left(\log _{2} \mathrm{FC}=0.65, p_{\mathrm{adj}}<0.02\right)$ and lignan 7-hydroxylariciresinol 9'-pcoumarate $\left(\log _{2} \mathrm{FC}=0.57, p_{\text {adj }}=0.034\right)$.

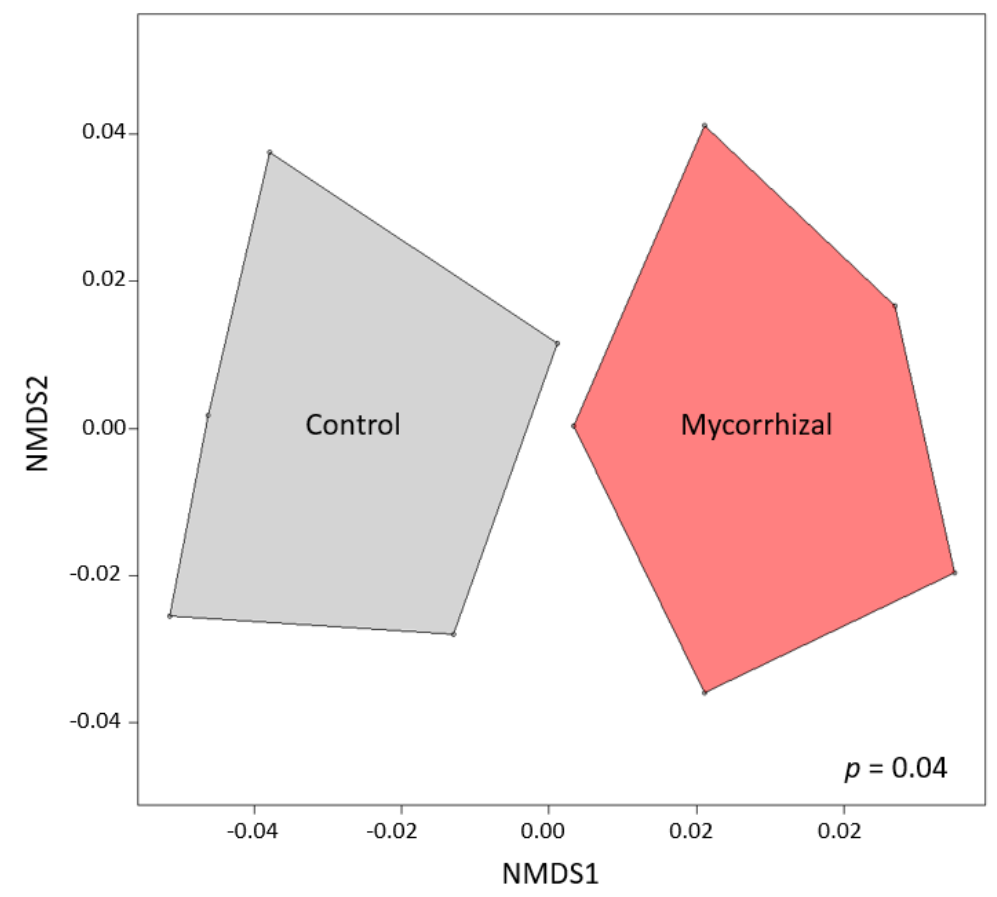

Figure 3.19: Non-metric multidimensional scaling (NMDS) of all putative metabolites identified by LC-MS in xylem sap of mycorrhizal (Laccaria bicolor) and non-mycorrhizal Populus x canescens plants. Samples were measured against empty runs to 1 ) reveal all potential metabolites and 2) to discriminate between treatments. ANOVA with Benjamini-Hochberg correction, FDR $<0.05$ was used to discriminate between putative metabolites in xylem sap samples and features that resulted from analytical misinterpretation of signals in empty runs. A permutation multivariate analyses was used to calculate the variance between treatments, $p<0.05$ indicates a statistical difference between metabolite data for the individual treatment. 


\subsubsection{Accumulation of salicylic acid and pipecolic acid are reduced in xylem sap of mycorrhizal plants}

Salicylic acid (SA), SA-glucoside (SAG), pipecolic acid (Pip), jasmonic acid (JA), JA-isoleucine (JA-lle) and abscisic acid (ABA) were identified in xylem sap (Fig. 3.20). The concentrations of SA and of Pip were approximately 20 to $30 \%$ higher in XS of control poplars than in XS of ECM-poplars (Fig. 3.20).

a

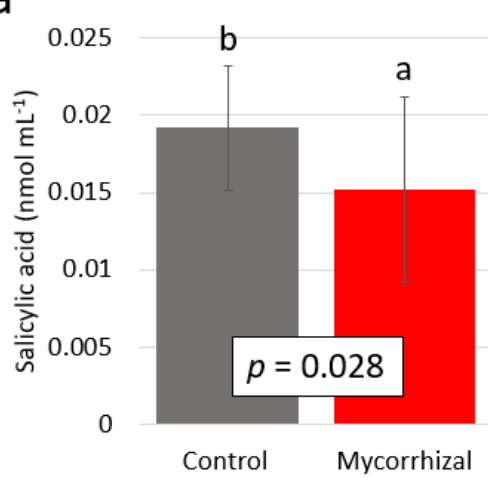

d

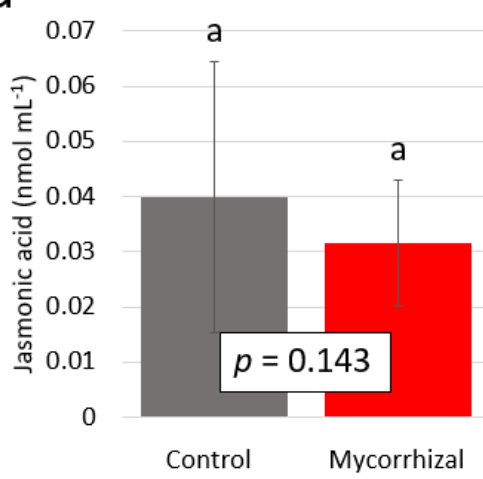

b

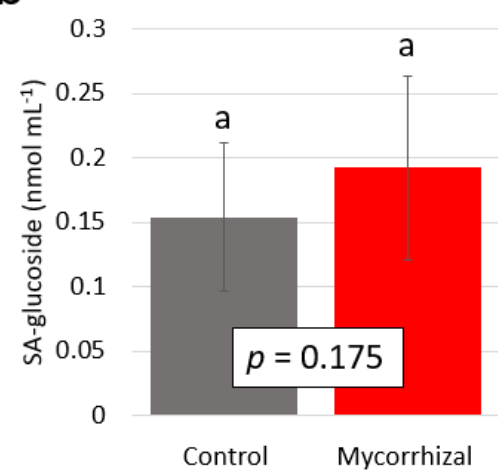

e

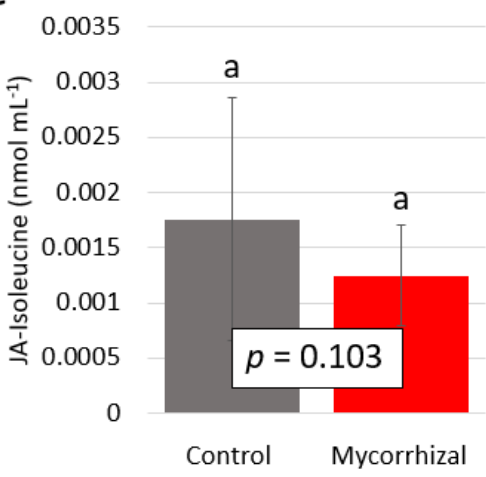

C

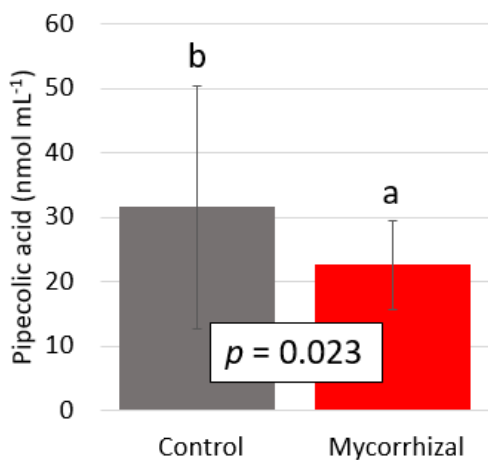

f

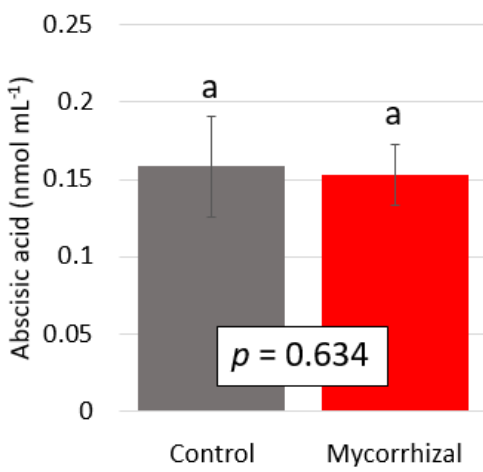

Figure 3.20: Concentrations of phytohormones in xylem sap of control (grey) and mycorrhizal (red) plants. Means denoted by same letters did not significantly differ at $p<0.05$ according to generalized mixedeffects model analysis, using experiments as random factor. $n=11$ per treatment. 


\subsubsection{Reduced growth of pathogenic bacteria in xylem sap of mycorrhizal poplars}

Brennaria salicis growth rate was higher in xylem sap of control- compared with mycorrhizal plants (Fig. 3.21). The mean OD values of xylem sap from ECM and Non-ECM plants were significantly different after $9 \mathrm{~h}$ of incubation and thereafter. However, the magnitude of this difference was small.

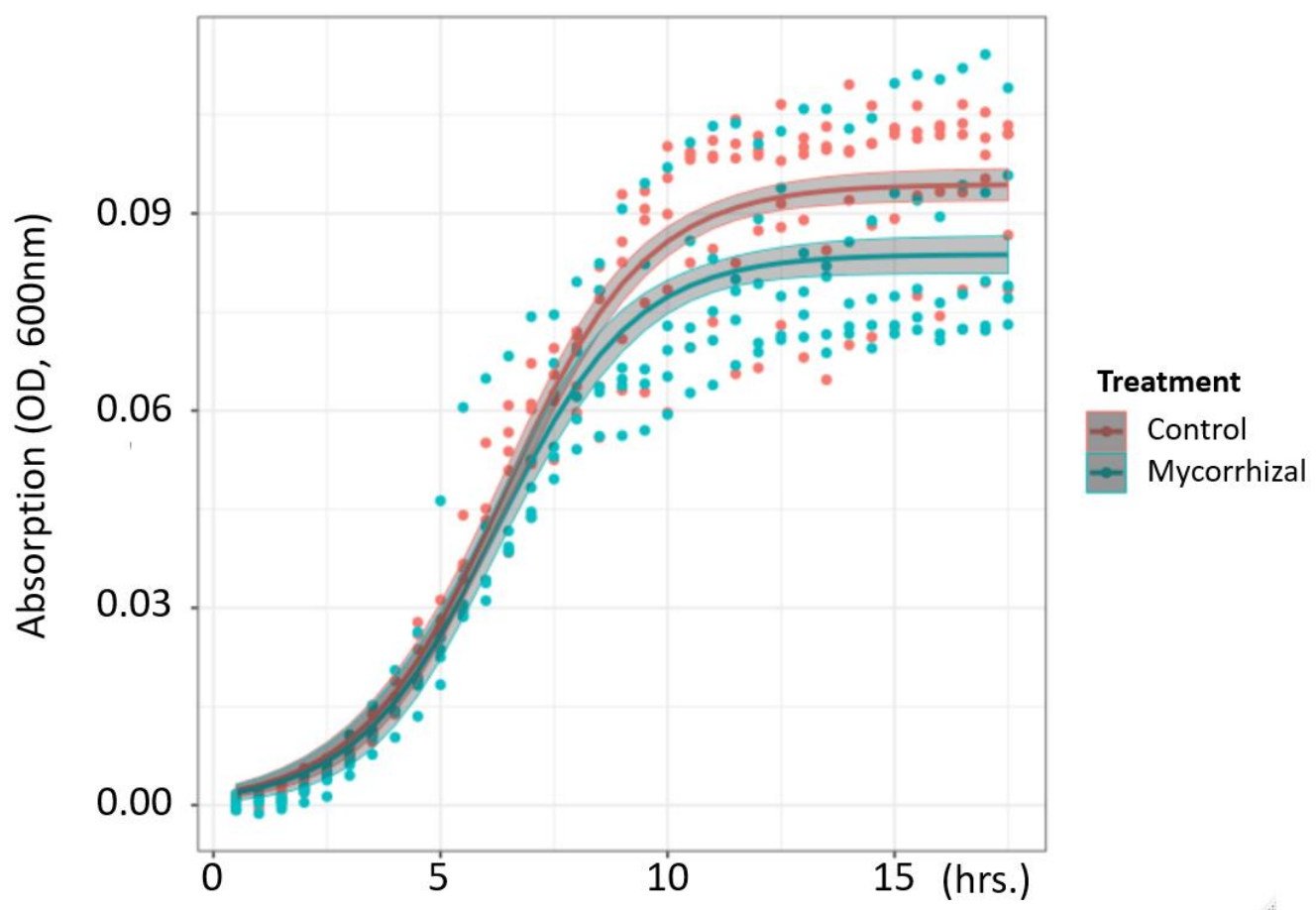

Figure 3.21: Visualization of Brennaria salicis growth rate in xylem sap of control (red) and mycorrhizal (turquoise) plants. Growth rate was evaluated by measurement of optical density (OD) at $600 \mathrm{~nm} . \mathrm{n}=8$, the grey area indicates the $95 \%$ confidence interval for the true mean. 
Discussion

\subsection{Discussion}

\subsubsection{Interaction with Laccaria bicolor systemically activates Populus $x$ canescens leaf defense}

Leaf transcriptome analysis of $P . x$ canescens plants grown axenically with or without ectomycorrhizal symbiosis showed a clear systemic effect, extending results from our earlier study conducted outdoors (Kaling et al., 2018). The expression of genes involved in the response to jasmonic acid (JA) was increased in the new leaf transcriptome data, which is contradictory to what we published before (Kaling et al., 2018). A dependence on JA signaling in L. bicolormediated defense responses was shown in the non-host Arabidopsis (Vishwanathan et al., 2020). Taken together, these results indicate a pivotal role of JA in L. bicolor induced systemic defense responses. Additionally, SA-related responses were involved in the systemic reaction, supporting the findings of Kaling et al. (2018) and Vishwanathan et al. (2020).

To further elucidate the effect of ECM on leaf defense, we compared the current DEGs with published data from earlier poplar experiments (Kaling et al., 2018; J. Luo et al., 2019; Philippe et al., 2010; Rinaldi et al., 2007). Genes involved in poplar defense, related to the JA-, ETH-, and SAsignaling pathways were induced. Interestingly, one homologue of EIN3 and one homologue of JAZ1, both negative regulators of JA- and MYC2-dependent responses, were upregulated. Another homologue EIN3 was down-regulated by mycorrhizal interaction, indicating a fine-tuning of $J A, J A / E T H$, and SA mediated pathways, which is apparently common under biotic stress (Koornneef \& Pieterse, 2008). Kaling and colleagues (2018) found that EMF systemically causes enhanced transcript abundances of genes involved in biosynthesis of flavonoids, a class of metabolites containing important poplar defense compounds (Miranda et al., 2007; Ullah et al., 2017). We observed enhanced expression of genes involved in proanthocyanidin biosynthesis, genes which were reported to be down-regulated in poplar by interaction with L. bicolor earlier (Kaling et al., 2018). Proanthocyanidins, are polyphenols that can contribute to defense against microbes (e.g. Hébert et al., 2000; Jersch et al., 1989) and herbivores (Barbehenn \& Peter Constabel, 2011).

Besides these pathways producing defense metabolites, the accumulation of transcripts of genes encoding proteins with distinct anti-microbial features was influenced by mycorrhizal interaction. A putative JA/ETH-dependent basic chitinase (PR3), which was also induced in poplar by a 


\section{Discussion}

biotrophic fungal pathogen (J. Luo et al., 2019) and by herbivory (Kaling et al., 2018) was upregulated while a potential ETH-dependent chitinase (PR4) was down-regulated. In line with Kaling and colleagues (2018), we found an EMF-induced upregulation of a Kunitz-trypsin inhibitor, a protein known for its anti-herbivory function in poplar (Major \& Constabel, 2008). Taken together, EMF systemically induced activation of JA-, JA/ETH- and SA-dependent signaling pathways and the upregulation of genes expressing for anti-microbial and anti-herbivory molecules, indicating an increased systemic investment in a broad-spectrum of defenses.

Interestingly, the transcript abundances of chitin elicitor receptor kinase 1 (CERK1), of a closely related chitin binding-lysine motif-domain containing receptor kinase (LYK4, Wan et al., 2012), and of genes down-stream of chitin-perception were upregulated by the interaction with $L$. bicolor, suggesting a PAMP-triggered basal-defense response (J. Jones \& Dangl, 2006). The dependence on CERK1 for L. bicolor induced resistance in non-host Arabidopsis was recently shown (Vishwanathan et al., 2020). By which mechanism these putative receptors for chitin, its derivates and peptidoglycans (Desaki et al., 2019), were upregulated in systemic poplar tissues, not in contact with the fungus is currently elusive.

\subsubsection{ECM promoted accumulation of two proteins involved in apoplastic plant defense}

The XS proteome analysis of three independent experiments led to the identification and quantification of $383 \mathrm{XS}$ proteins in the size range of 8.9 to $147.7 \mathrm{kDa}$. This number is a significant improvement compared to previously released poplar XS proteomes (Dafoe \& Constabel, 2009; Pechanova et al., 2010). The fraction of poplar xylem sap proteins containing a signal peptide (38.6\%) was more than the 33\% reported by Dafoe and Constable (2009) but less than the $57 \%$ reported by Pechanova et al. (2010). Interestingly, the fraction is also lower than the $51.6 \%$ we reported in chapter 1.3.4. The difference might have been caused by the formation of a core proteome of all three independent mycorrhiza experiments while in the nitrogen experiment only one repetition was analyzed. A methodological draw-back of the method used here is that small peptides could not be detected. Small peptides can act as effectors for the establishment of mycorrhizal symbioses (Martin et al. 2008) or signal nutrient conditions (Tabata et al. 2014). Whether or not small peptides are secreted into the XS of ECM poplars and act as long-range signals needs further studies. 


\section{Discussion}

Here, the comparison of control and mycorrhizal xylem sap proteomes of proteins $>8.9$ kDa showed only minor differences between the treatments. Interestingly, over all three independent repetitions, only two proteins were significantly higher accumulated in xylem sap of mycorrhizal plants, while no protein showed higher enrichment in xylem sap of control plants. Both enhanced proteins were assigned to the GO term 'immune system process' and possessed an apoplastic signal peptide. The class III peroxidase PtPRX77 is a homologue of AtPRX52, which was increased in Arabidopsis apoplast upon Verticillium longisporum infection (Floerl et al., 2012), Pseudomonas syringae interaction (Z. Zhang et al., 2007) and oxidative stress (Ludwikow et al., 2004), suggesting a key role in plant defense. DIR1 (DEFECTIVE IN INDUCED RESISTANCE) and DIR1-like proteins are crucial SAR long-distance signals (Shah \& Zeier, 2013) but their increase in response to biotic stress was so far only shown in phloem (Champigny et al., 2013; Isaacs et al., 2016; H. W. Jung et al., 2009; Maldonado et al., 2002). Our study is the first report linking this protein with symbiotic interactions. DIR1-like proteins belong to the class of non-specific lipid-transfer proteins with a lipid binding pocket (Champigny et al., 2013). They can bind fatty acids, lipids and phospholipids and it is thought that this interaction facilitates the translocation of lipid signals to systemic tissues (Isaacs et al., 2016). A signaling potential of DIR1 or DIR1-like proteins themselves has also been suggested (Champigny et al., 2013). Non-specific lipid-transfer proteins, isolated from barley and maize leaves showed in vitro anti-bacterial and anti-fungal activity (A. Molina et al., 1993). However, no evidence has been published, that DIR1 or DIR1-like proteins possess this activity as well. Information on non-specific lipid-transfer proteins in poplar is scarce. Overexpression of lipid-transport protein-like LJAMP2 led to increased resistance of poplar towards a necrotrophic and a hemibiotrophic pathogen (Huang et al., 2012; Jia et al., 2010). In conclusion, the xylem sap proteome of ECM-poplar showed only minor modifications compared to the xylem sap proteome of control plants. The two upregulated proteins have distinct functions in the apoplast and are linked to plant defense, suggesting a protective effect of ECM for P. $x$ canescens. 


\section{Discussion}

\subsubsection{ECM modified xylem sap phytohormone concentrations}

We found, that poplar root colonization reduced the XS concentration of SA and pipecolic acid, compounds known for their central roles in local (Vlot et al., 2009) and systemic (Bernsdorff et al., 2016) signaling of induced resistance (Pieterse et al., 2014). Promotion (synergism) and suppression (antagonism) are critical components of phytohormone cross talk in plant defense (Robert-Seilaniantz et al., 2011). Since JA-dependent defense can be antagonized by SAdependent responses (e.g. Li et al., 2006), a reduction of SA-dependent defense induction in the first place could promote JA-dependent defense responses. By this hypothesis, the downregulation of phytohormonal signal-components inducing SA-dependent responses would facilitate JA-dependent responses. But this suggestion does not explain the systemic upregulation of both, SA- and JA-dependent signaling pathways. In the previous chapter, we observed stronger changes in XS phytohormone concentrations, which were however, opposite to the transcriptional responses found in the leaf transcriptome. It appears therefore not very likely that XS SA and pipecolic acid concentrations were the main long-distance signals regulating systemic defense responses.

\subsubsection{The influence of ECM on xylem sap metabolite composition is low}

No differences were found in the abundance of primary metabolites in XS in response to poplar mycorrhizal interaction. We found a high abundance of pyroglutamate in XS. Since this compound is formed by non-enzymatic cyclization of glutamine and glutamate during GC-MS analysis (T. Ischebeck, personal communication, June $\left.16^{\text {th }}, 2020\right)$ as reported before for LC-MS analysis (Purwaha et al., 2014), it is likely that poplar XS contained glutamine as the major amino acid, in agreement with previous studies (Dickson et al., 1985; Siebrecht \& Tischner, 1999).

The exploratory analysis of non-targeted metabolite fingerprinting revealed 1039 putative metabolites in XS of ECM poplars and control plants, but a profound shift of the metabolome as found in leaves (Kaling et al. 2018), was not observed. Seven putative metabolites were differentially enriched in XS of ECM and control plants. Among these compounds, flavonol rhamnetin was tentatively identified (Chapter 3.3.6). Rhamnetin is possessing antimicrobial properties (Papp, 2005). 


\subsubsection{EMF root colonization has only a small effect on endophyte growth in poplar xylem sap}

Xylem inhabiting pathogens cause severe economic losses in fruit orchards and crop plants (Heale \& Karapapa, 1999; Saponari et al., 2017). We developed a micro-assay to evaluate the development of XS occupying bacteria. Growth of Brennaria salicis was slightly decreased in XS of mycorrhizal poplars compared to XS of control plants. Since the maximum density of the growth assay was lower than that of the controls but the initial growth rate similar, our results suggest that nutrients in XS of ECM poplars were a little bit more limited than in XS from control plants. Overall, these results support that B. salicis, which can colonize the vascular system of poplar as an endophyte, is well adapted to the XS environment. In willows, which are tree species phylogenetically closely related to poplars, B. salicis causes the watermark disease. It may be useful to study xylem sap of ECM- and control willows to address the role of mycorrhizal effects in a typical host of this pathogen. The micro-assay developed here is of interest for breeding programs. It can be used to screening the resistance of tree species against XS inhabiting bacteria, such as the devastating Xylella fastidiosa (Hopkins, 1989), currently destroying acres of olive trees in Italy (Schneider et al., 2020).

\subsection{Conclusions}

The mutualistic interaction of $L$. bicolor with $P . x$ canescens roots resulted in systemic responses in leaves. Under these conditions, leaf SA-, JA- and JA/ETH-dependent defense responses were activated. Furthermore, genes encoding a putative basic plant chitinases (PR3) and enzymes involved in the production of secondary metabolites with defensive properties, e.g. proanthocyanidins, were upregulated. The impact of ECM interaction on the XS metabolome composition was minor with regard to the appearance of new substances but the identified differentially enriched metabolites may be involved in defense. The influence of ECM interaction on the XS proteome was also small with only two, a peroxidase and DIR1 like protein, of almost 400 proteins being significantly affected. Homologues of these two proteins have been functionally characterized in Arabidopsis or crops and are involved pathogen defense and SAR signaling. Here, we demonstrate for the first time that the DIR1-like protein is upregulated by a symbiotic interaction in xylem sap. This result deserves attention in future studies. 


\subsection{Supplemental materials}

Table S3.1: Composition of M-MMNS medium, a phosphorus reduced version of modified MelinNorkrans medium by Kulmann (2005)

\begin{tabular}{|c|c|}
\hline Compound & $\mathrm{g} \mathrm{L}^{-1}$ \\
\hline Saccharose (Duchefa) & 10 \\
\hline$\left(\mathrm{NH}_{4}\right)_{2} \mathrm{SO}_{4}$ (Roth) & 0.25 \\
\hline $\mathrm{KH}_{2} \mathrm{PO}_{4}$ (Roth) & 0.5 \\
\hline $\mathrm{MgSO}_{4} \times 7 \mathrm{H}_{2} \mathrm{O}$ (Roth) & 0.15 \\
\hline $\mathrm{CaCl}_{2} \times 2 \mathrm{H}_{2} \mathrm{O}$ (Roth) & 0.5 \\
\hline $\mathrm{NaCl}$ (Roth) & $2.5 \times 10^{-2}$ \\
\hline $\mathrm{MnSO}_{4} \times \mathrm{H}_{2} \mathrm{O}$ (Merck) & $1.1 \times 10^{-2}$ \\
\hline $\mathrm{ZnSO}_{4} \times 7 \mathrm{H}_{2} \mathrm{O}$ (Merck) & $2.2 \times 10^{-2}$ \\
\hline $\mathrm{CuSO}_{4} \times 5 \mathrm{H}_{2} \mathrm{O}$ (Merck) & $0.49 \times 10^{-2}$ \\
\hline$\left(\mathrm{NH}_{4}\right)_{6} \mathrm{MO}_{7} \mathrm{O}_{24} \times 4 \mathrm{H}_{2} \mathrm{O}$ (Merck) & $0.23 \times 10^{-2}$ \\
\hline Thiamin $\mathrm{HCl}$ (Merck) & $0.01 \times 10^{-2}$ \\
\hline $\mathrm{FeCl}_{3} \times 6 \mathrm{H}_{2} \mathrm{O}$ (Roth) & $1 \times 10^{-2}$ \\
\hline Micro Agar (Duchefa) & 17.4 \\
\hline
\end{tabular}


Table S3.2: Composition of modified Long Ashton nutrient solution containing $2 \mathrm{mM} \mathrm{KNO}_{3}$ as nitrogen source

\begin{tabular}{|c|c|}
\hline Compound & $\mathrm{g} \mathrm{L}^{1}$ \\
\hline $\mathrm{KNO}_{3}$ (Roth) & 1.01 \\
\hline $\mathrm{KCl}$ (Merck) & 0.75 \\
\hline $\mathrm{CaCl}_{2} \times 2 \mathrm{H}_{2} \mathrm{O}$ (Roth) & 1.47 \\
\hline $\mathrm{MgSO}_{4} \times 7 \mathrm{H}_{2} \mathrm{O}$ (Roth) & $7.4 \times 10^{-2}$ \\
\hline $\mathrm{KH}_{2} \mathrm{PO}_{4}$ (Roth) & $81.64 \times 10^{-3}$ \\
\hline $\mathrm{K}_{2} \mathrm{HPO}_{4}$ (Merck) & $7.2 \times 10^{-3}$ \\
\hline $\mathrm{H}_{3} \mathrm{BO}_{3}$ (Roth) & $6.18 \times 10^{-4}$ \\
\hline $\mathrm{MnSO}_{4} \times \mathrm{H}_{2} \mathrm{O}$ (Merck) & $3.38 \times 10^{-4}$ \\
\hline $\mathrm{Na}_{2} \mathrm{MoO}_{4} \times 2 \mathrm{H}_{2} \mathrm{O}$ (Merck) & $16.92 \times 10^{-4}$ \\
\hline $\mathrm{CoSO}_{4} \times 7 \mathrm{H}_{2} \mathrm{O}$ (Merck) & $1.12 \times 10^{-5}$ \\
\hline $\mathrm{ZnSO}_{4} \times 7 \mathrm{H}_{2} \mathrm{O}$ (Merck) & $5.76 \times 10^{-5}$ \\
\hline $\mathrm{CuSO}_{4} \times 5 \mathrm{H}_{2} \mathrm{O}$ (Merck) & $3.2 \times 10^{-5}$ \\
\hline EDTA - Fe $\times 3 \mathrm{H}_{2} \mathrm{O}$ (Roth) & $36.71 \times 10^{-4}$ \\
\hline
\end{tabular}

Table S3.3: Daily doses of modified Long Ashton nutrient solution were dependent on plant height

\begin{tabular}{rr}
\hline Plant height $(\mathbf{c m})$ & Daily amount of modified LA nutrient solution $(\mathbf{m L})$ \\
\hline 0 to 20 & 30 \\
21 to 40 & 100 \\
41 to 60 & 150 \\
61 to 100 & 250 \\
\hline
\end{tabular}


Table S3.4: Spectrophotometer measurement results for nucleic acid concentration and purity, as well as quality and output from RNAseq procedure and subsequent data processing of extracted RNA samples from Laccaria bicolor-mycorrhizal (Myc) and nonmycorrhizal (Control) Populus $\mathrm{x}$ canescens plants

\begin{tabular}{|c|c|c|c|c|c|c|c|c|}
\hline & \multicolumn{2}{|c|}{ Batch 1} & \multicolumn{2}{|c|}{ Batch 2} & \multicolumn{2}{|c|}{ Batch 3} & \multicolumn{2}{|c|}{ Batch 4} \\
\hline & Control & Myc & Control & Myc & Control & Myc & Control & Myc \\
\hline $\begin{array}{l}\text { Nucleic acid } \\
\text { concentration }\end{array}$ & & & & & & & & \\
\hline (ng $\mu \mathrm{L}^{-1}$ ) & 170.7 & 118.2 & 102.9 & 113.8 & 105.6 & 97.4 & 266.84 & 368.36 \\
\hline$A_{260} / A_{280}$ & 2.03 & 2.05 & 2.04 & 2.05 & 2.04 & 2.05 & 2.035 & 2.049 \\
\hline RIN values & 6.3 & 6.4 & 6 & 6.1 & 5.7 & 6 & 6.3 & 6.8 \\
\hline Raw reads & 16391082 & 14066464 & 15048209 & 15009379 & 17069726 & 18134357 & 17736507 & 16544976 \\
\hline Processed (fastp) & 16322853 & 14009047 & 14992415 & 14952518 & 17006667 & 18057233 & 17672366 & 16482366 \\
\hline Mapped & 15345329 & 13129095 & 13589240 & 14072411 & 15180620 & 16071792 & 16640229 & 15281973 \\
\hline Mapped (\%) & 94.01 & 93.72 & 90.64 & 94.11 & 89.26 & 89 & 94.16 & 92.72 \\
\hline
\end{tabular}


Table S3.5: List of significantly up- or downregulated GO terms in leaf transcriptome analysis of Populus $\mathrm{x}$ canescens plants with or without Laccaria bicolor root colonization

\begin{tabular}{|c|c|c|c|}
\hline GO term & $\log _{2} \mathrm{FC}$ & $p$ value & Description \\
\hline \multicolumn{4}{|c|}{ Upregulated } \\
\hline GO:0010023 & 2.72 & $7.46 \mathrm{E}-05$ & proanthocyanidin biosynthetic process \\
\hline GO:0006559 & 2.37 & $4.36 \mathrm{E}-03$ & L-phenylalanine catabolic process \\
\hline GO:1902222 & 2.37 & $4.36 \mathrm{E}-03$ & $\begin{array}{l}\text { erythrose } 4 \text {-phosphate/phosphoenolpyruvate family amino acid } \\
\text { catabolic process }\end{array}$ \\
\hline GO:0009074 & 2.35 & $4.40 \mathrm{E}-04$ & aromatic amino acid family catabolic process \\
\hline GO:0019632 & 2.33 & $2.26 \mathrm{E}-02$ & shikimate metabolic process \\
\hline GO:0046271 & 2.15 & 3.30E-06 & phenylpropanoid catabolic process \\
\hline GO:0046274 & 2.15 & $3.30 \mathrm{E}-06$ & lignin catabolic process \\
\hline GO:0009819 & 2.1 & $2.69 \mathrm{E}-03$ & drought recovery \\
\hline GO:0006558 & 1.98 & $2.19 \mathrm{E}-02$ & L-phenylalanine metabolic process \\
\hline GO:1902221 & 1.98 & $2.19 \mathrm{E}-02$ & $\begin{array}{l}\text { erythrose } 4 \text {-phosphate/phosphoenolpyruvate family amino acid } \\
\text { metabolic process }\end{array}$ \\
\hline GO:0010413 & 1.97 & $1.00 \mathrm{E}-02$ & glucuronoxylan metabolic process \\
\hline GO:0010417 & 1.97 & 1.00E-02 & glucuronoxylan biosynthetic process \\
\hline GO:0045492 & 1.92 & $4.42 \mathrm{E}-06$ & xylan biosynthetic process \\
\hline GO:0006084 & 1.86 & 3.11E-02 & acetyl-CoA metabolic process \\
\hline GO:0009694 & 1.79 & $1.75 \mathrm{E}-04$ & jasmonic acid metabolic process \\
\hline GO:0009699 & 1.78 & $5.84 \mathrm{E}-19$ & phenylpropanoid biosynthetic process \\
\hline GO:0006637 & 1.76 & $3.84 \mathrm{E}-02$ & acyl-CoA metabolic process \\
\hline GO:0035383 & 1.76 & $3.84 \mathrm{E}-02$ & thioester metabolic process \\
\hline GO:0009698 & 1.75 & $2.00 \mathrm{E}-25$ & phenylpropanoid metabolic process \\
\hline GO:0009834 & 1.71 & $8.98 \mathrm{E}-11$ & plant-type secondary cell wall biogenesis \\
\hline GO:0009808 & 1.7 & $1.43 \mathrm{E}-14$ & lignin metabolic process \\
\hline GO:0009809 & 1.67 & $1.25 \mathrm{E}-08$ & lignin biosynthetic process \\
\hline GO:0070592 & 1.64 & $3.19 \mathrm{E}-06$ & cell wall polysaccharide biosynthetic process \\
\hline GO:0044038 & 1.62 & 4.79E-06 & cell wall macromolecule biosynthetic process \\
\hline GO:0070589 & 1.62 & 4.79E-06 & cellular component macromolecule biosynthetic process \\
\hline GO:0045491 & 1.59 & $2.72 \mathrm{E}-04$ & xylan metabolic process \\
\hline GO:0030244 & 1.54 & $1.54 \mathrm{E}-05$ & cellulose biosynthetic process \\
\hline GO:0046189 & 1.54 & $1.06 \mathrm{E}-02$ & phenol-containing compound biosynthetic process \\
\hline GO:0071456 & 1.49 & $3.08 \mathrm{E}-02$ & cellular response to hypoxia \\
\hline GO:0044550 & 1.48 & $7.65 \mathrm{E}-17$ & secondary metabolite biosynthetic process \\
\hline GO:0030243 & 1.48 & $3.00 \mathrm{E}-05$ & cellulose metabolic process \\
\hline GO:0009072 & 1.46 & $1.79 \mathrm{E}-04$ & aromatic amino acid family metabolic process \\
\hline GO:0033692 & 1.42 & $3.45 \mathrm{E}-13$ & cellular polysaccharide biosynthetic process \\
\hline GO:0010410 & 1.4 & $5.02 \mathrm{E}-05$ & hemicellulose metabolic process \\
\hline GO:0018958 & 1.38 & $2.88 \mathrm{E}-04$ & phenol-containing compound metabolic process \\
\hline GO:0000271 & 1.37 & $9.25 \mathrm{E}-13$ & polysaccharide biosynthetic process \\
\hline GO:0009813 & 1.36 & $2.16 \mathrm{E}-06$ & flavonoid biosynthetic process \\
\hline GO:0051274 & 1.36 & $2.63 \mathrm{E}-04$ & beta-glucan biosynthetic process \\
\hline
\end{tabular}




\begin{tabular}{|c|c|c|c|}
\hline GO:0009250 & 1.33 & $5.58 \mathrm{E}-07$ & glucan biosynthetic process \\
\hline GO:0009832 & 1.32 & 6.17E-10 & plant-type cell wall biogenesis \\
\hline GO:0051273 & 1.32 & 4.12E-04 & beta-glucan metabolic process \\
\hline GO:0034637 & 1.27 & $2.35 \mathrm{E}-11$ & cellular carbohydrate biosynthetic process \\
\hline GO:0042546 & 1.27 & $5.08 \mathrm{E}-11$ & cell wall biogenesis \\
\hline GO:0071248 & 1.27 & 4.45E-02 & cellular response to metal ion \\
\hline GO:0010383 & 1.26 & $5.32 \mathrm{E}-05$ & cell wall polysaccharide metabolic process \\
\hline GO:0042537 & 1.26 & $1.20 \mathrm{E}-02$ & benzene-containing compound metabolic process \\
\hline GO:0044264 & 1.25 & $2.26 \mathrm{E}-13$ & cellular polysaccharide metabolic process \\
\hline GO:0044036 & 1.23 & 7.56E-06 & cell wall macromolecule metabolic process \\
\hline GO:0009812 & 1.21 & $1.06 \mathrm{E}-05$ & flavonoid metabolic process \\
\hline GO:0019748 & 1.18 & $3.86 \mathrm{E}-18$ & secondary metabolic process \\
\hline GO:0006073 & 1.15 & $5.32 \mathrm{E}-08$ & cellular glucan metabolic process \\
\hline GO:0044042 & 1.15 & $5.32 \mathrm{E}-08$ & glucan metabolic process \\
\hline GO:0005976 & 1.13 & $3.22 \mathrm{E}-12$ & polysaccharide metabolic process \\
\hline GO:0016051 & 1.1 & 4.19E-11 & carbohydrate biosynthetic process \\
\hline GO:0019362 & 1.08 & $1.78 \mathrm{E}-02$ & pyridine nucleotide metabolic process \\
\hline GO:0032787 & 1.06 & $1.90 \mathrm{E}-17$ & monocarboxylic acid metabolic process \\
\hline GO:0016054 & 1.04 & $1.51 \mathrm{E}-02$ & organic acid catabolic process \\
\hline GO:0046395 & 1.04 & $1.51 \mathrm{E}-02$ & carboxylic acid catabolic process \\
\hline GO:0044262 & 1.03 & $5.24 \mathrm{E}-11$ & cellular carbohydrate metabolic process \\
\hline GO:0015711 & 1.01 & $1.50 \mathrm{E}-02$ & organic anion transport \\
\hline GO:0006733 & 0.99 & 4.44E-02 & oxidoreduction coenzyme metabolic process \\
\hline GO:0009867 & 0.98 & $1.46 \mathrm{E}-02$ & jasmonic acid mediated signaling pathway \\
\hline GO:0072330 & 0.97 & $2.75 \mathrm{E}-06$ & monocarboxylic acid biosynthetic process \\
\hline GO:0006732 & 0.96 & $1.15 \mathrm{E}-05$ & coenzyme metabolic process \\
\hline GO:0044723 & 0.94 & $5.23 \mathrm{E}-12$ & single-organism carbohydrate metabolic process \\
\hline GO:0071669 & 0.94 & $1.52 \mathrm{E}-05$ & plant-type cell wall organization or biogenesis \\
\hline GO:0071395 & 0.93 & 3.89E-02 & cellular response to jasmonic acid stimulus \\
\hline GO:0019439 & 0.92 & $2.33 \mathrm{E}-03$ & aromatic compound catabolic process \\
\hline GO:0030001 & 0.91 & $6.89 \mathrm{E}-05$ & metal ion transport \\
\hline GO:1901361 & 0.91 & $1.86 \mathrm{E}-03$ & organic cyclic compound catabolic process \\
\hline GO:1901617 & 0.91 & $5.80 \mathrm{E}-03$ & organic hydroxy compound biosynthetic process \\
\hline GO:0009611 & 0.9 & $1.03 \mathrm{E}-06$ & response to wounding \\
\hline GO:0006820 & 0.9 & $6.40 \mathrm{E}-05$ & anion transport \\
\hline GO:1901615 & 0.86 & $2.56 \mathrm{E}-05$ & organic hydroxy compound metabolic process \\
\hline GO:0006631 & 0.83 & $4.58 \mathrm{E}-03$ & fatty acid metabolic process \\
\hline GO:0044712 & 0.81 & $1.62 \mathrm{E}-06$ & single-organism catabolic process \\
\hline GO:0009753 & 0.81 & 9.67E-05 & response to jasmonic acid \\
\hline GO:0080167 & 0.79 & $5.02 \mathrm{E}-03$ & response to karrikin \\
\hline GO:0071554 & 0.74 & 2.00E-05 & cell wall organization or biogenesis \\
\hline GO:0006811 & 0.72 & $1.05 \mathrm{E}-07$ & ion transport \\
\hline GO:0009415 & 0.72 & 4.77E-07 & response to water \\
\hline
\end{tabular}




\begin{tabular}{|c|c|c|c|}
\hline GO:0009620 & 0.72 & $2.92 \mathrm{E}-06$ & response to fungus \\
\hline GO:0019752 & 0.71 & $3.46 \mathrm{E}-13$ & carboxylic acid metabolic process \\
\hline GO:0005975 & 0.71 & $1.75 \mathrm{E}-10$ & carbohydrate metabolic process \\
\hline GO:0050832 & 0.71 & $3.29 \mathrm{E}-04$ & defense response to fungus \\
\hline GO:0044711 & 0.7 & $1.55 \mathrm{E}-21$ & single-organism biosynthetic process \\
\hline GO:0009414 & 0.7 & $2.18 \mathrm{E}-06$ & response to water deprivation \\
\hline GO:0016053 & 0.7 & $1.76 \mathrm{E}-05$ & organic acid biosynthetic process \\
\hline GO:0046394 & 0.7 & $1.76 \mathrm{E}-05$ & carboxylic acid biosynthetic process \\
\hline GO:0044283 & 0.66 & 4.41E-06 & small molecule biosynthetic process \\
\hline GO:0043436 & 0.64 & $3.10 \mathrm{E}-11$ & oxoacid metabolic process \\
\hline GO:0006812 & 0.64 & $9.50 \mathrm{E}-03$ & cation transport \\
\hline GO:0006082 & 0.63 & $3.43 \mathrm{E}-11$ & organic acid metabolic process \\
\hline GO:0055085 & 0.63 & 3.39E-06 & transmembrane transport \\
\hline GO:0051186 & 0.6 & 2.89E-02 & cofactor metabolic process \\
\hline GO:0009891 & 0.59 & 2.69E-02 & positive regulation of biosynthetic process \\
\hline GO:0001101 & 0.58 & $7.43 \mathrm{E}-15$ & response to acid chemical \\
\hline GO:0016310 & 0.56 & $3.92 \mathrm{E}-10$ & phosphorylation \\
\hline GO:0071229 & 0.55 & $8.88 \mathrm{E}-04$ & cellular response to acid chemical \\
\hline GO:0006468 & 0.54 & $6.51 \mathrm{E}-08$ & protein phosphorylation \\
\hline GO:0009755 & 0.54 & $3.80 \mathrm{E}-04$ & hormone-mediated signaling pathway \\
\hline GO:1901700 & 0.53 & $1.81 \mathrm{E}-16$ & response to oxygen-containing compound \\
\hline GO:0071495 & 0.51 & $2.54 \mathrm{E}-04$ & cellular response to endogenous stimulus \\
\hline GO:0032870 & 0.5 & 3.00E-04 & cellular response to hormone stimulus \\
\hline GO:1901701 & 0.49 & $6.34 \mathrm{E}-04$ & cellular response to oxygen-containing compound \\
\hline GO:0033993 & 0.48 & $1.60 \mathrm{E}-05$ & response to lipid \\
\hline GO:0097305 & 0.48 & $9.54 \mathrm{E}-04$ & response to alcohol \\
\hline GO:0009719 & 0.47 & 2.93E-11 & response to endogenous stimulus \\
\hline GO:0009725 & 0.47 & $3.52 \mathrm{E}-11$ & response to hormone \\
\hline GO:0044281 & 0.47 & $5.92 \mathrm{E}-08$ & small molecule metabolic process \\
\hline GO:0010035 & 0.47 & $5.41 \mathrm{E}-07$ & response to inorganic substance \\
\hline GO:0044710 & 0.46 & $3.86 \mathrm{E}-21$ & single-organism metabolic process \\
\hline GO:0009607 & 0.46 & 3.59E-06 & response to biotic stimulus \\
\hline GO:0009737 & 0.46 & $2.40 \mathrm{E}-03$ & response to abscisic acid \\
\hline GO:0043207 & 0.45 & 7.97E-06 & response to external biotic stimulus \\
\hline GO:0051707 & 0.45 & 7.97E-06 & response to other organism \\
\hline GO:0006629 & 0.45 & $9.48 \mathrm{E}-03$ & lipid metabolic process \\
\hline GO:0070887 & 0.44 & $5.56 \mathrm{E}-05$ & cellular response to chemical stimulus \\
\hline GO:0010033 & 0.43 & $8.11 \mathrm{E}-12$ & response to organic substance \\
\hline GO:0055114 & 0.43 & $1.30 \mathrm{E}-04$ & oxidation-reduction process \\
\hline GO:0071310 & 0.42 & $2.62 \mathrm{E}-03$ & cellular response to organic substance \\
\hline GO:0006793 & 0.41 & $3.52 \mathrm{E}-07$ & phosphorus metabolic process \\
\hline GO:0006952 & 0.41 & 4.50E-04 & defense response \\
\hline GO:0042221 & 0.4 & $1.57 \mathrm{E}-14$ & response to chemical \\
\hline
\end{tabular}




\begin{tabular}{|c|c|c|c|}
\hline GO:0009605 & 0.4 & $2.73 \mathrm{E}-06$ & response to external stimulus \\
\hline GO:0098542 & 0.39 & $1.85 \mathrm{E}-02$ & defense response to other organism \\
\hline GO:0006796 & 0.38 & 8.47E-06 & phosphate-containing compound metabolic process \\
\hline GO:0006970 & 0.38 & $3.86 \mathrm{E}-02$ & response to osmotic stress \\
\hline GO:0006810 & 0.36 & $3.62 \mathrm{E}-05$ & transport \\
\hline GO:0051234 & 0.35 & 8.59E-05 & establishment of localization \\
\hline GO:0007154 & 0.34 & 8.99E-04 & cell communication \\
\hline GO:0051179 & 0.33 & $1.11 \mathrm{E}-04$ & localization \\
\hline GO:1901362 & 0.29 & 7.60E-04 & organic cyclic compound biosynthetic process \\
\hline GO:0019438 & 0.29 & $1.09 \mathrm{E}-03$ & aromatic compound biosynthetic process \\
\hline GO:0051704 & 0.29 & 7.33E-03 & multi-organism process \\
\hline GO:0006950 & 0.28 & $6.46 \mathrm{E}-06$ & response to stress \\
\hline GO:0009628 & 0.25 & $2.55 \mathrm{E}-03$ & response to abiotic stimulus \\
\hline GO:0050896 & 0.24 & $3.25 \mathrm{E}-09$ & response to stimulus \\
\hline GO:0044763 & 0.24 & $4.39 \mathrm{E}-07$ & single-organism cellular process \\
\hline GO:0044699 & 0.22 & $4.32 \mathrm{E}-13$ & single-organism process \\
\hline GO:0009058 & 0.18 & $1.75 \mathrm{E}-02$ & biosynthetic process \\
\hline GO:1901576 & 0.17 & $3.72 \mathrm{E}-02$ & organic substance biosynthetic process \\
\hline GO:0008152 & 0.11 & $3.71 \mathrm{E}-04$ & metabolic process \\
\hline GO:0071704 & 0.11 & $6.47 E-03$ & organic substance metabolic process \\
\hline \multicolumn{4}{|c|}{ Downregulated } \\
\hline GO:0006310 & -2.95 & 2.93E-02 & DNA recombination \\
\hline GO:0006281 & -2.61 & $1.44 \mathrm{E}-07$ & DNA repair \\
\hline GO:0006412 & -2.35 & $2.16 \mathrm{E}-21$ & translation \\
\hline GO:0006399 & -2.35 & $1.08 \mathrm{E}-02$ & tRNA metabolic process \\
\hline GO:0034470 & -2.27 & $1.53 \mathrm{E}-04$ & ncRNA processing \\
\hline GO:0043043 & -2.07 & $4.48 \mathrm{E}-19$ & peptide biosynthetic process \\
\hline GO:0034660 & -2.02 & $3.62 \mathrm{E}-06$ & ncRNA metabolic process \\
\hline GO:0006397 & -2.01 & $1.95 \mathrm{E}-04$ & mRNA processing \\
\hline GO:0022613 & -2 & $5.75 \mathrm{E}-06$ & ribonucleoprotein complex biogenesis \\
\hline GO:0043604 & -1.81 & 7.11E-17 & amide biosynthetic process \\
\hline GO:0042254 & -1.78 & $5.73 \mathrm{E}-04$ & ribosome biogenesis \\
\hline GO:0006518 & -1.76 & $2.48 \mathrm{E}-16$ & peptide metabolic process \\
\hline GO:0006259 & -1.74 & $1.50 \mathrm{E}-10$ & DNA metabolic process \\
\hline GO:0006396 & -1.7 & $1.08 \mathrm{E}-12$ & RNA processing \\
\hline GO:0019684 & -1.7 & $8.64 \mathrm{E}-03$ & photosynthesis, light reaction \\
\hline GO:0016071 & -1.66 & $1.22 \mathrm{E}-05$ & mRNA metabolic process \\
\hline GO:0006974 & -1.6 & $1.75 \mathrm{E}-04$ & cellular response to DNA damage stimulus \\
\hline GO:0015979 & -1.41 & $1.35 \mathrm{E}-03$ & photosynthesis \\
\hline GO:0043603 & -1.38 & $1.04 \mathrm{E}-12$ & cellular amide metabolic process \\
\hline GO:0034622 & -1.1 & $3.22 \mathrm{E}-04$ & cellular macromolecular complex assembly \\
\hline GO:0051276 & -1 & $9.01 \mathrm{E}-04$ & chromosome organization \\
\hline GO:0007049 & -1 & $1.48 \mathrm{E}-03$ & cell cycle \\
\hline
\end{tabular}




$\begin{array}{llll}\text { GO:0006886 } & -0.98 & 1.48 \mathrm{E}-02 & \text { intracellular protein transport } \\ \text { GO:0022402 } & -0.96 & 3.05 \mathrm{E}-02 & \text { cell cycle process } \\ \text { GO:0045184 } & -0.95 & 4.74 \mathrm{E}-03 & \text { establishment of protein localization } \\ \text { GO:0015031 } & -0.93 & 8.06 \mathrm{E}-03 & \text { protein transport } \\ \text { GO:0043933 } & -0.87 & 8.27 \mathrm{E}-04 & \text { macromolecular complex subunit organization } \\ \text { GO:0065003 } & -0.84 & 4.58 \mathrm{E}-03 & \text { macromolecular complex assembly } \\ \text { GO:0042886 } & -0.84 & 1.94 \mathrm{E}-02 & \text { amide transport } \\ \text { GO:0015833 } & -0.84 & 2.18 \mathrm{E}-02 & \text { peptide transport } \\ \text { GO:0006996 } & -0.7 & 5.30 \mathrm{E}-08 & \text { organelle organization } \\ \text { GO:0022607 } & -0.65 & 1.10 \mathrm{E}-02 & \text { cellular component assembly } \\ \text { GO:1901566 } & -0.63 & 1.18 \mathrm{E}-06 & \text { organonitrogen compound biosynthetic process } \\ \text { GO:0010467 } & -0.4 & 1.53 \mathrm{E}-07 & \text { gene expression } \\ \text { GO:0034641 } & -0.36 & 2.77 \mathrm{E}-09 & \text { cellular nitrogen compound metabolic process } \\ \text { GO:0090304 } & -0.36 & 1.64 \mathrm{E}-05 & \text { nucleic acid metabolic process } \\ \text { GO:0016043 } & -0.34 & 1.87 \mathrm{E}-03 & \text { cellular component organization } \\ \text { GO:0006139 } & -0.26 & 3.34 \mathrm{E}-03 & \text { nucleobase-containing compound metabolic process }\end{array}$




\begin{tabular}{|c|c|c|c|c|c|c|c|c|c|c|c|c|}
\hline \multirow[b]{2}{*}{ Amino acids } & \multicolumn{5}{|c|}{ Control } & \multicolumn{6}{|c|}{ Mycorrhizal } & \multirow[b]{2}{*}{$p$ value } \\
\hline & 2 & 4 & 5 & 8 & 10 & 1 & 2 & 4 & 5 & 10 & 11 & \\
\hline$\beta$-Alanine & 3.12 & 7.44 & 3.72 & 4.21 & 4.82 & 2.68 & 6.49 & 5.15 & 3.68 & 4.10 & 6.78 & 0.883 \\
\hline Alanine & 9.55 & 5.16 & 21.02 & 5.68 & 7.02 & 9.72 & 11.08 & 10.26 & 6.43 & 14.04 & 13.29 & 0.736 \\
\hline 3-cyano-Alanine & 0.00 & 0.09 & 0.00 & 0.05 & 0.00 & 0.00 & 0.00 & 0.00 & 0.00 & 0.00 & 0.45 & 0.576 \\
\hline Asparagine & 6.3 & 16.6 & 49.5 & 10.1 & 2.7 & 17.0 & 6.5 & 8.2 & 5.2 & 13.2 & 18.5 & 0.551 \\
\hline Aspartate & 2.62 & 5.62 & 5.47 & 3.31 & 4.03 & 3.76 & 2.49 & 3.69 & 2.83 & 4.70 & 15.22 & 0.571 \\
\hline GABA & 0.65 & 1.69 & 1.47 & 1.04 & 1.79 & 1.07 & 1.29 & 0.93 & 1.19 & 2.38 & 1.96 & 0.664 \\
\hline Glutamate & 0.49 & 4.18 & 5.18 & 1.48 & 1.08 & 1.46 & 0.55 & 0.70 & 0.55 & 3.05 & 4.65 & 0.586 \\
\hline Glutamine & 79.5 & 207.5 & 316.4 & 72.4 & 13.2 & 177.1 & 123.8 & 86.5 & 47.8 & 96.7 & 61.6 & 0.532 \\
\hline Glycine & 0.22 & 0.05 & 0.13 & 0.03 & 0.10 & 0.13 & 0.00 & 0.18 & 0.09 & 0.08 & 0.36 & 0.574 \\
\hline Isoleucine & 17.37 & 10.41 & 29.08 & 9.04 & 20.94 & 18.59 & 22.58 & 20.98 & 15.02 & 17.50 & 33.08 & 0.409 \\
\hline Leucine & 2.43 & 0.96 & 3.09 & 1.21 & 3.97 & 1.37 & 3.00 & 3.57 & 1.88 & 2.23 & 7.36 & 0.414 \\
\hline Lysine & 0.14 & 0.23 & 0.36 & 0.16 & 0.13 & 0.22 & 0.21 & 0.22 & 0.16 & 0.26 & 0.19 & 0.919 \\
\hline Proline & 0.05 & 0.07 & 0.07 & 0.04 & 0.00 & 0.04 & 0.00 & 0.00 & 0.08 & 0.08 & 0.00 & 0.482 \\
\hline Pyroglutamate & 427.48 & 574.49 & 683.79 & 504.98 & 897.95 & 439.65 & 736.30 & 841.72 & 510.79 & 626.63 & 1685.6 & 0.383 \\
\hline Serine & 5.48 & 3.20 & 10.68 & 3.39 & 4.55 & 5.59 & 3.91 & 4.49 & 2.36 & 5.56 & 11.06 & 0.986 \\
\hline Threonine & 26.49 & 25.90 & 60.46 & 19.64 & 29.39 & 36.63 & 31.73 & 26.57 & 23.00 & 32.88 & 58.74 & 0.781 \\
\hline Tyrosine & 1.45 & 2.32 & 3.11 & 1.22 & 0.79 & 1.65 & 2.25 & 1.36 & 1.15 & 2.56 & 0.99 & 0.815 \\
\hline Valine & 60.72 & 32.59 & 92.33 & 32.93 & 64.13 & 54.14 & 60.01 & 67.09 & 45.82 & 61.10 & 93.29 & 0.605 \\
\hline \multicolumn{13}{|l|}{ Organic acids } \\
\hline $\begin{array}{l}\text { 2-Imidazolidone- } \\
\text { 4-carboxylate }\end{array}$ & 0.11 & 0.22 & 0.35 & 0.17 & 0.16 & 0.16 & 0.11 & 0.17 & 0.14 & 0.18 & 0.28 & 0.551 \\
\hline$\alpha$-Ketoglutarate & 1.33 & 1.98 & 1.97 & 0.77 & 0.96 & 1.99 & 1.32 & 1.86 & 1.46 & 1.53 & 1.03 & 0.663 \\
\hline Citrate & 24.11 & 35.68 & 30.07 & 22.33 & 24.48 & 23.65 & 28.52 & 20.79 & 16.76 & 26.57 & 20.44 & 0.174 \\
\hline Fumarate & 11.65 & 11.93 & 13.40 & 5.67 & 11.31 & 15.20 & 11.06 & 14.96 & 10.63 & 9.66 & 9.18 & 0.579 \\
\hline Glycerate & 0.37 & 0.34 & 0.28 & 0.23 & 0.38 & 0.33 & 0.32 & 0.53 & 0.31 & 0.33 & 0.43 & 0.259 \\
\hline Malate & 214.9 & 227.2 & 240.7 & 156.8 & 287.7 & 211.4 & 296.4 & 349.8 & 225.3 & 215.0 & 365.0 & 0.180 \\
\hline Pentonate & 0.19 & 0.25 & 0.25 & 0.14 & 0.18 & 0.24 & 0.26 & 0.28 & 0.21 & 0.22 & 0.00 & 0.956 \\
\hline Quinate & 5.46 & 4.67 & 3.30 & 4.11 & 4.12 & 3.50 & 4.79 & 5.14 & 4.93 & 4.94 & 3.40 & 0.812 \\
\hline Succinate & 30.19 & 26.82 & 29.72 & 14.61 & 27.20 & 32.67 & 29.01 & 36.85 & 27.05 & 28.42 & 26.86 & 0.220 \\
\hline Threonate & 0.27 & 0.25 & 0.32 & 0.18 & 0.24 & 0.28 & 0.28 & 0.44 & 0.34 & 0.31 & 0.29 & 0.078 \\
\hline
\end{tabular}




\begin{tabular}{|c|c|c|c|c|c|c|c|c|c|c|c|c|}
\hline \multirow[b]{2}{*}{ Sugars } & \multicolumn{4}{|c|}{ Control } & \multirow[b]{2}{*}{10} & \multicolumn{6}{|c|}{ Mycorrhizal } & \multirow[b]{2}{*}{$p$ value } \\
\hline & 2 & 4 & 5 & 8 & & 1 & 2 & 4 & 5 & 10 & 11 & \\
\hline Deoxyhexose & 0.53 & 0.62 & 0.55 & 0.48 & 0.65 & 0.63 & 0.72 & 0.59 & 0.62 & 0.70 & 0.59 & 0.087 \\
\hline Fructose & 26.65 & 18.49 & 19.04 & 17.74 & 24.76 & 20.57 & 27.97 & 14.28 & 18.34 & 41.82 & 11.52 & 0.831 \\
\hline Glucose & 6.55 & 4.49 & 4.22 & 5.23 & 9.86 & 4.86 & 9.01 & 3.72 & 4.71 & 14.30 & 2.54 & 0.832 \\
\hline Hexoaldose & 0.83 & 0.70 & 0.52 & 0.76 & 0.80 & 0.77 & 0.70 & 0.61 & 0.69 & 1.36 & 0.46 & 0.771 \\
\hline Hexoketose & 0.92 & 1.17 & 0.90 & 1.12 & 1.51 & 1.22 & 1.47 & 1.49 & 1.49 & 1.51 & 0.99 & 0.126 \\
\hline Pentose 1 & 0.41 & 0.54 & 0.57 & 0.39 & 0.75 & 0.53 & 0.60 & 0.66 & 0.48 & 0.70 & 0.65 & 0.370 \\
\hline Pentose 2 & 0.47 & 0.64 & 0.66 & 0.57 & 1.21 & 0.71 & 0.58 & 0.73 & 0.59 & 0.88 & 0.65 & 0.902 \\
\hline Pentose 3 & 0.43 & 0.39 & 0.45 & 0.29 & 0.46 & 0.38 & 0.42 & 0.57 & 0.39 & 0.48 & 0.34 & 0.590 \\
\hline Sucrose & 75.5 & 81.0 & 56.4 & 35.9 & 79.2 & 76.8 & 86.2 & 100.0 & 83.4 & 126.4 & 44.9 & 0.173 \\
\hline \multicolumn{13}{|l|}{ Others } \\
\hline Ethanolamine & 2.08 & 1.99 & 1.70 & 1.55 & 3.51 & 1.36 & 2.31 & 2.73 & 2.27 & 3.00 & 5.09 & 0.339 \\
\hline Hexitol & 0.17 & 0.18 & 0.16 & 0.14 & 0.16 & 0.16 & 0.19 & 0.15 & 0.13 & 0.16 & 0.07 & 0.273 \\
\hline myo-Inositol & 30.66 & 25.44 & 24.21 & 18.60 & 31.51 & 28.65 & 27.58 & 36.30 & 24.07 & 38.38 & 21.03 & 0.394 \\
\hline Pentol & 0.36 & 0.44 & 0.41 & 0.29 & 0.39 & 0.45 & 0.56 & 0.38 & 0.39 & 0.48 & 0.32 & 0.234 \\
\hline Phosphate & 94.0 & 332.2 & 275.1 & 190.8 & 239.7 & 254.4 & 295.2 & 225.3 & 309.9 & 297.9 & 338.7 & 0.220 \\
\hline
\end{tabular}

Control $n=5$, mycorrhizal $n=6, p$ values were calculated with Welch Two Sample t-test, values $<0.05$ 


\section{Chapter 4: General discussion and outlook}

Nitrogen (N) supply and symbiosis with ectomycorrhizal fungi (EMF) are key factors for tree development. Nutrients, phytohormones, and defense compounds are present in xylem saps (reviews: Carella et al., 2016; Rodríguez-Celma et al., 2016) and are transported acropetally by transpirational pull and root pressure. Information on the influence of $\mathrm{N}$ availability or EMFinteraction on tree xylem sap is scarce. In the present work, I analyzed the effects of Populus $\mathrm{x}$ canescens $\mathrm{N}$ nutrition and $P$. x canescens - Laccaria bicolor interaction on xylem sap composition and plant defense. I characterized the influence of increasing nitrate and ammonium concentrations on the one hand and the impact of EMF-interaction on the other hand on the poplar xylem sap metabolome and proteome and on systemic responses of the leaf transcriptome. The significance of xylem sap for plant defenses is understudied. Therefore, the present comprehensive multi-omics study fills an important knowledge gap. To analyze the resistance of poplars against microbes in response to these treatments, new test-systems were set-up. A micro-scale xylem sap assay allows us to monitor the development of xylem sapinhabiting bacteria in small xylem sap quantities and the newly established detached leaf assay gives the opportunity to test $P$. x canescens resistance towards a necrotrophic pathogen.

One goal of this PhD project was to identify xylem sap signaling compounds induced by $\mathrm{N}$ availability or EMF-interaction. Unfortunately, we were not successful to detect an obvious new candidate metabolite or protein. A mechanistic functional analysis of putative candidate compounds was beyond the scope of this work. Although the xylem sap analysis was very comprehensive, small peptides could not be analyzed due to the detection limit for small proteins of the method applied here. It has been shown, that soil nutrient status and rhizobial symbiosis are communicated to the shoots via xylem-mobile peptides (Okamoto et al., 2013, 2016; Staehelin et al., 2011). These peptides are usually smaller than 20 amino acids $(<2.4 \mathrm{kDa})$ (Okamoto et al., 2015). The lower detection limit of the proteomics approach used here was $6.5 \mathrm{kDa}$. If $\mathrm{N}$ availability or EMF-interaction had led to the induction of xylem-mobile small signaling peptides, they would not have been identified. Additional experiments using the proteome method according to Okamoto et al. (2015) are recommended to test the presence of small peptides in xylem sap of ECM trees.

Another reason, which may explain the rather small differences between the xylem sap 
metabolome and proteome of control and mycorrhizal plants, might be the fertilization regime applied to the plants during the experiment. We worked with daily irrigation of nutrient solution containing $2 \mathrm{mM} \mathrm{KNO}_{3}$ as $\mathrm{N}$ source. This $\mathrm{N}$ form and concentration was chosen because it served in the $\mathrm{N}$ experiments (chapter 2 ) as the control condition for well-supplied plants. This $\mathrm{N}$ concentration has also been used in previous studies with poplars (e.g. Luo et al., 2015). Under this treatment, no difference was observed in shoot $\mathrm{N}$ content between control and mycorrhizal plants, implying that nitrogen was supplied in non-limiting amounts. Earlier studies showed that nitrogen-limiting conditions can enhance the fraction of ectomycorrhizal root tips (Runion et al., 1997; Wallander \& Nylund, 1992). Since a main benefit of ectomycorrhizas to their host is facilitation of $\mathrm{N}$ supply under $\mathrm{N}$ limiting conditions (S. Smith \& Read, 2008), the current $\mathrm{N}$ sufficient conditions may have prevented a stronger impact of ECM on xylem sap composition. Lowering the $\mathrm{N}$ supply during cultivation and thereby increasing the plants' need for a functional symbiosis may therefore result in an enhanced difference of the response of the plant to the fungus. When the $\mathrm{N}$ supply is too low, plants might suffer from fungal interaction (Ågren et al., 2019). When searching for small signaling peptides or metabolites, careful adjustment of $\mathrm{N}$ availability will be useful to stimulate higher mycorrhization rates and trigger more pronounced xylem sap compositional modifications.

Despite the experimental limitations, interaction of $P . \times$ canescens with $L$. bicolor led to an increase in a DIR1-like protein in xylem sap. DIR1 and DIR1-like proteins accumulate in the phloem subsequent to local pathogen infection and are necessary to induce systemic acquired resistance in distal tissues (Isaacs et al., 2016). DIR 1 and DIR1-like proteins can bind other compounds (Chanda et al., 2011; Chaturvedi et al., 2012; H. W. Jung et al., 2009) and successfully transmit signals for the induction of systemic resistance through the phloem. Here, we show DIR1-like accumulation for the first time in response to root symbiosis and in the xylem sap. While it might be possible that DIR1-like originated from the phloem and was transferred to the xylem, it is also possible that the protein was de novo synthesized in the roots and plays a role in mycorrhizainduced long-distance signaling. The role of DIR1 and DIR1-like proteins in xylem sap needs to be further investigated. 
An important goal of this thesis was to establish test systems for poplar as a read-out to measure changes in susceptibility or resistance towards biotic cues. Here, we established a leaf assay for P. x canescens to assess the resistance towards a necrotrophic pathogen. The bioassay was successful in terms of achieving consistent infections of poplar leaves. Pre-tests, not included in this thesis (according to Spiers, 1978), with leaf disks showed highly variable outcomes and strong interference with the wounding caused by cutting the disks. While this problem was overcome by using whole leaves, we noted the appearance of vein necrosis during the incubation time, caused by another, hemi-biotrophic fungus. It will therefore be necessary to repeat the experiments separating effects of the target pathogen from those of endophytes. For the quantification of fungal growth, a molecular quantification technique is desirable. An interesting and important outcome our study was that the susceptibility towards the hemi-biotrophic fungus was enhanced under high $\mathrm{NH}_{4}{ }^{+}$-supply.

Poplars are nutrient-demanding species and poplar plantations are usually fertilized to achieve high yields (Bredemeier et al., 2015). Our study suggests that high $\mathrm{N}$ fertilization may have negative consequences for pathogen resistance because of higher susceptibility towards (hemi)biotrophic leaf pathogens and facilitated growth of a vascular endophyte in xylem sap from poplars treated with high amounts of $\mathrm{NH}_{4}{ }^{+}$. These findings agree with studies in crop plants (Mur et al., 2017). A significant influence of $\mathrm{N}$ availability or ECM interaction on biotic stress defense was furthermore supported by the leaf transcriptome data. The leaves showed upregulated JAdependent defense responses in high $\mathrm{N}$ treated poplars. This pathway generally antagonizes defense against biotrophic and hemi-biotrophic pathogens (e.g. Glazebrook, 2005). Interaction with ectomycorrhizal fungi L. bicolor appears to induce defenses against a broader spectrum of pests and pathogens than N by activation of SA- and JA-dependent defense responses. Since high $\mathrm{N}$ deposition has negative effects on ectomycorrhizal fungi (Wallenda \& Kottke, 1998), the beneficial effects of ECM, such as controlling for phytophagus insects (Kaling et al. 2018), may suffer from excess $\mathrm{N}$ availability in ecosystems. Our results are of special interest in times of intense nitrogen application to agricultural land (Baumgarten et al., 2018) and increasing Ndeposition in forest soils (Rennenberg \& Dannenmann, 2015). Under these conditions, trees may increasingly be endangered by emerging biotic pests (Hinze \& John, 2020) and pathogens 
Chapter 4: General discussion and outlook

(Hultberg et al., 2020). The results of this thesis emphasize the urge to find ways to PRoTECT trees from biotic threats. 


\section{References}

\section{References}

Abreu, I. N., Johansson, A. I., Sokołowska, K., Niittylä, T., Sundberg, B., Hvidsten, T. R., Street, N. R., \& Moritz, T. (2020). A metabolite roadmap of the wood-forming tissue in Populus tremula. New Phytologist. https://doi.org/10.1111/nph.16799

Ågren, G. I., Hyvönen, R., \& Baskaran, P. (2019). Ectomycorrhiza, Friend or Foe? Ecosystems, 22(7), 15611572. https://doi.org/10.1007/s10021-019-00356-y

Antico, C. J., Colon, C., Banks, T., \& Ramonell, K. M. (2012). Insights into the role of jasmonic acidmediated defenses against necrotrophic and biotrophic fungal pathogens. Frontiers in Biology, 7(1), 48-56. https://doi.org/10.1007/s11515-011-1171-1

Arisi, A.-C. M., Noctor, G., Foyer, C. H., \& Jouanin, L. (1997). Modification of thiol contents in poplars (Populus tremula $\times$ P. alba) overexpressing enzymes involved in glutathione synthesis. Planta, 203(3), 362-372. https://doi.org/10.1007/s004250050202

Armenteros, J. J. A., Tsirigos, K. D., Sønderby, C. K., Petersen, T. N., Winther, O., Brunak, S., Heijne, G. von, \& Nielsen, H. (2019). SignalP 5.0 improves signal peptide predictions using deep neural networks. Nature Biotechnology, 37(4), 420. https://doi.org/10.1038/s41587-019-0036-z

Ausubel, F. M. (2005). Are innate immune signaling pathways in plants and animals conserved? Nature Immunology, 6(10), 973-979. https://doi.org/10.1038/ni1253

Babicki, S., Arndt, D., Marcu, A., Liang, Y., Grant, J. R., Maciejewski, A., \& Wishart, D. S. (2016).

Heatmapper: Web-enabled heat mapping for all. Nucleic Acids Research, 44(W1), W147-W153. https://doi.org/10.1093/nar/gkw419

Bai, H., Euring, D., Volmer, K., Janz, D., \& Polle, A. (2013). The nitrate transporter (NRT) gene family in poplar. PLoS ONE, 8(8). https://doi.org/10.1371/journal.pone.0072126

Barbehenn, R. V., \& Peter Constabel, C. (2011). Tannins in plant-herbivore interactions. Phytochemistry, 72(13), 1551-1565. https://doi.org/10.1016/j.phytochem.2011.01.040 
Barker, H. L., Holeski, L. M., \& Lindroth, R. L. (2019). Independent and interactive effects of plant genotype and environment on plant traits and insect herbivore performance: A meta-analysis with Salicaceae. Functional Ecology, 33(3), 422-435. https://doi.org/10.1111/1365-2435.13249

Bates, D., Mächler, M., Bolker, B., \& Walker, S. (2015). Fitting linear mixed-effects models using Ime4. Journal of Statistical Software, 67(1). https://doi.org/10.18637/jss.v067.i01

Baum, C., \& Makeschin, F. (2000). Effects of nitrogen and phosphorus fertilization on mycorrhizal formation of two poplar clones (Populus trichocarpa and P. tremula $\mathrm{x}$ tremuloides). Journal of Plant Nutrition and Soil Science, 163(5), 491-497. https://doi.org/10.1002/15222624(200010)163:5<491::AID-JPLN491>3.0.CO;2-3

Baumgarten, C., Bilharz, M., Döring, U., Eisold, A., Friedrich, B., Frische, T., Gather, C., Günther, D., Große Wichtrup, W., Hofmeier, K., Hofmeier, M., Jering, A., Klatt, A., Köder, L., Lamfried, D., Langner, M., Leujak, W., Marx, M., Matthey, A., ... Zimmermann, A. (2018). Daten zur Umwelt 2018: Umwelt und Landwirtschaft. Umweltbundesamt. https://www.umweltbundesamt.de/publikationen/daten-zur-umwelt-2018-umweltlandwirtschaft

Bergmeyer, H. U. (1974). Methods of Enzymatic Analysis (2. Aufl.). Chemie Weinheim.

Bernsdorff, F., Döring, A.-C., Gruner, K., Schuck, S., Bräutigam, A., \& Zeier, J. (2016). Pipecolic acid orchestrates plant systemic acquired resistance and defense priming via salicylic acid-dependent and -independent pathways. The Plant Cell, 28(1), 102-129. https://doi.org/10.1105/tpc.15.00496

BioBam Bioinformatics. (2019). OmicsBox-Bioinformatics made easy (1.2.4) [Computer software]. BioBam Bioinformatics. https://www.biobam.com/omicsbox Bonfante, P., \& Genre, A. (2010). Mechanisms underlying beneficial plant-fungus interactions in mycorrhizal symbiosis. Nature Communications, 1, 48. https://doi.org/10.1038/ncomms1046 
References

Bradford, M. M. (1976). A rapid and sensitive method for the quantitation of microgram quantities of protein utilizing the principle of protein-dye binding. Anal Biochem, 72. https://doi.org/10.1016/0003-2697(76)90527-3

Bredemeier, M., Busch, G., Hartmann, L., Jansen, M., Richter, F., \& Lamersdorf, N. P. (2015). Fast Growing Plantations for Wood Production - Integration of Ecological Effects and Economic Perspectives. Frontiers in Bioengineering and Biotechnology, 3.

https://doi.org/10.3389/fbioe.2015.00072

Bryant, J. P., Clausen, T. P., Reichardt, P. B., McCarthy, M. C., \& Werner, R. A. (1987). Effect of nitrogen fertilization upon the secondary chemistry and nutritional value of quaking aspen (Populus tremuloides Michx.) leaves for the large aspen tortrix (Choristoneura conflictana (Walker)). Oecologia, 73(4), 513-517. https://doi.org/10.1007/BF00379408

Bücking, H., \& Heyser, W. (2001). Microautoradiographic localization of phosphate and carbohydrates in mycorrhizal roots of Populus tremula $\times$ Populus alba and the implications for transfer processes in ectomycorrhizal associations. Tree Physiology, 21.

Call, A. C., \& St. Clair, S. B. (2017). Outbreak of Drepanopeziza fungus in aspen forests and variation in stand susceptibility: Leaf functional traits, compensatory growth and phenology. Tree Physiology, 37(9), 1198-1207. https://doi.org/10.1093/treephys/tpx088

Cameron, R. K., Paiva, N. L., Lamb, C. J., \& Dixon, R. A. (1999). Accumulation of salicylic acid and PR-1 gene transcripts in relation to the systemic acquired resistance (SAR) response induced by Pseudomonas syringae pv. Tomato in Arabidopsis. Physiological and Molecular Plant Pathology, 55(2), 121-130. https://doi.org/10.1006/pmpp.1999.0214

Campos-Soriano, L., García-Martínez, J., \& Segundo, B. S. (2012). The arbuscular mycorrhizal symbiosis promotes the systemic induction of regulatory defence-related genes in rice leaves and confers resistance to pathogen infection. Molecular Plant Pathology, 13(6), 579-592. 
Carella, P., Wilson, D. C., Kempthorne, C. J., \& Cameron, R. K. (2016). Vascular sap proteomics: Providing insight into long-distance signaling during stress. Frontiers in Plant Science, 7. https://doi.org/10.3389/fpls.2016.00651

Chalot, M., Blaudez, D., \& Brun, A. (2006). Ammonia: A candidate for nitrogen transfer at the mycorrhizal interface. Trends in Plant Science, 11(6), 263-266. https://doi.org/10.1016/j.tplants.2006.04.005

Chalot, M., \& Brun, A. (1998). Physiology of organic nitrogen acquisition by ectomycorrhizal fungi and ectomycorrhizas. FEMS Microbiology Reviews, 22(1), 21-44. https://doi.org/10.1111/j.15746976.1998.tb00359.x

Champigny, M. J., Isaacs, M., Carella, P., Faubert, J., Fobert, P. R., \& Cameron, R. K. (2013). Long distance movement of DIR1 and investigation of the role of DIR1-like during systemic acquired resistance in Arabidopsis. Frontiers in Plant Science, 4. https://doi.org/10.3389/fpls.2013.00230

Chanda, B., Xia, Y., Mandal, M. K., Yu, K., Sekine, K.-T., Gao, Q., Selote, D., Hu, Y., Stromberg, A., Navarre, D., Kachroo, A., \& Kachroo, P. (2011). Glycerol-3-phosphate is a critical mobile inducer of systemic immunity in plants. Nature Genetics, 43(5), 421-427. https://doi.org/10.1038/ng.798

Chandanie, W. A., Kubota, M., \& Hyakumachi, M. (2006). Interactions between plant growth promoting fungi and arbuscular mycorrhizal fungus Glomus mosseae and induction of systemic resistance to anthracnose disease in cucumber. Plant and Soil, 286(1), 209-217. https://doi.org/10.1007/s11104-006-9038-y

Chang, S., Puryear, J., \& Cairney, J. (1993). A simple and efficient method for isolating RNA from pine trees. Plant Molecular Biology Reporter, 11(2), 113-116. https://doi.org/10.1007/BF02670468

Chaturvedi, R., Venables, B., Petros, R. A., Nalam, V., Li, M., Wang, X., Takemoto, L. J., \& Shah, J. (2012). An abietane diterpenoid is a potent activator of systemic acquired resistance. The Plant Journal, 71(1), 161-172. https://doi.org/10.1111/j.1365-313X.2012.04981.x

Chen, S., Zhou, Y., Chen, Y., \& Gu, J. (2018). fastp: An ultra-fast all-in-one FASTQ preprocessor. Bioinformatics, 34(17), i884-i890. https://doi.org/10.1093/bioinformatics/bty560 
Choi, J., Summers, W., \& Paszkowski, U. (2018). Mechanisms underlying establishment of arbuscular mycorrhizal symbioses. Annual Review of Phytopathology, 56(1), 135-160. https://doi.org/10.1146/annurev-phyto-080516-035521

Chowdhury, S., Basu, A., \& Kundu, S. (2017). Biotrophy-necrotrophy switch in pathogen evoke differential response in resistant and susceptible sesame involving multiple signaling pathways at different phases. Scientific Reports, 7(1), 1-17. https://doi.org/10.1038/s41598-017-17248-7

Cope, K. R., Bascaules, A., Irving, T. B., Venkateshwaran, M., Maeda, J., Garcia, K., Rush, T. A., Ma, C., Labbé, J., Jawdy, S., Steigerwald, E., Setzke, J., Fung, E., Schnell, K. G., Wang, Y., Schleif, N., Bücking, H., Strauss, S. H., Maillet, F., ... Ané, J.-M. (2019). The ectomycorrhizal fungus Laccaria bicolor produces lipochitooligosaccharides and uses the common symbiosis pathway to colonize Populus roots. The Plant Cell, 31(10), 2386-2410. https://doi.org/10.1105/tpc.18.00676

Couto, D., \& Zipfel, C. (2016). Regulation of pattern recognition receptor signalling in plants. Nature Reviews Immunology, 16(9), 537-552. https://doi.org/10.1038/nri.2016.77

Couturier, J., Montanini, B., Martin, F., Brun, A., Blaudez, D., \& Chalot, M. (2007). The expanded family of ammonium transporters in the perennial poplar plant. New Phytologist, 174(1), 137-150. https://doi.org/10.1111/j.1469-8137.2007.01992.x

Cox, J., \& Mann, M. (2008). MaxQuant enables high peptide identification rates, individualized p.p.b.range mass accuracies and proteome-wide protein quantification. Nature Biotechnology, 26(12), 1367-1372. https://doi.org/10.1038/nbt.1511

Craig, L. S., Palmer, M. A., Richardson, D. C., Filoso, S., Bernhardt, E. S., Bledsoe, B. P., Doyle, M. W., Groffman, P. M., Hassett, B. A., Kaushal, S. S., Mayer, P. M., Smith, S. M., \& Wilcock, P. R. (2008). Stream restoration strategies for reducing river nitrogen loads. Frontiers in Ecology and the Environment, 6(10), 529-538. https://doi.org/10.1890/070080 
Crawford, N. M., \& Forde, B. G. (2002). Molecular and developmental biology of inorganic nitrogen nutrition. The Arabidopsis Book / American Society of Plant Biologists, 1. https://doi.org/10.1199/tab.0011

Cripps, C. L. (2001). Mycorrhizal fungi of aspen forests: Natural occurrence and potential applications. 15. Cui, H., Tsuda, K., \& Parker, J. E. (2015). Effector-triggered immunity: From pathogen perception to robust defense. Annual Review of Plant Biology, 66(1), 487-511. https://doi.org/10.1146/annurev-arplant-050213-040012

Dafoe, N. J., \& Constabel, C. P. (2009). Proteomic analysis of hybrid poplar xylem sap. Phytochemistry, 70(7), 856-863. https://doi.org/10.1016/j.phytochem.2009.04.016

Dangl, J., \& Jones, J. (2001). Plant pathogens and integrated defence responses to infection. Nature, 411(6839), 826-833. https://doi.org/10.1038/35081161

Day, W. R. (1924). The watermark disease of the cricket bat Willow (Salix caerulea). Oxford Forestry Memoirs, 3. https://www.cabdirect.org/cabdirect/abstract/19251100597

de la Noval, B., Pérez, E., Martínez, B., León, O., Martínez-Gallardo, N., \& Délano-Frier, J. (2007). Exogenous systemin has a contrasting effect on disease resistance in mycorrhizal tomato (Solanum lycopersicum) plants infected with necrotrophic or hemibiotrophic pathogens. Mycorrhiza, 17(5), 449-460. https://doi.org/10.1007/s00572-007-0122-9

Delaney, K. J., Wawrzyniak, M., Lemańczyk, G., Wrzesińska, D., \& Piesik, D. (2013). Synthetic cis-jasmone exposure induces wheat and barley volatiles that repel the pest cereal leaf beetle, Oulema melanopus L. Journal of Chemical Ecology, 39(5), 620-629. https://doi.org/10.1007/s10886-0130281-4

Dempsey, D. A., \& Klessig, D. F. (2012). SOS - too many signals for systemic acquired resistance? Trends in Plant Science, 17(9), 538-545. https://doi.org/10.1016/j.tplants.2012.05.011 
Desaki, Y., Kohari, M., Shibuya, N., \& Kaku, H. (2019). MAMP-triggered plant immunity mediated by the LysM-receptor kinase CERK1. Journal of General Plant Pathology, 85(1), 1-11. https://doi.org/10.1007/s10327-018-0828-x

Di Battista, C., Selosse, M.-A., Bouchard, D., Stenström, E., \& Le Tacon, F. (1996). Variations in symbiotic efficiency, phenotypic characters and ploidy level among different isolates of the ectomycorrhizal basidiomycete Laccaria bicolor strain S 238. Mycological Research, 100(11), 1315-1324. https://doi.org/10.1016/S0953-7562(96)80058-X

Dickson, R. E., Vogelmann, T. C., \& Larson, P. R. (1985). Glutamine transfer from xylem to phloem and translocation to developing leaves of Populus deltoides. Plant Physiology, 77(2), 412-417. https://doi.org/10.1104/pp.77.2.412

Dietz, S., Bülow, J. von, Beitz, E., \& Nehls, U. (2011). The aquaporin gene family of the ectomycorrhizal fungus Laccaria bicolor: Lessons for symbiotic functions. New Phytologist, 190(4), 927-940. https://doi.org/10.1111/j.1469-8137.2011.03651.x

Dluzniewska, P., Gessler, A., Dietrich, H., Schnitzler, J.-P., Teuber, M., \& Rennenberg, H. (2007). Nitrogen uptake and metabolism in Populus $\times$ canescens as affected by salinity. New Phytologist, 173(2), 279-293. https://doi.org/10.1111/j.1469-8137.2006.01908.x

Du, Z., Zhou, X., Ling, Y., Zhang, Z., \& Su, Z. (2010). agriGO: A GO analysis toolkit for the agricultural community. Nucleic Acids Research, 38(suppl_2), W64-W70. https://doi.org/10.1093/nar/gkq310

Escher, P., Eiblmeier, M., Hetzger, I., \& Rennenberg, H. (2004). Spatial and seasonal variation in amino compounds in the xylem sap of a mistletoe (Viscum album) and its hosts (Populus spp. And Abies alba). Tree Physiology, 24(6), 639-650. https://doi.org/10.1093/treephys/24.6.639

Euring, D., Bai, H., Janz, D., \& Polle, A. (2014). Nitrogen-driven stem elongation in poplar is linked with wood modification and gene clusters for stress, photosynthesis and cell wall formation. $B M C$ Plant Biology, 14(1), 391. https://doi.org/10.1186/s12870-014-0391-3 
Euring, D., \& Polle, A. (2015). Photosynthetic nitrogen use efficiency of two poplar varieties commonly grown in short rotation coppice plantations and implications for fertiliser management. Bioenergy from Dendromass for the Sustainable Development of Rural Areas.

Fabisch, T., Gershenzon, J., \& Unsicker, S. B. (2019). Specificity of herbivore defense responses in a woody plant, black poplar (Populus nigra). Journal of Chemical Ecology, 45(2), 162-177. https://doi.org/10.1007/s10886-019-01050-y

Fernández, I., Cosme, M., Stringlis, I. A., Yu, K., Jonge, R. de, Wees, S. M. van, Pozo, M. J., Pieterse, C. M. J., \& Heijden, M. G. A. van der. (2019). Molecular dialogue between arbuscular mycorrhizal fungi and the nonhost plant $<i<$ Arabidopsis thaliana $<$ i $>$ switches from initial detection to antagonism. New Phytologist, 223(2), 867-881. https://doi.org/10.1111/nph.15798

Feussner, I., \& Polle, A. (2015). What the transcriptome does not tell-Proteomics and metabolomics are closer to the plants' patho-phenotype. Current Opinion in Plant Biology, 26, 26-31. https://doi.org/10.1016/j.pbi.2015.05.023

Feussner, K., \& Feussner, I. (2019). Comprehensive LC-MS-based metabolite fingerprinting approach for plant and fungal-derived samples. In High-Throughput Metabolomics: Methods and Protocols. Springer Science+Business Media, LLC, part of Springer Nature.

Floerl, S., Druebert, C., Majcherczyk, A., Karlovsky, P., Kües, U., \& Polle, A. (2008). Defence reactions in the apoplastic proteome of oilseed rape (Brassica napus var. Napus) attenuate Verticillium longisporum growth but not disease symptoms. BMC Plant Biology, 8(1), 129. https://doi.org/10.1186/1471-2229-8-129

Floerl, S., Majcherczyk, A., Possienke, M., Feussner, K., Tappe, H., Gatz, C., Feussner, I., Kües, U., \& Polle, A. (2012). Verticillium longisporum infection affects the leaf apoplastic proteome, metabolome, and cell wall properties in Arabidopsis thaliana. PLOS ONE, 7(2). https://doi.org/10.1371/journal.pone.0031435 
References

Fritz, M., Jakobsen, I., Lyngkjær, M. F., Thordal-Christensen, H., \& Pons-Kühnemann, J. (2006). Arbuscular mycorrhiza reduces susceptibility of tomato to Alternaria solani. Mycorrhiza, 16(6), 413-419. https://doi.org/10.1007/s00572-006-0051-z

Furukawa, J., Abe, Y., Mizuno, H., Matsuki, K., Sagawa, K., Kojima, M., Sakakibara, H., Iwai, H., \& Satoh, S. (2011). Seasonal fluctuation of organic and inorganic components in xylem sap of Populus nigra. Plant Root, 5, 56-62. https://doi.org/10.3117/plantroot.5.56

Gago, J., Daloso, D. de M., Figueroa, C. M., Flexas, J., Fernie, A. R., \& Nikoloski, Z. (2016). Relationships of leaf net photosynthesis, stomatal conductance, and mesophyll conductance to primary metabolism: A multispecies meta-analysis approach. Plant Physiology, 171(1), 265-279. https://doi.org/10.1104/pp.15.01660

Gan, H., Jiao, Y., Jia, J., Wang, X., Li, H., Shi, W., Peng, C., Polle, A., \& Luo, Z.-B. (2016). Phosphorus and nitrogen physiology of two contrasting poplar genotypes when exposed to phosphorus and/or nitrogen starvation. Tree Physiology, 36(1), 22-38. https://doi.org/10.1093/treephys/tpv093

Gange, A. C., Gane, D. R. J., Chen, Y., \& Gong, M. (2005). Dual colonization of Eucalyptus urophylla ST Blake by arbuscular and ectomycorrhizal fungi affects levels of insect herbivore attack. Agricultural and Forest Entomology, 7(3), 253-263. https://doi.org/10.1111/j.14619555.2005.00268.x

García-Alcalde, F., García-López, F., Dopazo, J., \& Conesa, A. (2011). Paintomics: A web based tool for the joint visualization of transcriptomics and metabolomics data. Bioinformatics, 27(1), 137-139. https://doi.org/10.1093/bioinformatics/btq594

Genre, A., Chabaud, M., Balzergue, C., Puech-Pagès, V., Novero, M., Rey, T., Fournier, J., Rochange, S., Bécard, G., Bonfante, P., \& Barker, D. G. (2013). Short-chain chitin oligomers from arbuscular mycorrhizal fungi trigger nuclear $\mathrm{Ca}_{2}{ }^{+}$spiking in Medicago truncatula roots and their production is enhanced by strigolactone. New Phytologist, 198(1), 190-202. https://doi.org/10.1111/nph.12146 
Gessler, A., Kopriva, S., \& Rennenberg, H. (2004). Regulation of nitrate uptake at the whole-tree level: Interaction between nitrogen compounds, cytokinins and carbon metabolism. Tree Physiology, 24(12), 1313-1321. https://doi.org/10.1093/treephys/24.12.1313

Gessler, A., Schneider, S., Weber, P., Hanemann, U., \& Rennenberg, H. (1998). Soluble N compounds in trees exposed to high loads of N: A comparison between the roots of Norway spruce (Picea abies) and beech (Fagus sylvatica) trees grown under field conditions. New Phytologist, 138(3), 385-399. https://doi.org/10.1046/j.1469-8137.1998.00134.x

Glass, A. D. M., Britto, D. T., Kaiser, B. N., Kinghorn, J. R., Kronzucker, H. J., Kumar, A., Okamoto, M., Rawat, S., Siddiqi, M. Y., Unkles, S. E., \& Vidmar, J. J. (2002). The regulation of nitrate and ammonium transport systems in plants. Journal of Experimental Botany, 53(370), 855-864. https://doi.org/10.1093/jexbot/53.370.855

Glazebrook, J. (2005). Contrasting mechanisms of defense against biotrophic and necrotrophic pathogens. Annual Review of Phytopathology, 43(1), 205-227. https://doi.org/10.1146/annurev.phyto.43.040204.135923

Gobert, A., \& Plassard, C. (2008). The beneficial effect of mycorrhizae on N utilization by the host-plant: Myth or reality? In A. Varma (Hrsg.), Mycorrhiza: State of the Art, Genetics and Molecular Biology, Eco-Function, Biotechnology, Eco-Physiology, Structure and Systematics (S. 209-240). Springer. https://doi.org/10.1007/978-3-540-78826-3_11

Grassi, G., Millard, P., Wendler, R., Minotta, G., \& Tagliavini, M. (2002). Measurement of xylem sap amino acid concentrations in conjunction with whole tree transpiration estimates spring $\mathrm{N}$ remobilization by cherry (Prunus avium L.) trees. Plant, Cell \& Environment, 25(12), 1689-1699. https://doi.org/10.1046/j.1365-3040.2002.00949.x

Green, K. A., Berry, D., Feussner, K., Eaton, C. J., Ram, A., Mesarich, C. H., Solomon, P., Feussner, I., \& Scott, B. (o. J.). Lolium perenne apoplast metabolomics for identification of novel metabolites 
produced by the symbiotic fungus Epichloë festucae. New Phytologist, $n / a(n / a)$. https://doi.org/10.1111/nph.16528

Grothendieck, G. (2013). Non-linear regression with brute force. $R$ package version 0.2.

Grunze, N., Willmann, M., \& Nehls, U. (2004). The impact of ectomycorrhiza formation on monosaccharide transporter gene expression in poplar roots. New Phytologist, 164(1), 147-155.

Gunderson, J. J., Knight, J. D., \& Van Rees, K. C. J. (2007). Impact of ectomycorrhizal colonization of hybrid poplar on the remediation of diesel-contaminated soil. Journal of Environmental Quality, 36(4), 927-934. https://doi.org/10.2134/jeq2006.0260

Guttenberger, M. (2000). Arbuscules of vesicular-arbuscular mycorrhizal fungi inhabit an acidic compartment within plant roots. Planta, 211(3), 299-304.

https://doi.org/10.1007/s004250000324

Hakulinen, J. (1998). Nitrogen-induced reduction in leaf phenolic level is not accompanied by increased rust frequency in a compatible willow (Salix myrsinifolia)-Melampsora rust interaction. Physiologia Plantarum, 102(1), 101-110. https://doi.org/10.1034/j.1399-3054.1998.1020114.x Halldórsson, G., Sverrisson, H., Eyjólfsdóttir, G. G., \& Oddsdóttir, E. S. (2000). Ectomycorrhizae reduce damage to Russian larch by Otiorhyncus larvae. Scandinavian Journal of Forest Research, 15(3), 354-358. https://doi.org/10.1080/028275800447986

Hansen, H., \& Dörffling, K. (1999). Changes of free and conjugated abscisic acid and phaseic acid in xylem sap of drought-stressed sunflower plants. Journal of Experimental Botany, 50(339), 1599-1605. https://doi.org/10.1093/jxb/50.339.1599

Harding, S. A., Jarvie, M. M., Lindroth, R. L., \& Tsai, C.-J. (2009). A comparative analysis of phenylpropanoid metabolism, $\mathrm{N}$ utilization, and carbon partitioning in fast- and slow-growing Populus hybrid clones. Journal of Experimental Botany, 60(12), 3443-3452.

https://doi.org/10.1093/jxb/erp180 
Hartmann, M., Kim, D., Bernsdorff, F., Ajami-Rashidi, Z., Scholten, N., Schreiber, S., Zeier, T., Schuck, S., Reichel-Deland, V., \& Zeier, J. (2017). Biochemical principles and functional aspects of pipecolic acid biosynthesis in plant immunity. Plant Physiology, 174(1), 124-153.

https://doi.org/10.1104/pp.17.00222

Hartmann, M., \& Zeier, J. (2019). N-hydroxypipecolic acid and salicylic acid: A metabolic duo for systemic acquired resistance. Current Opinion in Plant Biology, 50, 44-57. https://doi.org/10.1016/j.pbi.2019.02.006

Häußermann, U., Bach, M., Klement, L., \& Breuer, L. (2019). Stickstoff-Flächenbilanzen für Deutschland mit Regionalgliederung Bundesländer und Kreise - Jahre 1995 bis 2017. Umweltbundesamt. https://www.umweltbundesamt.de/publikationen/stickstoff-flaechenbilanzen-fuer-deutschland Heale, J. B., \& Karapapa, V. K. (1999). The Verticillium threat to Canada's major oilseed crop: Canola. Canadian Journal of Plant Pathology, 21(1), 1-7. https://doi.org/10.1080/07060661.1999.10600114

Heberle, H., Meirelles, G. V., da Silva, F. R., Telles, G. P., \& Minghim, R. (2015). InteractiVenn: A webbased tool for the analysis of sets through Venn diagrams. BMC Bioinformatics, 16(1), 169. https://doi.org/10.1186/s12859-015-0611-3

Hébert, C., Charles, M. T., Gauthier, L., Willemot, C., Khanizadeh, S., \& Cousineau, J. (2000). Strawberry proanthocyanidins: Biochemical markers for Botrytis cinerea resistance and shelf-life predictability. IV International Strawberry Symposium 567, 659-662.

Herrfurth, C., \& Feussner, I. (2020). Quantitative jasmonate profiling using a high-throughput UPLCnanoESI-MS/mMS method. In A. Champion \& L. Laplaze (Hrsg.), Jasmonate in Plant Biology: Methods and Protocols (S. 169-187). Springer US. https://doi.org/10.1007/978-1-0716-0142$6 \_13$ 
References

Hewitt, E. J. (1952). Sand and water culture methods used in the study of plant nutrition. Technical Communication No. 22 of the Commonwealth Bureau of Horticulture and Plantation Crops, 22, $241+$.

Hinze, J., \& John, R. (2020). Effects of heat on the dispersal performance of Ips typographus. Journal of Applied Entomology, 144(1-2), 144-151. https://doi.org/10.1111/jen.12718

Hirner, A., Ladwig, F., Stransky, H., Okumoto, S., Keinath, M., Harms, A., Frommer, W. B., \& Koch, W. (2006). Arabidopsis LHT1 is a high-affinity transporter for cellular amino acid uptake in both root epidermis and leaf mesophyll. The Plant Cell, 18(8), 1931-1946.

https://doi.org/10.1105/tpc.106.041012

Hofvander, P., Ischebeck, T., Turesson, H., Kushwaha, S. K., Feussner, I., Carlsson, A. S., \& Andersson, M. (2016). Potato tuber expression of Arabidopsis WRINKLED1 increase triacylglycerol and membrane lipids while affecting central carbohydrate metabolism. Plant Biotechnology Journal, 14(9), 1883-1898. https://doi.org/10.1111/pbi.12550

Hopkins, D. L. (1989). Xylella fastidiosa: Xylem-limited bacterial pathogen of plants. Annual review of phytopathology, 27(1), 271-290.

Horianopoulos, L. C., Hu, G., Caza, M., Schmitt, K., Overby, P., Johnson, J. D., Valerius, O., Braus, G. H., \& Kronstad, J. W. (2020). The novel J-domain protein Mrj1 is required for mitochondrial respiration and virulence in Cryptococcus neoformans. MBio, 11(3). https://doi.org/10.1128/mBio.01127-20 Hörtensteiner, S., \& Feller, U. (2002). Nitrogen metabolism and remobilization during senescence. Journal of Experimental Botany, 53(370), 927-937. https://doi.org/10.1093/jexbot/53.370.927 Hothorn, T., Bretz, F., \& Westfall, P. (2008). Simultaneous inference in general parametric models. Biometrical Journal, 50(3), 346-363. https://doi.org/10.1002/bimj.200810425

Huang, Y., Liu, H., Jia, Z., Fang, Q., \& Luo, K. (2012). Combined expression of antimicrobial genes (Bbchit1 and LJAMP2) in transgenic poplar enhances resistance to fungal pathogens. Tree Physiology, 32(10), 1313-1320. https://doi.org/10.1093/treephys/tps079 
Hultberg, T., Sandström, J., Felton, A., Öhman, K., Rönnberg, J., Witzell, J., \& Cleary, M. (2020). Ash dieback risks an extinction cascade. Biological Conservation, 244, 108516. https://doi.org/10.1016/j.biocon.2020.108516

Hunt, E., Gattolin, S., Newbury, H. J., Bale, J. S., Tseng, H.-M., Barrett, D. A., \& Pritchard, J. (2010). A mutation in amino acid permease AAP6 reduces the amino acid content of the Arabidopsis sieve elements but leaves aphid herbivores unaffected. Journal of Experimental Botany, 61(1), 55-64. https://doi.org/10.1093/jxb/erp274

Husted, S., Hebbern, C. A., Mattsson, M., \& Schjoerring, J. K. (2000). A critical experimental evaluation of methods for determination of $\mathrm{NH}_{4}{ }^{+}$in plant tissue, xylem sap and apoplastic fluid. Physiologia Plantarum, 109(2), 167-179. https://doi.org/10.1034/j.1399-3054.2000.100209.x

Huvenne, H., Messens, E., \& Maes, M. (2009). Willow wood sap promotes the density-dependent pathogenesis of Brenneria salicis. Environmental Microbiology, 11(6), 1463-1472. https://doi.org/10.1111/j.1462-2920.2009.01874.x

Ingestad, T., Arveby, A. S., \& Käfar, M. (1986). The influence of ectomycorrhiza on nitrogen nutrition and growth of Pinus sylvestris seedlings. Physiologia Plantarum, 68(4), 575-582. https://doi.org/10.1111/j.1399-3054.1986.tb03399.x

Irmisch, S., McCormick, A. C., Boeckler, G. A., Schmidt, A., Reichelt, M., Schneider, B., Block, K., Schnitzler, J.-P., Gershenzon, J., Unsicker, S. B., \& Köllner, T. G. (2013). Two herbivore-induced cytochrome P450 enzymes CYP79d6 and CYP79d7 catalyze the formation of volatile aldoximes involved in poplar defense. The Plant Cell, 25(11), 4737-4754. https://doi.org/10.1105/tpc.113.118265 Isaacs, M., Carella, P., Faubert, J., Champigny, M. J., Rose, J. K. C., \& Cameron, R. K. (2016). Orthology analysis and in vivo complementation studies to elucidate the role of DIR1 during systemic acquired resistance in Arabidopsis thaliana and Cucumis sativus. Frontiers in Plant Science, 7. https://doi.org/10.3389/fpls.2016.00566 
Jandl, R., Smidt, S., Mutsch, F., Fürst, A., Zechmeister, H., Bauer, H., \& Dirnböck, T. (2012). Acidification and nitrogen eutrophication of Austrian forest soils. Applied and Environmental Soil Science, 2012, e632602. https://doi.org/10.1155/2012/632602

Jansson, M., Andersson, R., Berggren, H., \& Leonardson, L. (1994). Wetlands and lakes as nitrogen traps. Ambio, 23(6), 320-325. JSTOR.

Jensen, B., \& Munk, L. (1997). Nitrogen-induced changes in colony density and spore production of Erysiphe graminis f.sp. Hordei on seedlings of six spring barley cultivars. Plant Pathology, 46(2), 191-202. https://doi.org/10.1046/j.1365-3059.1997.d01-224.x

Jentschke, G., Brandes, B., Kuhn, A. J., Schröder, W. H., \& Godbold, D. L. (2001). Interdependence of phosphorus, nitrogen, potassium and magnesium translocation by the ectomycorrhizal fungus Paxillus involutus. New Phytologist, 149(2), 327-337. https://doi.org/10.1046/j.14698137.2001.00014.x

Jersch, S., Scherer, C., Huth, G., \& Schlösser, E. (1989). Proanthocyanidins as basis for quiescence of Botrytis cinerea in immature strawberry fruits. Zeitschrift für Pflanzenkrankheiten und Pflanzenschutz / Journal of Plant Diseases and Protection, 96(4), 365-378. JSTOR.

Jia, Z., Gou, J., Sun, Y., Yuan, L., Tang, Q., Yang, X., Pei, Y., \& Luo, K. (2010). Enhanced resistance to fungal pathogens in transgenic Populus tomentosa Carr. By overexpression of an nsLTP-like antimicrobial protein gene from motherwort (Leonurus japonicus). Tree Physiology, 30(12), 1599-1605. https://doi.org/10.1093/treephys/tpq093

Jones, C. G., \& Last, F. T. (1991). Ectomycorrhizae and trees: Implications for aboveground herbivory. Microbial mediation of plant-herbivore interactions. Wiley, New York, 65-103.

Jones, J., \& Dangl, J. (2006). The plant immune system. Nature, 444(7117), 323-329. https://doi.org/10.1038/nature05286

Jung, H. W., Tschaplinski, T. J., Wang, L., Glazebrook, J., \& Greenberg, J. T. (2009). Priming in systemic plant immunity. Science, 324(5923), 89-91. https://doi.org/10.1126/science.1170025 
References

Jung, S. C., Martinez-Medina, A., Lopez-Raez, J. A., \& Pozo, M. J. (2012). Mycorrhiza-induced resistance and priming of plant defenses. Journal of Chemical Ecology, 38(6), 651-664. https://doi.org/10.1007/s10886-012-0134-6

Kaling, M., Schmidt, A., Moritz, F., Rosenkranz, M., Witting, M., Kasper, K., Janz, D., Schmitt-Kopplin, P., Schnitzler, J.-P., \& Polle, A. (2018). Mycorrhiza-triggered transcriptomic and metabolomic networks impinge on herbivore fitness. Plant Physiology, 176(4), 2639. https://doi.org/10.1104/pp.17.01810

Kanehisa, M., \& Goto, S. (2000). KEGG: kyoto encyclopedia of genes and genomes. Nucleic Acids Research, 28. https://doi.org/10.1093/nar/28.1.27

Kato, T. (1981). Major nitrogen compounds transported in xylem vessels from roots to top in Citrus trees. Physiologia Plantarum, 52(2), 275-279. https://doi.org/10.1111/j.1399-3054.1981.tb08505.x Kielland, K. (1994). Amino acid absorption by arctic plants: Implications for plant nutrition and nitrogen cycling. Ecology, 75(8), 2373-2383. https://doi.org/10.2307/1940891

Kim, H.-Y. (2013). Statistical notes for clinical researchers: Assessing normal distribution (2) using skewness and kurtosis. Restorative Dentistry \& Endodontics, 38(1), 52-54. https://doi.org/10.5395/rde.2013.38.1.52

Koornneef, A., \& Pieterse, C. M. J. (2008). Cross talk in defense signaling. Plant Physiology, 146(3), 839844. https://doi.org/10.1104/pp.107.112029

Kopka, J., Schauer, N., Krueger, S., Birkemeyer, C., Usadel, B., \& Bergmuller, E. (2005). GMD@CSB.DB: the Golm metabolome database. Bioinformatics, 21(8). https://doi.org/10.1093/bioinformatics/bti236

Koricheva, J., Gange, A. C., \& Jones, T. (2009). Effects of mycorrhizal fungi on insect herbivores: A metaanalysis. Ecology, 90(8), 2088-2097. https://doi.org/10.1890/08-1555.1

Korovetska, H., Novák, O., Jůza, O., \& Gloser, V. (2014). Signalling mechanisms involved in the response of two varieties of Humulus lupulus L. to soil drying: I. changes in xylem sap pH and the 


\section{References}

concentrations of abscisic acid and anions. Plant and Soil, 380(1), 375-387.

https://doi.org/10.1007/s11104-014-2101-1

Kreuzwieser, J., Scheerer, U., \& Rennenberg, H. (1999). Metabolic origin of acetaldehyde emitted by poplar (Populus tremula $\times$ P. alba) trees. Journal of Experimental Botany, 50(335), 757-765. https://doi.org/10.1093/jxb/50.335.757

Kulmann, C. (2005). Lokalisation und regulation der sauren invertase in mykorrhizierten Kurzwurzeln. Universität Bremen.

Langmead, B., \& Salzberg, S. L. (2012). Fast gapped-read alignment with Bowtie 2. Nature Methods, 9(4), 357-359. https://doi.org/10.1038/nmeth.1923

LeBauer, D. S., \& Treseder, K. K. (2008). Nitrogen limitation of net primary productivity in terrestrial ecosystems is globally distributed. Ecology, 89(2), 371-379. https://doi.org/10.1890/06-2057.1

Lee, C.-S., Lee, Y.-J., \& Jeun, Y.-C. (2005). Observations of infection structures on the leaves of cucumber plants pre-treated with arbuscular mycorrhiza Glomus intraradices after challenge inoculation with Colletotrichum orbiculare. The Plant Pathology Journal, 21(3), 237-243.

https://doi.org/10.5423/PPJ.2005.21.3.237

Lenth, R., Singmann, H., \& Love, J. (2018). Emmeans: Estimated marginal means, aka least-squares means. $R$ package version, $1(1)$.

Leple, J. C., Brasileiro, A. C. M., Michel, M. F., Delmotte, F., \& Jouanin, L. (1992). Transgenic poplars: Expression of chimeric genes using four different constructs. Plant Cell Reports, 11(3), 137-141. https://doi.org/10.1007/BF00232166

Leser, C., \& Treutter, D. (2005). Effects of nitrogen supply on growth, contents of phenolic compounds and pathogen (scab) resistance of apple trees. Physiologia Plantarum, 123(1), 49-56. https://doi.org/10.1111/j.1399-3054.2004.00427.x 
Li, J., Brader, G., Kariola, T., \& Palva, E. T. (2006). WRKY70 modulates the selection of signaling pathways in plant defense. The Plant Journal: For Cell and Molecular Biology, 46(3), 477-491. https://doi.org/10.1111/j.1365-313X.2006.02712.x

Li, J.-Y., Fu, Y.-L., Pike, S. M., Bao, J., Tian, W., Zhang, Y., Chen, C.-Z., Zhang, Y., Li, H.-M., Huang, J., Li, L.G., Schroeder, J. I., Gassmann, W., \& Gong, J.-M. (2010). The Arabidopsis nitrate transporter NRT1.8 functions in nitrate removal from the xylem sap and mediates cadmium tolerance. The Plant Cell, 22(5), 1633-1646. https://doi.org/10.1105/tpc.110.075242

Lima, V. F., Anjos, L. dos, Medeiros, D. B., Cândido-Sobrinho, S. A., Souza, L. P., Gago, J., Fernie, A. R., \& Daloso, D. M. (2019). The sucrose-to-malate ratio correlates with the faster CO2 and light stomatal responses of angiosperms compared to ferns. New Phytologist, 223(4), 1873-1887. https://doi.org/10.1111/nph.15927

Lin, S.-H., Kuo, H.-F., Canivenc, G., Lin, C.-S., Lepetit, M., Hsu, P.-K., Tillard, P., Lin, H.-L., Wang, Y.-Y., Tsai, C.-B., Gojon, A., \& Tsay, Y.-F. (2008). Mutation of the Arabidopsis NRT1.5 nitrate transporter causes defective root-to-shoot nitrate transport. The Plant Cell, 20(9), 2514-2528. https://doi.org/10.1105/tpc.108.060244

Lindahl, B. D., \& Tunlid, A. (2015). Ectomycorrhizal fungi-potential organic matter decomposers, yet not saprotrophs. New Phytologist, 205(4), 1443-1447.

Lindroth, R. L., \& Hwang, S.-Y. (1996). Clonal variation in foliar chemistry of quaking aspen (Populus tremuloides Michx.). Biochemical Systematics and Ecology, 24(5), 357-364. https://doi.org/10.1016/0305-1978(96)00043-9

Liu, H., \& Brettell, L. E. (2019). Plant defense by VOC-induced microbial priming. Trends in Plant Science, 24(3), 187-189. https://doi.org/10.1016/j.tplants.2019.01.008

Love, M., Huber, W., \& Anders, S. (2014). Moderated estimation of fold change and dispersion for RNAseq data with DESeq2. Genome Biology, 15(550). https://doi.org/10.1186/s13059-014-0550-8 
Lucic, E., Fourrey, C., Kohler, A., Martin, F., Chalot, M., \& Brun-Jacob, A. (2008). A gene repertoire for nitrogen transporters in Laccaria bicolor. New Phytologist, 180(2), 343-364. https://doi.org/10.1111/j.1469-8137.2008.02580.x

Ludewig, U., Neuhäuser, B., \& Dynowski, M. (2007). Molecular mechanisms of ammonium transport and accumulation in plants. FEBS Letters, 581(12), 2301-2308. https://doi.org/10.1016/j.febslet.2007.03.034

Ludwikow, A., Gallois, P., \& Sadowski, J. (2004). Ozone-induced oxidative stress response in Arabidopsis: Transcription profiling by microarray approach. Cellular \& Molecular Biology Letters, 9(4B), 829842.

Luo, J., Xia, W., Cao, P., Xiao, Z., Zhang, Y., Liu, M., Zhan, C., \& Wang, N. (2019). Integrated transcriptome analysis reveals plant hormones jasmonic acid and salicylic acid coordinate growth and defense responses upon fungal infection in poplar. Biomolecules, 9(1), 12. https://doi.org/10.3390/biom9010012

Luo, J., Zhou, J., Li, H., Shi, W., Polle, A., Lu, M., Sun, X., \& Luo, Z.-B. (2015). Global poplar root and leaf transcriptomes reveal links between growth and stress responses under nitrogen starvation and excess. Tree Physiology, 35(12), 1283-1302. https://doi.org/10.1093/treephys/tpv091

Luo, Z.-B., Janz, D., Jiang, X., Göbel, C., Wildhagen, H., Tan, Y., Rennenberg, H., Feussner, I., \& Polle, A. (2009). Upgrading root physiology for stress tolerance by ectomycorrhizas: Insights from metabolite and transcriptional profiling into reprogramming for stress anticipation. Plant Physiology, 151(4), 1902-1917. https://doi.org/10.1104/pp.109.143735

Mader, M., Le Paslier, M.-C., Bounon, R., Berard, A., Faivre-Rampant, P., Fladung, M., Leplé, J.-C., \& Kersten, B. (2016). Whole-genome draft assembly of Populus tremula x P. alba clone INRA 7171B4. Silvae genetica : Zeitschrift für Forstgenetik und Forstpflanzenzüchtung, 65(2), 74-79. https://doi.org/10.1515/sg-2016-0019 
Madritch, M. D., \& Lindroth, R. L. (2015). Condensed tannins increase nitrogen recovery by trees following insect defoliation. New Phytologist, 208(2), 410-420. https://doi.org/10.1111/nph.13444

Maechler, M. (2019). "Finding groups in data": Cluster analysis extended Rousseeuw et. $R$ Packag. version 2.0, 6 .

Maeda, S., Konishi, M., Yanagisawa, S., \& Omata, T. (2014). Nitrite transport activity of a novel HPP family protein conserved in cyanobacteria and chloroplasts. Plant and Cell Physiology, 55(7), 1311-1324. https://doi.org/10.1093/pcp/pcu075

Maes, M., Huvenne, H., \& Messens, E. (2009). Brenneria salicis, the bacterium causing watermark disease in willow, resides as an endophyte in wood. Environmental Microbiology, 11(6), 14531462. https://doi.org/10.1111/j.1462-2920.2009.01873.x

Maillet, F., Poinsot, V., André, O., Puech-Pagès, V., Haouy, A., Gueunier, M., Cromer, L., Giraudet, D., Formey, D., Niebel, A., Martinez, E. A., Driguez, H., Bécard, G., \& Dénarié, J. (2011). Fungal lipochitooligosaccharide symbiotic signals in arbuscular mycorrhiza. Nature, 469(7328), 58-63. https://doi.org/10.1038/nature09622

Major, I. T., \& Constabel, C. P. (2008). Functional analysis of the Kunitz trypsin inhibitor family in poplar reveals biochemical diversity and multiplicity in defense against herbivores. Plant Physiology, 146(3), 888-903. https://doi.org/10.1104/pp.107.106229

Maldonado, A. M., Doerner, P., Dixon, R. A., Lamb, C. J., \& Cameron, R. K. (2002). A putative lipid transfer protein involved in systemic resistance signalling in Arabidopsis. Nature, 419(6905), 399-403. https://doi.org/10.1038/nature00962

Mamashita, T., Larocque, G. R., DesRochers, A., Beaulieu, J., Thomas, B. R., Mosseler, A., Major, J., \& Sidders, D. (2015). Short-term growth and morphological responses to nitrogen availability and plant density in hybrid poplars and willows. Biomass and Bioenergy, 81, 88-97. https://doi.org/10.1016/j.biombioe.2015.06.003 
References

Manninen, A.-M., Holopainen, T., \& Holopainen, J. K. (1998). Susceptibility of ectomycorrhizal and nonmycorrhizal Scots pine (Pinus sylvestris) seedlings to a generalist insect herbivore, Lygus rugulipennis, at two nitrogen availability levels. The New Phytologist, 140(1), 55-63. https://doi.org/10.1046/j.1469-8137.1998.00246.x

Marschner, H. (2011). Marschner's mineral nutrition of higher plants. Academic press.

Martin, F., Aerts, A., Ahren, D., Brun, A., Danchin, E. G. J., Duchaussoy, F., Gibon, J., Kohler, A., Lindquist, E., Pereda, V., Salamov, A., Shapiro, H. J., Wuyts, J., Blaudez, D., Buee, M., Brokstein, P., Canback, B., Cohen, D., Courty, P. E., ... Grigoriev, I. V. (2008). The genome of Laccaria bicolor provides insights into mycorrhizal symbiosis. Nature, 452(7183), 88-92. https://doi.org/10.1038/nature06556

Martin, F., Cõté, R., \& Canet, D. (1994). $\mathrm{NH}_{4}{ }^{+}$assimilation in the ectomycorrhizal basidiomycete Laccaria bicolor (Maire) Orton, a ${ }^{15} \mathrm{~N}-\mathrm{NMR}$ study. New Phytologist, 128(3), 479-485. https://doi.org/10.1111/j.1469-8137.1994.tb02994.x

Martin, F., Kohler, A., Murat, C., Veneault-Fourrey, C., \& Hibbett, D. S. (2016). Unearthing the roots of ectomycorrhizal symbioses. Nat Rev Micro, 14(12), 760-773.

Martinoia, E., Maeshima, M., \& Neuhaus, H. E. (2007). Vacuolar transporters and their essential role in plant metabolism. Journal of Experimental Botany, 58(1), 83-102.

https://doi.org/10.1093/jxb/erl183

Masclaux-Daubresse, C., Daniel-Vedele, F., Dechorgnat, J., Chardon, F., Gaufichon, L., \& Suzuki, A. (2010). Nitrogen uptake, assimilation and remobilization in plants: Challenges for sustainable and productive agriculture. Annals of Botany, 105(7), 1141-1157. https://doi.org/10.1093/aob/mcq028

Matyash, V., Liebisch, G., Kurzchalia, T. V., Shevchenko, A., \& Schwudke, D. (2008). Lipid extraction by methyl-tert-butyl ether for high-throughput lipidomics. Journal of Lipid Research, 49(5), 11371146. https://doi.org/10.1194/jlr.D700041-JLR200 
Mauch-Mani, B., Baccelli, I., Luna, E., \& Flors, V. (2017). Defense priming: An adaptive part of induced resistance. Annual Review of Plant Biology, 68(1), 485-512. https://doi.org/10.1146/annurevarplant-042916-041132

Mccormick, A. C., Irmisch, S., Reinecke, A., Boeckler, G. A., Veit, D., Reichelt, M., Hansson, B. S., Gershenzon, J., Köllner, T. G., \& Unsicker, S. B. (2014). Herbivore-induced volatile emission in black poplar: Regulation and role in attracting herbivore enemies. Plant, Cell \& Environment, 37(8), 1909-1923. https://doi.org/10.1111/pce.12287

McDowell, J. M., \& Dangl, J. L. (2000). Signal transduction in the plant immune response. Trends in Biochemical Sciences, 25(2), 79-82. https://doi.org/10.1016/S0968-0004(99)01532-7

Melin, E., \& Nilsson, H. (1952). Transport of labelled nitrogen from an ammonium source to pine seedlings through mycorrhizal mycelium. Svensk Botanisk Tidskrift, 46, 281-285.

Merbach, W., Augustin, J., Kalettka, T., \& Jacob, H. J. (1996). Nitrous oxide and methane emissions from riparian areas of ponded depressions of northeast Germany. Journal of Applied Botany, 70, 134136.

Microsoft, C. (2016). Microsoft Office 2016. Microsoft cooperation.

Miflin, B. J. (1974). The location of nitrite reductase and other enzymes related to amino acid biosynthesis in the plastids of root and leaves. Plant Physiology, 54(4), 550-555. https://doi.org/10.1104/pp.54.4.550

Miller, A. J., Fan, X., Orsel, M., Smith, S. J., \& Wells, D. M. (2007). Nitrate transport and signalling. Journal of Experimental Botany, 58(9), 2297-2306. https://doi.org/10.1093/jxb/erm066

Miranda, M., Ralph, S. G., Mellway, R., White, R., Heath, M. C., Bohlmann, J., \& Constabel, C. P. (2007). The transcriptional response of hybrid poplar (Populus trichocarpa $\times$ P. deltoids) to infection by Melampsora medusae leaf rust involves induction of flavonoid pathway genes leading to the accumulation of proanthocyanidins. Molecular Plant-Microbe Interactions, 20(7), 816-831. https://doi.org/10.1094/MPMI-20-7-0816 
Molina, A., Segura, A., \& García-Olmedo, F. (1993). Lipid transfer proteins (nsLTPs) from barley and maize leaves are potent inhibitors of bacterial and fungal plant pathogens. FEBS Letters, 316(2), 119122. https://doi.org/10.1016/0014-5793(93)81198-9

Molina, R., \& Chamard, J. (1983). Use of the ectomycorrhizal fungus Laccaria laccata in forestry. II. Effects of fertilizer forms and levels on ectomycorrhizal development and growth of containergrown Douglas-fir and Ponderosa pine seedlings. Canadian Journal of Forest Research, 13(1), 8995. https://doi.org/10.1139/x83-013

Mueller, G. M., \& Gardes, M. (1991). Intra- and interspecific relations within Laccaria bicolor sensu lato. Mycological Research, 95(5), 592-601. https://doi.org/10.1016/S0953-7562(09)80073-7

Müller, A. (2014). Communication between mycorrhizal fungi and poplar. Georg-August-Universität Göttingen.

Müller, A., Volmer, K., Mishra-Knyrim, M., \& Polle, A. (2013). Growing poplars for research with and without mycorrhizas. Frontiers in Plant Science, 4. https://doi.org/10.3389/fpls.2013.00332

Mur, L. A. J., Simpson, C., Kumari, A., Gupta, A. K., \& Gupta, K. J. (2017). Moving nitrogen to the centre of plant defence against pathogens. Annals of Botany, 119(5), 703-709. https://doi.org/10.1093/aob/mcw179

Murashige, T., \& Skoog, F. (1962). A revised medium for rapid growth and bio assays with tobacco tissue cultures. Physiologia Plantarum, 15(3), 473-497. https://doi.org/10.1111/j.13993054.1962.tb08052.x

Nason, A. (1962). II. Enzymatic pathways of nitrate, nitrite, and hydroxylamine metabolisms. Bacteriological Reviews, 26(1), 16-41.

Nehls, U., Grunze, N., Willmann, M., Reich, M., \& Küster, H. (2007). Sugar for my honey: Carbohydrate partitioning in ectomycorrhizal symbiosis. Phytochemistry, 68(1), 82-91. https://doi.org/10.1016/j.phytochem.2006.09.024 
Nehls, U., \& Plassard, C. (2018). Nitrogen and phosphate metabolism in ectomycorrhizas. New Phytologist, 220(4), 1047-1058. https://doi.org/10.1111/nph.15257

Nerg, A.-M., Kasurinen, A., Holopainen, T., Julkunen-Tiitto, R., Neuvonen, S., \& Holopainen, J. K. (2008). The significance of ectomycorrhizas in chemical quality of silver birch foliage and above-ground insect herbivore performance. Journal of Chemical Ecology, 34(10), 1322-1330. https://doi.org/10.1007/s10886-008-9542-z

Nie, X., Xiong, F., Yang, L., Li, C., \& Zhou, G. (2017). Soil nitrogen storage, distribution, and associated controlling factors in the Northeast Tibetan plateau shrublands. Forests, 8(11), 416.

Oddsdottir, E. S., Eilenberg, J., Sen, R., Harding, S., \& Halldorsson, G. (2010). Early reduction of Otiorhynchus spp. Larval root herbivory on Betula pubescens by beneficial soil fungi. Applied Soil Ecology, 45(3), 168-174. https://doi.org/10.1016/j.apsoil.2010.03.009

Okamoto, S., Shinohara, H., Mori, T., Matsubayashi, Y., \& Kawaguchi, M. (2013). Root-derived CLE glycopeptides control nodulation by direct binding to HAR1 receptor kinase. Nature Communications, 4, 2191. https://doi.org/10.1038/ncomms3191

Okamoto, S., Suzuki, T., Kawaguchi, M., Higashiyama, T., \& Matsubayashi, Y. (2015). A comprehensive strategy for identifying long-distance mobile peptides in xylem sap. The Plant Journal, 84(3), 611-620. https://doi.org/10.1111/tpj.13015

Okamoto, S., Tabata, R., \& Matsubayashi, Y. (2016). Long-distance peptide signaling essential for nutrient homeostasis in plants. Current Opinion in Plant Biology, 34, 35-40. https://doi.org/10.1016/j.pbi.2016.07.009

Oksanen, J., Kindt, R., Legendre, P., O’Hara, B., Stevens, M. H. H., Oksanen, M. J., \& Suggests, M. (2007). The vegan package. Community ecology package, 10, 631-637.

Okumoto, S., Koch, W., Tegeder, M., Fischer, W. N., Biehl, A., Leister, D., Stierhof, Y. D., \& Frommer, W. B. (2004). Root phloem-specific expression of the plasma membrane amino acid proton co- 


\section{References}

transporter AAP3. Journal of Experimental Botany, 55(406), 2155-2168.

https://doi.org/10.1093/jxb/erh233

OriginLab, C. (2011). Origin 8.5. OriginLab Cooperation.

Papp, N. (2005). Antimicrobial activity of extracts of five Hungarian Euphorbia species and some plant metabolits. Acta Botanica Hungarica, 46(3-4), 363-371. https://doi.org/10.1556/abot.46.2004.3-4.8

Pate, J. S., Sharkey, P. J., \& Lewis, O. A. M. (1975). Xylem to phloem transfer of solutes in fruiting shoots of legumes, studied by a phloem bleeding technique. Planta, 122(1), 11-26. https://doi.org/10.1007/BF00385400

Pechanova, O., Hsu, C.-Y., Adams, J. P., Pechan, T., Vandervelde, L., Drnevich, J., Jawdy, S., Adeli, A., Suttle, J. C., Lawrence, A. M., Tschaplinski, T. J., Séguin, A., \& Yuceer, C. (2010). Apoplast proteome reveals that extracellular matrix contributes to multistress response in poplar. $B M C$ Genomics, 11(1), 674. https://doi.org/10.1186/1471-2164-11-674

Petutschnig, E. K., Jones, A. M. E., Serazetdinova, L., Lipka, U., \& Lipka, V. (2010). The lysin motif receptor-like kinase (LYSM-RLK) CERK1 is a major chitin-binding protein in Arabidopsis thaliana and subject to chitin-induced phosphorylation. Journal of Biological Chemistry, 285(37), 2890228911. https://doi.org/10.1074/jbc.M110.116657

Peuke, A. D., Jeschke, W. D., \& Hartung, W. (1998). Foliar application of nitrate or ammonium as sole nitrogen supply in Ricinus communis. II. The flows of cations, chloride and abscisic acid. The New Phytologist, 140(4), 625-636. https://doi.org/10.1046/j.1469-8137.1998.00304.x

Pfabel, C., Eckhardt, K.-U., Baum, C., Struck, C., Frey, P., \& Weih, M. (2012). Impact of ectomycorrhizal colonization and rust infection on the secondary metabolism of poplar (Populus trichocarpa $\times$ deltoides). Tree Physiology, 32(11), 1357-1364. https://doi.org/10.1093/treephys/tps093

Philippe, R. N., Ralph, S. G., Külheim, C., Jancsik, S. I., \& Bohlmann, J. (2009). Poplar defense against insects: Genome analysis, full-length cDNA cloning, and transcriptome and protein analysis of the 
References

poplar Kunitz-type protease inhibitor family. New Phytologist, 184(4), 865-884.

https://doi.org/10.1111/j.1469-8137.2009.03028.x

Philippe, R. N., Ralph, S. G., Mansfield, S. D., \& Bohlmann, J. (2010). Transcriptome profiles of hybrid poplar (Populus trichocarpa $\times$ deltoides) reveal rapid changes in undamaged, systemic sink leaves after simulated feeding by forest tent caterpillar (Malacosoma disstria). New Phytologist, 188(3), 787-802. https://doi.org/10.1111/j.1469-8137.2010.03392.x

Philips, R. (2006). Mushrooms. Pan MacMillan.

Pieterse, C. M. J., Zamioudis, C., Berendsen, R. L., Weller, D. M., Van Wees, S. C. M., \& Bakker, P. A. H. M. (2014). Induced systemic resistance by beneficial microbes. Annual Review of Phytopathology, 52(1), 347-375. https://doi.org/10.1146/annurev-phyto-082712-102340

Plothe, M. (2019). Daten, Fakten \& Hintergrundinformationen zur aktuellen Waldsituation. Fachagentur Nachwachsende Rohstoffe e. V., 12.

Polle, A., Altman, A., \& Jiang, X. (2006). Towards genetic engineering for drought tolerance in trees. In Tree Transgenesis: Recent Developments (S. 275-297). https://doi.org/10.1007/3-540-321993_13

Polle, A., Chakrabarti, K., Schürmann, W., \& Renneberg, H. (1990). Composition and properties of hydrogen peroxide decomposing systems in extracellular and total extracts from needles of norway spruce (Picea abies L., Karst.). Plant Physiology, 94(1), 312-319. https://doi.org/10.1104/pp.94.1.312

Polle, A., \& Douglas, C. (2010). The molecular physiology of poplars: Paving the way for knowledge-based biomass production. Plant Biology. https://doi.org/10.1111/j.1438-8677.2009.00318.x

Polle, A., Janz, D., Teichmann, T., \& Lipka, V. (2013). Poplar genetic engineering: Promoting desirable wood characteristics and pest resistance. Applied Microbiology and Biotechnology, 97(13), 56695679. https://doi.org/10.1007/s00253-013-4940-8 
References

Pozo, M. J., \& Azcón-Aguilar, C. (2007). Unraveling mycorrhiza-induced resistance. Current Opinion in Plant Biology, 10(4), 393-398. https://doi.org/10.1016/j.pbi.2007.05.004

Purwaha, P., Silva, L. P., Hawke, D. H., Weinstein, J. N., \& Lorenzi, P. L. (2014). An artifact in LC-MS/MS measurement of glutamine and glutamic acid: In-source cyclization to pyroglutamic acid. Analytical Chemistry, 86(12), 5633-5637. https://doi.org/10.1021/ac501451v

Quoreshi, A. M., \& Khasa, D. P. (2008). Effectiveness of mycorrhizal inoculation in the nursery on root colonization, growth, and nutrient uptake of aspen and balsam poplar. Biomass and Bioenergy, 32(5), 381-391. https://doi.org/10.1016/j.biombioe.2007.10.010

R Core Team. (2014). R: A language and environment for statistical computing. R Foundation for Statistical Computing, Vienna, Austria. http://www.R-project.org/

Rappsilber, J., Ishihama, Y., \& Mann, M. (2003). Stop and go extraction tips for matrix-assisted laser desorption/ionization, nanoelectrospray, and LC/MS sample pretreatment in proteomics. Analytical Chemistry, 75(3), 663-670. https://doi.org/10.1021/ac026117i

Ratzinger, A., Riediger, N., von Tiedemann, A., \& Karlovsky, P. (2009). Salicylic acid and salicylic acid glucoside in xylem sap of Brassica napus infected with Verticillium longisporum. Journal of Plant Research, 122(5), 571-579. https://doi.org/10.1007/s10265-009-0237-5

Rekhter, D., Lüdke, D., Ding, Y., Feussner, K., Zienkiewicz, K., Lipka, V., Wiermer, M., Zhang, Y., \& Feussner, I. (2019). Isochorismate-derived biosynthesis of the plant stress hormone salicylic acid. Science, 365(6452), 498-502. https://doi.org/10.1126/science.aaw1720

Rennenberg, H., \& Dannenmann, M. (2015). Nitrogen nutrition of trees in temperate forests-The significance of nitrogen availability in the pedosphere and atmosphere. Forests, 6(8), 2820-2835. https://doi.org/10.3390/f6082820

Rennenberg, H., Dannenmann, M., Gessler, A., Kreuzwieser, J., Simon, J., \& Papen, H. (2009). Nitrogen balance in forest soils: Nutritional limitation of plants under climate change stresses. Plant Biology, 11(s1), 4-23. https://doi.org/10.1111/j.1438-8677.2009.00241.x 
References

Rennenberg, H., Wildhagen, H., \& Ehlting, B. (2010). Nitrogen nutrition of poplar trees. Plant Biology, 12(2), 275-291. https://doi.org/10.1111/j.1438-8677.2009.00309.x

Rieske, L. K., Rhoades, C. C., \& Miller, S. P. (2003). Foliar chemistry and Gypsy moth, Lymantria dispar (L.), herbivory on pure American chestnut, Castanea dentata (Fam: Fagaceae), and a diseaseresistant hybrid. Environmental Entomology, 32(2), 359-365. https://doi.org/10.1603/0046$225 X-32.2 .359$

Rinaldi, C., Kohler, A., Frey, P., Duchaussoy, F., Ningre, N., Couloux, A., Wincker, P., Thiec, D. L., Fluch, S., Martin, F., \& Duplessis, S. (2007). Transcript profiling of poplar leaves upon infection with compatible and incompatible strains of the foliar rust Melampsora larici-populina. Plant Physiology, 144(1), 347-366. https://doi.org/10.1104/pp.106.094987

Robert, C., Bancal, M.-O., \& Lannou, C. (2002). Wheat leaf rust uredospore production and carbon and nitrogen export in relation to lesion size and density. Phytopathology ${ }^{\circledR}, 92(7), 762-768$. https://doi.org/10.1094/PHYTO.2002.92.7.762

Robert-Seilaniantz, A., Grant, M., \& Jones, J. D. G. (2011). Hormone crosstalk in plant disease and defense: More than just jasmonate-salicylate antagonism. Annual Review of Phytopathology, 49(1), 317-343. https://doi.org/10.1146/annurev-phyto-073009-114447

Robertson, G. P., \& Vitousek, P. M. (2009). Nitrogen in agriculture: Balancing the cost of an essential resource. Annual Review of Environment and Resources, 34(1), 97-125. https://doi.org/10.1146/annurev.environ.032108.105046

Rodríguez-Celma, J., Ceballos-Laita, L., Grusak, M. A., Abadía, J., \& López-Millán, A.-F. (2016). Plant fluid proteomics: Delving into the xylem sap, phloem sap and apoplastic fluid proteomes. Biochimica et Biophysica Acta (BBA) - Proteins and Proteomics, 1864(8), 991-1002. https://doi.org/10.1016/j.bbapap.2016.03.014

Röhrig, E., \& Bartsch, N. (1992). Waldbau auf ökologischer Grundlage. Band 1. Hamburg. Parey Verlag. 
Rotsch, A. H., Kopka, J., Feussner, I., \& Ischebeck, T. (2017). Central metabolite and sterol profiling divides tobacco male gametophyte development and pollen tube growth into eight metabolic phases. The Plant Journal, 92(1), 129-146. https://doi.org/10.1111/tpj.13633

Rousseau, J. V. D., \& Reid, C. P. P. (1991). Effects of phosphorus fertilization and mycorrhizal development on phosphorus nutrition and carbon balance of loblolly pine. New Phytologist, 117(2), 319-326. https://doi.org/10.1111/j.1469-8137.1991.tb04913.x

Rubert-Nason, K. F., Couture, J. J., Major, I. T., Constabel, C. P., \& Lindroth, R. L. (2015). Influence of genotype, environment, and gypsy moth herbivory on local and systemic chemical defenses in trembling aspen (Populus tremuloides). Journal of Chemical Ecology, 41(7), 651-661. https://doi.org/10.1007/s10886-015-0600-z

Runion, G. B., Mitchell, R. J., Rogers, H. H., Prior, S. A., \& Counts, T. K. (1997). Effects of nitrogen and water limitation and elevated atmospheric $\mathrm{CO} 2$ on ectomycorrhiza of longleaf pine. The New Phytologist, 137(4), 681-689. https://doi.org/10.1046/j.1469-8137.1997.00865.x

Ruohomaki, K., Chapin, F. S., Haukioja, E., Neuvonen, S., \& Suomela, J. (1996). Delayed inducible resistance in Mountain birch in response to fertilization and shade. Ecology, 77(8), 2302-2311. https://doi.org/10.2307/2265732

Sa, G., Yao, J., Deng, C., Liu, J., Zhang, Y., Zhu, Z., Zhang, Y., Ma, X., Zhao, R., Lin, S., Lu, C., Polle, A., \& Chen, S. (2019). Amelioration of nitrate uptake under salt stress by ectomycorrhiza with and without a Hartig net. New Phytologist, 222(4), 1951-1964. https://doi.org/10.1111/nph.15740 Sannigrahi, P., Ragauskas, A. J., \& Tuskan, G. A. (2010). Poplar as a feedstock for biofuels: A review of compositional characteristics. Biofuels, Bioproducts and Biorefining , 4(2), 209-226. https://doi.org/10.1002/bbb.206

Saponari, M., Boscia, D., Altamura, G., Loconsole, G., Zicca, S., D’Attoma, G., Morelli, M., Palmisano, F., Saponari, A., Tavano, D., Savino, V. N., Dongiovanni, C., \& Martelli, G. P. (2017). Isolation and 
pathogenicity of Xylella fastidiosa associated to the olive quick decline syndrome in southern Italy. Scientific Reports, 7(1), 17723. https://doi.org/10.1038/s41598-017-17957-z

Schachtman, D. P., \& Goodger, J. Q. D. (2008). Chemical root to shoot signaling under drought. Trends in Plant Science, 13(6), 281-287. https://doi.org/10.1016/j.tplants.2008.04.003

Schimel, J. P., \& Bennett, J. (2004). Nitrogen mineralization: Challenges of a changing paradigm. Ecology, 85(3), 591-602. https://doi.org/10.1890/03-8002

Schindelin, J., Arganda-Carreras, I., Frise, E., Kaynig, V., Longair, M., Pietzsch, T., Preibisch, S., Rueden, C., Saalfeld, S., Schmid, B., Tinevez, J.-Y., White, D. J., Hartenstein, V., Eliceiri, K., Tomancak, P., \& Cardona, A. (2012). Fiji: An open-source platform for biological-image analysis. Nature Methods, 9(7), 676-682. https://doi.org/10.1038/nmeth.2019

Schneider, K., Werf, W. van der, Cendoya, M., Mourits, M., Navas-Cortés, J. A., Vicent, A., \& Lansink, A. O. (2020). Impact of Xylella fastidiosa subspecies pauca in European olives. Proceedings of the National Academy of Sciences, 117(17), 9250-9259. https://doi.org/10.1073/pnas.1912206117 Schnitzler, J.-P., Zimmer, I., Bachl, A., Arend, M., Fromm, J., \& Fischbach, R. J. (2005). Biochemical properties of isoprene synthase in poplar (Populus $\times$ canescens). Planta, 222(5), 777-786. https://doi.org/10.1007/s00425-005-0022-1

Schulze, E.-D. (1994). Flux Control in Biological Systems: From Enzymes to Populations and Ecosystems. Academic Press.

Schurr, U. (1998). Xylem sap sampling-New approaches to an old topic. Trends in Plant Science, 3(8), 293-298. https://doi.org/10.1016/S1360-1385(98)01275-8

Selle, A., Willmann, M., Grunze, N., Geßler, A., Weiß, M., \& Nehls, U. (2005). The high-affinity poplar ammonium importer PttAMT1.2 and its role in ectomycorrhizal symbiosis. New Phytologist, 168(3), 697-706. https://doi.org/10.1111/j.1469-8137.2005.01535.x

Settler, R. F. (1998). Biology of Populus and Its Implications for Management and Conservation. NRC Research Press. 
Shah, J., \& Zeier, J. (2013). Long-distance communication and signal amplification in systemic acquired resistance. Frontiers in Plant Science, 4. https://doi.org/10.3389/fpls.2013.00030

Sibbesen, O., Koch, B., Halkier, B. A., \& Møller, B. L. (1995). Cytochrome P-450TYR is a multifunctional heme-thiolate enzyme catalyzing the conversion of L-tyrosine to $P$-hydroxyphenylacetaldehyde oxime in the biosynthesis of the cyanogenic glucoside dhurrin in Sorghum bicolor (L.) Moench. Journal of Biological Chemistry, 270(8), 3506-3511. https://doi.org/10.1074/jbc.270.8.3506

Siebrecht, Herdel, K., Schurr, U., \& Tischner, R. (2003). Nutrient translocation in the xylem of poplarDiurnal variations and spatial distribution along the shoot axis. Planta, 217(5), 783-793. https://doi.org/10.1007/s00425-003-1041-4

Siebrecht, S., \& Tischner, R. (1999). Changes in the xylem exudate composition of poplar (Populus tremula $\times$ P. alba)-Dependent on the nitrogen and potassium supply. Journal of Experimental Botany, 50, 1797-1806. https://doi.org/10.1093/jexbot/50.341.1797

Smith, R. L., \& Maguire, M. E. (1998). Microbial magnesium transport: Unusual transporters searching for identity. Molecular Microbiology, 28(2), 217-226. https://doi.org/10.1046/j.13652958.1998.00810.x

Smith, S., \& Read, D. (2008). Mycorrhizal Symbiosis (Third Edition) (3. Aufl.). Academic Press. Solomon, P. S., Tan, K.-C., \& Oliver, R. P. (2003). The nutrient supply of pathogenic fungi; a fertile field for study. Molecular Plant Pathology, 4(3), 203-210. https://doi.org/10.1046/j.13643703.2003.00161.x

Song, Y., Chen, D., Lu, K., Sun, Z., \& Zeng, R. (2015). Enhanced tomato disease resistance primed by arbuscular mycorrhizal fungus. Frontiers in Plant Science, 6. https://doi.org/10.3389/fpls.2015.00786

Spiers, A. G. (1978). An agar leaf-disc technique for screening poplars for resistance to Marssonina. Plant Disease Reporter, 62(2). 
Spiers, A. G. (1984). Comparative studies of host specificity and symptoms exhibited by poplars infected with Marssonina brunnea, Marssonina castagnei and Marssonina populi. European Journal of Forest Pathology, 14(4-5), 202-218. https://doi.org/10.1111/j.1439-0329.1984.tb00164.x

Spiers, A. G. (1989). Comparative studies of conidium morphology of Marssonina species pathogenic to poplars on agar and host tissue. New Zealand Journal of Botany, 27, 503-511.

Spiers, A. G., \& Hopcroft, D. H. (1998). Morphology of Drepanopeziza species pathogenic to poplars. Mycological Research, 102(9), 1025-1037. https://doi.org/10.1017/S0953756297005972

Staehelin, C., Xie, Z.-P., Illana, A., \& Vierheilig, H. (2011). Long-distance transport of signals during symbiosis. Plant Signaling \& Behavior, 6(3), 372-377. https://doi.org/10.4161/psb.6.3.13881

Stimm, B., \& Weisgerber, H. (2008). Populus $x$ canescens (S. 14 S.).

Sun, J.-Q., Jiang, H.-L., \& Li, C.-Y. (2011). Systemin/jasmonate-mediated systemic defense signaling in tomato. Molecular Plant, 4(4), 607-615. https://doi.org/10.1093/mp/ssr008

Szuba, A., Marczak, Ł., Karliński, L., Mucha, J., \& Tomaszewski, D. (2019). Regulation of the leaf proteome by inoculation of Populus $\times$ canescens with two Paxillus involutus isolates differing in root colonization rates. Mycorrhiza, 29(5), 503-517. https://doi.org/10.1007/s00572-019-00910-5

Tang, Y., Horikoshi, M., \& Li, W. (2016). ggfortify: Unified interface to visualize statistical results of popular R packages. The R Journal, 8(2), 474. https://doi.org/10.32614/RJ-2016-060

Tecan Trading AG. (2012). Application note 397705 V1.0: Automated growth monitoring of microaerophilic organisms.

Tegeder, M., \& Masclaux-Daubresse, C. (2018). Source and sink mechanisms of nitrogen transport and use. New Phytologist, 217(1), 35-53. https://doi.org/10.1111/nph.14876

Tegeder, M., \& Rentsch, D. (2010). Uptake and partitioning of amino acids and peptides. Molecular Plant, 3(6), 997-1011. https://doi.org/10.1093/mp/ssq047

Thimm, O., Bläsing, O., Gibon, Y., Nagel, A., Meyer, S., Krüger, P., Selbig, J., Müller, L. A., Rhee, S. Y., \& Stitt, M. (2004). MAPMAN: A user-driven tool to display genomics data sets onto diagrams of 
References

metabolic pathways and other biological processes. The Plant Journal: For Cell and Molecular Biology, 37(6), 914-939. https://doi.org/10.1111/j.1365-313x.2004.02016.x

Torvalds, L. (2015). Linux kernel source. In 2008-02-21. Http://www. Kernel. Org.

Tromp, J., \& Ovaa, J. C. (1976). Effect of time of nitrogen application on amino-nitrogen composition of roots and xylem sap of apple. Physiologia Plantarum, 37(1), 29-34. https://doi.org/10.1111/j.1399-3054.1976.tb01868.x

Tschaplinski, T. J., Plett, J. M., Engle, N. L., Deveau, A., Cushman, K. C., Martin, M. Z., Doktycz, M. J., Tuskan, G. A., Brun, A., Kohler, A., \& Martin, F. (2014). Populus trichocarpa and Populus deltoides exhibit different metabolomic responses to colonization by the symbiotic fungus Laccaria bicolor. Molecular Plant-Microbe Interactions ${ }^{\circledR}$, 27(6), 546-556. https://doi.org/10.1094/MPMI09-13-0286-R

Tscharntke, T., Thiessen, S., Dolch, R., \& Boland, W. (2001). Herbivory, induced resistance, and interplant signal transfer in Alnus glutinosa. Biochemical Systematics and Ecology, 29(10), 1025-1047. https://doi.org/10.1016/S0305-1978(01)00048-5

Turnbull, C. G. N., \& Lopez-Cobollo, R. M. (2013). Heavy traffic in the fast lane: Long-distance signalling by macromolecules. New Phytologist, 198(1), 33-51. https://doi.org/10.1111/nph.12167

Tuskan, G. A., DiFazio, S., Jansson, S., Bohlmann, J., Grigoriev, I., Hellsten, U., Putnam, N., Ralph, S., Rombauts, S., Salamov, A., Schein, J., Sterck, L., Aerts, A., Bhalerao, R. R., Bhalerao, R. P., Blaudez, D., Boerjan, W., Brun, A., Brunner, A., ... Rokhsar, D. (2006). The genome of Black Cottonwood, Populus trichocarpa (Torr. \&amp; Gray). Science, 313(5793), 1596-1604.

https://doi.org/10.1126/science.1128691

Ullah, C., Unsicker, S. B., Fellenberg, C., Constabel, C. P., Schmidt, A., Gershenzon, J., \& Hammerbacher, A. (2017). Flavan-3-ols are an effective chemical defense against rust infection. Plant Physiology, 175(4), 1560-1578. https://doi.org/10.1104/pp.17.00842 
Van Bel, M., Diels, T., Vancaester, E., Kreft, L., Botzki, A., Van de Peer, Y., Coppens, F., \& Vandepoele, K. (2018). PLAZA 4.0: An integrative resource for functional, evolutionary and comparative plant genomics. Nucleic Acids Research, 46(D1), D1190-D1196. https://doi.org/10.1093/nar/gkx1002 van Loon, L. C. (2007). Plant responses to plant growth-promoting rhizobacteria. In P. A. H. M. Bakker, J. M. Raaijmakers, G. Bloemberg, M. Höfte, P. Lemanceau, \& B. M. Cooke (Hrsg.), New Perspectives and Approaches in Plant Growth-Promoting Rhizobacteria Research (S. 243-254). Springer Netherlands. https://doi.org/10.1007/978-1-4020-6776-1_2

van Loon, L. C., Rep, M., \& Pieterse, C. M. J. (2006). Significance of inducible defense-related proteins in infected plants. Annual Review of Phytopathology, 44, 135-162. https://doi.org/10.1146/annurev.phyto.44.070505.143425

Vega, A., Canessa, P., Hoppe, G., Retamal, I., Moyano, T. C., Canales, J., Gutiérrez, R. A., \& Rubilar, J. (2015). Transcriptome analysis reveals regulatory networks underlying differential susceptibility to Botrytis cinerea in response to nitrogen availability in Solanum lycopersicum. Frontiers in Plant Science, 6. https://doi.org/10.3389/fpls.2015.00911

Vernooij, B., Friedrich, L., Morse, A., Reist, R., Kolditz-Jawhar, R., Ward, E., Uknes, S., Kessmann, H., \& Ryals, J. (1994). Salicylic acid is not the translocated signal responsible for inducing systemic acquired resistance but is required in signal transduction. The Plant Cell, 6(7), 959-965. https://doi.org/10.1105/tpc.6.7.959

Vishwanathan, K., Zienkiewicz, K., Liu, Y., Janz, D., Feussner, I., Polle, A., \& Haney, C. H. (2020). Ectomycorrhizal fungi induce systemic resistance against insects on a nonmycorrhizal plant in a CERK1-dependent manner. New Phytologist. https://doi.org/10.1111/nph.16715

Vlot, A. C., Dempsey, D. A., \& Klessig, D. F. (2009). Salicylic acid, a multifaceted hormone to combat disease. Annual Review of Phytopathology, 47(1), 177-206. https://doi.org/10.1146/annurev.phyto.050908.135202 
Wallander, H., \& Nylund, J.-E. (1992). Effects of excess nitrogen and phosphorus starvation on the extramatrical mycelium of ectomycorrhizas of Pinus sylvestris L. New Phytologist, 120(4), 495503. https://doi.org/10.1111/j.1469-8137.1992.tb01798.x

Wallenda, T., \& Kottke, I. (1998). Nitrogen deposition and ectomycorrhizas. The New Phytologist, 139(1), 169-187. https://doi.org/10.1046/j.1469-8137.1998.00176.x

Wan, J., Tanaka, K., Zhang, X.-C., Son, G. H., Brechenmacher, L., Nguyen, T. H. N., \& Stacey, G. (2012). LYK4, a lysin motif receptor-like kinase, is important for chitin signaling and plant innate immunity in Arabidopsis. Plant Physiology, 160(1), 396-406. https://doi.org/10.1104/pp.112.201699

Wang, C., Reid, J. B., \& Foo, E. (2018). The art of self-control - autoregulation of plant-microbe symbioses. Frontiers in Plant Science, 9. https://doi.org/10.3389/fpls.2018.00988

Wang, X., Jiang, N., Liu, J., Liu, W., \& Wang, G.-L. (2014). The role of effectors and host immunity in plant-necrotrophic fungal interactions. Virulence, 5(7), 722-732. https://doi.org/10.4161/viru.29798

Weber, P., Stoermer, H., Geßler, A., Schneider, S., Sengbusch, D. V., Hanemann, U., \& Rennenberg, H. (1998). Metabolic responses of Norway spruce (Picea abies) trees to long-term forest management practices and acute (NH4)2SO4 fertilization: Transport of soluble non-protein nitrogen compounds in xylem and phloem. New Phytologist, 140(3), 461-475. https://doi.org/10.1111/j.1469-8137.1998.00285.x

Wei, H., Yordanov, Y. S., Georgieva, T., Li, X., \& Busov, V. (2013). Nitrogen deprivation promotes Populus root growth through global transcriptome reprogramming and activation of hierarchical genetic networks. New Phytologist, 200(2), 483-497. https://doi.org/10.1111/nph.12375

Will, B. (1999). Die Bedeutung von Glutathion für die Streßtoleranz von Pappeln (Populus tremula x Populus alba): 6 Tab. Wiss.-Verlag Maraun. 
References

Willmann, A., Thomfohrde, S., Haensch, R., \& Nehls, U. (2014). The poplar NRT2 gene family of high affinity nitrate importers: Impact of nitrogen nutrition and ectomycorrhiza formation.

Environmental and Experimental Botany, 108, 79-88.

https://doi.org/10.1016/j.envexpbot.2014.02.003

Winter, H., Lohaus, G., \& Heldt, H. W. (1992). Phloem transport of amino acids in relation to their cytosolic levels in barley leaves. Plant Physiology, 99(3), 996-1004.

https://doi.org/10.1104/pp.99.3.996

Xu, G., Fan, X., \& Miller, A. J. (2012). Plant nitrogen assimilation and use efficiency. Annual Review of Plant Biology, 63(1), 153-182. https://doi.org/10.1146/annurev-arplant-042811-105532

Yang, J., Wang, X., Xie, M., Wang, G., Li, Z., Zhang, Y., Wu, L., Zhang, G., \& Ma, Z. (2020). Proteomic analyses on xylem sap provides insights into the defense response of Gossypium hirsutum against Verticillium dahliae. Journal of Proteomics, 213, 103599.

https://doi.org/10.1016/j.jprot.2019.103599

Yang, L., Li, B., Zheng, X., Li, J., Yang, M., Dong, X., He, G., An, C., \& Deng, X. W. (2015). Salicylic acid biosynthesis is enhanced and contributes to increased biotrophic pathogen resistance in Arabidopsis hybrids. Nature Communications, 6(1), 7309. https://doi.org/10.1038/ncomms8309

Zhang, C., Han, L., Slewinski, T. L., Sun, J., Zhang, J., Wang, Z.-Y., \& Turgeon, R. (2014). Symplastic phloem loading in poplar. Plant Physiology, 166(1), 306-313. https://doi.org/10.1104/pp.114.245845

Zhang, Z., Li, Q., Li, Z., Staswick, P. E., Wang, M., Zhu, Y., \& He, Z. (2007). Dual regulation role of GH3.5 in salicylic acid and auxin signaling during Arabidopsis-Pseudomonas syringae interaction. Plant Physiology, 145(2), 450-464. https://doi.org/10.1104/pp.107.106021

Zhou, Y., Zhou, B., Pache, L., Chang, M., Khodabakhshi, A. H., Tanaseichuk, O., Benner, C., \& Chanda, S. K. (2019). Metascape provides a biologist-oriented resource for the analysis of systems-level datasets. Nature Communications, 10(1), 1523. https://doi.org/10.1038/s41467-019-09234-6 


\section{References}

Zimmermann, U., Meinzer, F. C., Benkert, R., Zhu, J. J., Schneider, H., Goldstein, G., Kuchenbrod, E., \& Haase, A. (1994). Xylem water transport: Is the available evidence consistent with the cohesion theory? Plant, Cell \& Environment, 17(11), 1169-1181. https://doi.org/10.1111/j.13653040.1994.tb02015.x 


\section{Appendix}

1. Kaling, M., Schmidt, A., Moritz, F., Rosenkranz, M., Witting, M., Kasper, K., Janz, D., Schmitt-Kopplin, P., Schnitzler, J.-P., \& Polle, A. (2018). Mycorrhiza-triggered transcriptomic and metabolomic networks impinge on herbivore fitness. Plant Physiology, 176(4), 2639. https://doi.org/10.1104/pp.17.01810 


\section{Declaration}

The following analyses presented in this work have been accomplished with support by the technological platforms at Georg-August Universität Göttingen:

Göttingen Proteomics Forum at the Department for Microbiology and Genetics (head: Prof. Dr. Braus), proteome analyses supervised by Dr. Oliver Valerius and Dr. Kerstin Schmitt.

Göttingen Metabolomics and Lipidomics Platform at the department of Plant Biochemistry (head Prof. Dr. I. Feussner), non-targeted metabolic finger printing supervised by Dr. Kirstin Feussner and Dr. Ilka de Abreu and phytohormone analyses supervised by Dr. Cornelia Herrfurth and Dr. Krzysztof Zienkiewicz

Dr. Till Ischebeck (Plant Biochemistry, Georg-August-Universität Göttingen, Germany) provided data of targeted metabolite analyses. 


\section{Acknowledgements}

First, I would like to thank my supervisor Prof. Dr. Andrea Polle for her continuous support during the whole PhD project, for her trust in my abilities and many advices I received beyond science. This work would not have been possible without her participation. I would also like to thanks my co-supervisor Prof. Dr. Ivo Feussner for his input during my project, for letting me work with half of his staff and machinery for metabolome analyses and especially for leading the PhD program IRTG2172: PRoTECT calmly through rough episodes. Many thanks to my third and Canadian supervisor Prof. Dr. Guus Bakkeren for his advice during thesis advisory committee meetings and supporting my stay at AAFC in Summerland in every possible way. My best thanks to PD Dr. Till Ischebeck for introducing me to GC-MS based metabolome analysis and constructive discussions. Many thanks to Prof. Dr. Gerhard Braus for supporting my proteome analysis in his wonderful department. And last but not least I'd like to thank PD Dr. Marcel Wiermer for inspiring debates. And many thanks to all named for being part of my examination board.

This multi-omics project would not have been possible without the commitment of many. Firstly, I have to thank Dr. Andrzej Majcherczyk for endless support with establishment of suitable methods to analyze the xylem sap proteome, and Prof. Dr. Ursula Kües for letting me use the facilities of her group, especially during the first two years of my project and subsequently to Dr. Oliver Valerius and Dr. Kerstin Schmitt for proteome analysis in the last two years.

I would like to thank especially Dr. Kirstin Feussner for all the hours she spent to process my samples and to discuss the mysteries of secondary metabolome analysis with me. In that context also many thanks to Dr. Ilka de Abreu for MS-MS spectra-based metabolite confirmation, to Dr. Cornelia Herrfurth and Dr. Krzysztof Zienkiewicz for working out the best way to analyze xylem sap phytohormones and to Sabine Freitag for preparation of my endless samples. For introducing me to ectomycorrhiza confocal microscopy l'd like to thank Dr. Clémence Bonnot (French National Institute for Agriculture, Food, and Environment, Nancy, France) and Michael Weiser (Agriculture and AgriFood Canada, Summerland, Canada) for sharing their experience in mycorrhiza laser confical microscopy with me and additionally Dr. Clémence Bonnot and Prof. Dr. Francis Martin (French National Institute for Agriculture, Food, and Environment, Nancy, France) for providing a picture of ectomycorrhizal poplar root tips for this thesis. 
My gratitude goes to all members of the department of Forest Botany and Tree Physiology at University of Goettingen for not only supporting my work in every way but also for being friends and great colleagues for the last four years. Special thanks to Dr. Christian Eckert for help when ever needed, Dr. Dennis Janz for assisting so many times in statistical affairs and Dr. des. Johannes Ballauf for his manifold support and friendship. Many thanks to Thomas Klein for introduction to RNA extraction and laboratory routines, as well as for RNA extraction of leaf samples and all the small times he helped me with minor problems. I am very grateful to Monika Franke-Klein for helping me with enzyme kinetic measurements and supporting my work all the time, to Merle Fastenrath for poplar propagation, Gabriele Lehmann for assisting with knowledge in fungal cultivation, Marianne Smiatacz and Cathrin Leibecke for assisting in greenhouse related problems. Special thanks to Bernd Kopka for fixing all IT problems and his nice attitude and to Ronny Thoms for supporting my work when we were colleagues. And to be named last of the department because without her chaos would emerge, many thanks to Nina-Christin Lindeman for organization of everything.

I can't thank the colleagues of my department and PRoTECT enough. Many thanks for all the constructive discussions, for the fun we had, the hard times we survived and everything we have accomplished together. The last four years were a lot of fun, quite some stress and would not have been possible without you.

I would like to thank the German Science Foundation (DFG) for funding the International Research Training Group 2172: PRoTECT: Plant Response to Eliminate Critical Threats and especially this project (M1), which was part of a collaboration between the Georg-August-Universität Göttingen and University of British Columbia.

And finally, I have to thank my family and especially my wife Miriam, this work would not have been finalized without your support besides science. 
Curriculum vitae

9 Curriculum vitae 


\section{Publications and conferences}

Kaling, M., Schmidt, A., Moritz, F., Rosenkranz, M., Witting, M., Kasper, K., Janz, D., SchmittKopplin, P., Schnitzler, J.-P., \& Polle, A. (2018). Mycorrhiza-triggered transcriptomic and metabolomic networks impinge on herbivore fitness. Plant Physiology, 176(4), 2639. https://doi.org/10.1104/pp.17.01810

Kasper, K., Majcherczyk, A., Polle, A. (23.11.2017) Poster: „Xylem sap proteome analysis of woody plants", Symposium of the Goettingen Proteomics Forum 2017, Göttingen

Kasper, K., Majcherczyk, A., Kües, U., Polle, A. (14. \& 15.06.2018) Poster: „Chasing Mycorrhizal Systemic Signals", International Plant Immunity Symposium, Göttingen

Kasper, K., Majcherczyk, A, Valerius, O., Feussner, K., Ischebeck, T., Kües, U., Braus, G., Feussner, I., Polle, A. (27.11.2018 - 30.11.2018) Poster: „Are There Mycorrhizal Signals In The Xylem Sap?“, Molecular Plant-Fungal Interaction workshop, Cologne 